\title{
The Influence of Market States on Security Returns
}

\author{
Warren Thomson \\ B. Com Griffith, banking, finance, Financial Planning \\ Honours $1^{\text {st }}$ Class (Fin)
}

The school of Accounting, Economics and finance

Griffith University

Gold Coast Campus, Australia

Submitted in partial fulfilment of the requirements

Of the degree of

Doctor of Philosophy

April 29 2016 


\section{Abstract}

Business and economic cycles have played a major factor in economies and people lives for centuries; indeed, it could be argued that the economic crises and economic good times affect all people's wellbeing. As financial markets have developed in modern economies, researchers have observed that market cycles tend to be leading indicators of business cycles. While there is a long history of academic research into business cycles, academic research into how market states differentially influence security returns is a more recent phenomenon.

The aim of this thesis is to explore not only new methods but also to create innovative schemes that enable the examination of how market states influence security returns in new and significant ways. The encompassing theme is the interplay between stock market anomalies and market states. The resulting empirical research in the thesis involves three separate but related empirical studies.

The first study of the thesis examines whether market states (defined simply by past market performance) are able to provide information about the future performances of individual industries. In other words, can market states predict future industry returns? Specifically, I investigate whether an industry's past relative performance in the same market state as the current one predicts the industry's future performance. The findings show that market states can be used to construct profitable dynamic industry rotation strategies. Moreover, in support of market practitioners' preferences for specific industries in different states of the market, certain industries are shown to have predictable returns in different market states.

The second study of this thesis extends the notion of market states in an innovate approach that creates states by combining recent market performance with the recent performances of 
two important components of the market: the size and value factors. The resulting two new schemes are used to examine the predictability of momentum, one of the most studied anomalous capital market phenomena. The findings show that momentum's future profitability depends on the particular market states and different size or value states. Importantly, the results show that one market-size state and one market-value state are able to predict momentum crashes in average returns because more than $80 \%$ of the worst 15 momentum crashes occur in these two states. Momentum crashes typically occur when the market transitions from DOWN to UP. Finally, I also examine an extended market state scheme which combines market performance with return dispersion, utilising the same methodology as with the size and value factors. I find that return dispersions' previously reported anomalous effect is driven by only one state.

The third and final study in the thesis continues the investigation with the previously created market-size scheme from study two. In the third study, I examine whether the four states of the market-size scheme contain information about the future performances of the Fama-French (FF) three factors. The findings show that that the market-size scheme is successful in this respect. For example, all three factors produce their strongest returns following a negative market in which small firms outperformed large firms. That is, this state (negative market with small firm outperformance) tends to be followed by an upturn in the market, with small firms strongly outperforming large firms and with value firms strongly outperforming growth firms.

The results in the thesis highlight the important role market states play in understanding the anomalous behaviour of the Fama-French three factors and of momentum. This thesis 
contributes to the anomalies literature by showing market states have a predictive effect, and by creating new market state schemes that open up new fields for future investigations. 
Table of Contents

\section{Contents}

Abstract

Table of Contents .........................................................................................................................................

List of Tables .............................................................................................................................................vii

List of Figures .................................................................................................................................................ix

Key words and Abbreviations ..............................................................................................................

Statement of original Authorship ......................................................................................................

Acknowledgements................................................................................................................................

Dedications ........................................................................................................................................... xiii

Chapter 1: Introduction .............................................................................................................1

1.1 Overview and Rationale …………………………............................................

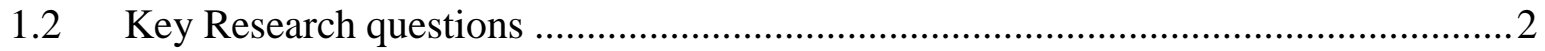

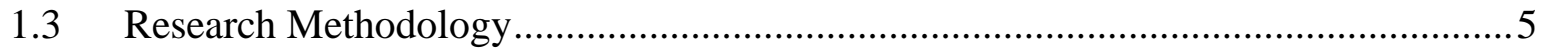

1.4 Thesis Structure and Research Contributions .........................................................

Chapter 2: Literature review ...............................................................................................................11

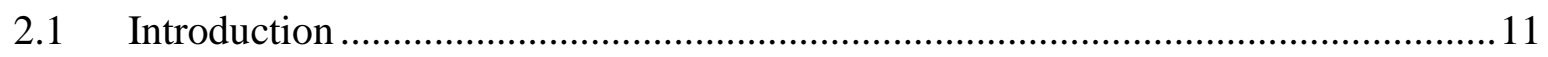

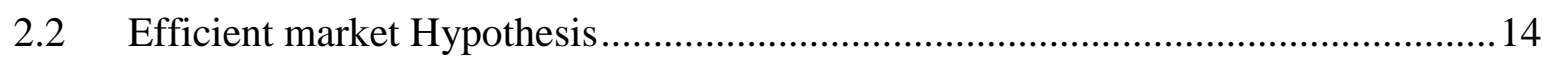

2.3 Capital Asset Pricing Model ……………………............................................... 16

$2.4 \quad$ The Arbitrage Pricing Theory ……………………………………………….... 18

2.5 Fama and French Three-Factor Model.................................................................... 19

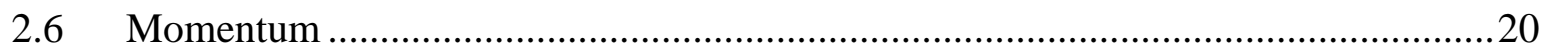

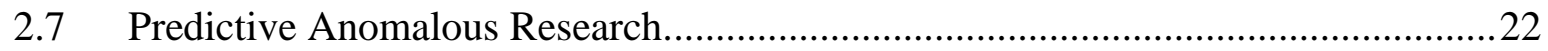

2.8 Business Cycles ...........................................................................................

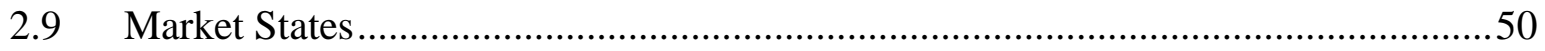

2.9.1 Constructing Market States...........................................................................5

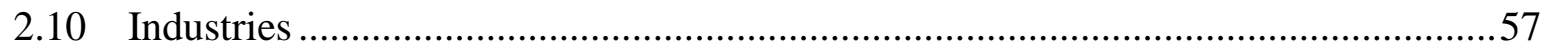




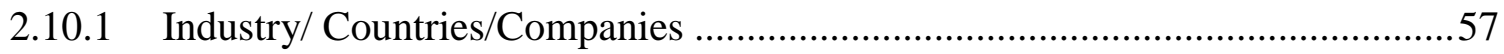

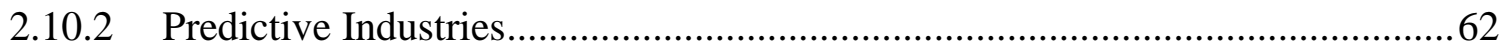

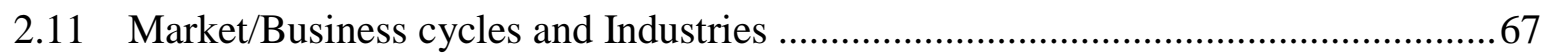

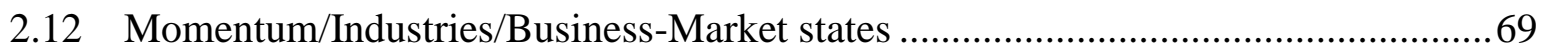

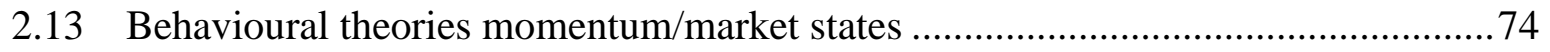

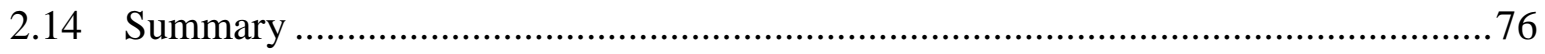

Chapter 3: The Influence of Market States on Industry Returns ...................................78

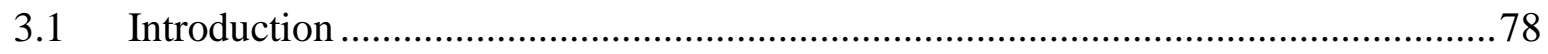

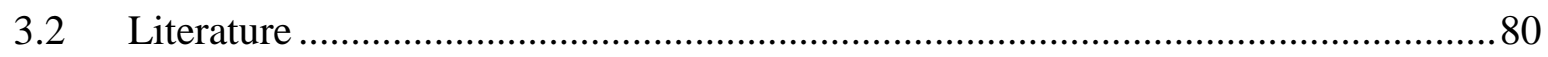

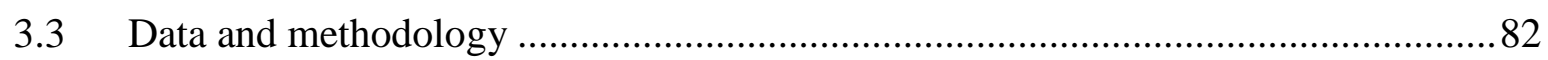

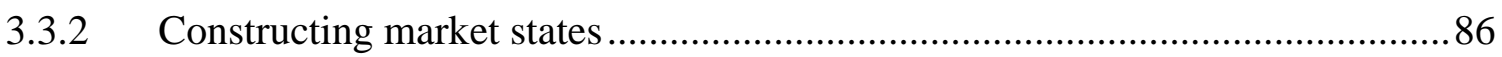

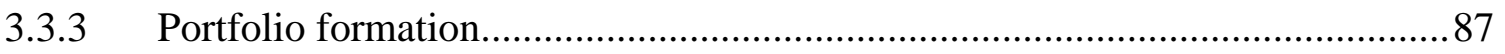

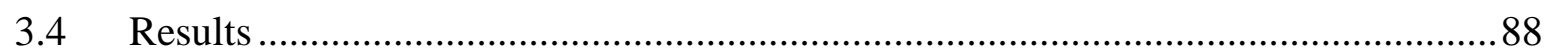

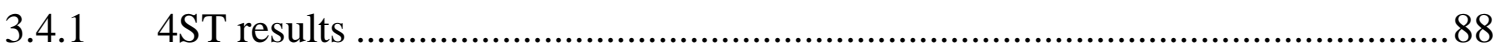

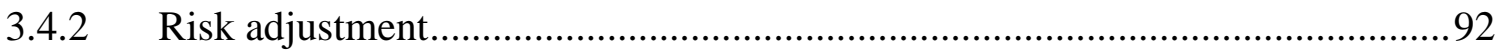

3.4.3 Analyses of strategy profitability in different states .....................................94

3.4.4 Industry profitability at different stages of the market ................................97

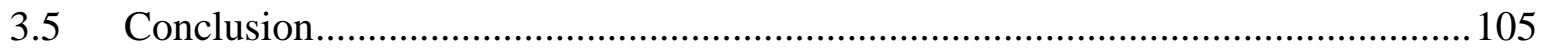

Chapter 4: Size- and Value-based Market States and Momentum....................................109

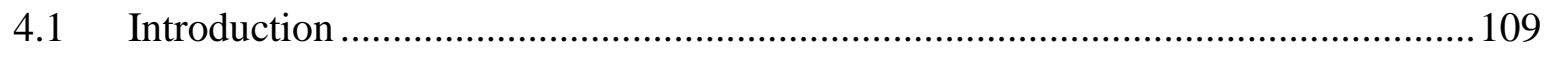

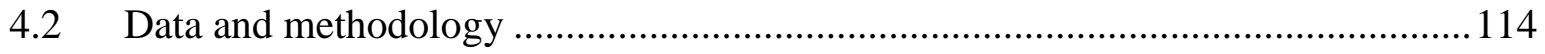

4.2.1 Constructing Market-Size and Market-Value States ...................................... 114

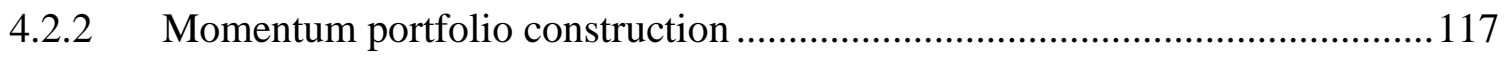

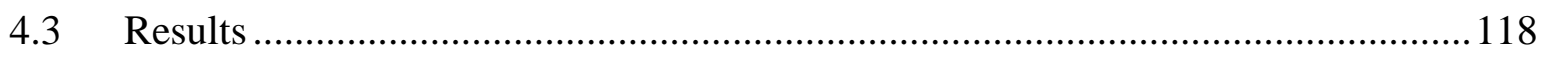

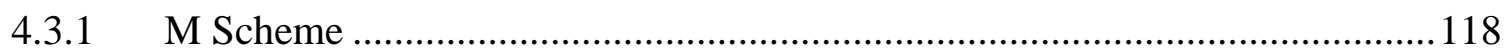

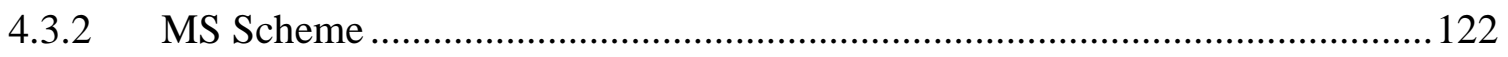

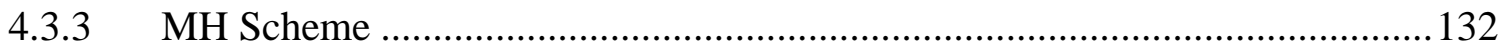




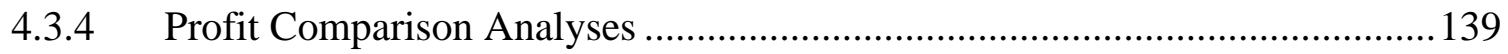

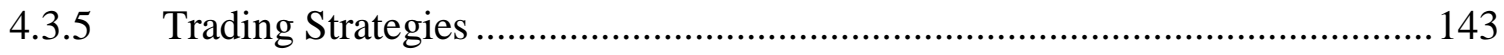

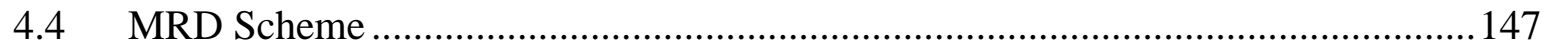

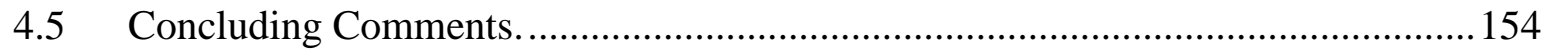

Chapter 5: Size based Market States and FF Three Factors ..............................................160

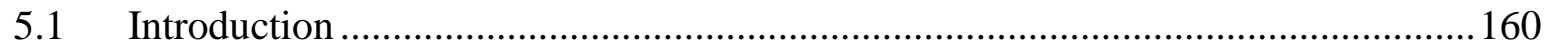

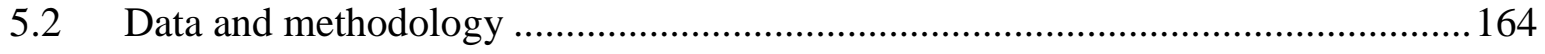

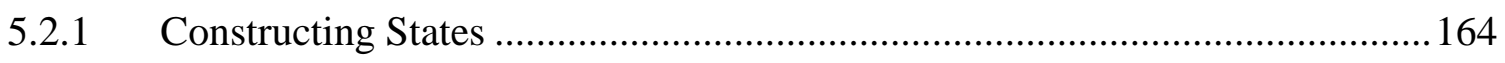

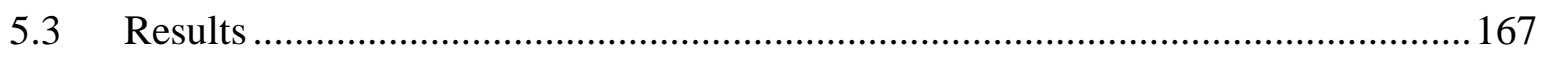

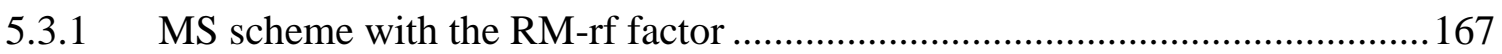

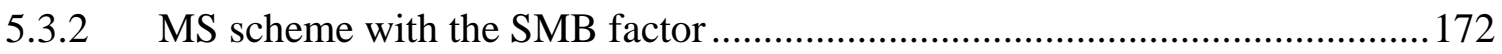

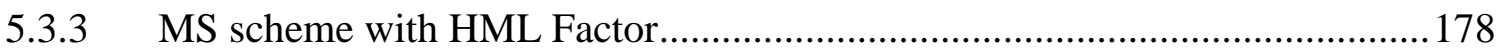

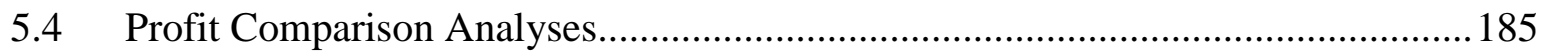

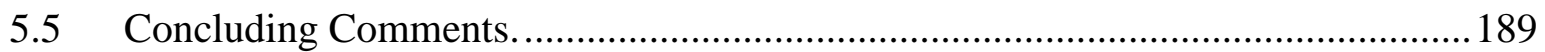

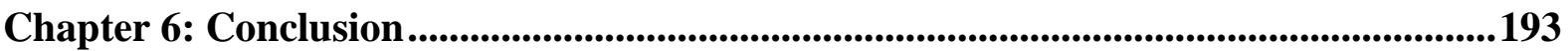

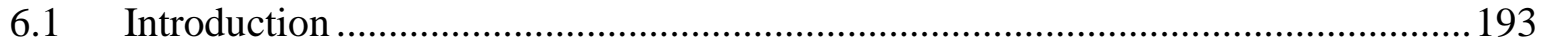

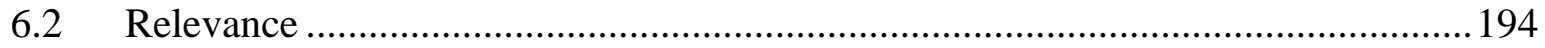

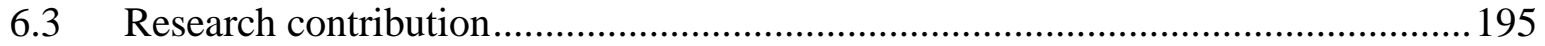

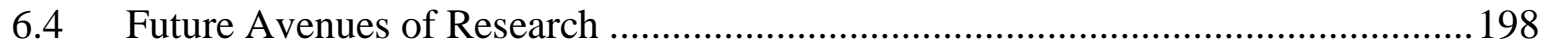

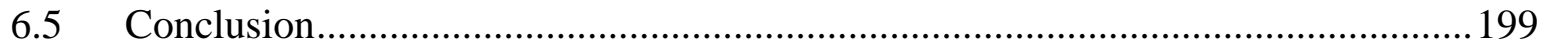

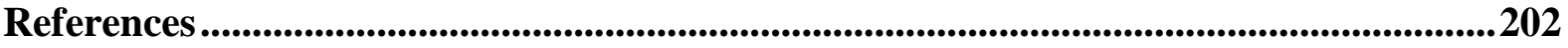




\section{List of Tables}

Table 3.1: Summary Statistics

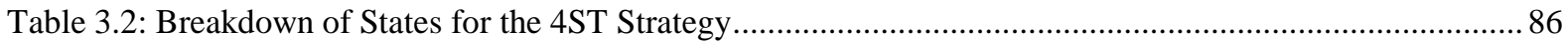

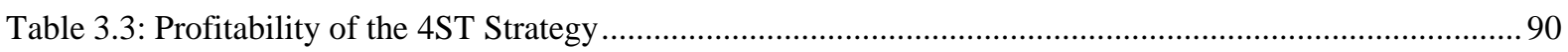

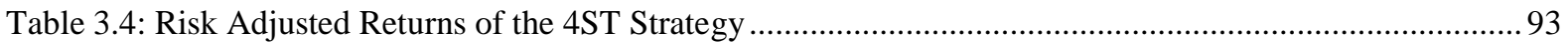

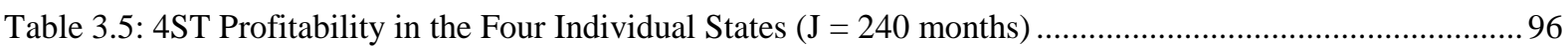

Table 3.6: 4ST Profitability in the Four Individual States $(\mathrm{J}=360$ months $)$................................................96

Table 3.7: Industry representation in winner and loser portfolio for 4 states $(\mathrm{J}=240$ months $)$......................99

Table 3.8: Industry representation in winner and loser portfolio for 4 states $(\mathrm{J}=360$ months $)$.................... 100

Table 3.9: Industry representation: Profits in winner and loser portfolio for 4 states $(\mathrm{J}=240$ months $) \ldots \ldots \ldots . . . .103$

Table 3.10: Industry representation: Profits in winner and loser portfolio for 4 states $(\mathrm{J}=360$ months $) \ldots \ldots \ldots . . .104$

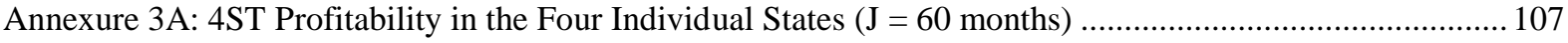

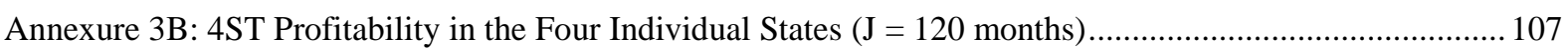

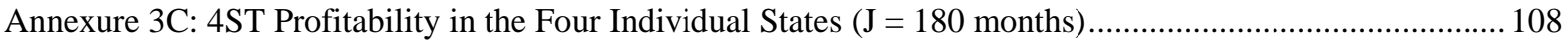

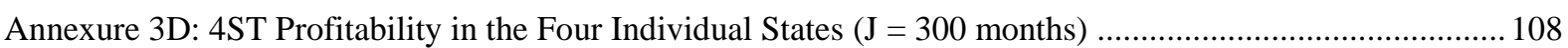

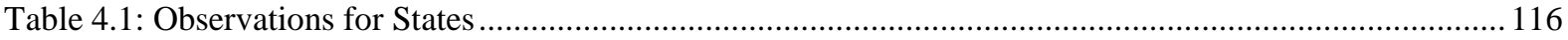

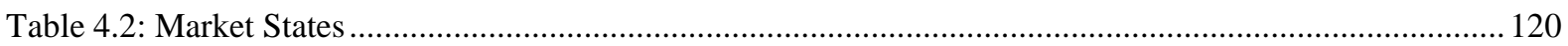

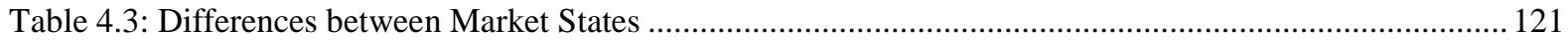

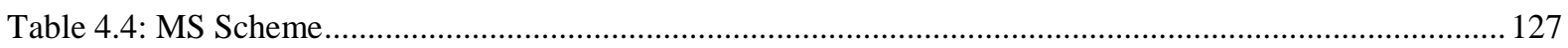

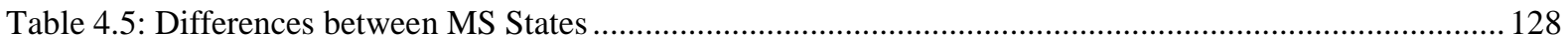

Table 4.6: MS scheme with Market Return ............................................................................................... 130

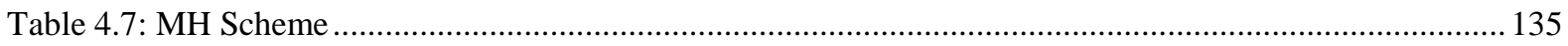

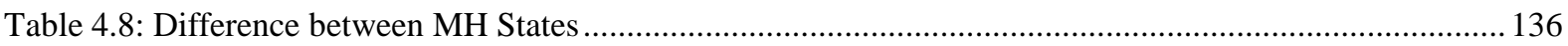

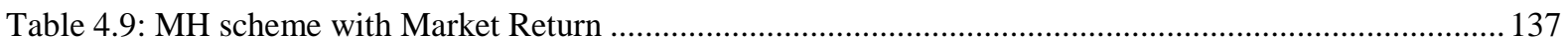

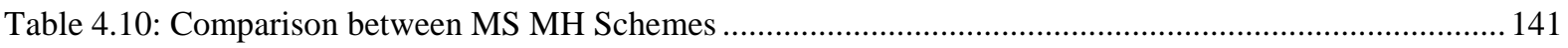

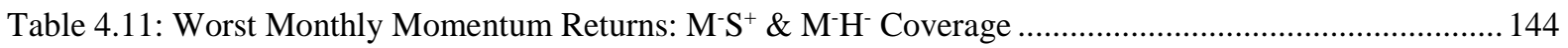

Table 4.12: Analyses of Risk, $\mathrm{M}^{-} \mathrm{S}^{+}$and $\mathrm{M}^{-} \mathrm{H}^{-}$States vs Momentum ${ }^{-}$Sharpe Ratio .................................. 147

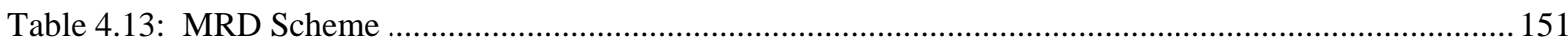

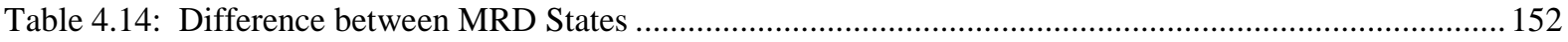




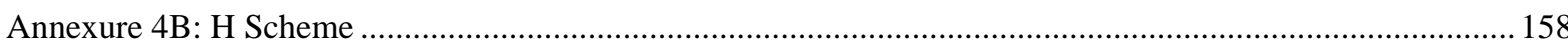

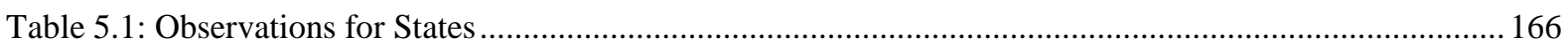

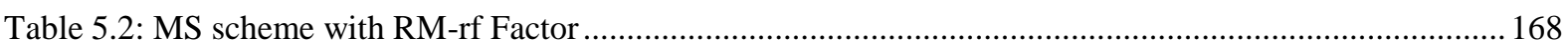

Table 5.3: MS scheme with the RM-rf Factor-Difference between States .................................................. 169

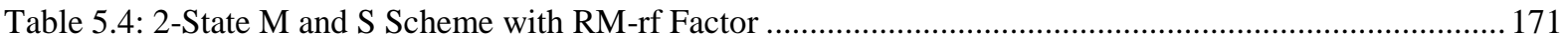

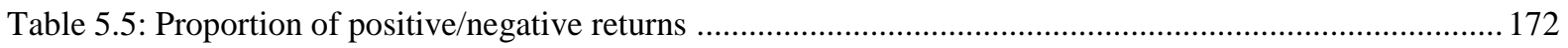

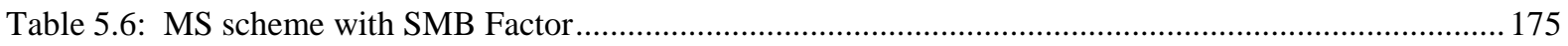

Table 5.7: MS scheme with SMB Factor-Differences between States ................................................... 177

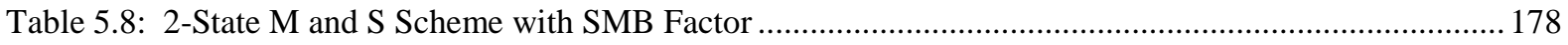

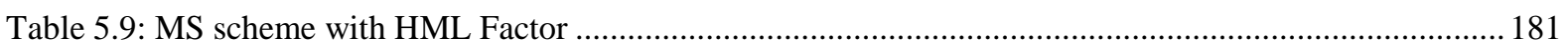

Table 5.10: MS scheme with HML Factor-Differences between states ................................................... 182

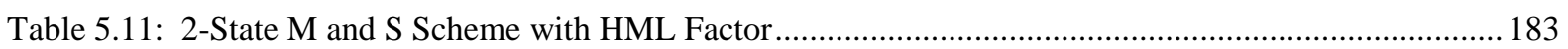

Table 5.12: MS Scheme: SMB and HML 5x5 portfolio Returns in the Four States..................................... 185

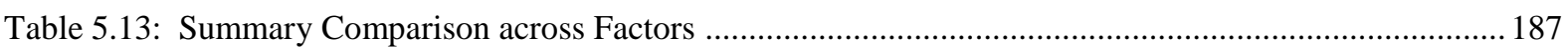

Annexure 5A: 2-State H with RM-rf, SMB and HML Factor ............................................................. 191 


\section{List of Figures}

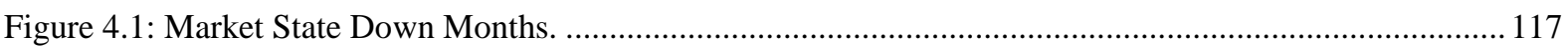

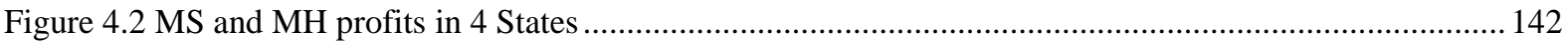

Figure 4.3: Cumulative Monthly Returns to Momentum with $\mathrm{M}^{-} \mathrm{S}^{+}{ }_{\mathrm{t}+12}$ and $\mathrm{M}^{-} \mathrm{H}_{\mathrm{t}+12}^{-}$Trading Strategies........... 146

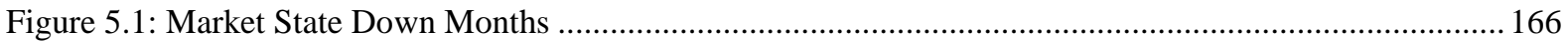

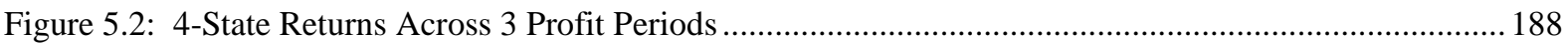




\section{Key words and Abbreviations}

Four state scheme (4ST)

High minus Low (HML)

High minus Low state $(\mathrm{H})$

Market-High minus Low scheme (MH)

Market-Size scheme (MS)

Market state (M)

Market-Return Dispersion scheme (MRD)

Momentum (MOM)

Return of the Market minus risk-free rate (RM-rf)

Size state (S)

Small minus Big (SMB) 
Statement of original Authorship

I, Warren Thomson, confirm that this work has not previously been submitted for a degree or diploma in any university. To the best of my knowledge and belief, the dissertation contains no material previously published or written by another person except where due reference is made in the dissertation itself.

Signature:

Date: 


\section{Acknowledgements}

I wish to express my gratitude to all those who made the writing of this dissertation possible. I sincerely thank my principle supervisor, Dr Graham Bornholt, for all his valuable advice and guidance, especially in his new ways of thinking re Financial models, and Michael Drew and Mirela Malin, my associate supervisors, who gave me very pragmatic and sound advice. Their patience and guidance are much appreciated.

As well, I wish to thank Dr Robert Bianchi for passing on his insight and knowledge of the financial world. I would also like to express my appreciation to my friends and colleagues Tracey West, Jakhongir Kakhkharov, Omar Gharaibeh, Carolyn Cichero, Michael Howard, and Sonja Kobinger for providing a vibrant happy contentious environment in which to work. I wish all of my fellow colleagues all the best for the years ahead. It has been a pleasure.

I have one paper accepted for publication (Journal of Asset Management), derived from chapter three, and utilized the professional editorial assistance of Academic Word for that publication. 


\section{Dedications}

I dedicate this dissertation to my children, Luke, Ashlee, Kirsty and especially my youngest child who had to miss out on so many events in support of my Doctoral thesis- Ethan. My thoughts and prayers to my children and others who have supported me. 


\section{Chapter 1: Introduction}

\subsection{Overview and Rationale}

This thesis focuses on researching the interaction of various anomalies with market states to ascertain if new ways to classify market states can enhance my understanding of some of these anomalies. I am motivated by the fact that asset allocation plays an important part in the trading strategies of managed, superannuation, and hedge funds throughout the financial world. Indeed, a vast literature explores profitable trading strategies and anomalies in asset allocation. Recently, there has been a growing acknowledgment that market states can provide valuable information about known anomalous effects (see, for example Cooper, Gutierez and Hameed (2004), Asem and Tian (2010), and Stivers and Sun (2013) with regard to the momentum anomaly).

An examination of the literature involving the interaction between anomalous effects and market states exposed that there was a lack of research in some areas. Therefore, the main focus of the three empirical chapters is to undertake research into market states and their usefulness for understanding certain anomalous effects. The first part of this thesis examines if market states can predict future industry returns. Asset allocation plays a major role in determining industry allocation, during different phases of market states throughout the world. In addition, market practitioners frequently give advice about which industries to invest in at different phases of the market cycle. While previous research has investigated industry rotation and business cycles (Sorensen and Bourke, 1986), I add to this literature by showing that market states can predict future industry performance. 
The second part of this thesis, considers the relationship of two important components of the market, small minus big (SMB) factor and the high book-to-market minus low book-tomarket (HML) factor effect on momentum returns across market states. There has been numerous research studies investigating the anomalous behaviour of the SMB and HML factors, and recently some research into how these components of the market influence momentum (Asness, Moskowitz and Pedersen 2013, Fama and French 2012). There has also been some research into how market states effect momentum profits (Cooper, et al. 2004). I add to the scholarly literature by investigating how the combination of market states and these two market components affect future momentum profitability. My motivation was to not only ascertain how these important factors, size and value effected momentum returns across market states, but also which factor had the greatest effect on momentum returns.

The third part considers the predictability of the future returns of the Fama and French (1993) (FF) three factors, the return of the market minus the risk free rate (RM-rf), small minus big (SMB) and high book-to-market minus low book-to-market (HML)] determined by the market-size scheme introduced in the second study. There has been plentiful research into SMB and HML factors having an anomalous predictive effect. There has also been some research into how market states affect anomalous variables. My motivation was to investigate whether the past performance of the SMB factor in combination with the past performance of the market provides information about the future performances of the market, the size factor and the value factor.

\subsection{Key Research questions}

Research Objectives and Questions 
The objective of this thesis is to empirically examine the relationship between different assets and anomalous phenomena and their interaction with market states, with particular attention as to whether market states can predict future asset returns. To pursue this aim, three interlinked studies will be conducted. Titles and research questions for each of the three studies are given as follows.

Research Question One

I formulate my research question based on the extant literature concerning the interaction between market states and stock market cross-section anomalies. There has been limited research into how the relative performance of industries interacts with different market states. This first study considers whether industries that outperform (underperform) in a particular market state are more likely to outperform (underperform) when that market state arises in the future. In other words, does the past performance of industries in the current market state provide any useful information about which industry or industries investors should invest in and which they should avoid? The answer to this question will depend on the method for determining market states, so the first step requires deciding on a classification scheme. As will be described later, this study uses a four state methodology to determine market states.

Specifically, the first research question is as follows:

Does an industry's past relative performance in the same market state as the current market state predict the industry's future performance? 


\section{Research Question Two}

The second research question investigates the predictability of momentum profits by considering not only the past performance of the overall stock market but also either the past performance of the size factor or the past performance of the value factor. The intuition is that the state of the market is not just determined by the market's performance as a whole but also by how important components of the market are performing. For example, a weak overall market but with small firms outperforming large firms is a different market situation to occasions when there is a weak overall market but with large firms outperforming small firms. Perhaps future momentum profitability will be different following these different types of market situations.

To investigate the predictability of momentum profitability, I create two new schemes: the market-size (MS) scheme and the market-value (MH) scheme. Each scheme provides four different states based on the recent performances of the market and the size factor (the MS scheme) or on the recent performances of the market and the value factor (the MH scheme).

Specifically, my second research question is as follows:

Can the recent performances of the size factor and the market, or the recent performances of the value factor and the market, predict future momentum profitability?

Research question Three

The third research question examines the predictability of the Fama and French three factors through the market-size state scheme (MS) developed in research question two of this thesis. Given the obvious importance of the market as a whole, and that both the size and value 
factors are widely regarded as important components of the market, this third study investigates if the MS scheme provided useful information about the future performances of the three factors.

This study will empirically examine if the MS scheme, or its separate components, can predict the RM-rf, SMB and HML factor returns, and determine which component of the MS scheme (market or size) is the most important driver of any such predictability.

Specifically, the third research question is as follows:

Can the market-size scheme (MS) predict the future returns of the RM-rf, SMB and HML factors, and which component of the MS scheme is the main driver of any such predictability?

\subsection{Research Methodology}

This section will only lightly touch on the highlights of each empirical chapter's methodology, with full in-depth explanations to be found in the relevant methodology sections of Chapters 3, 4 and 5.

The first empirical chapter creates four market states and utilizes different formation periods and a portfolio approach to determine future industry performance. The second empirical chapter creates two new schemes, developed by combining two market states with two SMB or HML states to create four states for each of the MS and MH schemes. The schemes are then used to determine future stock and industry momentum profitability following each state utilising three different holding periods and a portfolio approach. The third and final empirical chapter employs the MS scheme, and its individual components, to examine the returns for the Fama-French three factors (RM-rf, SMB and HML) following each state. 
The main underlying theme for all three questions, is utilising market states as the key component to determine anomalous predictive future returns. Market states in the three empirical chapters are determined in the same manner, by utilising a non-parametric method as used by Cooper et al (2004) and Asem and Tian (2010). While Cooper et al. (2004) utilized the 36-month, 24-month, or 12-month lagged market return to determine the market state, I follow Asem and Tian's (2010) approach and utilize the 12-month lagged market return. Specifically, I employ the return on the CRSP value-weighted market index over the 12 months prior to the beginning of the strategy's profit period. If the market's prior 12-month return is positive (negative), I define the state of the market as positive (negative). All three questions also use the same data and time period to create the market (M) states.

\section{Methodology for Question One}

For question one, I create four market states based on the most-recent 12-month market return using a non-parametric method, following Asem and Tian (2010). The four-state scheme utilizes $\pm 20 \%$ for the extreme breakpoints for market returns over the last 12 months, with the third breakpoint being $0 \%$. Industries are selected for the long portfolio (LW) in a particular month and market state if those industries have performed relatively well in the 12 months following that state in the past. Similarly, industries are selected for the short portfolio (LL) in a particular month and market state if those industries have performed relatively poorly in the 12 months following that state in the past. A 12-month gap between the end of the formation periods and the beginning of holding periods ensures that the portfolio construction process does not have any look-ahead bias. 
A portfolio approach using different formations periods is then used to determine future strategy profitability. The equal-weighted portfolio returns for each strategy are calculated for K-month holding periods $(\mathrm{K}=1,3,6,9,12)$ using Jegadeesh and Titman's $(1993,2001)$ overlapping portfolio approach. The returns are risk-adjusted by regressing the time-series of portfolio returns (LW, LL, and LW-LL) on the market, size, book-to-market and momentum factors. If the intercept $\alpha$ (alpha) is statistically significantly different from zero then this is evidence of abnormal portfolio returns. The $t$-values are corrected by White' (1980) heteroscedasticity-consistent standard errors adjustment.

\section{Methodology for Question Two}

The four-state schemes in the second study are derived by combining two two-state schemes together. The market state (M) is positive (negative) if most-recent 12-month market return is positive (negative). The size and value states are determined by using a similar methodology as the market states are determined. Specifically, if the SMB or HML's most-recent cumulative average 12-month return is positive (negative), I define that factor's state as positive (negative). I then combine the size or value states with the market states, to create the four states of the market-size scheme (MS) and the market-value scheme (MH). The classification of each state is determined at the end of each month and the average momentum portfolio returns over the following 6-month and 12-month periods are recorded. These momentum portfolio returns are aggregated together for set periods following each state. Both stock momentum and industry momentum portfolios are included in the study.

\section{Methodology for Question Three}

The third study uses the new market-size (MS) scheme introduced in the second study to investigate the predictability of the market, the size effect and the value effect. Specifically, 
the Fama-French RM-rf, SMB, and HML factor returns following each of the four states are cumulated and averaged for the periods 1-6 months, 1-12 months, and 13-24 months following each state. Differences in these average returns are tested to investigate whether or not these three factors' returns are predictable from the past performance of the market combined with the past relative performances of small and large firms.

\subsection{Thesis Structure and Research Contributions}

The final section of this introductory chapter outlines the structure of the thesis. Chapter 2 begins with a review of the scholarly literature, which provides the contextual framework and motivation for the research considered in this thesis. The review in Chapter 2 also provides an in-depth analysis of the major concepts in the fields of asset pricing, asset selection, and asset location through examination of anomalous effects, including market states, industries, Fama and French 3 factors, momentum, and literature regarding their interactions.

Chapter 3 is the first empirical contribution. This chapter considers the relevance of market states to future industry returns. More specifically, I investigate whether an industry's past relative performance in the same market state as the current one predicts the industry's future performance. To do this I introduced new four-state scheme for determining market states. The findings reveal strong evidence that market states can be used to construct profitable dynamic industry rotation strategies. I also examine the difference in industry returns between the four states, and show the strongest profitability is to be found following the extreme market states. In support of market practitioners' approach that invests in specific industries at different states of the market, the results show that industries dependant on discretionary (non-discretionary) spending, are heavily featured in the extreme positive state, 
in long winner (long loser) portfolios, and in the extreme negative state in long loser (long winner) portfolios. In essence, Chapter 3 identifies a new stock market anomaly: a strong form of predictability in industry returns not previously reported in the literature.

Chapter 4 of this thesis extends the notion of market states in an innovate approach that creates states by combining recent market performance with the recent performances of two important components of the market: the size and value factors. The resulting schemes are the market-size (MS) and market-value (MH) schemes. These are used to examine the predictability of momentum, one of the most pervasive and persistent of all anomalies so far identified in financial markets. The analysis includes both stock-level and industry-level momentum, and covers the period from 1926 to 2013.

Our findings show that following an UP market, momentum shows positive average profitability, regardless of whether the size $(\mathrm{S})$ or value $(\mathrm{H})$ state is positive or negative. However, a DOWN market with a positive $\mathrm{S}$ state (small firm outperformance) predicts negative future momentum profits, while a DOWN market with a negative $S$ state (large firm outperformance) predicts positive future momentum profits. If the $\mathrm{H}$ component of the $\mathrm{MH}$ scheme in the DOWN market is positive (value firm outperformance), this state predicts positive momentum profits, wheras a negative $\mathrm{H}$ component (growth firm outperformance) in a DOWN market predicts negative momentum profits. Overall, the findings show strong evidence that past market performance combined with the past relative performances of small firms versus large firms or value firms versus growth firms is able to predict momentum's future profitability. 
Chapter 4 also includes an examination of Stivers and Sun's (2013) return dispersion (RD) effect on momentum profits within the context of market states. Using a market-return dispersion (MRD) scheme, the study shows that return dispersion's ability to predict momentum profits is evident only in a negative market, since both a high and low return dispersions in a positive market state produce similar momentum returns. Only following a negative market state is momentum profitable when return dispersion is low. This result partially disputes the findings by Stivers and Sun (2013).

Chapter 5 is the third and final empirical chapter, which examines whether size and market states combined provide information about the future returns of the market, the size effect and the value effect (as measured by the Fama-French three market, size and value factors). Empirically, I utilize Chapter 4's new market-size (MS) scheme to study the returns of the RM-rf, SMB and HML factors from 1926 to 2013. My results show that I are able to predict significant differences in returns for the FF three factors across the market-size states, and in particular, I am able to predict when the transition from down markets to up markets is likely. This has major implications for asset allocation and investors. I find that future size and value profitability is strongly dependant on prior positive size state, whilst the future RM-rf and size profitability was greatly enhanced by a prior combination of a positive size state and negative market state.

Chapter 6 provides a summary of the main conclusions, along with limitations of the research, a synopsis of the thesis, and a discussion of avenues for future research. 


\section{Chapter 2: Literature review}

\subsection{Introduction}

This next chapter will present a review of the historical literature that forms the basis for my thesis. Neuman (2006) states that the purpose of a literature review is to summarise and review the current knowledge on a particular subject area to demonstrate the value and contribution of the study. This is the purpose of this chapter.

My research questions investigate market states in relation to stocks, industries, and the anomalous behaviour of different variables. Nevertheless, I have broadened my literature review to include business cycles as well as market states because academic literature shows a correlation between these two sectors (Bolten \& Weigand, 1998; N. Chen, 2012; Cheung, He, \& Ng, 1997; E. F. Fama, 1990; W.E. Ferson \& Harvey, 1993; Maysami \& Sim, 2001; Næs, Skjeltorp, \& Ødegaard, 2011; Schwert, 1990), and cyclical links between the two sectors (Beaudry \& Portier, 2004; B. Candelon \& Metiu, 2011; Chauvet, 1998; A. Estrella \& F.S. Mishkin, 1998; J.D. Hamilton \& Lin, 1998) which show that stock market indices constitute potential leading indicators of economic activity.

The literature on the anomalous behaviour of predictive variables is extremely voluminous. Therefore, this review will focus on the important highlights which are informative, and motivate the research questions considered in this thesis.

Section 2.2 will outline a review of market efficiency. The efficient market hypothesis $(\mathrm{EMH})$ is considered a cornerstone of modern financial theory. The theory proclaims that 
stock market efficiency causes existing share prices to always incorporate and reflect all relevant information.

Section 2.3 will expound the evolution of the Capital Asset Pricing Model (CAPM), with a brief outline of the empirical support and rejection of CAPM. CAPM was developed by Sharpe (1964), Lintner (1965) and Black (1972), and describes the relationship between risk and expected return, and it is used in the pricing of securities.

Section 2.4 outlines the literature pertaining to the APT model, developed by Ross (1976) and provides one alternative to the CAPM, but it only approximated the relationship between factors and returns.

Section 2.5 examines the literature for the Fama-French three-factor model, with a brief outline of support and criticism. The three-factor model can be considered an extension of the CAPM model with size and book-to-market ratios as additional factors. Fama and French (1993) claimed that their model captured most of the anomalies not found in the CAPM.

Section 2.6 looks at literature relating to momentum research, Another major breakthrough in helping to explain anomalies in cross-section of results is Jegadeesh and Titman (1993) research. It was shown that stocks with strong past performance continue to outperform stocks with poor past performance in the next period.

Section 2.7 examines the history of predictive variable research, with an internationally focus, starting from the earliest studies through to recent research. 
Section 2.8 examines business cycles literature. The research literature on business cycles has a long and extensive history, including analyses back to the industrial revolution. However, this thesis will only show research dating back to the 1980s.

Section 2.9 examines market state literature. The examination of market states is a more recent phenomenon, with the majority of the research dating back to the 1990s. However, recent work by Cooper et al (2004) and Asem and Tian (2010) has shown the significant impact of market states influence on the returns of anomalous variables.

Section 2.10 outlines the literature for industries. This section investigates the historical literature pertaining to industries, including the importance of industries, anomalies interaction with industries and predictive industries.

Section 2.11 examines the literature for interaction between market cycles, business cycles and industries. There is a close correlation between business and market cycles; this section displays previous research with industries interaction with these two cyclical effects.

Section 2.12 examines the literature for interaction between market cycles, business cycles and industries for momentum profitability. This section follows the previous section, with the main focus for industries being momentum profitability over business/ market cycles.

Section 2.13 outlines the different behavioural theories regarding momentum profitability, including momentum's interaction with market states. Several behavioural theories have been developed to explain momentum returns, and long-run reversals. 
Finally, Section 2.14 completes the literature review, and offers a synopsis of the various strands of the literature offered in this chapter.

\section{$2.2 \quad$ Efficient market Hypothesis}

The efficient market hypothesis $(\mathrm{EMH})$ is considered a cornerstone of modern financial theory. The theory proclaims that stock market efficiency causes existing share prices to always incorporate and reflect all relevant information. The theory states that securities markets are extremely efficient in reflecting information about individual stocks and about the stock market as a whole. Thus, neither technical analysis, which is the study of past stock prices in an attempt to predict future prices, nor even fundamental analysis, which is the analysis of financial information such as company earnings, asset values, etc., help investors select "undervalued" stocks, and that the only way an investor can possibly obtain higher returns is by purchasing riskier investments.

There are three major versions of the hypothesis: "strong" "semi-strong", and "weak". Strong EMH claims that prices instantly reflect even hidden or "insider" information, semi-strong EMH claims that prices reflect all publicly available information and those prices instantly change to reflect new public information. Weak EMH claims that prices on traded assets (e.g., bonds, stocks or property) already reflect all past publicly available price information. There is powerful evidence against strong $\mathrm{EMH}$, while there is evidence for and against the weak and semi-strong EMH's (Fama, 1970).

The EMH hypothesis was developed by Eugene Fama at the University of Chicago as an academic concept of study through his published Ph.D. thesis in the early 1960s. Fama argued that competition ensured an efficient market (Fama, 1965). In support of the EMH, 
Basu (1977) claimed that in an efficient capital market, security prices fully reflect available information and thus provide unbiased estimates of the underlying values. Malkiel (2005) research shows that professional investment managers, both in the U.S. and abroad, do not outperform their index benchmarks. Further, the author argues that if market prices were often irrational and if market returns were as predictable as some critics have claimed, then professionally managed investment funds should easily be able to outdistance a passive index fund. Therefore, the paper concludes that this result provides evidence that market prices do seem to reflect all available information.

However, the EMH is highly controversial and often disputed. Empirical analyses have consistently found anomalies, with early studies, such as Nicholson (1968) who disputed the EMH when he investigated the variable price earnings ratio. His research shows that returns of stocks with low P/E ratios tend to be larger than warranted by the underlying risks, even after adjusting for any transactions costs and differential taxes, and therefore, would be inconsistent with the efficient market hypothesis. In addition, when Rosenberg, Reid and Lanstein (1985) utilized a book-to-price strategy and a specific return-reversal strategy on shares on the NYSE, they found persuasive evidence of market inefficiency, and argued that the results led to the inescapable conclusion that prices on the NYSE were inefficient.

Another blow to the EMH was the Fama and French (1992) paper "The Cross-Section of Expected Stock Returns" which found that size and book-to-market equity capture the crosssectional variation in average stock returns associated with size, E/P, book-to-market equity, and leverage anomalies. Another finding that disputed the EMH was Haugen and Baker (1996), who found in their paper that stocks with higher expected and realized rates of return are unambiguously lower in risk than stocks with lower returns. The authors state that the 
determinants of the cross-section of expected stock returns are stable in their identity and influence from period to period and from country to country. In addition, out-of-sample predictions of expected return are strongly and consistently accurate. The authors concluded by arguing the results seem to reveal a major failure in the Efficient Markets Hypothesis.

\subsection{Capital Asset Pricing Model}

Capital Asset Pricing Model (CAPM) is a model that describes the relationship between risk and expected return and it is used in the pricing of risky securities. It can be written:

$$
E\left[R_{i}\right]=r_{f}+\beta_{i}\left(E\left[R_{m}\right]-r_{f}\right)
$$

where $E\left[R_{i}\right]$ is the expected return of security i, $r_{f}$ is the risk-free rate, $\beta_{i}$ is the security's beta, and where $E\left[R_{m}\right]$ is the expected return of the market.

The theory behind CAPM is that investors need to be compensated in two ways: time value of money and risk. The time value of money is represented by the risk-free $\left(r_{f}\right)$ rate in the formula and compensates the investors for placing money in any investment over a period of time. The other half of the formula represents risk and calculates the amount of compensation the investor needs for taking on additional risk. This is measured by the systematic risk measure, beta.

The CAPM states that the expected return of a security or a portfolio equals the rate on a riskfree security plus a risk premium. If the estimated return does not meet or beat this required return, then the investment should not be undertaken. The security market line plots the results of the CAPM for all different risks (betas).The CAPM is a model for pricing an 
individual security or a portfolio. For individual securities, the capital asset pricing model (CAPM) is used to determine a theoretically appropriate required rate of return of an asset.

Sharpe (1964), Lintner (1965) and Black (1972) developed the CAPM in the belief that CAPM could explain the cross-section of stock returns, and that it could be used to test the theory of market efficiency hypothesis. Although Jensen, Black and Scholes (1972), Fama and MacBeth (1973) and Blume and Husic (1973) presented convincing evidence for CAPM's beta, the persistent anomalies in the empirical evidence that followed challenged the model. A major blow to CAPM was the Banz (1981) study, which examined the empirical relationship between the return and the total market value of NYSE common stocks. The author found that smaller firms have higher risk-adjusted returns on average than larger firms, and the size effect is not linear in the market value. Further, Banz (1981) argues that this size effect has been in existence for at least forty years, therefore the author concludes that this is evidence that the capital asset pricing model is misspecified.

In addition, another contradiction of the CAPM model is the positive relationship between leverage and average return documented by Bhandari (1988). The author argued that it is reasonable that leverage is associated with expected return and risk, but in the CAPM model, leverage risk should be captured by the market. Further critics of CAPM who found predictive anomalies are Stattman (1980), Rosenberg et al.(1985), and Chan, Hamao and Lakonishok (1991). These anomalies have steered academics towards finding a better measure of risk. 


\subsection{The Arbitrage Pricing Theory}

The Arbitrage Pricing Theory (APT) developed by Ross (1976) provided one alternative to the CAPM, but it only approximated the relationship between factors and returns.

The APT developed by Ross (1976) is an asset pricing model based on the idea that an asset's returns can be predicted using the relationship between that same asset and many common risk factors. This theory predicts a relationship between the returns of a portfolio and the returns of a single asset through a linear combination of many independent (but unspecified) macro-economic variables.

Roll and Ross (1980) examined the APT model using US data for individual equities over the 1962-72 period. The authors found at least three and probably four "priced" factors in the generating process of returns. The APT theory is supported in that estimated expected returns rely on estimated factor loadings, and variables such as the own standard deviation, and even though highly correlated with estimated expected returns, they do not add any further explanatory power to that of the factor loadings.

Further, in conditional support of APT model, Connor and Korajczyk (1988) conducted several multivariate tests of cross equation restrictions imposed by the APT using U.S. monthly data. Over a period of four non-overlapping five-year sub-periods from 1964 to 1983, the authors found that a five-factor version of the APT model was able to explain the January size effect that had been well documented in previous U.S. research. They argued that this success to seasonality in the estimated risk premiums of the multi-factor model, is not captured by the single-factor CAPM. However, the results showed that the APT cannot explain non-January specific mispricing. Therefore, they concluded that while neither the 
CAPM nor the APT are perfect models, their data suggests that the APT is a realistic empirical alternative. In Australia, Faff (1992) also tests for time variation in risk premia using an APT model. The author found that the APT model performs better than the CAPM, however, neither model could explain monthly seasonal mispricing.

\subsection{Fama and French Three-Factor Model}

The three-factor model introduced by Fama and French (1993) offered another asset pricing alternative. The three-factor model can be considered an extension of the CAPM model with size and book-to-market ratios as additional factors. Fama and French (1992) claimed that their model captured most of the anomalies not explained by the CAPM. The model can be written:

$$
E\left[R_{i}\right]=r_{f}+\beta_{i}\left(E\left[R_{m}\right]-r_{f}\right)+s_{i} E[S M B]+h_{i} E[H M L]
$$

where $S M B$ stands for "small (market capitalization) minus big" and $H M L$ for "high (book-tomarket ratio) minus low". The size factor measures the excess returns of small caps over big caps and the book-to-market factor measures the excess returns of value stocks over growth stocks. These factors are calculated from combinations of portfolios constructed by ranking stocks on the market capitalisation and book-to-market ratios of firms.

Fama and French (1993) based their paper on the results on Fama and French (1992) study which examined the variables of size, E/P, leverage, and book-to-market equity in the crosssection of average stock returns. They found that used alone, size, E/P, leverage, and book-tomarket equity have explanatory power. However, in combinations, size (S) and book-tomarket equity $(\mathrm{B} / \mathrm{M})$ seem to absorb the apparent roles of leverage and $\mathrm{E} / \mathrm{P}$ in average returns. FF added size and $\mathrm{B} / \mathrm{M}$ factors to beta, to create the FF three factor model as an asset 
pricing explanatory model. FF further claimed that their result showed that the two empirically determined variables, size and book-to-market equity, do a good job explaining the cross-section of average returns on NYSE, Amex, and NASDAQ stocks for the 19631990 period, as the three-factor model captures $96 \%$ of the variation on returns on portfolios of small, and high book-to-market firms.

There were early criticisms of the FF three-factor model, such as Chan and Lakonishok (1993), Kothari, Shanken and Sloan (1995) and Clare, Priestly and Stephen (1997) who argued that FF (1993) results could be due to noisy data and inefficient methodologies. Kothari et al. (1995), for example, argued that their research over a similar period showed the relation between book-to-market equity and returns is weaker and less consistent than that in Fama and French (1992) study, and that past book-to-market results using COMPUSTAT data are affected by a selection bias. However, in their 2004 paper Fama and French (2004) argue that their three-factor model is now the dominant risk-adjusted methodology in finance research. Although critics will argue that other factors are needed, such as momentum, which was added to FF three factors to create Carhart's four factors. As well, Fama and French (2015) created a five factor model, with profitability and investment added to the three factor model. FF argues this model enables a better performance than the three factor model, however, FF acknowledges that the five factor model's main problem is its failure to capture the low average returns on small stocks.

\subsection{Momentum}

Another major anomaly in cross-section of returns was identified by Jegadeesh and Titman's (1993) paper, which documented that a measure of momentum was an important predictive variable. The authors found that firms which underperform (outperform) over the preceding 
six-month period tend to on average underperform (outperform) over a subsequent six-month period. They found that stocks with strong past performance continue to outperform stocks with poor past performance in the next period with an average excess return of about $1 \%$ per month (Jegadeesh and Titman, 1993; Chan, Jegadeesh and Lakonishok, 1999).

Carhart (1997) utilized the momentum factor as part of his asset pricing model. His study investigated whether funds following the momentum strategy would realize better performance before management fees and transaction expenses. Using the momentum variable from Jegadeesh and Titman (1993) study, Carhart proposed his four-factor model (Carhart, 1997) which has a momentum factor added to the Fama-French three- factor model. He was careful not to claim that his momentum factor was a risk-factor. Thus the proper use of the four-factor model is to see if the model can explain other anomalies. A number of international studies have since confirmed momentum is a persistent anomaly, specifically, Rouwenhorst (1998) and Chan, Hameed and Tong (2000). However, the four-factor model has not been able to explain a number of more-recent anomalies. For example, Cooper, Gulen and Schill (2008) show that the asset growth effect could not be explained by the Fama and French (1993) and Carhart (1997) three-factor and four-factor models.

Finally, Hou, Karolyi and Kho (2011) show that over a three decade period, a multifactor model that includes factor-mimicking portfolios based on momentum captures significant time series variation for over 27,000 stocks from 49 countries. In addition, researching international stock returns across four regions, Fama and French (2012) claim that momentum has been pervasive across the regions of North America, Europe and Asia Pacific, but not in Japan. Asness, Moskowitz and Pedersen (2013) argue that they find consistent momentum return premia across eight asset classes and diverse markets. The study 
investigated the financial markets of the United States, United Kingdom, continental Europe and Japan, as well as 18 equity index futures, spot exchange of 10 currencies, 10 government bonds and 27 commodity futures, across the time period of 1972 to 2011.

\subsection{Predictive Anomalous Research.}

This section examines predictive variable research internationally over a time line, concentrating on research studies from 1968 through to recent literature. It is noted that predictive variable anomalies have more (less) effect in different countries and in different time lines leading to an ongoing debate about the importance and relevance of these variables.

The idea of ratio analyses began approximately in 300 BCE, when Euclid's accomplished his rigorous analysis of the properties of ratios in Book V of his Elements (Horrigan, 1968). Horrigan (1968) further claims that the adoption of ratios as a tool of financial statement analysis began in about the 1890 's, where there arose the practice of comparing current assets of an enterprise to its current liabilities. The next major stage was in 1912, when Alexander Wall began a compilation of a large sample of financial statements from the files of commercial paper brokers. This analysis culminated in his classic report of 1919, "Study of Credit Baro-metrics" (Horrigan, 1968).

Horrigan (1968) further states that arguably the most notable early achievement in ratio analyses was when the du Pont Company began to use a ratio "triangle" system in evaluations of its operating results in 1919. The top of the triangle was a return on investment ratio (profits/total assets) and the base consisted of profit margin ratio (profits/sales) and a capital 
turnover ratio (sales/total assets). In the early 1940's, Merwin's (1942) study is considered the earliest ratio predictors paper. He concluded that three ratios were very sensitive predictors of discontinuance, up to as early as four to five years in some instances (Horrigan, 1968).

\section{Pre 1980s}

One of the major early contributors who analysed anomalies was Basu (1977), who claimed that low P/E portfolios earn superior returns on a risk-adjusted basis. The author investigated the proposition of the price-ratio hypothesis on the relationship between investment performance of equity securities and taxes. During the period April 1957-March 1971, and utilising COMPUSTAT files of NYSE Industrial firms, Basu claimed that the low P/E portfolios seem to have, on average, earned higher absolute and risk-adjusted rates of return than the high P/E portfolios, even after adjusting for any additional search and transactions costs.

In dispute of Fisher hypothesis that returns are compensated for inflation, Nelson (1976) examined the monthly stock returns of the Standard and Poor's 500 Index for January 1973 through June 1974, and the Scholes Index of value-weighted returns for the period January 1953 through December 1972. The author found that there is a negative relationship between returns of both anticipated and unanticipated changes in the rates of inflation, over the postwar period. Further, between the post-sample prediction tests for 1973 and the first half of 1974, the results indicate that past rates of inflation could have been used to pursue trading rules that generated higher returns than a buy-and-hold policy during that period.

Also investigating inflation's effect on returns, Fama and Schwert (1977) found that common stock returns were negatively related to the expected component of the inflation rate, and probably also to the unexpected component. Data includes stock returns for the equal and 
value weighted portfolios from the New York Stock Exchange (NYSE), inflation was estimated from the Bureau of Labor Statistics Consumer Price Index, and US bonds and treasury bills was used, for the period of 1953 to1971. The authors argue their results showed that U.S. government bills and bonds were a complete hedge against expected inflation, and private residential real estate was a complete hedge against both expected and unexpected inflation.

Another early major contributor was Ball (1978), whose research studied the cross-section of returns between high and low earnings per share, and dividend yield. Ball (1978) claimed that the earnings yield is the inverse of the price-earnings ratio and can be so defined even when earnings per share are zero or negative. In addition, empirical evidence has indicated that portfolios of stocks with high earnings yields tend to outperform portfolios of stocks with low earnings yields. Further, studies of the market reaction to earnings announcements reveal post-announcement excess returns. Therefore, Ball hypothesised that this persistent result is due to earnings acting as a proxy for omitted variables or other misspecification effects in the two-parameter asset pricing model.

\section{0s}

Prominent research showing the book-to-market (B/M) effect was in 1980, where Stattman's (1980) research shows high B/M firms earned higher returns than low B/M firms, and further, both find a significant negative relation between abnormal returns and the degree to which market value of equity exceeds book value of equity, whereby they interpreted this relation as a proxy for the size effect.

In one of the pervasive empirical facts in financial economics literature, Banz (1981) study shows that that smaller firms have higher average risk adjusted returns than do larger firms. 
Banz (1981) claims that this size effect has been in existence for at least forty years and is evidence that the capital asset pricing model is misspecified. In examining the empirical relationship between the total market value of NYSE common stocks and their returns for the period of 1936 to 1975 , Banz found that the main effect occurs for very small firms, with little difference in returns between average sized and large firms, and that the size effect is not linear in market value. In addition the author points out, it is not known whether size per se is responsible for the effect or whether size is just a proxy for one or more true unknown factors correlated with size.

Keim (1983) followed up with further research which demonstrates the relationship between abnormal returns and size is always negative. The study examines the empirical relationship between monthly returns and market value of NYSE and AMEX common stocks, between 1963 to 1979 . The author found the effect is more pronounced in January than in any other month, and concluded that there is size effect (on average small firms earn larger riskadjusted returns than large firms).

In his study over the $4^{\text {th }}$ quarter 1975 to $3^{\text {rd }}$ quarter 1977 period with stocks noted in the Wall Street Journal, Reinganum (1981) found that portfolios based on earnings/price (E/P) or firm size ratios experience average returns systematically different from those predicted by the CAPM. In addition, the 'abnormal returns persist for at least two years, leading to his claim that the evidence seems to indicate that the equilibrium pricing model is misspecified, as this persistence reduces the likelihood that these results are being generated by market inefficiency. However, the author further claims that the data also shows that the firm size effect largely subsumes the E/P effect, as the E/P effect does not emerge after returns are controlled for the firm size. Thus, while the value anomaly E/P exists when each variable is 
considered separately, the two anomalies seem to be related to the same set of missing factors, and these factors appear to be more closely associated with firm size than E/P ratios. The author concludes that his study reports empirical anomalies that suggest that either capital markets are inefficient, or the simple one-period capital asset pricing model (CAPM) is misspecified.

In another important early paper, Basu (1983) also investigates earnings-price ratios and the size effect on cross-section of average returns on the common stock in NYSE firms over the time period of 1962-1978. Basu (1983) claims that the common stock of high E/P firms earn, on average, higher risk-adjusted returns than the common stock of low E/P firms. Moreover, this effect is clearly significant even if differences in firm size are controlled for. However, while the common stock of large firms appear to have earned substantially lower returns than the common stock of small firms, the size effect is substantially reduced when returns are controlled for differences in risk and $\mathrm{E} / \mathrm{P}$ ratios. The author claims the results indicate that the $\mathrm{E} / \mathrm{P}$ effect is not entirely independent of firm size and that the effect of both variables on expected returns is considerably more complex than previously recognised in the literature.

In a study that contradicts Reinganum (1981) and Basu (1977) studies, Cook and Rozeff (1984) examined size and earnings/price ratio effects to see if one effect subsumes the other or if are there two separate effects. Utilising NYSE stocks for the period of 1964 to 1981, the study demonstrates that equity returns are related to size and the earnings/price ratio, as well as the month of January. In rebutting Reinganum's (1981) research, the authors claim that Reinganum's finding that size subsumes the E/P ratio is caused by a fortuitous choice of methods, and that Basu (1977) finding that E/P ratio subsumes size appears to be samplespecific. 
Important research in 1984 unveiled the predictive effects of the dividend yield on future stock returns. Rozeff (1984) argues that his research provides evidence that dividend yields are directly related to and predict future stock returns, with higher yield predicting higher returns. During the period of 1926 to 1961, and using the S\&P 500 returns, the author argues that the results show that dividend yields provide superior predictions of equity risk premiums in terms of lower mean absolute error, lower mean square error, and lower bias compared with the method of using historical realized returns. In addition, the author utilizes the Golden Rule of Accumulation view that real long-term growth equals the real rate of interest, with the constant dividend growth model, to show that dividend yield is directly related to the risk premium.

Rosenberg, Reid and Lanstein (1985) utilized two defined strategies to investigate book-tomarket and specific-return-reversal strategies. Data consists of 1,400 of the largest firms in the COMPUSTAT database for the period 1980-1984, the authors show that a strategy buying stocks with a high book/market per share and selling stocks with a low book/market ratio has unusually high average returns. The specific-return-reversal strategy selects on the basis of positive or negative monthly specific returns, which tend to reverse themselves, and also shows above average returns. Finally, the authors argue that the success of the two strategies imply that the actual market prices were inefficient

In a paper spanning 16 years, from 1962-1978, and utilising NYSE and AMEX stocks, Kross (1985) investigates if a low share price effect influences abnormal positive returns by analysing share price, shares outstanding for market value and earnings per share. The study finds that share price represents approximately three quarters of the relationship between 
stock returns and either earning yields or market value. Also, although the size variable had excess $9.3 \%$ returns for the period, most of the strength of the return can be attributed to the price component, as well as the excess return for E/P variable. Kross (1985) concludes that the low price effect seems to subsume the earning yield and size effect.

Amihud and Mendelson's (1986) study is credited with being the first to report a liquidity effect: the observation that as liquidity increased, returns then decreased. The authors investigate the bid-ask spread on asset pricing, and analyse a model in which investors with different expected holding period's trade assets with different relative spreads. Over the period from 1961-1980, the average portfolio risk-adjusted returns increase with the bid-ask spread, while the slope of the return spread relationship decreases with the spread. Finally, the authors verify that the spread effect persists when firm size is added as an explanatory variable in the regression equations.

Utilising U.S. monthly stock return data, Campbell (1987) during the periods of 1959-1979 and 1979-1983, shows that the state of the term structure of interest rates predicts stock returns. The results also show that risk premia on Treasury bills move somewhat independently with those on 20 year Treasury bonds, whilst risk premia on stocks appear to move closely together with those on 20 year Treasury bonds. The author also argues that the data strongly rejects a single latent variable model. The paper examines the relationship between conditional means and variances of returns on stocks, bills, and bonds, with the results showing there is uncertainty about whether nominal interest rates are important in pricing both short and long term assets. 
Bhandari's (1988) research reports a leverage effect by observing a significant positive relationship between leverage and returns. Bhandari (1988) controlled for the beta and firm size, and shows expected common stock returns are positively related to the ratio of debt (non-common equity liabilities) to equity. Utilizing monthly US stock return data from CRSP and COMPUSTAT, over two-year sub periods that go from 1948-1949 to 1980-1981, the study also shows this effect whilst testing for the January effect (by including as well as excluding January) though the relationship is much larger in January. The author claims this relationship is not sensitive to variations in the estimation technique, market proxy, etc. and the study indicates that the debt/equity ratio premium is not likely to be just some kind of risk premium.

Campbell and Shiller (1988) investigate if the long historical averages of real earnings help forecast present values of future real dividends. The authors utilized aggregate U.S. stock market data, for the period 1871 to 1986 , and claim their results predicted the present value of future dividends each year, which is roughly the weighted average of moving-average earnings and current real price, with between $2 / 3$ and $3 / 4$ of the weight on the earnings measure. The authors argue that long horizon stock returns are highly forecastable.

Following up on previous research on interest rates, Breen, Glosten and Jagannathan's (1989) research finds that the one-month interest rate is useful in forecasting the variance and sign of the excess return on stocks. During the period of 1954 to 1986 , and using the value weighted and the equally weighted indices of stocks in the NYSE obtained from CRSP, the authors examined if their findings would provide a trading stratagem that would benefit portfolio managers. Their results show that asset shifting would provide a monthly two basis points 
higher average return on the value weighted index, with the variance of monthly returns on the managed portfolio being about $60 \%$.

\section{0s}

Chan, Hamao and Lakonishok (1991) study show that a high ratio of cash flow to price also predicts higher returns. Their study was over the time frame of 1971 to 1988 with a comprehensive high-quality data set that includes both manufacturing and nonmanufacturing firms from both sections of the Tokyo Stock Exchange, as well as delisted firms. Their research relates cross-sectional differences in returns on Japanese stocks to the underlying behaviour of four variables: size, book-to-market ratio, earnings yield and cash flow yield. The authors findings reveal a significant positive relationship between these variables and expected returns in the Japanese market. Of the four variables considered, the cash flow yield and book-to-market ratio have the most significant positive impact on expected returns.

In a seminal paper, Fama and French (1992) study over the time period of 1963-1990, utilized stocks from the NYSE, Amex, and NASDAQ. Fama and French examined four variables, size, leverage, book-to-market equity, and earnings-price ratios for their capacity to predict abnormal positive returns. Their results show that two variables, book-to-market equity and size, combine to capture the cross-sectional variation in average stock returns associated with market returns.

In a paper that seemingly contradicts FF (1992) findings, Bhardwaj and Brooks (1992) argue that several recent studies show that the size effect is subsumed by a stock price effect. They refer to several studies showing a strong inverse relationship between risk-adjusted returns and stock price e.g. Fritzemeier (1936), Blume and Husic (1973), Bacharach and Galai (1979). Ibbotson and Sinquefield (1989) also show that in general, small firm outperformance 
was substantially larger between 1971 to 1980 , than between 1981 to 1990 . In addition, Kross (1985) and Bhardwaj and Brooks (1992) provide evidence that the size effect is subsumed by a low price effect. The authors investigate the neglected firm effect, and whether excess returns on neglected stocks are a manifestation of a stock price effect. The authors claim their results suggest that the independent neglected firm effect is still significant, although the results are much weaker than in prior studies.

In a ground breaking paper, Jegadeesh and Titman (1993) study finds the momentum effect. Their study demonstrates that stocks with low returns over the last year tend to have low returns for the next few months and stocks with high past returns tend to have high future returns. In a time period from 1965 to 1989 and utilising US data from CRSP, the study selects stocks based on their past 6-month returns and holds them for a further 6 months. The returns are then designated into a portfolio of winners and losers, the trading scheme then buys the winners and sells the losers, with the result realising a compounded excess return of $12.01 \%$ per year on average. In addition, the authors claim that the profitability of these strategies are not due to their systematic risk or to delayed stock price reactions to common factors. Importantly, the authors found that part of the abnormal returns generated in the first year after portfolio formation dissipates in the following two years.

In another notable study, Lakonishok, Shleifer (1994) combined variables, cash flow to price and growth in sales as explanatory variables to investigate which combination would produce the best results. They reported that they found high Cash flow to Price $(\mathrm{C} / \mathrm{P})$ firms outperformed low C/P firms. Over a time span of April 1968 to April 1990, and using stocks quoted on the NYSE and AMEX, they examined the combination of three variables C/P, growth in sales (GS), and earning to price (E/P). The authors claim both $\mathrm{GS}$ and $\mathrm{C} / \mathrm{P}$ 
contribute a great deal of explanatory power in these bivariate classifications. A variety of investment strategies involving sorting into portfolios and buying out-of-favour (value) stocks have outperformed glamour strategies over a 22 year period. They discovered that low $\mathrm{C} / \mathrm{P}$ stocks with low past sales growth, which aren't defined as glamour stocks, have an average annual future return of 16.2 percent, but low $\mathrm{C} / \mathrm{P}$ stocks with a high past sales growth, which are defined as glamour stocks, have an average annual future return of only 11.4 percent.

In addition, the results from the GS and the E/P ratio show that the average annual difference in returns over the 5-year period between the two extreme portfolios is 11.2 percent per year. However, their findings suggest the combination of $\mathrm{C} / \mathrm{P}$ and $\mathrm{GS}$, the (E/P, GS) strategy produces substantially higher returns than either the E/P or the GS strategy alone. The authors found that among firms with the lowest E/P ratios, the average annual future return varies from 18.3 percent for those with the lowest past sales growth to 10.9 percent for firms with the highest past sales growth. Also, using an E/P strategy seems to require differentiating between the stocks with depressed earnings expected to recover and the true glamour firms. Their results show that GS has significant explanatory power for returns even after sorting by $\mathrm{B} / \mathrm{M}$.

Barbee, Mukherji and Raines (1996) also takes issue with FF (1992) claim that the book-tomarket $(\mathrm{B} / \mathrm{M})$ is) capture the roles of various other factors that have been proposed for explaining stock returns, namely the earnings-price ratio, the stock's beta and leverage measures. Their study shows that the sales to price $(\mathrm{S} / \mathrm{P})$, as well as the debt to equity $(\mathrm{D} / \mathrm{E})$, absorb the roles of the B/M and MV in explaining stock returns during the 1979-91 period. The stock return data was obtained from the CRSP tapes and financial data from the annual 
COMPUSTAT tapes. The authors claim their methodology is generally similar to that described in Fama and French's (1992) paper and involved monthly regressions of stock returns on financial data from the previous year. Their results show the sales-price ratio captures the role of the debt-equity ratio in explaining stock returns, and neither the bookmarket value of equity ratio nor the market value of equity has consistent explanatory power for stock returns, therefore reinforcing the argument of Kothari et al. (1995) that the apparent significance of the $\mathrm{B} / \mathrm{M}$ for expected stock returns may be data specific and/or period specific. In addition, the authors' findings support Bhandari's (1988) conclusion that the D/E has a significant positive relationship with stock returns.

Haugen and Baker (1996) show in a comprehensive study of stock return predictors in the cross-section returns, that the strongest determinants of expected returns are the trading volume, past returns, and accounting ratios such as price/earnings. In a time period of 1979 through 1993 with data obtained from several countries, they find no evidence that risk measures such as total volatility or systematic risk are material for a cross-section of equity returns. Further, they find stocks with higher expected and realised rates of return are unambiguously lower in risk than stocks with lower returns. Second, the important determinants of expected stock returns are strikingly common to the major equity markets of the world.

Kothari and Shanken (1997) examined if two financial ratios would show abnormal predictive effects. Their research finds reliable evidence that both book-to-market and the dividend yield track time-series variation in expected real stock returns over the period 1926 1991 and the sub period 1941-1991. Their results show that book-to-market produced the overall stronger results, with the dividend yield showing stronger returns in the sub period. 
Data for returns and dividend yield information is from equal and value weighted CRSP indexes. Both ratios individually and combined returned significantly positive results.

In a significant paper, Carhart (1997) utilized the momentum effect as part of a measurement model. In this case he investigated whether funds following the momentum strategy would realise better performance before management fees and transaction expenses. Following Jegadeesh and Titman's (1993) landmark paper investigating momentum as an explanatory variable for abnormal returns, Carhart (1997) proposed his four-factor model which is constructed by adding a momentum factor to the Fama-French three-factor model. His findings show that momentum has several explanatory values and limitations. Specifically, the paper indicated that Jegadeesh and Titman's (1993) one-year momentum in stock returns accounts for Hendricks, Patel, and Zeckhauser's (1993) hot hands effect in mutual fund performance. The authors' findings also compliments Wermers (1996) study, which suggests that it is the momentum strategies themselves that generate short-term persistence, and Grinblatt, Titman, and Wermers (1995) who find that funds following momentum strategies realise better performance before management fees and transaction expenses. Carhart (1997) also found that whilst his sample was imperfect, individual mutual funds that appear to follow the one-year momentum strategy earn significantly higher abnormal returns after expenses.

Reinforcing the findings from Kothari and Shanken (1997), Ponti and Schall (1998) published a paper that examined the predictive qualities of book-to-market, interest yield spreads and dividend yields variables over the period 1926-1994. Their paper covered a similar time span, and testing for three ratios [two the same] as Kothari and Shanken (1997), although with different stock data from the DJIA and S\&P 500 indexes. Their paper also 
finds strong predictive qualities for the book-to-market variable, and interest yield spreads with dividend yield showing significantly positive results in sub periods.

Campbell and Shiller (1998) argue their findings show that the dividend to price ratio does not predict future dividend growth, rather, it predicts future price changes. In the period between 1872 to 1983 , using US data, their results also showed that earnings per share is not good at predicting stock prices in the year ahead, however, the ratio is a good predictor for ten year growth in stock prices. Lamont (1998) also investigates another predictive element of dividends, in this case the dividend payout ratio. The author argues that the aggregate dividend payout ratio forecasts excess returns on both stocks and corporate bonds, with high dividends forecasting future high returns. During the period 1947 to 1994, and utilising U. S. data, their findings also show that high earnings forecast low returns, with the correlation of earnings with business conditions giving them predictive power for returns. Moreover, dividends and earnings contribute substantial explanatory power at short horizons. However, long horizon stock returns in the mid-1990s are caused not by dividends or earnings, but by high stock prices.

\section{0s}

Contributing another aspect of predictive anomalies, Baker and Wurgler's (2000) research shows that share equity issues as a proportion of the total of new equity and debt issues is a strong predictor of US stock market returns. In the period between 1928 and 1997, their results show that firms issue relatively more equity than debt just before periods of low market returns; the fact that the equity share issuance sometimes predicts significantly negative market returns suggests inefficiency, and that firms "time" the market component of their returns when issuing securities. The results have stable predictive power after controlling for other known predictors. 
Leledakis and Davidson's (2001) research investigates whether Barbee, Mukherji et al.'s (1996) research contradicting FF (1993) is still relevant. The authors investigate whether two alternative variables, the debt-to-equity ratio and the sales-to-price ratio $(\mathrm{S} / \mathrm{P})$, have more explanatory power for stock returns than the market value of equity and the ratio of book value of equity to market value of equity. Instead of using US data, the authors utilize data from the London Share Price Database and DataStream International to provide a sample of 1,420 nonfinancial U.K. companies for the period between 1980 through 1996. They found that the S/P ratio does have significant explanatory power beyond the contribution of $\mathrm{B} / \mathrm{M}$ and $\mathrm{MV}$, and the explanatory power of $\mathrm{D} / \mathrm{E}$ is captured by $\mathrm{S} / \mathrm{P}$. However, in contrast to the Barbee, Mukherji et al. (1996) paper, they found that for the London stock exchange data, $\mathrm{S} / \mathrm{P}$ and $\mathrm{D} / \mathrm{E}$ do not fully absorb the roles of $\mathrm{B} / \mathrm{M}$ and $\mathrm{MV}$ in explaining the cross-section of average stock returns (although B/M and MV had only limited effects as they were only significant in two periods).

In investigating the role of fluctuations in the aggregate consumption-wealth ratio for predicting stock returns, Lettau and Ludvigson (2001) utilized U.S. quarterly stock market data for the period between 1952 to 1998 . They find that fluctuations in the consumptionwealth ratio are strong predictors of both excess returns over a Treasury bill rate, and real stock returns. The authors also claim that this variable is a better forecaster of future returns at short and intermediate horizons than is the dividend payout ratio, dividend yield, and other popular forecasting variables. Further, the findings imply that a widespread class of optimum models of consumer behaviour indicate that the log consumption aggregate wealth ratio summarizes expected returns on market portfolio or aggregate wealth. 
In updating a previous paper, Campbell and Shiller (2001) again examine the use of dividend price ratios and price earnings ratios as forecasting variables for the stock market. Data consists of US stock returns, in an updated time frame of 1871 to 2000, and aggregate quarterly data for twelve countries since 1970. The authors found a similar result to their 1998 paper, that the ratios do poorly in forecasting future productivity growth, future earnings growth and future dividend growth. Rather, the ratios were useful primarily in forecasting future stock price changes.

Lau, Lee and McInish (2002) investigate the Singapore and Malaysian share markets for the period 1988-1996. Their paper examined the relationship between stock returns and beta [risk], size, the earnings-to-price ratio, cash flow-to-price ratio, book-to-market equity ratio, and sales growth and their ability of these ratios to predict stock returns. The authors found the presence of anomalous behaviour for only some ratios in these two emerging markets. With beta, size (sales growth) having positive (negative) significant results during different sub periods. The authors argue that although Singapore is considered a more mature market, Malaysia is considered an emerging opaque market with accompanying problems.

Chan, Jason and Lakonishok (2003) study examined if certain variables are predictive over the long term. The authors examine if earnings yields, book-to-market equity and sales-toprice, are associated with growth on an ex ante as well as ex post basis. Over the time span of 1951-1997, and utilising US monthly stock returns from the Compustat Active and Research files, the authors show that an expanded set of forecasting variables of net sales, operating income before depreciation and income before extraordinary items available for common equity, has scant success in predicting future earnings growth. Sales growth shows some persistence, but there is essentially no predictability or persistence in growth of earnings 
across all firms. Further, market valuation ratios have little ability to discriminate between firms with high or low future earnings growth. The study also found only about 10 percent of firms grow at a rate in excess of 18 percent per year over 10 years The authors conclude that investors should be wary of stocks that trade at very high multiples over time, and very few firms are able to live up to the high hopes for consistent growth that are built into such rich valuations.

Lewellen (2004) research further emphasises certain ratios predictive effect, by examining the ability of dividend yield, book-to-market and the earnings-price ratios to predict aggregate stock returns over the time frame of 1946-2000 in the US stock market. Lewellen reports that dividend yield predicts market returns over the entire period, as well as in various subsamples. The book-to-market and the earnings-price ratios predict returns during the shorter sample 1963-2000. Interestingly, Lewellen investigated previous papers on dividend yield for small sample bias and reported that the small sample bias indicated less predictive ability than the dividend yield actually has.

Another research paper investigating dividend's yield predictive effect shows that inflation explains a majority of the yield's effect. Campbell and Vuolteenaho (2004) decompose the S\&P 500's dividend yield between 1927 to 1997 into the subjectively expected risk premium, a rational forecast of long-run real dividend growth, and residual mispricing attributed to the market's forecast of dividend growth deviating from the rational forecast. The authors argue that persistent use of the Fed model' by Wall Street, and Modigliani and Cohn's (1979) hypothesis, infer that the stock market incorrectly extrapolates past nominal growth rates without taking into account the impact of time-varying inflation. The authors argue that their 
results are consistent with the Modigliani-Cohn hypothesis, and the level of inflation explains almost $80 \%$ of the time-series variation in stock-market mispricing.

Utilizing international G-7 data for the period between 1929 to 2003, Rangvid (2006) claims his results show that the ratio of share prices to GDP tracks a major fraction of the variation over time in expected returns on the aggregate stock market. The author argues the ratio captures more of the variation than does price-dividend and price-earnings ratios, including often providing additional information about excess returns. Further, the author also claims that the price-output ratio tracks long-term U.S. cumulative stock returns almost as well as the consumption wealth (cay) ratio, although the cay ratio tracks variation in U.S. excess returns better. However, the price-output ratio is easily constructed for non-U.S. countries, and involves no parameter estimation.

Ang and Bekaert (2007) examine the predictive power of dividend yields, earning yields and short rates for forecasting interest rates, cash flows and stock excess returns. Utilising data from several countries, including US data for the time span of 1935 to 2001, the authors report that dividend yields predict excess stock returns only at short horizons, and high dividend yields predict future high interest rates. As well, dividend yields are able to predict future cash-flow growth rates, however, not future cash-flow excess returns. The authors also claim that the short rate predicts excess returns only at short horizons, and has a stronger predictive effect compared to dividend yield, and earnings yields significantly predict future cash flows. Finally, a present value model that matches the data shows that short rate and discount rate movements play a large role in explaining the variation in dividend yields. 
Pursuing a different predictive effect than the dividend yield, Boudoukh, Michaely, Richardson, and Roberts's (2007) research uses various measures of payout yield rather than dividend yield for asset pricing models. Their results find significant predictability in the time series when net payout (dividends plus repurchases minus issuances) and payout (dividends plus repurchases) and yields are used. Utilising US stock return data from 1971 to 2003, the authors find that net payout yields has a stronger predictive effect for the cross section of expected stock returns than dividend yields, and that the high minus low payout yield portfolio is a priced factor.

Guo (2006) claims that the consumption-wealth ratio in conjunction with a degree of aggregate stock market volatility displays substantial out-of-sample forecasting power for excess stock market returns. Utilising the value weighted stock market U.S. returns obtained from CRSP, for the period of 1952 to 2002, the authors also report trading strategies based on the documented predictability, produce returns of higher mean and lower volatility than the buy-and-hold strategy does. The authors also argue that stock return predictability is not inconsistent with rational pricing, a point that has been emphasized by Campbell and Cochrane (1999) and Guo (2004) amongst others.

In their 2008 study, Fama and French (2008) examine the anomalous returns associated with net stock issues, accruals, and momentum, and conclude they are pervasive; they show up in all size groups (micro, small, and big) in cross-section regressions, and they are also strong in sorts, at least in the extremes. Over a time span of 1963 to 2005, data consists of monthly stock returns from NYSE, Amex, and (after 1972) NASDAQ indexes, with stocks returns organized into three size groups - microcaps, small and big stocks. The authors explore the pervasiveness of these return anomalies via sorts and cross-section regressions estimated 
separately on the three size groups. Their result shows that there is an asset growth anomaly in average returns on microcaps and small stocks, but it is absent for big stocks. The asset growth and profitability anomalies are less robust. Among profitable firms, higher profitability tends to be associated with abnormally high returns, but there is little evidence that unprofitable firms have unusually low returns.

Investigating oil prices as a predictive variable, Driesprong, Jacobsen and Maat (2008) report that oil prices provide statistically and economically significant predictability of stock returns, in 18 countries indexes from 1973 to 2003. Further, oil price changes have a negative correlation with future stock returns. The authors argue their results cannot be explained by time-varying risk premia, as positive oil price changes also significantly predict negative excess returns, and their findings are consistent with the hypothesis of a delayed reaction by investors.

Extending previous research, that cash flow is a positive cross-sectional predictor of returns Desai, Rajgopal, and Venkatachalam, (2004) investigate whether the accruals anomaly is a manifestation of the glamour stock phenomenon documented in the finance literature. Utilising the universe of stock returns from NYSE, AMEX and NASDAQ, for the period of 1973 to 1997, the authors argue their research shows that accruals is a negative crosssectional predictor of abnormal stock returns. Hirshleifer, Hou and Teoh (2009) examines whether the cash flow effects, and firm-level accrual extend to the aggregate stock market. Their results show that cash flows is a negative predictor of aggregate stock returns, and aggregate accruals is a strong positive time series predictor. Utilising the value-weighted portfolio of the subsample of value-weighted CRSP US real estate index (CRSPRET), over the time period of 1965 to 2005, the authors argued that innovations in cash flows are 
positively correlated with returns, and innovations in accruals are negatively contemporaneously correlated with aggregate returns.

Goyal and Welch (2008) claim they utilize a comprehensive look at the empirical performance of equity premium prediction, and investigate the performance of variables that have been suggested by the academic literature to be good predictors of the equity premium. The authors claim their research shows these models have predicted poorly both in-sample and out-of-sample for 30 years. Data consists of monthly returns from the S\&P 500 index from 1926 to 2005, utilising CRSP month-end values.

\section{0 onwards}

Alexakisa, Patrab and Poshakwalec (2010), examine the predictability of stock returns in the Athens Stock Exchange during 1993 to 2006 by utilising 10 accounting and financial variables, with 47 companies in the sample data. Their results indicated that the selected set of financial/accounting ratios contained significant information for predicting the crosssection of stock returns, with portfolios selected on the basis of financial ratios producing higher than average returns.

In a 2011 study, Fama and French (2011) investigate whether empirical asset pricing models capture the value and momentum patterns in international average returns and whether asset pricing seems to be integrated across the four regions. They find that for three regions (North America, Europe, and Japan), local models that use local explanatory returns provide passable descriptions of local average returns for portfolios formed on size and value. However, even local models were less successful in tests on portfolios formed on momentum and size. Data is from Bloomberg, supplemented by DataStream and Worldscope, over a time period of 1989 to 2011. The authors also find there are value premiums in average returns in 
all four regions, and value premiums are larger for small stocks except for Japan. In addition, there are strong momentum returns in all regions except Japan.

\subsection{Business Cycles}

The research literature on business cycles has a long and extensive history, including in-depth analyses back to the industrial revolution. However, this thesis will only include recent research dating back to the 1980s.

In the 1980's, different models and variables interaction with business cycles were studied, including Arnott and Copeland (1985) who claimed that many investors use different security selection models to evaluate a broad spectrum of investment information. The authors further claimed that individual models often prove vulnerable to the dynamics of the business cycle, and a model that performs well in one economic environment is likely to perform poorly in a different economic environment. Therefore, to the extent that model weakness or strength can be forecast, investors can employ models with greater effectiveness. The authors utilize US stock returns, and Department of Commerce (DOC) Coincident Indicators Index to determine business cycles, over the time frame of 1968 to 1982.

In developing an analytical and empirical framework for examining strategy over the business cycle, Mascarenhas (1989) research shows that a variable-parameter profitability model of strategy in a cyclical industry advocated the importance of a strategy's contemporaneous and inter-temporal relationships with performance, however, discrepancies were observed between actual strategies and optimal strategies over the business cycle stages. Finally, the author argues that companies were observed to adjust their strategies significantly 
and asymmetrically over business cycle stages, although there was no consistency in performance between up markets and down markets.

Examining expected returns on common stocks and long-term bonds across business cycles, Fama and French (1989) report that stocks and bonds contain a term or maturity premium that has a clear business-cycle pattern, low near peaks and high near troughs. Data includes CRSP value and equal weighted portfolios from the New York stock exchange, for stocks, and a sample from Ibbotson for bonds, over the period for 1926 to 1987. Investigating default spread, dividend yield and term spread interaction with business cycles, the results show default spread and the dividend yield capture similar variation in expected bond and stock returns, forecasting high returns when business conditions are persistently weak and low returns when conditions are strong. The expected return components they track, and the major movements in these variables, are found to be related to long-term business episodes that span several measured business cycles. The findings also show that the term spread are low around measured business cycle peaks and high near troughs, and therefore, is more closely related to the shorter-term business cycles identified by NBER.

In 1993, Victor (1993) investigated literature of the history and dimensions of business cycles over a 200 year history, from 1792 to 1992, utilising NBER reference chronologies, and found that business cycles have varied greatly over that period of time in length, spread, and size. At the same time, they are distinguished by their persistence, recurrence, and pervasiveness. Further, the author claims they make up a class of complex, varied and evolving phenomena of both historical and economic dynamics. Zarnowitz (1997) somewhat agrees and after researching pertinent 19th and 20th century literature, stated that business cycles are fairly well defined yet they have no generally accepted explanation. As well, 
classical literature developed in late 19th-early 20th century favoured the idea of selfsustaining or endogenous fluctuations, but recent models stress impacts from outside factors and random shocks.

According to Arnott and Copeland (1985), variables, such as interest rates and inflation play an important part in interacting with business cycles. The authors claim correlations between various models and measures of interest rates and inflation indicate that value-oriented models perform well in periods of low inflation and in poor economic climates, and growth models are more effective during periods of high inflation and less effective in a strong economy. Finally, most of the models tested perform better in periods of low real interest rates, and past model performance is a generally good indicator of future performance. Zarnowitz (1997) also claims historical studies have shown that certain variables have long been critically important in business cycles as shown by within and across countries: including profits, investment, interest rates, money and credit.

In a follow up study, Zarnowitz (1999) researches $20^{\text {th }}$ century business cycle literature, and discusses new estimates of profit and investment functions with important roles for growth of demand and productivity, price and cost levels, risk perception, credit volume and credit difficulties, across business cycles. The author also asserts that business cycles after the 1980s have moderated in severity. Kose, Otrok and Whiteman (2003) also show that common components in macroeconomic aggregates (consumption, output, and investment) indicate that a common world factor is an important source of volatility for aggregates in most countries, providing evidence for a world business cycle. Data includes output, consumption, and investment data from the Penn World Tables, over the period of 1960-1990. The authors also found that region-specific factors play only a minor role in explaining fluctuations in 
economic activity, and further, they document similarities and differences across regions, countries, and aggregates.

Several studies have shown an interaction between various financial variables and business cycles. Fama and French (1989) utilize term and default spreads and a dividend-price ratio and show that expected returns on common stocks and long-term bonds contain a term or maturity premium that has a clear business-cycle pattern (low near peaks, high near troughs). In addition, the authors findings show that expected returns also contain a risk premium that is related to longer-term aspects of business conditions, and the variation through time in this premium is stronger for low-grade bonds than for high-grade bonds and stronger for stocks than for bonds. Data consists of value- and equal-weighted portfolios of NYSE stocks obtained from CRSP, and corporate bond returns, from Ibbotson Associates over the period 1926 to 1987 . The authors conclude by claiming that expected returns are higher when conditions are weak and lower when economic conditions are strong.

Bolten and Weigand (1998) theorised that there is relationship between the stock market and business cycle dynamics by utilising a dividend discount model. The authors claim the interaction of changes in interest rates and earnings throughout the economic cycle are shown to cause changes in the level of stock prices. Also, this result indicates that monitoring and forecasting these factors can help explain and possibly forecast stock price behaviour over time. Estrella and Mishkan's (1998) study also shows that stock prices, interest rates and spreads can forecast business cycles. However, beyond one quarter, the slope of the yield curve emerges as the clear individual choice as a predictor of recessions, and typically achieves better results by itself out of sample than in combination with other variables. Data consists of US stock returns, and explanatory variables from the Commerce Department's 
index of leading economic indicators, and economic cycles are defined by NBER, over the time frame of 1959 to 1995.

Destefano (2004) examines whether movements in economic factors dictated by the dividend discount model, can explain extensive movements in stock returns over the business cycle. The author's results show that stock returns decrease throughout economic expansions and become negative during the first half of recessions, and intuitively, returns are largest during the second half of recessions, suggesting an important role for expected earnings. Business cycles are defined by NBER; measure of the stock price is the S\&P 500 index, over the period of 1948 to 2001. The author also suggests that the results are consistent with the concept that expected stock returns vary inversely with economic conditions, and the results also suggest that realized returns are particularly poor indicators of expected returns prior to turning points in the business cycles.

In investigating whether the profitability of HML, SMB, and WML can be linked to future gross domestic product (GDP) growth, Liew and Vassalou (2000) utilize data from ten countries and find that HML and SMB in a risk-based explanation contain significant information about future GDP growth. As well, in the presence of popular business cycle variables, HML and SMB retain their ability to predict future economic growth in some countries. However, there is little evidence to be found to support such an explanation in the case of WML, further, this information is to a large degree independent of the market factor. Stock returns were obtained from DataStream International, for 10 countries, including the U.S., over the time frame of 1978 to 1996. Seung-Woog and Lee (2006) examine two strategies (growth and value investing) in the context of business cycle, specifically, contraction and expansion of the economy. Their research indicates that value investing 
based on high valuation ratios tends to outperform growth investing based on low valuation ratios. The findings show this superior performance is robust for all economic conditions, and the benefits of value investing are superior during periods of contraction compared to periods of expansion. Value weighted monthly returns were obtained from Wharton Research Data Services, over the period of 1954 to 2002.

Chauvet (1998) explores the dynamic relationship between stock market fluctuations and the business cycle, on the supposition that stock market movements reflect positions taken by market participants based on their assessment about the current state of the economy. Therefore, given the forward-looking behaviour of stock market investors, the author explores the possibility of predicting business cycle turning points using promptly available financial variables. Data is obtained from the CRSP valued-weighted index, over the time span of 1954 to 1994 . The author further states stock market fluctuations and business cycles are represented by nonlinear dynamic factors at monthly frequencies, and the proposed model generates predictions of business cycle turning points using the business cycle factor, and anticipation of these predicted turns using the stock market factor. Finally, the results indicate that the extracted stock market factor is a leading indicator of the state of the business cycle and can be used to anticipate turning points in real time.

In an investigation of size and value effects over business cycles, Arshanapalli and Nelson (2007), for the period of 1962 to 2005, examined the performance of portfolios sorted by size and book-to-market during the periods when the economy is in recession, and in expansionary phases. Data for the twenty-five value and growth portfolios come from Ken French's website. The portfolios are constructed from all of the stocks on the NYSE, AMEX, and NASDAQ index. The results reveal that small size outperformed large size during non- 
recessionary times; however, large size produced better results during recessionary times. As there are far less recessionary periods than non-recessionary periods, the overall results show small size outperforming large size. The results for value versus growth show value investments surpassed the growth portfolios during recessionary periods, however, did not do as well as growth investment in the expansionary phases. However, overall, value investment beat growth investment and could act as a hedge during recessions.

In another investigation into predictive variables, Cooper and Priestley (2009) examine the output gap, a production-based macroeconomic variable, which the authors claim is a strong predictor of U.S. and G7 stock returns and U.S. excess bond returns. Utilising data from the CRSP value-weighted index and the S\&P 500 index, measuring output from the total Industrial Production index, and over a period of 1948 to 2005, the authors claim the output gap is a prime business cycle indicator, with the output gap forecasting returns both insample and out-of-sample, and it is robust to a host of checks.

Campbell and Diebold (2009) claim that expected business conditions consistently affect expected excess returns in a counter-cyclical fashion. The authors utilized CRSP value weighted portfolio data, 90-day U.S. Treasury bill rate, and the Livingston Six-Month Growth Forecasts, to provide expected business conditions, with business cycles determined by real gross domestic product (GDP) growth expectations, from the nominal GDP and consumer price index. The authors claim that inclusion of expected business conditions in otherwise-standard predictive return regressions, substantially reduce the explanatory power of the financial predictors, including term premium, the default premium and the dividend yield, whilst simultaneously increasing $\mathrm{R}^{2}$. However, expected business conditions retain their predictive power, despite including the generalized consumption/wealth ratio. Finally, 
the authors argue that time-varying consumption/wealth may capture time-varying risk aversion, and time-varying expected business conditions are likely to capture time-varying risk.

Henkel, Martin and Nardari (2011) investigate several predictive anomalies over business cycles, with the authors finding that short-horizon performance of aggregate return predictors such as the short rate and dividend yield appears non-existent during business cycle expansions but sizable during contractions. Utilising the G7 index returns, short bond yields, term spreads and dividend yields, over several periods from 1953 to 2007, the authors argue their results for short rate and dividend yield, show they are related to countercyclical risk premiums as well as the time-variation in the dynamics of predictors. Finally, their empirical model results are mixed compared to historical average, however, the results outperforms the U.S. historical average returns.

\subsection{Market States}

Several studies have investigated market states across different time-spans. Bauman and Miller (1995) investigated portfolio performance ranking in stock market states, and found the ranking of investment performance of mutual funds and pension funds is more consistent over time when evaluations are made over complete stock market states. Further, the authors found that the performance characteristics of the portfolios managed by those organizations also differ from each other, and the extent of relative consistency of performance over time varies, based on the type of investment management organization and type of portfolio style. Data includes quarterly closing prices of the S\&P 500 Index, over the time period of 1972, to 1991. 
Utilising a long time span of two centuries, Gonzalez et al. (2005) employ bull and bear market turning points using a formal turning-point identification procedure to investigate stock returns across bull and bear markets. Data is US stocks from January 1800 to September 2000, and the results show that the bull and bear market phases are associated with distinct and persistent mean return shifts. In an interesting paper, Harris (2009) examines U.S. stock market returns for a period of 120 years and suggests that financial markets move in long-run cycles. The author examines long-run secular cycles and the interaction of safe withdrawal rates (SWR). Utilising data from S\&P 500 Composite Index from 1881-2000, the results show the average annualized compound growth rate of the index was $4.8 \%$. In contrast, during this same period the annualized compound growth rate of the four secular bull and four secular bear markets averaged $3.3 \%$ and $-1.4 \%$ respectively. Therefore, the author suggests that secular market states can result in lower SWRs because the sequence of investment returns matters in the presence of recurring portfolio withdrawals.

Bhardwaj and Brooks (1993) investigated the size effect in bull and bear stock markets during 1926-88, utilising common stocks from the NYSE and AMEX index, to create 20 value weighted portfolios, and using a dual-beta market model to adjust for risk differences in bear and bull markets. Utilising a dual-beta market model to adjust for risk differences in bull and bear markets, the authors claim they found that large firm stocks on average earn significant positive excess returns and small firm stocks earn significant negative excess returns. The authors also claim that small firms do not outperform large firms in a varying risk model, and any outperformance of small firm stocks in a bull market is due to a constant risk model and the January effect. Kim and Burnie (2002) found small size effect occurs in the expansion phase of the economic cycle, with no significant small firm effect, either positive or negative in the contraction phase of the economic cycle. In addition, they did not 
find significantly larger abnormal returns for large firms in bear markets, as shown in Bhardwaj and Brooks (1993), during the same time frame. Compustat file provides stock return data, from 1976 to 1995 , and S\&P 500 provide index returns.

In studies embracing Asian market states, Edwards, Biscarri and Perez De Gracia (2003) analyse stock market states, financial liberalization and volatility in the behaviour of stock markets in six emerging countries. Data corresponds to the Emerging Market Indexes of Standard \& Poors (S\&P/IFCG), and is from 1975 to 200. Specifically, they describe the bull and bear cycles of four Latin American and two Asian countries. The authors claim that cycles in emerging countries tend to have shorter duration, larger amplitude and volatility than in developed countries. As well, after financial liberalization, Latin American stock markets have behaved more similarly to stock markets in developed countries whereas Asian countries have become more dissimilar. Further, the concordance of cycles across markets has increased significantly over time, particularly for Latin American countries after liberalization.

In investigating Singapore acquisitions, Pangarkar and Lie (2004) examine the impact of market states on the performance of Singapore acquirers, by hypothesizing that acquisitions undertaken during low market states will exhibit better performance than other acquisitions. The results of an analysis of 115 acquisitions by Singapore firms between 1990 and 1999 show strong support for the hypothesized relationship.

Guidolin and Timmermann (2008) claim that they find strong evidence of time-variations in the returns on stock market portfolios and portfolios tracking value and size effects, utilising different market states. The authors use a Markov chain algorithmic regime changing model, 
to form four states, in the period of 1927 to 2005, using common stocks from the valueweighted CRSP index. The authors find that the first regime is a moderately persistent bear state, with negative significant excess returns, with size and value anomalies largely absent from the data, due to insignificant mean returns on the SMB and HML portfolios. The second regime is a highly persistent, low-volatility bull state with mean returns in this state being significantly positive for the market and HML portfolios, however, slightly insignificantly negative for the SMB portfolio. The SMB returns are uncorrelated with both the market and HML returns; although, HML portfolio returns are positively correlated with returns on the market portfolio.

Regime three is a highly persistent low-volatility state bull market state where all equity portfolios earn positive mean returns. Regime four is a highly volatile, short duration transient state that captures stock prices during parts of the Great Depression and 1999-2000. Mean returns in this state are high for the size and value effects. Finally, the authors argue that the scale of the premia on the size and value portfolios and their hedging properties are found to vary across regimes, and different regimes are shown to have a large impact both on investors' utility and the optimal asset allocation.

Several studies show that macroeconomic variables can predict bear markets in the stock market. Chen (2009) evaluates series such as interest rate spreads, inflation rates, money stocks, federal government debt, aggregate output, unemployment rates, federal funds rates, and nominal exchange rates. Data consists of monthly stock returns on the S\&P 500 price index from 1957 to 2007. The author utilized parametric and nonparametric processes to identify recession periods in the stock market, with in-sample and out-of-sample tests of the variables' predictive ability. The results suggest that the macroeconomic variables such as 
yield curve spreads and inflation rates are the most useful predictors of recessions in the US stock market.

In addition, comparing the bear market prediction to the stock return predictability has shown that it is easier to predict bear markets using macroeconomic variables. Kole and Van Dijk (2010) examine several macro-economic and financial variables and their ability to predict whether the next stock market period will be bullish or bearish. Data is from the US stock market, proxied by the S\&P500 price index on a weekly frequency, and time the period is from 1885 until 1962. The authors claim their results show that rules-based methods are preferable for identification, (separate periods with price increases from periods with price. decreases because ex post only the direction of the market matters). The authors argue that regime-switching models perform significantly better in making predictions, whilst focusing on average returns and volatilities leads to more prudent forecasts, which then provides a higher utility from the perspective of risk-averse investors who engages in market timing.

Utilising monthly NYSE and AMEX stock returns, over the period of 1962 to 2005, Stivers and Sun's (2010) findings show that the market's recent cross-sectional dispersion in stock returns is negatively related to the subsequent momentum premium, and positively related to the subsequent value book-to-market premium. The authors also examine the relationship between return dispersion and recessions, utilising data from NBER, and find that the market's return dispersion may serve as a leading countercyclical state variable, that the momentum premium is procyclical, and the value premium is countercyclical. The authors also show that the partial relation between return dispersion (RD), and the subsequent momentum and value premiums, remains strong when controlling for macroeconomic state variables, as suggested by literature. 
Finally, Menzly and Ozbas (2010) investigate suppliers and their customers interaction over market states, and they find that stocks that are economically related between supplier and customer industries, cross-predict each other's returns. Further, the magnitude of return crosspredictability declines with the number of informed investors in the market, as proxied by the level of analyst coverage and institutional ownership. Data contains monthly returns from CRSP, and is over the period from 1963 to 2005. Finally, changes in the stock holdings of institutional investors mirror the model trading behaviour of informed investors.

\subsubsection{Constructing Market States}

Literature shows there have been two main approaches to identifying the bull and bear market phrases in the market cycle. The first one advocates a parametric methodology of the data generating process, where two different regimes are allowed, one that correspond to the expansions, and therefore contains some type of upward trends, and another one that corresponds to the contractions and therefore contains a downward trend. Previous examples of these methods are Goodwin (1993), Diebold and Rudebusch (1994), Kim and Nelson (1999), Hamilton and Lin (1998), Ramchand and Susmel (1998), Maheu and McCurdy (2000) and Stangl, Jacobsen and Visaltanachoti (2009).

The second method takes a nonparametric approach and, instead of fitting a fully specified statistical data generating process, looks at the original data series in search for periods of generalised upward trend, which will be identified with the expansions, and periods of a generalized downward trend which will be identified with the contractions. The key feature of the analysis is the location of turning points or breakpoints, in peaks and troughs in the series, and these turning points will determine the different phases of the cycle which can be 
subsequently analysed. Previous examples of these approaches are Bry and Boschan (1971), Watson (1994), Artis, Kontolemis and Osborn (1997), Harding and Pagan (2000) and Harding and Pagan (2002) for business cycles. Previous authors utilising non parametric methods for constructing market states are Watson (1994), Kaminsky and Schmukler (2003), Pagan and Sossounov (2003), Lunde and Timmermann (2004), Pangarkar and Lie (2004), Biscarri and Perez de Gracia (2004), Candelon and Metiu (2009), Kole and Van Dijk (2010) and Lee, Yen and Chanc (2013).

Another method was utilized by Cooper et al (2004), who adapted a non-parametric cumulative compound methodology to construct market states. The authors investigated whether momentum is influenced by market states and identified market states by claiming that if the 36 month lagged return is nonnegative (negative), the market is in an up (down) state. Asem and Tian (2010) and Daniel and Moskowitz (2013) also examined momentum's interaction with market states, and followed with the same methodology, with different time frames of 12 month and 24 month lagged return respectively.

There has been comprehensive research into algorithmic regime switching, which has produced several models which have shown strong significant results. However, as this thesis does not utilize any of these methods, I will only lightly touch on the history of algorithmic regime switching and provide an example of research. According to Hamilton (2005), Markov switching regressions were introduced by Goldfeld and Quandt (1973), with the likelihood correctly calculated by Cosslett and Lee (1985). Further advances incorporated Markov-switching vector regressions, which allowed the analyses of comovements between stocks and economic output, for example, by Hamilton and Lin (1996) and the tendency for some series to move into recessions before other (Hamilton and Perez-Quiros, 1996). 
Hamilton (2005) claims the most popular method is the Bayesian approach, which was enhanced utilising the Monte Carlo Markov chain methods, enabling a natural device for handling transition probabilities that are functions of observable variables.

Guidolin and Timmermann (2007) utilize a Markov chain method with constant transition probabilities, incorporating four breakpoints, and therefore, producing four market states. The four separate regimes are characterized as crash, slow growth, bull and recovery states, and show that optimal asset allocations vary considerably across these states and change over time as investors revise their estimates of the state probabilities. Data consists of NYSE, AMEX and NASDAQ stock monthly returns derived from CRSP, 10 year US bonds, and US 30 day T-bills, and the period is from 1980 to 1999. Also, the authors claim that the wellknown predictive effect of the dividend yield was heavily influenced by the different states. The results were robust for out of sample forecasting experiments, and confirm the economic importance of accounting for the presence of regimes in asset returns.

\subsection{Industries}

This section investigates the historical literature pertaining to industries, including importance of industries, and predictive industry effects.

\subsubsection{Industry/ Countries/Companies}

There have been several studies investigating whether an industry or corporations are the major sources of profitability and risk diversification. In an early paper comparing the profitability differences between industry, business-unit and corporate parentage, Rumelt's (1991) research shows that there are negligible corporate effects, a small stable industry effect, and very large stable business-unit effects. Monthly data is from the Federal Trade 
Commission Line of Business Program, and the period is from 1974 to1977. The authors argue that their results indicate that the most important sources of economic rents are business-specific, with industry membership less important and corporate parentage having no significant value.

Following Rumelt's (1991) research, McGahan and Porter (1997) examined the profitability breakdown of industries and corporations. Their results show that year, industry, corporateparent, and business-specific effects account for $2 \%, 19 \%, 4 \%$, and $32 \%$, respectively, of the aggregate variance in profitability. Data is from COMPUSTAT data base, with a time frame of 1981 to 1994 . Further, the authors examined whether there was an intra-industry effect, and found that industry effects account for a smaller portion of profit variance in manufacturing but a larger portion in lodging, entertainment, services, wholesale, retail trade and transportation.

Finally, Hawawini, Subramanian and Verdin (2003) investigate whether firms or industry effects are stronger. Their research shows that a significant proportion of the absolute estimates of the variance of firm factors is due to the presence of a few exceptional firms in any given industry. In other words, only for a few dominant value creators (leaders) and destroyers (losers) do firm-specific assets seem to matter significantly more than industry factors. For most other firms, however, the industry effect turns out to be more important for performance than firm-specific factors. Economic profit (EP) and total market value (TMV) are the data sets provided by the consultancy Stern Stewart for the sample period from 1987 to 1996. 
In addition, Short, Ketchen, Palmer and Hult (2007) examine the firm versus strategic group versus industry effect and finds the firm effect is the strongest, while the strategic group effect rivals and for some measures outweighs the industry effect. Data is the monthly total returns for all firms in the Morgan Stanley Capital International (MSCI) indices of 12 European countries from 1978 to 1992. Whilst Brush, Bromiley and Hendricky (1999) investigate the influence of industry and corporations on business segment performance, and finds that both corporations and industries influence business unit profitability, however, corporations have the largest influence. Data was from FTC Line of Business data base, and COMPUSTAT, over the period from 1986 to 1995.

Previous literature has examined the question of which factors have shown the stronger benefits of diversification: country or industry? In an early research paper, Heston and Rouwenhorst (1994) research into international diversification between industry and countries indicated that country diversification is more efficient than industry diversification. The sample includes monthly total returns for all firms in the Morgan Stanley Capital International (MSCI) indices of 12 European countries from 1978 to 1992 . The authors followed with another paper investigating industry and country effects in international stock returns research in 1995, utilising a longer time period with similar results to the first paper. The authors conclude that there are several reasons to pay more attention to the geographical, rather than industrial composition in international portfolios (Heston and Rouwenhorst, 1995).

Cavaglia, Brightman and Aked (2000) claim that previous studies of the relative importance of industry and country factors determining equity returns generally concluded that country factors dominate industry factors. However, their findings suggest industry factors have been 
growing in relative importance and may now dominate country factors. Furthermore, the results imply that over the past five years, diversification across global industries has provided greater risk reduction than diversification by countries. Data covers the 21 countries that constitute the current MSCI World Developed Markets universe over a period of 1986 to 1999.

Wang, Lee and Huang (2003) also completed similar research, although concentrating on Asia and the U.S. The authors used a factor model for seven equity markets and 22 industrial group returns indexes to measure the relative importance of industry and country effects. Data is from DataStream Global Equity Indexes over a time period of 1990 to 2001. They found that industry effects have significantly dominated country effects since 1999 and that country effects tend to exhibit a cyclical trend. Flavin (2004) somewhat agrees with Wang et al. (2003) whilst investigating the relative benefits of industrial versus country diversification in the Euro zone before and after the introduction of the Euro. The author found evidence of a shift in factor importance; from country to industry, and from within and between Euro and non-Euro countries. Monthly total returns and market capitalisations are utilized from the stock exchanges of the 11 original members of the Euro zone, from 1995 to 2002.

Puchkov, Stefek and Davis (2004) also investigated the answer to the perennial question of international investing, which has the greatest influence on corporate profits- country, global industry or style selection, and is there a difference between developed and emerging markets. The authors identified a spike in the importance of global industries over country influence in the period of 1998-2002, and suggest it was likely a by-product of the technology bubble. Further, they claim world markets are integrating, but at a very gradual pace. Phylaktis and Xia (2006a) investigated global, country and industry impacts on stock returns, 
examining 1893 firms in MSCI global index from 1990 to 2002 from 37 countries. Their results show that country effects are more important than industry and global effects in emerging markets in contrast to developed markets. The authors also followed up with another paper, examining the roles of country and industry effects on international equity returns covering 50 industry groups and 34 countries over the period 1992 to 2001. The results show that although the country effects still dominate the industry effects in the full sample period, there has been a major upward shift in industry effects since 1999. The degree of this shift varies across regions and is prominent in Europe and North America, while in Asia Pacific and Latin America, country effects still dominate (Phylaktis \& Xia, 2006).

Ferreira and Gama (2005) also compare industry and country importance by using a volatility decomposition method to study the time-series behaviour of equity volatility at the country, world and local industry levels. Utilising daily U.S. dollar-denominated total return indices and market capitalizations for up to 38 industries calculated by DataStream International between 1974 and 2001, the authors results show that in the 1990s there is a sharp increase in local industry volatility compared to market and country volatility. The authors suggest that correlations among local industries have declined. Therefore, the authors conclude that more assets are needed to achieve a given level of diversification, and that local industry volatility leads the other volatility measures.

Campa and Fernandes (2006) somewhat agree, and found in their research of international portfolio returns (using a sample of forty eight countries and thirty nine industries) that country factors have remained relatively stable over their sample period of the last three decades, whilst industry effects have significantly increased during the last decade and dropped again since 2000. Their sample period is from 1990 to 2000. 
In comparing industry and country importance, Steliaros and Thomas (2006) compared value and equal weighted properties of the two groups. They found that in the value-weighted world portfolio, the country effect dominates although the sector effect increases markedly, and the country effect decreases in the post-2000 period. The authors claim the country effect is much stronger when the largest 300 companies are excluded from the analysis. However, the sector effect dominates the country effect in equally weighted portfolios. Data was obtained by MSCI Developed World Index, drawn from 21 countries, over the period 1992 to 2001.

\subsubsection{Predictive Industries}

This sub-section examines the predictability and profitable trading strategies utilising industries. Early studies investigated whether industry predictability was the result of industry rotation, mean-reverting behaviour, or by time variation in the risk premiums. Grauer, Hakansson and Shen (1990) utilized industry rotation in a multi-period portfolio model to examine which returns from passive, semi-passive and active strategies produced the best returns. Over a period from 1934-1986 with US industry data, the authors found that the active strategies of the multi-period model performed well when applied to the valueweighted industry indexes in the 1966-1986 period. The equal weighted portfolios generated statistically significant positive abnormal returns in both the full 1934-1986 period and 19661986 sub-periods. The authors argued that in the latter sub-period, with one exception, the results showed had abnormal returns which averaged $2 / 3$ of total excess returns.

Fama and French (1988) investigated the mean-reverting behaviour of long-horizon security returns, they estimated autoregressive models for returns of portfolios based on industry and 
size-decile classifications, and found for the overall time period of 1926-1985 for US data, significant long-horizon autoregressive coefficients for most industry portfolios. However, for the recent sub-period (1941-1985), few of the industry autoregressive coefficients were significantly different from zero.

Both Ferson and Harvey (1991) and Lo and MacKinlay (1995) investigated causes of predictability in industry groups, as well as other security returns. Ferson and Harvey (1991), during the period 1959 to 1986 , formed 12 industry groups, and utilising different predictor variables, was able to show that some of these variables, such as interest rate changes, influenced future returns from industries. Data consists of monthly stock returns from the NYSE, and long-term government and corporate bonds. Lo and MacKinlay (1995), during the period between 1947 to 1990 , utilize 11 sectors from CRSP monthly return files, which comprised groups of industries, other securities, and 5 predictive variables, was able to provided evidence that there was a significant level of predictability for future returns of some industries.

Boudoukh, Richardson and Whitelaw (1994) investigated the cross-sectional relation between industry-sorted stock returns and expected inflation, and found that this relation is linked to cyclical movements in industry output. The authors argued that their results showed that stock returns of noncyclical industries tend to co-vary positively with expected inflation, while the reverse holds for cyclical industries. The authors describe a model in which the spirit of the Fisher model is preserved, that captures both the negative and positive relation between stock returns and inflation at short and long horizons, and the cross-sectional variation in these relations across industries respectively. Stock data come from the monthly 
CRSP tapes, and production data was taken from the Board of Governors of the Federal Reserve System, for the period of 1953 to 1990.

Eleswarapu and Tiwari (1996) investigated whether the stock returns of certain sectors of the economy can predict future market returns even after controlling for the information contained in the aggregate market index. Data consists of CRSP monthly stock returns from the NYSE from 1926 to 1989. The authors claim their research shows that the stock returns of five industry-based portfolios have significant information about future market returns that is not in the market index. Further, that in the consumption-based models, aggregate output and consumption affect the discount rates of all assets synchronously, therefore, no particular sectoral return should have any more predictive ability than the others. The authors argue that their result is not consistent with existing models relating output to stock returns.

Investigating if industry returns are predictable, Beller, Kling and Levinson (1998) provide strong evidence that utilising predictive variables, including mean-variance optimization criteria, combined with quarterly industry rotation, was useful for forecasting models for industry excess returns. Utilising capitalization-weighted and equal-weighted quarterly excess returns for 55 US industries over the 1973-95 period, the authors argue that there is a predictive element to about 80 percent of the capital-weighted industries and about 90 percent of the equal-weighted industries. Further, the authors argue that the out-of-sample analysis provided strong evidence that mean-variance optimization criteria combined with their forecasting models is useful for portfolio selection.

Hong, Torous and Valkanov (2007) investigated whether the returns of industry portfolios can predict stock market movements. Data consists of 38 value-weighted industry portfolios, 
down loaded from Ken French website, for the years 1946-2002. The authors claim their results show that several industries in the US stock market, including retail, services, commercial real estate, metal, and petroleum, can forecast the stock market by up to two months. Further, the ability to predict the market is correlated with its propensity to forecast various indicators of economic activity. Research into the eight largest non-US stock markets show similar results, with the authors arguing that that stock markets react with a delay to information contained in industry returns about their fundamentals and that information diffuses only gradually across markets. The results also show that 33 lagged industry returns are significant predictors of aggregate market returns.

In addition, Hou (2007) finds a significant lead/lag relation between the different responses of sectors to new economic information. Commodity or basic material industries respond more quickly to economic news than consumer goods industries. Data is from CRSP, with a time frame of 1963 to 2001. Pollet (2005) argues that oil can predict stock returns and most interestingly, that the Norwegian stock market (which is dominated by oil) leads the world stock market. Data is monthly value-weighted market returns and industry returns CRSP from 1974 until 2002, and gross price indices from MSCI are used to calculate monthly total returns for Norway stock exchange, from 1969 to 2002.

Anomalies interaction with industries has also been investigated. An early research into effects and industries was carried out by Willard and Lakonishok (1986) who investigated the size anomaly. Utilising an analysis of 13 US industries for the period 1961-1980, the authors investigated whether at least part of the small firm effect can be attributed to the joint effects of inter-industry differences and seasonality. Their results show that small firms outperformed large firms, even after controlling for industry effects. However, when January 
returns were eliminated, the author's results showed no significant difference between large and small firms. Whilst no significant non-January size effect was indicated, each of the industries analysed showed a substantial January size effect.

Chou, Ho and Ko (2012) investigate whether asset pricing models can explain industry returns. Data consists of NYSE, AMEX, and NASDAQ return files from CRSP from1963 (1973 for NASDAQ firms) to 2006. The authors claim their research show common factors extracted from industry returns carry significant risk premiums that go beyond the explanatory power of book-to-market, size ratios, and momentum. Specifically, their study shows that the BM effect is an intra-industry phenomenon, the small-firm effect is significant only for firms whose market capitalization is below their industry average, and a 12 month momentum effect is significant only for firms whose BM ratio is smaller than the industry average and limited to non-January months. Further, the authors claim there is seasonality in all effects that cannot be explained by risk-based asset-pricing models. Finally, the authors argue neither behavioural nor rational theories alone can explain industry returns, and it is probably too hasty to attribute asset pricing anomalies to a single factor.

In another paper examining the predictability of US industry portfolios, TsuJi (2010) utilized US industry portfolios and the extracted factors from US industries' returns for Fama and French's small minus-big (SMB) and high-minus-low (HML) factors. Time frame is from 1960 to 2002. The author argues that the empirical analysis reveals that 30 US industry returns and the extracted factors from US industries' returns through factor analysis can accurately forecast one-month-ahead SMB factor returns. In a follow up paper, TsuJi (2012) examines whether the returns of US industry portfolios predict the returns and volatility of Fama and French's and high-minus-low (HML) factors and small-minus-big (SMB). SMB 
and HML factors were downloaded from Ken French website, and the time frame was from 1947 to 2002 . The analysis reveals a noteworthy number of industry returns forecast the volatility of the SMB and HML factors by up to two or three months. The author state his results indicate that US industry returns contain profitable information on Fama-French SMB and HML factors. Finally, TsuJi argues that since most investors cannot extract the profitable information contained in industry returns in a timely manner, this information only gradually diffuses in equity markets.

\subsection{Market/Business cycles and Industries}

This section examines historical literature for interaction between market/business cycles and industries.

Sorensen and Burke (1986) investigates whether an active industry group rotation is profitable, utilising 43 US industry groups over the $1972-84$ period. The authors found that a strategy based on rotating portfolio holdings among the three, five or 10 best performing industry groups resulted in superior gross returns over the period, ranging from a low of 9.32 per cent annually for a five-group portfolio to a high of 16.8 per cent for a three-group portfolio, compared with an annual market return (as measured by the S\&P 500) of 6.56 per cent. The risk adjustment results, transaction costs, showed that more than half the portfolios outperformed the market; however, the strategy can result in negative excess returns in certain market environments.

Stangl et al. (2009) findings disagree with Sorensen and Burke (1986). Their results show sector rotation would have only generated at best a $2.3 \%$ annual outperformance since 1948 , with a naive approach which anticipates business cycle stages perfectly and rotates sectors following popular strategies. Economic cycle data was obtained from NBER which defined 
phases of economic expansion and recession, and market return and 48 industry data from Ken French website, from 1948 to 2007. The authors utilized an unbiased approach and found that outperformance quickly dissipates. Finally, the authors show an alternative rotation strategy that would have historically beaten the market by $7 \%$ per annum; however, the authors concluded that more research is needed.

In addition, Beber, Brandt and KavaJecz (2011) also investigated sector order flows, and results show that aggregate portfolio rebalancing across equity sectors is consistent with sector rotation. Data consists of equity order flow data constructed using the Trades and Quotes (TAQ) dataset for the period of 1993-2005. Common stock returns were generated from the stocks covered in the CRSP dataset. The authors use an investment strategy that exploits perceived differences in the relative performance of sectors at different stages of the business cycle and argues that sector rotation has predictive power for the evolution of the economy and future bond market returns, even after controlling for relative sector returns. The authors create a forecast model which include the one-month Treasury bill, term-spread, default-spread and dividend yield as business cycle variables.

Hou and Robinson (2006) investigate differences in returns from industries, and found firms in more concentrated industries earn lower returns, even after controlling for size, book-tomarket, momentum, and other return factors. Data includes all NYSE, AMEX, and NASDAQ-listed securities with share codes 10 or 11 that are contained in the CRSP monthly returns file and the COMPUSTAT industrial annual file between 1963 and 2001. The authors examined if explanations based on chance, capital structure, measurement error, and persistent in-sample cash flow shocks explain these findings. The authors argue that either firms in highly concentrated industries are less risky because they engage in less innovation, 
or barriers to entry in highly concentrated industries insulate firms from undiversifiable distress risk, and thereby command lower expected returns. The authors found that additional time-series tests support these risk-based interpretations.

Woodward and Anderson (2009) investigate whether 'bull' and 'bear' market betas for Australian industry portfolios returns differ. Their results indicate that 'bull' and 'bear' betas are significantly different for most industries, and that up-market risk is not always lower than down-market risk. Data consists of Australian industry portfolios over the period 19792002. The logistic smooth transition model indicate that the transition between 'bull' and 'bear' states is abrupt, supporting a dual-beta market modelling framework.

\subsection{Momentum/Industries/Business-Market states}

This section discusses previous literature on momentum's interaction with industry, and/or business/market states.

The Moskowitz and Grinblatt (1999) investigation compares stock and industry momentum investment strategies. Their research shows a strong and prevalent momentum effect in industry components of stock returns which the authors claim accounts for much of the individual stock momentum anomaly. Data consists of CRSP and COMPUSTAT data files, 20 value-weighted industry portfolios are formed for every month from July 1963 to July 1995. The authors state that momentum investment strategies, which buy past winning stocks and sell past losing stocks, are significantly less profitable once they control for industry momentum. Further, industry momentum investment strategies, which buy stocks from past winning industries and sell stocks from past losing industries, appear highly profitable, even after controlling for individual stock momentum, size, book-to-market, the cross-sectional dispersion in mean returns, and possible microstructure influences. 
In addition, O’Neal (2000) examined momentum effect and industry performance. The author utilized strategies of buying previous intermediate-term top-performing sector funds over the 10-year period from May 1989 through April 1999 on a total-return basis, and found the returns outstripped the S\&P 500 Index. The author showed that in the intermediate term, strong (weak) industry performance is followed by continued strong (weak) industry performance. The industry-specific aspect of momentum gives rise to profitable trading strategies that use industry-sector mutual funds. However, these strategies entailed greater total and systematic risk than the index. Sectors were derived from the Fidelity Select Portfolios sector funds.

Chordia and Shivakumar (2002) research shows that size, value, and momentum factors track business cycles. However, their results are similar whether they measured outperformance using the single index model, the Fama and French three-factor model, or the Carhart fourfactor model. Data consists of NYSE-AMEX monthly stocks returns, derived from CRSP, over the period of 1926 to 1994 . Their paper shows that profits to momentum strategies can be explained by a set of lagged macroeconomic variables and payoffs to momentum strategies disappear once stock returns are adjusted for their predictability based on these macroeconomic variables Returns.

Menzly and Ozbas (2006) examined the cross-momentum effect among industries for an anomalous effect. Their results show a strong cross-momentum effect amongst industries that are related to each other along the supply chain. Specifically, trading strategies that buy and sell industries based on respectively high and low past returns in related upstream or downstream industries yield significant profits. Further, the authors argue their results show 
cross-industry momentum is distinct from previously documented stock- and industry-level momentum, and other known return factors. Data consists of Input-Output Benchmark Survey of the Bureau of Economic Analysis, and CRSP monthly stock returns from 1963 to 2002.

International research into momentum has produced interesting results. Griffin and Martin (2003) examined international momentum investing and business cycle risk by utilising an unconditional model based on the Chen, Roll, and Ross (1986) factors. They find no evidence that macroeconomic risk variables can explain momentum. In addition, the authors claim momentum profits around the world are economically large and statistically reliable in both good and bad economic states. The authors also claim that momentum profits bear basically no economic or statistically significant relation to the Chen et al. (1986) macroeconomic factors, and momentum reverses over 1 to 5-year horizon, an action inconsistent with existing risk-based explanations of momentum. Data consists of common shares of all NYSE and AMEX listed firms available from CRSP, and DataStream International for countries that have at least 50 international stocks.

Huang (2006) tests the previous research of Cooper et al. (2004) concerned with market states and momentum in an international setting, and finds qualified support. Momentum profits exist only in the up market but this holds for only two of three market state classifications based on past returns. The sample consists of monthly index returns from Morgan Stanley Capital International (MSCI) for 17 countries from 1969 to 1999. The author further found that using lagged world industrial production growth to classify market states largely supports the proposition, although (statistically insignificant) profits also arise in the down market. 
Hung and Glascock (2008) examined momentum profitability and market trend in the real estate investment trust (REIT) sector by examining the differences between winners and losers dividend/price ratios over the market state and momentum. The authors found that winners' dividend/price ratios are higher than those of losers, and momentum returns are positively correlated with the difference between winners' and losers' dividend/price ratios. In addition, their research shows that momentum returns are higher after the legislation change of REITs in 1992, and that dividend/price ratios of REITs are also higher after 1992, suggesting that a persistent shock to REIT's dividend/price ratios in 1992 partly explains REITs' higher momentum returns after 1992. Finally, the authors argue their results suggest that the momentum returns of REITs can be jointly explained by the cross-sectional variance in dividend yields and a time-varying factor (market state). REIT data is derived by the National Association of Real Estate Investment Trusts (NAREIT) for the years 1972 to 2000.

The Daniel and Moskowitz's (2011) study shows that the returns to momentum strategies are skewed and momentum returns experience infrequent but strong and persistent strings of negative returns. . Data contains firms listed on NYSE, AMEX and NASDAQ, derived from CRSP, over the period of 1947 to 2006. Further, that these momentum crashes are forecastable in that they occur following market declines (when market volatility is high) and that they are contemporaneous with market rebounds.

Cooper et al. (2004) investigate the interaction of market states and momentum. The authors test overreaction theories of short-run momentum and long-run reversal in the cross section of stock returns over market states. The authors argue that momentum profits depend on the state of the market as they predicted. Utilising all stocks listed on the NYSE and AMEX 
listed on the CRSP monthly file, from 1929 to 1995, the results show that mean monthly momentum profit following positive market returns is $0.93 \%$, whereas the mean profit following negative market returns is $-0.37 \%$ per month. However, the authors claim the upmarket momentum reverses in the long-run, and their results are robust to the conditioning information in macroeconomic factors.

Xiaowei et al. (2010) examines Cooper et al. (2004) market states and momentum research in an international setting with over 20,000 stocks over market states in 10 developed countries for the period 1973-2001. The authors claim their findings contradict the predictions of Cooper et al. (2004) that the strength of momentum effect depends on aggregate market conditions. In addition, the authors argue that their results demonstrate the need to search for new explanations for the momentum effect in a behavioural theory context.

Moskowitz et al. (2011) examine "time series momentum" in equity index, currency, commodity, and bond futures for 58 liquid instruments over the time period of 1965 through to 2009. The authors found persistence in returns from one to 12 months, which is consistent with sentiment theories of initial under-reaction and delayed over-reaction theories. Further, diversified portfolios of time series momentum strategies across all asset classes deliver substantial abnormal returns with little exposure to standard asset pricing factors and perform best during extreme markets. Further, Moskowitz et al. (2011) and Daniel and Moskowitz (2011) claim that across numerous asset classes, momentum strategies have produced high Sharpe ratios, high returns, and strong positive alphas relative to standard asset pricing models. 
Examining the effect of market cycles on both medium-run and long-run relative strength trading strategies in stocks and industries, Stivers and Sun (2013) find that momentum is more profitable within a market state (rising or falling markets), although momentum profitability is substantially lower in transitions between states. The authors utilize US individual stock return data from CRSP, and industry data from 30 value-weighted industry portfolios from the Ken French data library, over the period of 1926 to 2010. The authors point out these results help reconcile the puzzling fact that medium-run strategies are profitable but long-run strategies are not because shorter duration strategies are relatively less likely to include market transitions. Finally, the authors also examined cross-sectional return dispersion accross market cycles and found that the market's cross-sectional return dispersion is negatively related to the subsequent payoffs for both medium-run and long-run strategies.

Sagi \& Seasholes (2007) argue that higher growth options in a positive market leads to higher return autocorrelations, resulting in higher momentum profits following these markets. Therefore, depending on the past market state, momentum profits should be higher when the subsequent market is positive than when it is negative. Data includes quarterly revenues, cost of goods sold, and book value of equity from the CRSP/Compustat merged data set for all available companies over the time period of 1963 to 2004.

\subsection{Behavioural theories momentum/market states}

There have been several behavioural theories developed to explain short run cross-sectional momentum, discovered by Jegadeesh and Titman (1993) and the reversal in momentum longrun cross-sectional stock determined De Bondt and Thaler, (1985). Daniel, Hirshleifer, and Subrahmanyam (1998) (DHS) assert that investors overreact to private information signals 
and underreact to public information signals, which leads to investor overconfidence resulting from biased self-attribution of investment outcomes.

Previous self-attribution literature, such as Bem (1965) argues that individuals attribute successes to their own ability more than they should and attribute failures to external noise more than they should. This leads to overconfidence during UP markets, as price appreciation reinforces their belief in their own skill, or overconfidence during DOWN markets, as price depreciation reinforces their belief. DHS then argues that short run momentum profits should be higher when the markets continue in the UP state, and also profitable when the market continues in a DOWN market. It is only when the market transitions that momentum suffers reversals.

DHS also claims that investors are overconfident about their private information and underreact to public information. This leads to investors attributing successes to their own skill more than they should and attribute failures to external noise more than they should. The result of this behaviour is that investors' minimise contrary news, which leads to overconfidence following the arrival of confirming news, and which leads to a stronger momentum. However, as investors observe future contradictory news and realize their errors, there is an overreaction in prices, which will eventually be corrected in the long-run. Therefore, DHS argues, increased overconfidence results in short-run momentum and longrun reversal.

Another prominent theory from Hong and Stein (1999) (HS) argues that news watchers rationally use fundamental news, although they ignore prices. However, as information diffuses gradually across the population, prices will underreact in the short run, allowing 
trend chasers, or momentum traders who ignore fundamental news to be profitable in the short term. However, momentum traders activity results in an eventual overreaction and prices revert to their fundamental levels in the long-run. HS also found that risk aversion decreases as wealth increases, leading to a delayed overreaction, which leads to greater momentum profitability following market gains.

\subsection{Summary}

The scholarly literature discussed in this section provides a comprehensive, albeit, not exhaustive review, as the field of anomalous research is ever growing. Over time, the empirical finance literature has identified abnormalities that appear to be persuasive within cross-section returns. These patterns have generally been referred to as anomalies because they are inconsistent, either with market efficiency or with existing asset pricing models. However, research of these variables or components of the market that can predict significant abnormal returns, has been mixed and contradictory regarding which individual variables or market components are predictive over a consistent timeline.

The CAPM and the APT measurement models were break throughs in allowing the financial community to measure returns. However, they were shown to have major weaknesses. Several anomalies were consistently shown to produce abnormal returns, the most wellknown of these are earnings per share, CAPM, size, book-to-market and momentum, and their discovery has led to new and improved models of expected returns. The new models have been shown to subsume several anomalies, the most famous is Fama and French (1992) three-factor model, as well, as Carhart's (1997) four-factor model which includes momentum. 
Research into market states and their interaction with anomalies is a more recent phenomenon, with papers such as Cooper (2004) and Asem and Tian (2010), who investigated market states and momentum. This thesis follows in their footsteps by investigating market states interaction with other variables, such as SMB and HML, sector rotation in industries, and FF 3 factors interaction with momentum.

The remaining chapters of this thesis are organized as follows. Chapter 3 examines whether industries that outperform (underperform) in a particular market state are more likely to outperform (underperform) when that market state arises in the future. Chapter 4 extends the study of market states, by creating new schemes or states, by combining market state with SMB and HML states. These new states examine momentum profitability over future profit periods. Chapter 5 utilizes the new combined market/size state to examine Fama and French 3 factors anomalous predictive capabilities across market states. Chapter 6 provides concluding remarks and possible future avenues for research. 


\section{Chapter 3: The Influence of Market States on Industry Returns}

\subsection{Introduction}

This empirical study considers the impact of market states on future industry returns. Market commentators frequently suggest that investors should take note of market states when determining industry selection. I examine this theory by utilizing industry rotation, with market states determining when the industries are rotated. Specifically, I investigate whether an industry's past relative performance in the same market state as the current one predicts the industry's future performance. This new approach sorts industries into portfolios and shows that market states can be used to construct profitable dynamic industry rotation strategies.

I am motivated by the fact that asset allocation plays an important part in the trading strategies of managed, superannuation, and hedge funds throughout the financial world; indeed, a vast literature explores profitable trading strategies and anomalies in asset allocation. Industry allocation plays a major role, particularly in different phases of market states in asset allocation throughout the world. Previous research has investigated industry rotation and business cycles (Sorensen and Bourke, 1986). I add to this literature by showing market states can predict future industry performance.

Previous studies investigating market states have utilized two states (Asem and Tien, 2010); however, I felt that this method would not capture the difference between extreme movements up and down as well as between less extreme movements up and down in the market. I investigated both a four-state (4ST) and a six-state model; however, the 4ST model 
was thought best, since the paucity of observations in the negative states in the six-state model weakened the significance of returns.

To determine the breakpoints of the 4ST model, I looked to previous research that utilizes breakpoints for market states. Pagan and Sossounov (2003) claim that bull and bear markets are a common way of describing market cycles in equity prices, with the definition of bull and bear markets seemingly corresponding to that given by Chauvet and Potter (2000): "In stock market terminology, bull (bear) market corresponds to periods of generally increasing (decreasing) market prices". Further, the financial press seems to have refined this definition to insist on the rise (fall) of the market being greater (less) than $20 \%$ to qualify for these names (Pagan and Sossounov, 2003). Therefore, following previous literature, I utilize $+20 \%$ or $-20 \%$ market returns as breakpoints to form four states.

This new dynamic model utilizes seven formation periods for my investigation, $J=$ ALL, $360,300,240,180,120$, and 60 months, and shows how industries performed in the past and is able to predict how these same industries would perform in the future. From July 1926 to December 2013, my results show that all formation periods provide significantly predictive risk-adjusted profitable returns.

I also examine the difference in industry returns between the four states and show the greatest profitability is to be found in the extreme market states. In support of market practitioners' approach to investments of specific industries in different states of the market, my results show that industries dependent on discretionary (non-discretionary) spending are heavily featured in the extreme positive state in long winner (long loser) portfolios and in the extreme negative state in long loser (long winner) portfolios. 
In summary, the evidence shows that market states have the ability to predict future industry returns. The remaining sections are organized as follows. Section 3.2 reviews the literature. Section 3.3 details the data and methodology. Section 3.4 presents the results, including those of four state analyses, risk adjustment, and individual state profitability. Section 3.5 concludes the paper.

\subsection{Literature}

Previous literature shows industry rotation provides abnormal returns. Grauer (1990), utilizing an active quarterly industry rotation strategy based on multi-period investment theory and an empirical probability assessment approach applied to past realized returns, finds that equal-weighted portfolios generated statistically significant positive abnormal returns throughout the entire 1934-1986 period. Utilizing equal and capitalization-weighted quarterly excess returns for 55 industries from 1973 to 1995, Beller et al (1998) provide strong evidence that utilizing predictive variables, including mean-variance optimization criteria, combined with quarterly industry rotation is useful in forecasting models for industry excess returns. Conover, Jensen, and Mercer (2008) utilize sector rotation from a defensive (aggressive) position when Fed monetary policy changed from restrictive to expansive and vice versa. The authors equally weight four noncyclical sectors during the restrictive monetary policy period and six cyclical sectors during the expansive monetary policy period on an ex ante basis to generate excess returns.

Utilizing sector rotation of 43 industries, Sorensen and Burke (1986) use three, five, and 10 best-performing industry groups over the 1972-1982 period. Each portfolio is revised quarterly to sell any group that dropped by a certain percentage in industry ranking and replace it with the best-performing industry group not already held. The authors argue that their risk adjustment results show that more than half the portfolios strongly outperform the 
market. However, the authors note that their strategy can also result in negative excess returns in certain market environments, specifically, the market decline of 1974-1976.

In examining industry sector rotation over business cycles, Stangl et al (2009) follow Stovall's (1996) practitioner guide to sector investing, where the economy is divided into 10 basic industry group sectors and then the optimal performance of these sectors is mapped to one of five different business cycle stages. The authors find an annual underperformance of 2.3\% compared to the Standard \& Poor's 500 index for the period from 1948 to 2007.

Research shows industries are able to predict future returns, with the following research using industries to predict market returns. Eleswarapu and Tiwari (1996) claim that the lagged stock returns of five industry-based portfolios have significant information about future market returns that is not in the market index. Hong, Torous and Valkanov (2007) show that the lagged returns of several industries in the U.S. stock market-including retail, services, commercial real estate, metal, and petroleum - can forecast the stock market by up to two months, while Pollet (2005) finds that expected changes in the price of oil are able to predict market return and relative sector performance in the United States. My research differs from previous research, since I use previous industry returns in the same market state to determine future industry returns.

In defining market states, the literature shows two main approaches to identifying bull and bear market phases in the market cycle. Edwards et al (2003) claim the first approach advocates a parametric methodology for the data-generating process, where two different regimes are allowed, one that corresponds to expansions and therefore contains some type of 
upward trend and another one that corresponds to contractions and therefore contains a downward trend (Goodwin, 1993; Hamilton and Lin, 1998; Maheu and McCurdy, 2000).

Edwards et al (2003) also note that the second method takes a nonparametric approach, and, instead of fitting a fully specified statistical data generating process, examines the original data series in search of periods of a generalized upward trend, which will be identified with expansions, and periods of a generalized downward trend, which will be identified with contractions. The key feature of the analysis is the location of the turning points, or breakpoints, peaks, and troughs, in the series. These turning points determine the different phases of the cycle, which can be subsequently analyzed (Bry and Boschan, 1971; Watson, 1994; Artis et al, 1997; Harding and Pagan, 2000, 2002; Pagan and Sossounov, 2003). However, this method has look-ahead bias, since all the data must be known for the peaks and troughs to be identified.

I use an unbiased nonparametric method to construct market states, similar to the cumulative compound methodology used by Cooper et al (2004). These authors investigate whether momentum is influenced by market states and utilize a methodological approach to identify market states by claiming that if the 36, 24, and 12-month lagged returns is non-negative (negative), the market is in an up (down) state. Asem and Tien (2010) and Daniel and Moskowitz (2011) also examine the interaction of momentum with market states and follow the same methodology, except over 12 and 24-month lagged returns, respectively.

\subsection{Data and methodology}

The data for the study cover the sample period July 1926 to December 2013. The monthly returns from the Center for Research into Security Prices (CRSP) value-weighted market 
index constructed from all NYSE, AMEX, and NASDAQ stocks and the risk-free rate (the one-month Treasury bill rate from Ibbotson Associates) were downloaded from Ken French's website, as well as the Fama-French (1992) size and book-to-market factors SMB and HML. In addition, the industry returns used in this study are value-weighted industry monthly returns downloaded from Kenneth French's website for 49 U.S. industries. The 49 industries are listed in Table 3.1 
Table 3.1: Summary Statistics

\begin{tabular}{|c|c|c|c|c|c|c|c|}
\hline \multirow[b]{2}{*}{ Industry } & \multicolumn{3}{|c|}{ Std. } & \multirow[b]{2}{*}{ Industry } & \multicolumn{3}{|c|}{ Std. } \\
\hline & Mean & Dev. & N Obs. & & Mean & Dev. & N Obs. \\
\hline Agriculture & 0.009 & 0.065 & 744 & Insurance & 0.010 & 0.058 & 744 \\
\hline Aircraft & 0.013 & 0.067 & 744 & Machinery & 0.010 & 0.059 & 744 \\
\hline Apparel & 0.010 & 0.061 & 744 & Measuring and Control Equipment & 0.011 & 0.069 & 744 \\
\hline Automobiles and Trucks & 0.010 & 0.065 & 744 & Medical Equipment & 0.011 & 0.055 & 744 \\
\hline Banking & 0.010 & 0.057 & 744 & Miscellaneous & 0.008 & 0.066 & 744 \\
\hline Beer \& Liquor & 0.011 & 0.051 & 744 & Non-Metallic- Industrial Metal Mining & 0.011 & 0.068 & 744 \\
\hline Business Services & 0.009 & 0.054 & 744 & Personal Services & 0.009 & 0.067 & 744 \\
\hline Business Supplies & 0.010 & 0.058 & 744 & Petroleum and Natural Gas & 0.012 & 0.052 & 744 \\
\hline Candy \& Soda & 0.012 & 0.066 & 582 & Pharmaceutical Products & 0.012 & 0.051 & 744 \\
\hline Chemicals & 0.010 & 0.054 & 744 & Precious Metals & 0.011 & 0.103 & 582 \\
\hline Coal & 0.014 & 0.092 & 744 & Printing and Publishing & 0.011 & 0.059 & 744 \\
\hline Communication & 0.009 & 0.044 & 744 & Real Estate & 0.008 & 0.075 & 744 \\
\hline Computer Hardware & 0.012 & 0.069 & 744 & Recreation & 0.010 & 0.073 & 744 \\
\hline Computer Software & 0.009 & 0.120 & 558 & Restaurants, Hotels, Motels & 0.012 & 0.060 & 744 \\
\hline Construction & 0.010 & 0.071 & 744 & Retail & 0.010 & 0.051 & 744 \\
\hline Construction Materials & 0.010 & 0.059 & 744 & Rubber and Plastic Products & 0.011 & 0.059 & 744 \\
\hline Consumer Goods & 0.010 & 0.047 & 744 & Shipbuilding, Railroad Equipment & 0.010 & 0.068 & 744 \\
\hline Defence & 0.011 & 0.068 & 582 & Shipping Containers & 0.011 & 0.055 & 744 \\
\hline Electrical Equipment & 0.012 & 0.061 & 744 & Steel Works etc. & 0.009 & 0.071 & 744 \\
\hline Electronic Equipment & 0.011 & 0.073 & 744 & Textiles & 0.009 & 0.069 & 744 \\
\hline Entertainment & 0.013 & 0.074 & 744 & Tobacco Products & 0.013 & 0.059 & 744 \\
\hline Fabricated Products & 0.007 & 0.075 & 582 & Trading & 0.011 & 0.059 & 744 \\
\hline Food Products & 0.011 & 0.042 & 744 & Transportation & 0.010 & 0.057 & 744 \\
\hline \multirow[t]{2}{*}{ Healthcare } & 0.010 & 0.086 & 510 & Utilities & 0.009 & 0.038 & 744 \\
\hline & & & & Wholesale & 0.010 & 0.055 & 744 \\
\hline
\end{tabular}


Table 3.1 presents summary statistics of the 49 industries. For each industry, I provide the mean return, its standard deviation, and the number of observations. All industry observations are from July 1926 to December

2013, with the exception of soda, fabricated products, guns, and gold, which are from July 1963 to December 2013; software, which is from July 1965 to December 2013 ; and health, which is from July 1965 to

December 2013. The summary statistics have a monthly frequency. 


\subsubsection{Constructing market states}

To determine market states, this chapter uses the non-parametric method used by Cooper et al (2004) and Asem and Tian (2010). While Cooper et al (2004) utilize 36, 24, and 12-month lagged returns to determine the market state, I follow Asem and Tian (2010), who utilize a 12-month lagged return. Specifically, I employ the return on the CRSP value-weighted index over the 12 months prior to the beginning of the strategy's profit period. If the market's prior 12-month return is non-negative (negative), I define the state of the market as positive (negative).

As discussed previously, I utilize a four-state (4ST) scheme. The 4ST scheme classifies the market into states at the beginning of each month based on the magnitude of the most recent past 12-month market return. The 4ST scheme utilizes $20 \%$ for the extreme breakpoints for market returns over the last 12 months. Specifically, the three breakpoints of the 4ST scheme are zero and $\pm 20 \%$.

Table 3.2: Breakdown of States for the 4ST Strategy

\begin{tabular}{ccc}
\hline 4ST & $\begin{array}{c}\text { Past 12-Month } \\
\text { Return }(\mathrm{R} \%)\end{array}$ & $\begin{array}{c}\text { Percent of } \\
\text { Sample }\end{array}$ \\
\hline $\mathbf{2}$ & $R>20$ & $27.33 \%$ \\
$\mathbf{1}$ & $0<R \leq 20$ & $41.67 \%$ \\
$\mathbf{- 1}$ & $-20<R \leq 0$ & $22.43 \%$ \\
$\mathbf{- 2}$ & $R \leq-20$ & $8.57 \%$
\end{tabular}

$\overline{\text { Table } 3.2 \text { shows the annual and monthly breakpoints and states of the 4ST strategy. }}$

The four states are listed in Table 3.2, which shows for example, that the highest market state $(\mathrm{S}=2)$ occurs if the past 12 -month return exceeds $20 \%$. 


\subsubsection{Portfolio formation}

For each of the seven formation periods $J=$ ALL, 360, 300, 240, 180, 120, 60 months, the portfolio formation at the end of each month is utilized as follows: Each strategy buys the long-term winner (LW) portfolio and sells the long-term loser (LL) portfolio to form a longshort portfolio, denoted LW-LL. To enable a 12-month predictive effect, from July 1926 to December 2012, industry monthly returns are the future average 12-months returns for that particular industry. There is thus an overlap of up to 12 months in the formation periods of the 4 ST portfolio. Therefore, in each formation period, the most recent 12 months are skipped when calculating the performances of the industries over the past $J$ months. (The $J=$ ALL case refers to the formation period that begins with the first month in the sample.) For example, for $J=240$ months, the 4 ST long-term winner (loser) portfolio at the end of a particular month (out of the period from 240 months ago to 13 months ago) contains the $20 \%$ of the industries with the largest (smallest) average future 12-month return, where that average is only over those months that had the same 4ST market state as the current $4 \mathrm{ST}$ market state (ST).

In essence, industries are selected for the long portfolio (LW) in a particular month for a market state if those industries have performed relatively well in the 12 months following the same market state in the past. Similarly, industries are selected for the short portfolio (LL) in a particular month for a market state if those industries have performed relatively poorly in the 12 months following a market state in the past. The 12-month gap ensures that the portfolio construction process does not have any look-ahead bias.

The equal-weighted portfolio returns for each strategy are calculated for K-month holding periods $(K=1,3,6,9,12)$ using Jegadeesh and Titman's $(1993,2001)$ overlapping portfolio 
approach. In any given month $t$, the strategies hold a series of portfolios that are selected in the current month, as well as in the previous $K-1$ months, where $K$ is the holding period. Profitability is derived by utilizing long winner and short loser quintile monthly portfolios and holding the position for $K$ months.

To test whether risk considerations can explain the raw results that are produced by the various strategies, portfolio returns are risk adjusted using the Carhart (1997) four-factor model. For the 4ST strategy, I regress the time series of portfolio returns (LW, LL, and LWLL) on market, size, book-to-market and momentum factors. This regression can be written as

$R_{p t}-r_{f t}=\alpha_{p}+\beta_{p}\left(R_{m t}-r_{f t}\right)+s_{p} S M B_{t}+h_{p} H M L_{t}+u_{p} U M D_{t}+\varepsilon_{p t}$,

where the dependent variable $R_{p t}-r_{f t}$ is the monthly excess return of the equally weighted portfolio $p, R_{p t}$ represents the monthly return of portfolio $p$ at time $t$, and $r_{f t}$ is the monthly risk-free rate at time $t$ represented by the one-month U.S. T-bill return. The independent variables or factors are as follows: $R_{m t}$ is the market return, $S M B_{t}$ is the difference between the returns on diversified portfolios of small stocks and big stocks, $H M L_{t}$ is the difference between the returns on diversified portfolios of high book-to market (value) stocks and low book-to-market (growth) stocks, and $U M D_{t}$ is the difference between the month $t$ returns on diversified portfolios of the winners and losers of the past year.

\subsection{Results}

\subsubsection{ST results}

Table 3.3 reports the returns of the short (LL), long (LW), and long-short (LW-LL) portfolios for the 4ST strategy for various $J$-month formation periods $(J=$ ALL, 360, 300, 
240, 180, 120, and 60 months). Recall that the long-term winner (LW) portfolio is composed of the $20 \%$ of industries that performed the best in the same state as the current state over the past $J$ months, whereas the long-term loser (LL) portfolio is composed of the $20 \%$ of industries that performed the worst in the same state as the current state over the past $J$ months. The first column of Table 3.3 identifies the J-month formation period results. The third to seventh columns report the 4ST equal-weighted average monthly returns in percentages over the K-month holding periods $K=1,3,6,9,12$, respectively. 
Table 3.3: Profitability of the 4ST Strategy

\begin{tabular}{|c|c|c|c|c|c|c|}
\hline \multirow[t]{2}{*}{ J months } & \multirow[t]{2}{*}{ Portfolio } & \multicolumn{4}{|c|}{ Holding period return } & \multirow[b]{2}{*}{$K=12$} \\
\hline & & $\mathrm{K}=1$ & $\mathrm{~K}=3$ & $K=6$ & $\mathrm{~K}=9$ & \\
\hline \multirow[t]{6}{*}{ All } & LL & 0.29 & 0.28 & 0.33 & 0.41 & 0.52 \\
\hline & & $(1.35)$ & $(1.34)$ & $(1.56)$ & $(1.93)$ & $(2.45)$ \\
\hline & LW & 1.63 & 1.57 & 1.52 & 1.46 & 1.40 \\
\hline & & $(7.81)$ & $(7.84)$ & $(7.67)$ & $(7.42)$ & (7.11) \\
\hline & LW-LL & 1.33 & 1.29 & 1.19 & 1.05 & 0.87 \\
\hline & & $(9.84)$ & $(11.57)$ & (10.58) & $(9.60)$ & $(8.34)$ \\
\hline \multirow[t]{6}{*}{360} & LL & 0.48 & 0.45 & 0.51 & 0.57 & 0.66 \\
\hline & & $(2.19)$ & $(2.13)$ & $(2.38)$ & $(2.68)$ & (3.11) \\
\hline & LW & 1.47 & 1.43 & 1.37 & 1.32 & 1.26 \\
\hline & & $(7.12)$ & $(7.20)$ & $(6.97)$ & $(6.76)$ & $(6.49)$ \\
\hline & LW-LL & 0.99 & 0.98 & 0.86 & 0.75 & 0.60 \\
\hline & & $(7.11)$ & $(8.38)$ & $(7.35)$ & $(6.54)$ & $(5.49)$ \\
\hline \multirow[t]{6}{*}{300} & LL & 0.51 & 0.48 & 0.52 & 0.59 & 0.67 \\
\hline & & $(2.37)$ & $(2.29)$ & $(2.46)$ & $(2.75)$ & (3.14) \\
\hline & LW & 1.41 & 1.37 & 1.33 & 1.29 & 1.24 \\
\hline & & $(6.87)$ & $(6.95)$ & $(6.78)$ & $(6.63)$ & $(6.41)$ \\
\hline & LW-LL & 0.90 & 0.89 & 0.81 & 0.70 & 0.57 \\
\hline & & $(6.45)$ & $(7.60)$ & $(6.86)$ & $(6.15)$ & $(5.23)$ \\
\hline \multirow[t]{6}{*}{240} & LL & 0.53 & 0.51 & 0.54 & 0.62 & 0.71 \\
\hline & & $(2.43)$ & $(2.43)$ & $(2.54)$ & $(2.90)$ & (3.33) \\
\hline & LW & 1.34 & 1.31 & 1.26 & 1.24 & 1.20 \\
\hline & & $(6.44)$ & $(6.59)$ & $(6.32)$ & $(6.31)$ & (6.13) \\
\hline & LW-LL & 0.81 & 0.80 & 0.72 & 0.62 & 0.49 \\
\hline & & $(5.71)$ & $(6.67)$ & $(5.91)$ & (5.24) & (4.29) \\
\hline \multirow[t]{6}{*}{180} & $\mathrm{LL}$ & 0.64 & 0.63 & 0.67 & 0.76 & 0.84 \\
\hline & & $(2.96)$ & $(3.05)$ & (3.18) & $(3.56)$ & (3.93) \\
\hline & LW & 1.23 & 1.22 & 1.18 & 1.15 & 1.11 \\
\hline & & $(5.84)$ & $(6.04)$ & $(5.81)$ & $(5.73)$ & $(5.55)$ \\
\hline & LW-LL & 0.59 & 0.59 & 0.51 & 0.40 & 0.27 \\
\hline & & $(4.16)$ & $(4.94)$ & $(4.22)$ & $(3.31)$ & $(2.35)$ \\
\hline \multirow[t]{6}{*}{120} & $\mathrm{LL}$ & 0.69 & 0.66 & 0.69 & 0.78 & 0.87 \\
\hline & & $(3.20)$ & (3.17) & $(3.30)$ & $(3.71)$ & $(4.10)$ \\
\hline & LW & 1.30 & 1.26 & 1.22 & 1.17 & 1.14 \\
\hline & & $(6.08)$ & $(6.07)$ & (5.90) & $(5.66)$ & $(5.58)$ \\
\hline & LW-LL & 0.62 & 0.60 & 0.53 & 0.38 & 0.27 \\
\hline & & $(4.29)$ & $(4.92)$ & $(4.26)$ & $(3.09)$ & $(2.25)$ \\
\hline \multirow[t]{5}{*}{60} & & 0.84 & 0.81 & 0.80 & 0.85 & 0.96 \\
\hline & & (3.53) & $(3.46)$ & $(3.41)$ & (3.64) & $(4.15)$ \\
\hline & & 1.18 & 1.13 & 1.06 & 0.99 & 1.03 \\
\hline & & $(5.82)$ & $(5.63)$ & (5.13) & $(4.84)$ & $(5.06)$ \\
\hline & & 0.34 & 0.33 & 0.26 & 0.14 & 0.07 \\
\hline
\end{tabular}




$$
\begin{array}{lllll}
(2.17) & (2.17) & (1.77) & (0.99) & (0.48)
\end{array}
$$

Table 3.3 presents the average monthly holding period returns as percentages of the Long Loser, Long Winner and arbitrage portfolios of the 4ST strategy. The portfolios are constructed as follows: At the beginning of each month t, industries are ranked based on 1/. Previous returns from the same state as the current state of the market cycle S, ST = 2, 1, -1, 2 (four states); 2/. The past J-month formation period returns are $J=$ ALL, 360, 300, 240, 180, 120, 60 months. The long-term winner equal-weighted portfolio (LW) contains the $20 \%$ of industries with the largest returns and the long-term loser equal-weighted portfolio (LL) contains the $20 \%$ of industries with the lowest returns. The LW-LL strategy longs the long-term winner portfolio and shorts the long-term loser portfolio, to be held for $K=1,3,6,9$, or 12 months. The formation return is the portfolio's $J$-month average formation period return as a percentage. The sample period is from July 1926 to December 2013 and the periods, $J=$ ALL, 360, 300, 240, 180, 120, 60 months, represent the overlapping portfolio periods over the sample, with the future 12 month average returns as percentages of those periods. The $t$-statistics are presented in parentheses.

The results in Table 3.3 show significant strategy profits for all $J$ formations and all holding periods for the 4ST strategy, except for $J=60$ months, which is only significant for $K=1$ and 3. For example, with a 240 -month formation period $(J=240)$ and a six-month holding period $(\mathrm{K}=6)$, the $4 \mathrm{ST}$ long-term winners earn an average of $1.26 \%$ per month, whereas the $4 \mathrm{ST}$ long-term losers gain an average of only $0.54 \%$ per month. The 4ST strategy profit (LW-LL) is a significant $0.72 \%$ per month $(t$-stat 5.91$)$.

Table 3.3 shows that the profitability of the 4ST strategy is nearly monotonically decreasing as the formation period shortens, such that $J=$ ALL shows a $1.19 \%$ monthly profit $(t$-stat 10.58 ), compared to $J=60$ with a $0.26 \%$ monthly profit ( $t$-stat 1.77$)$. It is suggested that the incremental stronger returns are due to the greater number of observations in the increased formation periods. The other notable feature of the table is a monotonic weakening in strategy profitability as holding periods increase. In the 240 -month formation period $(J=$ $240), K=1$ is associated with a $0.81 \%$ average monthly profit ( $t$-stat 5.71$)$, compared to $K=$ 12 with a $0.49 \%$ average monthly profit ( $t$-stat 4.29$)$.

For robustness purposes, I also analyzed $J=240$ months case with portfolio proportions set at $15 \%$ and $25 \%$, rather than $20 \%$. The results (not tabled here) show that, for $\mathrm{K}=6$, the $15 \%$ portfolio weighting yields a profit of $0.83 \%$ ( $t$-stat 5.80 ) and, for the $25 \%$ portfolio weighting, 
profits are $0.68 \%$ ( $t$-stat 6.56$)$, compared to $0.72 \%$ ( $t$-stat 5.91$)$, the previously discussed profits of the $20 \%$ portfolio weighting.

\subsubsection{Risk adjustment}

To determine whether the profits of the 4ST strategy could be considered a reward for bearing risk, the profits of the 4ST strategy are risk adjusted using the Carhart (1997) fourfactor model. If the intercept $\alpha_{p}$ (alpha) is statistically significantly different from zero, then this is evidence of abnormal portfolio returns. Table 3.4 reports the risk-adjusted regression coefficients for the 4ST portfolios along with the associated White (1980) corrected t-values for the formation periods $J=$ ALL, 360, 300, 240, 180, 120, and 60 months and for a sixmonth holding period $(K=6)$. The first column identifies the formation period $(\mathrm{J})$ that applies to a section of the table. The 4ST results are shown in the third to sixth columns. The third column reports the monthly alphas in percentages for the 4ST strategy. 
Table 3.4: Risk Adjusted Returns of the 4ST Strategy

\begin{tabular}{|c|c|c|c|c|c|c|c|}
\hline $\mathrm{J}$ months & Portfolio & $\alpha_{p}$ & $\beta_{p}$ & $s_{p}$ & $h_{p}$ & $u_{p}$ & Adj $R^{2}$ \\
\hline \multirow[t]{6}{*}{ All } & LL & -0.634 & 0.987 & 0.354 & 0.129 & -0.124 & 0.82 \\
\hline & & $(-6.93)$ & (34.58) & $(7.24)$ & $(2.87)$ & $(-3.33)$ & \\
\hline & LW & 0.424 & 1.053 & 0.342 & 0.012 & 0.066 & 0.91 \\
\hline & & $(6.93)$ & (64.30) & $(7.21)$ & $(0.40)$ & $(2.64)$ & \\
\hline & & 1.058 & 0.066 & -0.012 & -0.117 & 0.190 & 0.08 \\
\hline & LW-LL & $(9.64)$ & $(1.86)$ & $(-0.26)$ & $(-2.55)$ & $(4.08)$ & \\
\hline \multirow[t]{6}{*}{360} & LL & -0.508 & 0.990 & 0.334 & 0.181 & -0.079 & 0.81 \\
\hline & & $(-5.53)$ & (33.16) & $(6.88)$ & $(3.87)$ & $(-2.04)$ & \\
\hline & LW & 0.302 & 1.038 & 0.316 & 0.022 & 0.046 & 0.89 \\
\hline & & $(4.63)$ & $(60.88)$ & $(6.01)$ & $(0.71)$ & $(1.65)$ & \\
\hline & & 0.810 & 0.049 & -0.018 & -0.158 & 0.125 & 0.06 \\
\hline & LW-LL & $(6.93)$ & $(1.28)$ & $(-0.37)$ & $(-3.09)$ & $(2.46)$ & \\
\hline \multirow[t]{6}{*}{300} & LL & -0.498 & 0.998 & 0.347 & 0.159 & -0.067 & 0.81 \\
\hline & & $(-5.36)$ & $(33.75)$ & $(7.44)$ & $(3.41)$ & $(-1.68)$ & \\
\hline & LW & 0.273 & 1.040 & 0.296 & 0.023 & 0.041 & 0.89 \\
\hline & & $(4.38)$ & (61.45) & $(5.22)$ & $(0.71)$ & $(1.66)$ & \\
\hline & & 0.770 & 0.042 & -0.051 & -0.137 & 0.108 & 0.04 \\
\hline & LW-LL & $(6.61)$ & (1.11) & $(-0.98)$ & $(-2.63)$ & $(2.13)$ & \\
\hline \multirow[t]{6}{*}{240} & LL & -0.451 & 0.988 & 0.349 & 0.174 & -0.080 & 0.81 \\
\hline & & $(-4.89)$ & (33.09) & $(7.44)$ & $(3.72)$ & $(-2.05)$ & \\
\hline & LW & 0.241 & 1.047 & 0.307 & -0.014 & 0.025 & 0.89 \\
\hline & & $(3.60)$ & (59.90) & $(5.44)$ & $(-0.41)$ & $(0.92)$ & \\
\hline & & 0.692 & 0.058 & -0.042 & -0.187 & 0.104 & 0.05 \\
\hline & LW-LL & $(5.67)$ & $(1.49)$ & $(-0.78)$ & $(-3.38)$ & $(1.99)$ & \\
\hline \multirow[t]{6}{*}{180} & LL & -0.334 & 0.990 & 0.355 & 0.195 & -0.077 & 0.84 \\
\hline & & $(-4.00)$ & (33.53) & $(7.49)$ & $(4.07)$ & $(-2.05)$ & \\
\hline & LW & 0.146 & 1.055 & 0.300 & -0.014 & 0.042 & 0.86 \\
\hline & & $(1.88)$ & $(58.17)$ & $(5.40)$ & $(-0.42)$ & $(1.50)$ & \\
\hline & & 0.479 & 0.066 & -0.055 & -0.209 & 0.119 & 0.07 \\
\hline & LW-LL & $(3.98)$ & $(1.69)$ & $(-1.00)$ & $(-3.67)$ & $(2.31)$ & \\
\hline \multirow[t]{6}{*}{120} & LL & -0.311 & 0.973 & 0.370 & 0.197 & -0.093 & 0.84 \\
\hline & & $(-3.73)$ & $(33.21)$ & (8.39) & $(4.36)$ & $(-2.52)$ & \\
\hline & LW & 0.172 & 1.095 & 0.303 & -0.074 & 0.035 & 0.88 \\
\hline & & $(2.29)$ & $(59.22)$ & $(5.59)$ & $(-2.17)$ & $(1.29)$ & \\
\hline & & 0.483 & 0.122 & -0.067 & -0.271 & 0.128 & 0.10 \\
\hline & LW-LL & $(3.92)$ & $(3.10)$ & $(-1.23)$ & $(-4.65)$ & $(2.45)$ & \\
\hline \multirow[t]{6}{*}{60} & LL & -0.223 & 0.979 & 0.557 & 0.320 & -0.156 & 0.86 \\
\hline & & $(-2.35)$ & $(35.06)$ & $(4.93)$ & $(5.60)$ & $(-2.81)$ & \\
\hline & LW & 0.058 & 1.083 & 0.212 & -0.114 & 0.072 & 0.85 \\
\hline & & $(0.67)$ & $(53.86)$ & $(6.13)$ & $(-3.29)$ & $(2.41)$ & \\
\hline & & 0.2812 & 0.104 & -0.345 & -0.434 & 0.228 & 0.27 \\
\hline & LW-LL & $(1.97)$ & $(2.71)$ & $(-3.11)$ & $(-6.07)$ & $(3.17)$ & \\
\hline
\end{tabular}


Table 3.4 presents the Carhart's (1997) four-factor risk adjusted results for the monthly returns of the 4ST portfolios with formation periods of $J=$ ALL, 360, 300, 240, 180, 120, 60 months, and a holding period of $K=6$ month. For this strategy, LW is the portfolio of long-term winners and LL is the portfolio of long-term losers (as described in Table 3.2). The four-factor regression model can be written as $R_{p t}-$ $r_{f t}=\alpha_{p}+\beta_{p}\left(R_{m t}-r_{f t}\right)+s_{p} S M B_{t}+h_{p} H M L_{t}+u_{p} U M D_{t}+\varepsilon_{p t}$, here $S M B$ stands for small (market capitalization) minus big and $H M L$ stands for high (book-to-market ratio) minus low (book-to-market ratio). $U M D_{t}$ is the difference between the month t returns on diversified portfolios of the winners and losers of the past year. The size factor measures the excess returns of small caps over big caps and the book-tomarket factor measures the excess returns of value stocks over growth stocks. The $t$-statistics are presented in parentheses.

The results in Table 3.4 show significant alphas for all $J$ values for the 4ST strategy winnerloser portfolios (W-L) and for the majority of long-winner and long-loser portfolios. Specifically, for the 4ST strategy with a 240 -month formation period $(J=240)$, the LW portfolio has an alpha of $0.24 \%$ per month ( $t$-stat 3.60$)$ and the LL portfolio has an alpha of $-0.45 \%$ per month ( $t$-stat -4.49$)$. The 4 ST strategy LW-LL earns an abnormal profit of $0.69 \%$ per month ( $t$-stat 5.67). Comparing the LW-LL alphas in Table 3.4 with the corresponding LW-LL raw profits with $K=6$ in Table 3.3 shows that the alphas tend to be similar to the corresponding raw profits. In summary, the risk-adjusted results in Table 3.4 indicate that the profitability of the 4ST strategy cannot be explained by Carhart's four-factor model.

\subsubsection{Analyses of strategy profitability in different states}

With previous sections having established that market states can be used to construct profitable dynamic industry rotation strategies, this section investigates how the portfolio returns of these strategies vary with each of the different states. To conserve space, this discussion is restricted to the formation period cases in which $J=240$ months, while $J=360$ months is included for robustness comparison. Here, $J=240$ months and $J=360$ months are chosen because these formation periods more than likely cover the market evolving through the four states at least once. Given the fact that each industry monthly return in the formation periods represents that industry's next 12-month average return, then each industry monthly return could also be capturing possible future transitions between different states. 
Table 3.5 shows the 4ST strategy's raw portfolio returns and associated t-statistics for $J=$ 240 months, while Table 3.6 reports the average monthly returns in each of the various states for $J=360$ months. The first column of Table 3.5 shows the different market states $(\mathrm{S}=2,1$, $-1,-2)$, from a $20 \%$ or higher return $(S=2)$ to a $20 \%$ or lower return $(S=-2)$ (see Table 3.2 for full details of these states). The table reports the results for the $K=1$ to $K=12$ holding periods. 
Table 3.5: 4ST Profitability in the Four Individual States ( $=240$ months)

\begin{tabular}{|c|c|c|c|c|c|c|c|c|c|c|c|c|c|c|c|}
\hline States & $\begin{array}{l}\mathrm{K}=1 \\
\mathrm{LW}\end{array}$ & $\begin{array}{c}\mathrm{K}=1 \\
\mathrm{LL}\end{array}$ & $\begin{array}{c}\mathrm{K}=1 \\
\mathrm{LW}-\mathrm{LL}\end{array}$ & $\begin{array}{l}K=3 \\
L W\end{array}$ & $\begin{array}{c}\mathrm{K}=3 \\
\mathrm{LL}\end{array}$ & $\begin{array}{c}\mathrm{K}=3 \\
\mathrm{LW}-\mathrm{LL}\end{array}$ & $\begin{array}{l}\mathrm{K}=6 \\
\mathrm{LW}\end{array}$ & $\begin{array}{c}\mathrm{K}=6 \\
\mathrm{LL}\end{array}$ & $\begin{array}{c}\mathrm{K}=6 \\
\mathrm{LW}-\mathrm{LL}\end{array}$ & $\begin{array}{l}\mathrm{K}=9 \\
\mathrm{LW}\end{array}$ & $\begin{array}{c}\mathrm{K}=9 \\
\mathrm{LL}\end{array}$ & $\begin{array}{c}\mathrm{K}=9 \\
\mathrm{LW}-\mathrm{LL}\end{array}$ & $\begin{array}{c}\mathrm{K}=12 \\
\mathrm{LW}\end{array}$ & $\begin{array}{c}\mathrm{K}=12 \\
\mathrm{LL}\end{array}$ & $\begin{array}{c}\mathrm{K}=12 \\
\mathrm{LW}-\mathrm{LL}\end{array}$ \\
\hline 2 & $\begin{array}{c}1.40 \\
(3.97)\end{array}$ & $\begin{array}{c}0.25 \\
(0.52)\end{array}$ & $\begin{array}{c}1.15 \\
(3.27)\end{array}$ & $\begin{array}{c}1.52 \\
(4.05)\end{array}$ & $\begin{array}{c}0.13 \\
(0.32)\end{array}$ & $\begin{array}{c}1.39 \\
(5.02)\end{array}$ & $\begin{array}{c}1.52 \\
(3.95)\end{array}$ & $\begin{array}{c}0.17 \\
(0.42)\end{array}$ & $\begin{array}{c}1.35 \\
(5.08)\end{array}$ & $\begin{array}{c}1.59 \\
(4.14)\end{array}$ & $\begin{array}{c}0.34 \\
(0.86)\end{array}$ & $\begin{array}{c}1.25 \\
(5.07)\end{array}$ & $\begin{array}{c}1.55 \\
(4.05)\end{array}$ & $\begin{array}{c}0.49 \\
(1.27)\end{array}$ & $\begin{array}{c}1.06 \\
(4.72)\end{array}$ \\
\hline 1 & $\begin{array}{c}1.35 \\
(5.55)\end{array}$ & $\begin{array}{c}1.01 \\
(4.22)\end{array}$ & $\begin{array}{c}0.34 \\
(2.23)\end{array}$ & $\begin{array}{c}1.32 \\
(5.59)\end{array}$ & $\begin{array}{c}0.98 \\
(4.21)\end{array}$ & $\begin{array}{c}0.35 \\
(2.52)\end{array}$ & $\begin{array}{c}1.26 \\
(5.38)\end{array}$ & $\begin{array}{c}1.00 \\
(4.33)\end{array}$ & $\begin{array}{c}0.25 \\
(1.97)\end{array}$ & $\begin{array}{c}1.23 \\
(5.32)\end{array}$ & $\begin{array}{c}1.03 \\
(4.40)\end{array}$ & $\begin{array}{c}0.21 \\
(1.64)\end{array}$ & $\begin{array}{c}1.26 \\
(5.46)\end{array}$ & $\begin{array}{c}1.10 \\
(4.75)\end{array}$ & $\begin{array}{c}0.15 \\
(1.25)\end{array}$ \\
\hline-1 & $\begin{array}{c}1.00 \\
(2.21)\end{array}$ & $\begin{array}{c}0.72 \\
(1.76)\end{array}$ & $\begin{array}{c}0.28 \\
(1.13)\end{array}$ & $\begin{array}{c}1.06 \\
(2.48)\end{array}$ & $\begin{array}{c}0.76 \\
(1.82)\end{array}$ & $\begin{array}{c}0.29 \\
(1.34)\end{array}$ & $\begin{array}{c}0.96 \\
(2.21)\end{array}$ & $\begin{array}{c}0.67 \\
(1.59)\end{array}$ & $\begin{array}{c}0.29 \\
(1.29)\end{array}$ & $\begin{array}{c}0.92 \\
(2.14)\end{array}$ & $\begin{array}{c}0.69 \\
(1.65)\end{array}$ & $\begin{array}{c}0.23 \\
(1.07)\end{array}$ & $\begin{array}{c}0.86 \\
(2.01)\end{array}$ & $\begin{array}{c}0.68 \\
(1.62)\end{array}$ & $\begin{array}{c}0.18 \\
(0.88)\end{array}$ \\
\hline-2 & $\begin{array}{c}1.67 \\
(1.14) \\
\end{array}$ & $\begin{array}{c}-1.33 \\
(-0.95) \\
\end{array}$ & $\begin{array}{r}3.00 \\
(4.15) \\
\end{array}$ & $\begin{array}{c}1.02 \\
(0.82) \\
\end{array}$ & $\begin{array}{c}-1.01 \\
(-0.71) \\
\end{array}$ & $\begin{array}{c}2.03 \\
(3.30)\end{array}$ & $\begin{array}{c}1.03 \\
(0.87) \\
\end{array}$ & $\begin{array}{r}-0.69 \\
(-0.47) \\
\end{array}$ & $\begin{array}{c}1.72 \\
(2.39)\end{array}$ & $\begin{array}{r}0.94 \\
(0.83) \\
\end{array}$ & $\begin{array}{r}-0.50 \\
(-0.34) \\
\end{array}$ & $\begin{array}{r}1.43 \\
(1.89) \\
\end{array}$ & $\begin{array}{c}0.74 \\
(0.66) \\
\end{array}$ & $\begin{array}{r}-0.36 \\
(-0.24) \\
\end{array}$ & $\begin{array}{c}1.10 \\
(1.44) \\
\end{array}$ \\
\hline
\end{tabular}

Table 3.5 presents the average monthly 4ST portfolio returns in percentages for the Long Winner (LW), Long Loser (LL), and Long Winner - Long Loser (LW-LL) portfolios in each of the four states with $J=240$ and holding periods of $K=1,3,6,9$, and 12 months. The $t$-statistics are presented in parentheses.

\section{Table 3.6: 4ST Profitability in the Four Individual States ( $J=360$ months)}

\begin{tabular}{|c|c|c|c|c|c|c|c|c|c|c|c|c|c|c|c|}
\hline States & $\begin{array}{l}\mathrm{K}=1 \\
\mathrm{LW}\end{array}$ & $\begin{array}{c}\mathrm{K}=1 \\
\mathrm{LL}\end{array}$ & $\begin{array}{c}\mathrm{K}=1 \\
\mathrm{LW}-\mathrm{LL}\end{array}$ & $\begin{array}{l}K=3 \\
L W\end{array}$ & $\begin{array}{c}\mathrm{K}=3 \\
\mathrm{LL}\end{array}$ & $\begin{array}{c}\mathrm{K}=3 \\
\mathrm{LW}-\mathrm{LL}\end{array}$ & $\begin{array}{l}K=6 \\
L W\end{array}$ & $\begin{array}{c}\mathrm{K}=6 \\
\mathrm{LL}\end{array}$ & $\begin{array}{c}\mathrm{K}=6 \\
\mathrm{LW}-\mathrm{LL}\end{array}$ & $\begin{array}{l}K=9 \\
L W\end{array}$ & $\begin{array}{c}\mathrm{K}=9 \\
\mathrm{LL}\end{array}$ & $\begin{array}{c}\mathrm{K}=9 \\
\mathrm{LW}-\mathrm{LL}\end{array}$ & $\begin{array}{c}\mathrm{K}=12 \\
\mathrm{LW}\end{array}$ & $\begin{array}{c}\mathrm{K}=12 \\
\mathrm{LL}\end{array}$ & $\begin{array}{c}\mathrm{K}=12 \\
\mathrm{LW}-\mathrm{LL}\end{array}$ \\
\hline 2 & $\begin{array}{c}1.61 \\
(4.51)\end{array}$ & $\begin{array}{c}0.17 \\
(0.35)\end{array}$ & $\begin{array}{c}1.44 \\
(4.19)\end{array}$ & $\begin{array}{c}1.69 \\
(4.50)\end{array}$ & $\begin{array}{c}0.05 \\
(0.12)\end{array}$ & $\begin{array}{c}1.64 \\
(6.16)\end{array}$ & $\begin{array}{c}1.68 \\
(4.37)\end{array}$ & $\begin{array}{c}0.09 \\
(0.22)\end{array}$ & $\begin{array}{c}1.60 \\
(6.18)\end{array}$ & $\begin{array}{c}1.65 \\
(4.29)\end{array}$ & $\begin{array}{c}0.22 \\
(0.57)\end{array}$ & $\begin{array}{c}1.42 \\
(5.96)\end{array}$ & $\begin{array}{c}1.60 \\
(4.22)\end{array}$ & $\begin{array}{c}0.39 \\
(1.04)\end{array}$ & $\begin{array}{c}1.21 \\
(5.61)\end{array}$ \\
\hline 1 & $\begin{array}{c}1.38 \\
(5.72)\end{array}$ & $\begin{array}{c}0.91 \\
(3.81)\end{array}$ & $\begin{array}{c}0.47 \\
(3.23)\end{array}$ & $\begin{array}{c}1.36 \\
(5.77)\end{array}$ & $\begin{array}{c}0.87 \\
(3.75)\end{array}$ & $\begin{array}{c}0.49 \\
(3.67)\end{array}$ & $\begin{array}{c}1.31 \\
(5.62)\end{array}$ & $\begin{array}{c}0.93 \\
(4.06)\end{array}$ & $\begin{array}{c}0.38 \\
(2.99)\end{array}$ & $\begin{array}{c}1.31 \\
(5.63)\end{array}$ & $\begin{array}{c}0.98 \\
(4.23)\end{array}$ & $\begin{array}{c}0.33 \\
(2.66)\end{array}$ & $\begin{array}{c}1.29 \\
(5.58)\end{array}$ & $\begin{array}{c}1.03 \\
(4.46)\end{array}$ & $\begin{array}{c}0.26 \\
(2.12)\end{array}$ \\
\hline-1 & $\begin{array}{c}1.22 \\
(2.75)\end{array}$ & $\begin{array}{c}0.73 \\
(1.76)\end{array}$ & $\begin{array}{c}0.49 \\
(1.87)\end{array}$ & $\begin{array}{c}1.20 \\
(2.82)\end{array}$ & $\begin{array}{c}0.69 \\
(1.64)\end{array}$ & $\begin{array}{c}0.51 \\
(2.25)\end{array}$ & $\begin{array}{c}1.17 \\
(2.77)\end{array}$ & $\begin{array}{c}0.68 \\
(1.60)\end{array}$ & $\begin{array}{c}0.49 \\
(2.26)\end{array}$ & $\begin{array}{c}1.07 \\
(2.55)\end{array}$ & $\begin{array}{c}0.69 \\
(1.64)\end{array}$ & $\begin{array}{c}0.38 \\
(1.89)\end{array}$ & $\begin{array}{c}1.00 \\
(2.39)\end{array}$ & $\begin{array}{c}0.70 \\
(1.68)\end{array}$ & $\begin{array}{c}0.30 \\
(1.59)\end{array}$ \\
\hline-2 & $\begin{array}{r}1.78 \\
(1.31) \\
\end{array}$ & $\begin{array}{c}-1.07 \\
(-0.82)\end{array}$ & $\begin{array}{c}2.86 \\
(4.30) \\
\end{array}$ & $\begin{array}{c}1.33 \\
(1.11) \\
\end{array}$ & $\begin{array}{c}-0.74 \\
(-0.54)\end{array}$ & $\begin{array}{c}2.07 \\
(3.58) \\
\end{array}$ & $\begin{array}{c}1.05 \\
(0.92) \\
\end{array}$ & $\begin{array}{c}-0.50 \\
(-0.35)\end{array}$ & $\begin{array}{c}1.56 \\
(2.29) \\
\end{array}$ & $\begin{array}{c}0.92 \\
(0.82) \\
\end{array}$ & $\begin{array}{c}-0.49 \\
(-0.33)\end{array}$ & $\begin{array}{r}1.41 \\
(1.93) \\
\end{array}$ & $\begin{array}{c}0.76 \\
(0.68) \\
\end{array}$ & $\begin{array}{c}-0.37 \\
(-0.24)\end{array}$ & $\begin{array}{c}1.13 \\
(1.52)\end{array}$ \\
\hline
\end{tabular}

Table 3.6 presents the average monthly 4ST portfolio returns in percentages for the Long Winner (LW), Long Loser (LL), and Long Winner - Long Loser (LW-LL) portfolios in each of the four states with $J=360$ and

holding periods of $K=1,3,6,9$, and 12 months. The $t$-statistics are presented in parentheses. 
The LW-LL results in Table 3.5 show significant profits for state ST $=2$ for all $K$-month holding periods. Specifically, past long-term winners in state ST $=2$ earn an average of $1.52 \%$ per month with a six-month holding period $(K=6)$, whereas past long-term losers gain an average of $0.17 \%$ per month over the same period, leading to a strategy that earns a profit of $1.35 \%$ per month ( $t$-stat 5.08$)$. The profits for states $\mathrm{ST}=1,-1$, and -2 are $0.25 \%$ ( $t$-stat 1.97), $0.29 \%$ ( $t$-stat 1.29), and $1.72 \%$ ( $t$-stat 2.39), respectively. The ST $=1$ state shows significant profits for $K=6$, while ST $=-1$ shows no significant profit. The ST $=-2$ state shows the strongest profitability, driven by a strong winner portfolio return and a strong negative return in the loser portfolio. However, the state shows significant profits only up to $\mathrm{K}=6$; the profit for $K=12$ of $1.10 \%$ ( $t$-stat 1.44$)$ indicates that the paucity of observations has reduced the significance of the $\mathrm{ST}=-2$ state returns.

The strong profit (loss) in the winner (loser) portfolio in state ST $=-2$ indicates that the industry 12-month future returns may be transitioning through different states (which is discussed more in-depth in a later segment). Table 3.6 reports the results of $J=360$ months. The results are similar to those of Table 3.5, with a slight increase in profitability and significance, with all states showing significance at $K=6$, probably due to the increase in the number of observations in the longer formation period. In summary, the two extreme states $\mathrm{ST}=2$ and $\mathrm{ST}=-2$ show the strongest future 12-month profit.

\subsubsection{Industry profitability at different stages of the market}

It could be argued that the largest profits from the extreme states support the arguments of market practitioners, who frequently give advice about which industries to invest in at different times in a given market cycle. To clarify this point, I hypothesize that I should find industries that are profitable in an expanding economy to be heavily featured in the winner 
portfolio in the positive state $\mathrm{ST}=2$ and industries that are negatively impacted in a weakening economy in the loser portfolio in the negative state ST $=-2$, which is exactly the result found.

To conserve space, this discussion is restricted to the formation period cases in which $J=240$ months, while $J=360$ months is included for robustness comparison. Table 3.7 reports the industries in the top (bottom) $20 \%$ of long winner and long loser portfolios for all four states for $J=240$ months. The results are determined by the highest (lowest) number of observations each industry was in the winner (loser) portfolio in percentage terms and includes their respective following 12-month average profitability. The winner portfolio in $\mathrm{ST}=2$ is picking up industries that are noted to excel in bull markets, such as hardware, fun, chips, and banks, while the winner portfolio in the negative state ST $=-2$ is showing industries that are noted as being resilient in bear markets, such as clothes, smoke, and personal services. 
Table 3.7: Industry representation in winner and loser portfolio for 4 states ( $\mathrm{J}=\mathbf{2 4 0}$ months)

\begin{tabular}{|c|c|c|c|c|c|c|c|c|c|c|c|c|}
\hline State & 2 & & & 1 & & & -1 & & & -2 & & \\
\hline & $>20 \%$ & & & $0+20 \%$ & & & $0-20 \%$ & & & $<-20 \%$ & & \\
\hline Portfolio & Industry & Count & Profit/Loss\% & Industry & Count & Profit/Loss\% & Industry & Count & Profit/Loss\% & Industry & Count & Profit/Loss\% \\
\hline \multirow[t]{9}{*}{ Winner } & Banks & 0.57 & $3.31 \%$ & Aero & 0.52 & $2.07 \%$ & Fun & 0.71 & $0.20 \%$ & Clths & 0.53 & $-2.29 \%$ \\
\hline & Hardw & 0.53 & $3.04 \%$ & Chips & 0.48 & $2.03 \%$ & MedEq & 0.53 & $1.48 \%$ & Other & 0.48 & $-1.09 \%$ \\
\hline & Chips & 0.42 & $2.68 \%$ & Toys & 0.45 & $1.60 \%$ & Coal & 0.44 & $0.35 \%$ & Smoke & 0.42 & $-1.14 \%$ \\
\hline & Beer & 0.41 & $2.96 \%$ & MedEq & 0.43 & $1.28 \%$ & Beer & 0.36 & $-0.89 \%$ & Rtail & 0.42 & $-1.41 \%$ \\
\hline & ElcEq & 0.39 & $3.19 \%$ & Gold & 0.40 & $2.39 \%$ & Books & 0.35 & $0.19 \%$ & PerSv & 0.40 & $0.43 \%$ \\
\hline & Fun & 0.38 & $2.83 \%$ & Beer & 0.38 & $1.18 \%$ & Rubbr & 0.33 & $-0.48 \%$ & Banks & 0.40 & $-0.73 \%$ \\
\hline & Steel & 0.38 & $3.26 \%$ & Smoke & 0.36 & $1.35 \%$ & PerSv & 0.33 & $0.47 \%$ & Aero & 0.37 & $-0.45 \%$ \\
\hline & Coal & 0.37 & $2.65 \%$ & Oil & 0.36 & $1.60 \%$ & Meals & 0.33 & $-0.12 \%$ & Fun & 0.35 & $-3.06 \%$ \\
\hline & Aero & 0.37 & $4.65 \%$ & Hardw & 0.36 & $1.32 \%$ & Hardw & 0.32 & $0.38 \%$ & Ships & 0.34 & $-0.52 \%$ \\
\hline \multirow[t]{9}{*}{ Loser } & Other & 0.53 & $2.00 \%$ & Ships & 0.48 & $1.84 \%$ & Util & 0.48 & $-0.37 \%$ & Fun & 0.56 & $-4.10 \%$ \\
\hline & Paper & 0.51 & $-1.75 \%$ & Paper & 0.45 & $2.10 \%$ & Agric & 0.44 & $0.25 \%$ & BusSv & 0.53 & $-2.39 \%$ \\
\hline & Clths & 0.50 & $1.94 \%$ & Other & 0.43 & $1.16 \%$ & Telcm & 0.41 & $0.56 \%$ & Cnstr & 0.48 & $-3.40 \%$ \\
\hline & Txtls & 0.41 & $2.90 \%$ & Autos & 0.43 & $1.20 \%$ & Ships & 0.40 & $1.23 \%$ & RIEst & 0.48 & $-5.73 \%$ \\
\hline & Smoke & 0.38 & $1.67 \%$ & Clths & 0.42 & $1.03 \%$ & Mines & 0.35 & $0.67 \%$ & Paper & 0.40 & $-6.71 \%$ \\
\hline & Rubbr & 0.37 & $-4.45 \%$ & Coal & 0.40 & $1.37 \%$ & Oil & 0.32 & $-0.24 \%$ & Other & 0.36 & $-2.26 \%$ \\
\hline & Insur & 0.36 & $1.26 \%$ & Txtls & 0.36 & $1.39 \%$ & Insur & 0.31 & $1.21 \%$ & Coal & 0.35 & $-0.18 \%$ \\
\hline & Whlsl & 0.27 & $3.77 \%$ & Steel & 0.35 & $1.31 \%$ & Hshld & 0.30 & $-0.14 \%$ & Util & 0.35 & $-2.47 \%$ \\
\hline & HIth & 0.26 & $1.08 \%$ & RIEst & 0.35 & $0.70 \%$ & Steel & 0.30 & $-0.50 \%$ & Hardw & 0.35 & $-2.44 \%$ \\
\hline
\end{tabular}


Table 3.8: Industry representation in winner and loser portfolio for 4 states ( $\mathrm{J}=360$ months)

\begin{tabular}{|c|c|c|c|c|c|c|c|c|c|c|c|c|}
\hline State & 2 & & & 1 & & & -1 & & & -2 & & \\
\hline & $>20 \%$ & & & $0+20 \%$ & & & $0-20 \%$ & & & $<-20 \%$ & & \\
\hline Portfolio & Industry & Count & Profit/Loss\% & Industry & Count & Profit/Loss\% & Industry & Count & Profit/Loss\% & Industry & Count & Profit/Loss\% \\
\hline \multirow[t]{9}{*}{ Winner } & Hardw & 0.71 & $2.93 \%$ & Toys & 0.59 & $1.61 \%$ & Fun & 0.80 & $0.07 \%$ & Clths & 0.70 & $-2.27 \%$ \\
\hline & Banks & 0.62 & $3.05 \%$ & Aero & 0.56 & $2.08 \%$ & MedEq & 0.49 & $0.77 \%$ & Aero & 0.51 & $-1.83 \%$ \\
\hline & Aero & 0.54 & $4.19 \%$ & MedEq & 0.54 & $1.45 \%$ & Autos & 0.48 & $-0.80 \%$ & Other & 0.48 & $-1.09 \%$ \\
\hline & Steel & 0.53 & $3.63 \%$ & Chips & 0.44 & $1.88 \%$ & Beer & 0.47 & $-0.83 \%$ & Coal & 0.40 & $0.29 \%$ \\
\hline & Chips & 0.53 & $2.79 \%$ & Oil & 0.40 & $1.75 \%$ & Hardw & 0.42 & $0.27 \%$ & PerSv & 0.40 & $0.43 \%$ \\
\hline & ElcEq & 0.41 & $3.21 \%$ & Gold & 0.39 & $2.35 \%$ & Txtls & 0.41 & $0.42 \%$ & Banks & 0.40 & $-0.73 \%$ \\
\hline & Soda & 0.37 & $2.41 \%$ & Hlth & 0.37 & $1.18 \%$ & Books & 0.40 & $0.82 \%$ & Fun & 0.33 & $-3.97 \%$ \\
\hline & Coal & 0.35 & $2.69 \%$ & LabEq & 0.36 & $1.59 \%$ & Coal & 0.39 & $0.61 \%$ & Rtail & 0.33 & $-2.15 \%$ \\
\hline & PerSv & 0.35 & $2.57 \%$ & Hardw & 0.35 & $1.60 \%$ & Softw & 0.38 & $0.81 \%$ & Smoke & 0.30 & $-1.71 \%$ \\
\hline \multirow[t]{9}{*}{ Loser } & Clths & 0.66 & $1.94 \%$ & Paper & 0.57 & $2.02 \%$ & Util & 0.84 & $0.00 \%$ & Fun & 0.56 & $-4.12 \%$ \\
\hline & Other & 0.59 & $1.95 \%$ & Txtls & 0.49 & $1.00 \%$ & Ships & 0.51 & $1.19 \%$ & RIEst & 0.56 & $-4.93 \%$ \\
\hline & Txtls & 0.55 & $2.65 \%$ & Other & 0.48 & $1.02 \%$ & Agric & 0.45 & $-0.21 \%$ & Cnstr & 0.48 & $-3.40 \%$ \\
\hline & Paper & 0.55 & $-1.48 \%$ & Coal & 0.47 & $1.55 \%$ & Telcm & 0.41 & $0.39 \%$ & Telcm & 0.39 & $-1.75 \%$ \\
\hline & Rubbr & 0.41 & $-3.91 \%$ & Autos & 0.42 & $1.33 \%$ & Smoke & 0.38 & $0.17 \%$ & Drugs & 0.38 & $-1.64 \%$ \\
\hline & Smoke & 0.41 & $1.32 \%$ & Ships & 0.41 & $1.88 \%$ & Mines & 0.37 & $0.55 \%$ & Paper & 0.37 & $-7.43 \%$ \\
\hline & Insur & 0.38 & $1.39 \%$ & Softw & 0.40 & $1.05 \%$ & Drugs & 0.36 & $-0.28 \%$ & BusSv & 0.36 & $-1.96 \%$ \\
\hline & MedEq & 0.31 & $2.62 \%$ & Rubbr & 0.37 & $-1.91 \%$ & Oil & 0.34 & $0.01 \%$ & Other & 0.35 & $-2.56 \%$ \\
\hline & Agric & 0.29 & $3.27 \%$ & Clths & 0.36 & $1.12 \%$ & FabPr & 0.33 & $1.01 \%$ & Coal & 0.33 & $-2.75 \%$ \\
\hline
\end{tabular}

the number of times an industry was in the winner/Loser portfolios, $1=100 \%$, and the Profit/Loss column shows the average monthly return for each industry. The formation period is $J=360$ months. 
It is notable that several industries in the winner portfolios in state ST $=2$ are also in the loser portfolios in state $\mathrm{ST}=-2$, such as hardware, fun, and coal. In addition, several industries in the loser portfolios in state $\mathrm{ST}=2$ are also in the winner portfolios in state $\mathrm{ST}=-2$, such as other, clothes, and smoke. In the discussions that follow, references to profitability of industries refers to average monthly returns for investors in those industries over the following 12 months.

It is noteworthy that industries in the winner and loser portfolios in states' ST $=2$ and ST $=1$ are profitable over the next 12 months, whereas in state $\mathrm{ST}=-1$ industries in both the winner and loser portfolios exhibit mixed profitability in the future 12-month period. Only the personal services industry records a future 12-month profit in state ST $=-2$. Industries that rely on economic growth, such as fun, real estate, construction, and paper, show the strongest declines in profit in the next 12 months. Table 3.8 reports the industries in the top (bottom) $20 \%$ of long winner and long loser portfolios for all four states for $J=360$ months. The results are similar to those for $J=240$ months, with some minor industry changes in the winner and loser portfolios in the four states. Again, it is noted that the fun, real estate, construction, and paper industries in the loser portfolio in state ST $=-2$ exhibit the strongest decline in profits in the next 12 months.

For robustness purposes, I list the industries that are in the winner/loser portfolios in the different states with the largest or smallest profitability, along with their respective percentages of observations. Table 3.9 reports the results for $J=240$ months, with Table 3.10 reporting the results for $J=360$ months. As expected, the results in Table 3.9 somewhat differ from those in Table 3.7. However, the returns also show similar results: Specifically, agriculture and personal services are in the winner portfolio in state $\mathrm{ST}=-2$, while toys and 
real estate are in the loser portfolio in state $\mathrm{ST}=-2$. However, Table 3.9 offers an explanation to why the winner portfolio results are strong and the loser portfolio shows a loss in Table 3.5 (difference between states). For example, the paper industry is represented in the winner portfolio with an $18.35 \%$ monthly profit ( 0.20 observations) and in the loser portfolio with a $6.71 \%$ monthly loss ( 0.40 observations), therefore revealing strong profits and losses for the same industry.

I suggest that the results in Table 3.7 are more robust, since the average monthly profit or loss is determined by a larger number of observations and is less influenced by possible abnormal returns over fewer observations. A case in point is the health industry in Table 3.9, which has a $8.75 \%$ monthly return in state $\mathrm{ST}=2$, the winner portfolio, with only $0.01 \%$ of observations in the state. The results show that the four states differentiate industry future profitability, depending on the how an industry performs in a market cycle. Hence, the 4ST results help substantiate the theory that certain industries are better to invest in at different stages of the market cycle. 
Table 3.9: Industry representation: Profits in winner and loser portfolio for 4 states ( $J=240$ months)

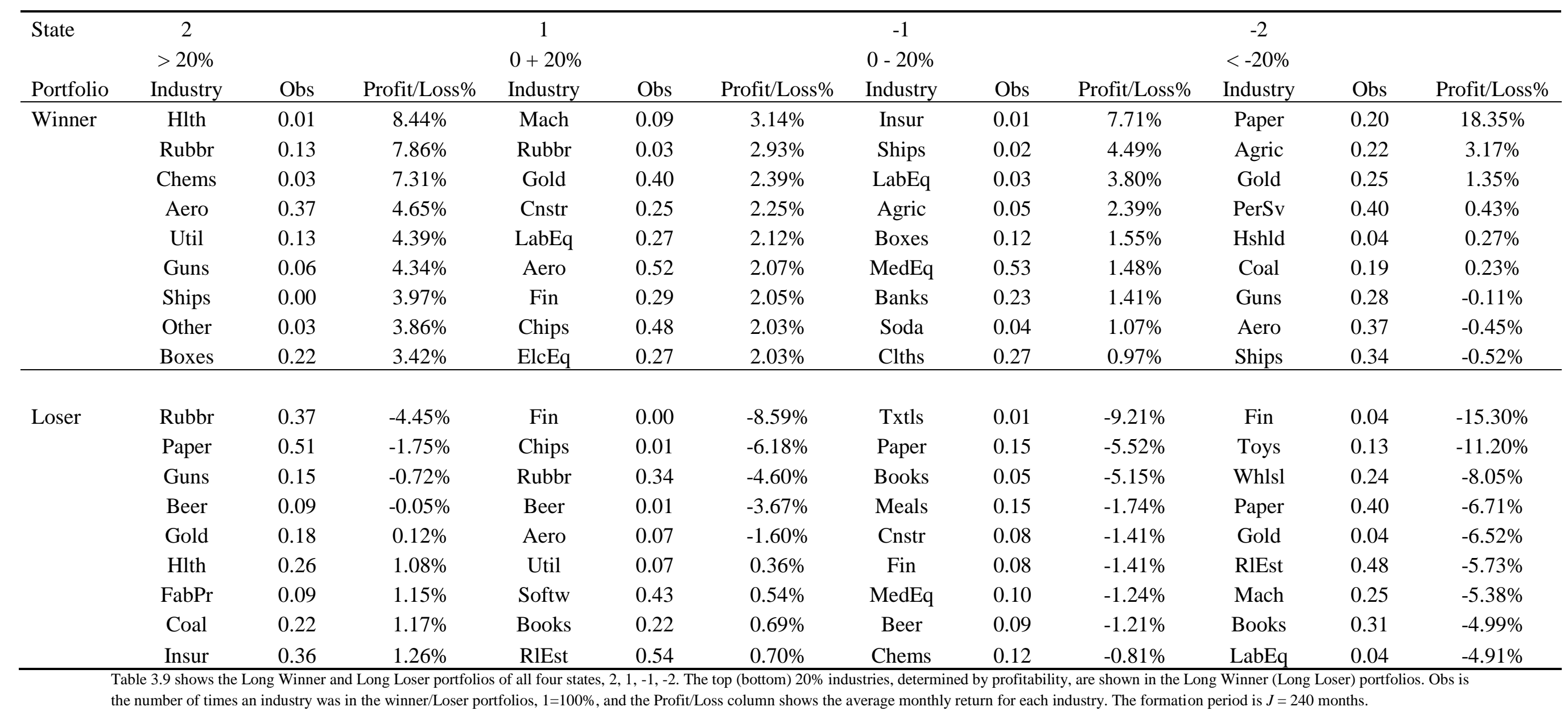


Table 3.10: Industry representation: Profits in winner and loser portfolio for 4 states ( $J=360$ months)

\begin{tabular}{|c|c|c|c|c|c|c|c|c|c|c|c|c|}
\hline State & 2 & & & 1 & & & -1 & & & -2 & & \\
\hline & $>20 \%$ & & & $0+20 \%$ & & & $0-20 \%$ & & & $<-20 \%$ & & \\
\hline Portfolio & Industry & Obs & Profit/Loss\% & Industry & Obs & Profit/Loss\% & Industry & Obs & Profit/Loss\% & Industry & Obs & Profit/Loss\% \\
\hline \multirow[t]{8}{*}{ Winner } & Rubbr & 0.13 & $7.70 \%$ & Mach & 0.09 & $3.14 \%$ & Agric & 0.03 & $6.23 \%$ & Paper & 0.28 & $12.40 \%$ \\
\hline & Chems & 0.03 & $7.31 \%$ & Rubbr & 0.03 & $2.93 \%$ & Ships & 0.02 & $4.49 \%$ & Agric & 0.22 & $3.17 \%$ \\
\hline & Util & 0.12 & $5.08 \%$ & Gold & 0.39 & $2.35 \%$ & LabEq & 0.03 & $3.80 \%$ & Ships & 0.21 & $2.49 \%$ \\
\hline & Guns & 0.10 & $4.48 \%$ & Aero & 0.56 & $2.08 \%$ & Fin & 0.06 & $2.86 \%$ & Boxes & 0.15 & $0.47 \%$ \\
\hline & Hshld & 0.01 & $4.18 \%$ & Chips & 0.44 & $1.88 \%$ & Guns & 0.10 & $1.16 \%$ & Gold & 0.17 & $0.36 \%$ \\
\hline & RIEst & 0.08 & $3.95 \%$ & FabPr & 0.07 & $1.87 \%$ & Aero & 0.23 & $1.07 \%$ & Coal & 0.40 & $0.29 \%$ \\
\hline & Fin & 0.04 & $3.87 \%$ & Smoke & 0.35 & $1.81 \%$ & PerSv & 0.36 & $1.02 \%$ & Beer & 0.28 & $-0.46 \%$ \\
\hline & Steel & 0.53 & $3.63 \%$ & Autos & 0.29 & $1.80 \%$ & Smoke & 0.27 & $0.98 \%$ & Autos & 0.19 & $-0.71 \%$ \\
\hline \multirow[t]{8}{*}{ Loser } & Rubbr & 0.41 & $-4.45 \%$ & Fin & 0.00 & $-8.59 \%$ & Txtls & 0.00 & $-9.21 \%$ & Fin & 0.10 & $-15.30 \%$ \\
\hline & Guns & 0.08 & $-0.72 \%$ & Rubbr & 0.37 & $-4.60 \%$ & Books & 0.05 & $-5.15 \%$ & Whlsl & 0.12 & $-8.05 \%$ \\
\hline & Beer & 0.12 & $-0.05 \%$ & Beer & 0.01 & $-3.67 \%$ & Meals & 0.17 & $-1.74 \%$ & Paper & 0.37 & $-6.71 \%$ \\
\hline & Gold & 0.19 & $0.12 \%$ & Aero & 0.00 & $-1.60 \%$ & Cnstr & 0.04 & $-1.41 \%$ & Gold & 0.04 & $-6.52 \%$ \\
\hline & Hlth & 0.27 & $1.08 \%$ & Util & 0.00 & $0.36 \%$ & Fin & 0.08 & $-1.41 \%$ & RIEst & 0.56 & $-5.73 \%$ \\
\hline & FabPr & 0.21 & $1.15 \%$ & Softw & 0.40 & $0.54 \%$ & MedEq & 0.10 & $-1.24 \%$ & Mach & 0.17 & $-5.38 \%$ \\
\hline & Coal & 0.23 & $1.17 \%$ & Books & 0.15 & $0.69 \%$ & Beer & 0.03 & $-1.21 \%$ & Books & 0.31 & $-4.99 \%$ \\
\hline & Insur & 0.38 & $1.26 \%$ & RIEst & 0.25 & $0.70 \%$ & Chems & 0.05 & $-0.81 \%$ & LabEq & 0.21 & $-4.91 \%$ \\
\hline
\end{tabular}

the number of times an industry was in the winner/Loser portfolios, $1=100 \%$, and the Profit/Loss column shows the average monthly return for each industry. The formation period is $J=240$ month. 


\subsection{Conclusion}

This paper contributes to the literature by utilizing a new adaptive model to create multiple market states, a 4ST model. The risk-adjusted results show that industry performance in the past can predict future industry performance, determined by different states of the market cycle. I utilized seven formation periods of $J=$ ALL, 360, 300, 240, 180, 120, and 60 months and show that past industry average returns are able to predict future 12-month average returns for the current market state. These results are significant for the $K=6$ holding period across all formation periods, with most formation periods significant for the $K=12$ holding period. All formation period profits are significant for the $K=6$ holding periods using risk adjusted Carhart's four-factor model, and which show results similar to the $K=6$ raw returns.

Further investigation into each state's contribution to the overall results, using formation periods of $J=240$ months and $J=360$ months, shows that the extreme states ST $=2$ and ST $=-2$ yield the strongest profits for industries in the next 12 months. However, the states ST $=$ 1 and $\mathrm{ST}=-1$ show robust profits.

I also examine which industries are featured in the winner and loser portfolios in the different states to determine if the market practitioners' theory of investing in specific industries in different states of the market would be profitable. My results show that industries dependent on an expanding economy are heavily featured in the winner portfolio in the positive state ST $=2$ and in the loser portfolio in the negative state $\mathrm{ST}=-2$. In addition, industries that show resilience in a declining economy are heavily featured in the loser portfolio in state $=2$ and in 
the winner portfolio state $\mathrm{ST}=-2$. Therefore, the $4 \mathrm{ST}$ results help substantiate the theory that certain industries are better to invest in at different stages of the market cycle.

In closing, this study contributes a number of new findings to the current body of scholarly work in asset selection, allocation, and asset pricing through examination of the interaction between market states and the future returns of industries. In addition, this study has significant practical implications for investors who wish to better understand the changing risk/return profiles of different industries. 
Annexure 3A: 4ST Profitability in the Four Individual States ( $=60$ months)

\begin{tabular}{|c|c|c|c|c|c|c|c|c|c|c|c|c|c|c|c|}
\hline States & $\begin{array}{l}\mathrm{K}=1 \\
\mathrm{LW}\end{array}$ & $\begin{array}{c}\mathrm{K}=1 \\
\mathrm{LL}\end{array}$ & $\begin{array}{c}\mathrm{K}=1 \\
\mathrm{LW}-\mathrm{LL}\end{array}$ & $\begin{array}{l}K=3 \\
L W\end{array}$ & $\begin{array}{c}\mathrm{K}=3 \\
\mathrm{LL}\end{array}$ & $\begin{array}{c}\mathrm{K}=3 \\
\mathrm{LW}-\mathrm{LL}\end{array}$ & $\begin{array}{l}K=6 \\
L W\end{array}$ & $\begin{array}{c}\mathrm{K}=6 \\
\mathrm{LL}\end{array}$ & $\begin{array}{c}\mathrm{K}=6 \\
\mathrm{LW}-\mathrm{LL}\end{array}$ & $\begin{array}{l}K=9 \\
L W\end{array}$ & $\begin{array}{c}\mathrm{K}=9 \\
\mathrm{LL}\end{array}$ & $\begin{array}{c}\mathrm{K}=9 \\
\mathrm{LW}-\mathrm{LL}\end{array}$ & $\begin{array}{c}\mathrm{K}=12 \\
\mathrm{LW}\end{array}$ & $\begin{array}{c}\mathrm{K}=12 \\
\mathrm{LL}\end{array}$ & $\begin{array}{c}\mathrm{K}=12 \\
\mathrm{LW}-\mathrm{LL}\end{array}$ \\
\hline 2 & $\begin{array}{c}1.09 \\
(2.83)\end{array}$ & $\begin{array}{c}1.26 \\
(2.64)\end{array}$ & $\begin{array}{c}-0.17 \\
(-0.48)\end{array}$ & $\begin{array}{c}1.08 \\
(2.80)\end{array}$ & $\begin{array}{c}1.23 \\
(2.67)\end{array}$ & $\begin{array}{c}-0.14 \\
(-0.43)\end{array}$ & $\begin{array}{c}1.14 \\
(2.98)\end{array}$ & $\begin{array}{c}1.22 \\
(2.68)\end{array}$ & $\begin{array}{c}-0.09 \\
(-0.27)\end{array}$ & $\begin{array}{c}1.04 \\
(2.68)\end{array}$ & $\begin{array}{c}1.16 \\
(2.51)\end{array}$ & $\begin{array}{c}-0.12 \\
(-0.36)\end{array}$ & $\begin{array}{c}1.18 \\
(2.99)\end{array}$ & $\begin{array}{c}1.26 \\
(2.72)\end{array}$ & $\begin{array}{c}-0.08 \\
(-0.26)\end{array}$ \\
\hline 1 & $\begin{array}{c}1.49 \\
(5.75)\end{array}$ & $\begin{array}{c}0.97 \\
(4.10)\end{array}$ & $\begin{array}{c}0.52 \\
(2.89)\end{array}$ & $\begin{array}{c}1.45 \\
(5.67)\end{array}$ & $\begin{array}{c}0.98 \\
(4.33)\end{array}$ & $\begin{array}{c}0.47 \\
(2.87)\end{array}$ & $\begin{array}{c}1.26 \\
(4.91)\end{array}$ & $\begin{array}{c}0.97 \\
(4.30)\end{array}$ & $\begin{array}{c}0.29 \\
(1.97)\end{array}$ & $\begin{array}{c}1.19 \\
(4.81)\end{array}$ & $\begin{array}{c}1.05 \\
(4.74)\end{array}$ & $\begin{array}{c}0.14 \\
(0.98)\end{array}$ & $\begin{array}{c}1.20 \\
(4.96)\end{array}$ & $\begin{array}{c}1.15 \\
(5.18)\end{array}$ & $\begin{array}{c}0.05 \\
(0.37)\end{array}$ \\
\hline-1 & $\begin{array}{c}0.98 \\
(2.25)\end{array}$ & $\begin{array}{c}0.72 \\
(1.56)\end{array}$ & $\begin{array}{c}0.27 \\
(1.00)\end{array}$ & $\begin{array}{c}0.93 \\
(2.16)\end{array}$ & $\begin{array}{c}0.65 \\
(1.36)\end{array}$ & $\begin{array}{c}0.27 \\
(1.01)\end{array}$ & $\begin{array}{c}0.69 \\
(1.51)\end{array}$ & $\begin{array}{c}0.54 \\
(1.14)\end{array}$ & $\begin{array}{c}0.14 \\
(0.53)\end{array}$ & $\begin{array}{c}0.86 \\
(1.94)\end{array}$ & $\begin{array}{c}0.75 \\
(1.63)\end{array}$ & $\begin{array}{c}0.11 \\
(0.44)\end{array}$ & $\begin{array}{c}0.80 \\
(1.82)\end{array}$ & $\begin{array}{c}0.78 \\
(1.72)\end{array}$ & $\begin{array}{c}0.02 \\
(0.09)\end{array}$ \\
\hline-2 & $\begin{array}{c}-0.64 \\
(-0.41) \\
\end{array}$ & $\begin{array}{r}-1.42 \\
(-0.56) \\
\end{array}$ & $\begin{array}{r}0.78 \\
(0.56) \\
\end{array}$ & $\begin{array}{c}-0.40 \\
(-0.30) \\
\end{array}$ & $\begin{array}{r}-1.16 \\
(-0.58) \\
\end{array}$ & $\begin{array}{c}0.76 \\
(0.70) \\
\end{array}$ & $\begin{array}{r}0.55 \\
(0.42) \\
\end{array}$ & $\begin{array}{c}-0.67 \\
(-0.38) \\
\end{array}$ & $\begin{array}{r}1.22 \\
(1.18) \\
\end{array}$ & $\begin{array}{r}0.02 \\
(0.01) \\
\end{array}$ & $\begin{array}{c}-0.78 \\
(-0.47) \\
\end{array}$ & $\begin{array}{r}0.80 \\
(0.83) \\
\end{array}$ & $\begin{array}{r}0.37 \\
(0.31) \\
\end{array}$ & $\begin{array}{c}-0.35 \\
(-0.21) \\
\end{array}$ & $\begin{array}{c}0.72 \\
(0.78) \\
\end{array}$ \\
\hline
\end{tabular}

This Table presents the average monthly 4ST portfolio returns in percentages for the Long Winner (LW), Long Loser (LL), and Long Winner - Long Loser (LW-LL) portfolios in each of the four states with $J=60$ and holding periods of $K=1,3,6,9$, and 12 months. The $t$-statistics are presented in parentheses.

\section{Annexure 3B: 4ST Profitability in the Four Individual States (J = 120 months)}

\begin{tabular}{|c|c|c|c|c|c|c|c|c|c|c|c|c|c|c|c|}
\hline States & $\begin{array}{l}\mathrm{K}=1 \\
\mathrm{LW}\end{array}$ & $\begin{array}{c}\mathrm{K}=1 \\
\mathrm{LL}\end{array}$ & $\begin{array}{c}\mathrm{K}=1 \\
\mathrm{LW}-\mathrm{LL}\end{array}$ & $\begin{array}{l}K=3 \\
L W\end{array}$ & $\begin{array}{c}\mathrm{K}=3 \\
\mathrm{LL}\end{array}$ & $\begin{array}{c}\mathrm{K}=3 \\
\mathrm{LW}-\mathrm{LL}\end{array}$ & $\begin{array}{l}K=6 \\
L W\end{array}$ & $\begin{array}{c}\mathrm{K}=6 \\
\mathrm{LL}\end{array}$ & $\begin{array}{c}\mathrm{K}=6 \\
\mathrm{LW}-\mathrm{LL}\end{array}$ & $\begin{array}{l}K=9 \\
L W\end{array}$ & $\begin{array}{c}\mathrm{K}=9 \\
\mathrm{LL}\end{array}$ & $\begin{array}{c}\mathrm{K}=9 \\
\mathrm{LW}-\mathrm{LL}\end{array}$ & $\begin{array}{c}\mathrm{K}=12 \\
\mathrm{LW}\end{array}$ & $\begin{array}{c}\mathrm{K}=12 \\
\mathrm{LL}\end{array}$ & $\begin{array}{c}\mathrm{K}=12 \\
\mathrm{LW}-\mathrm{LL}\end{array}$ \\
\hline 2 & $\begin{array}{c}1.43 \\
(3.82)\end{array}$ & $\begin{array}{c}0.69 \\
(1.50)\end{array}$ & $\begin{array}{c}0.74 \\
(2.19)\end{array}$ & $\begin{array}{c}1.47 \\
(3.74)\end{array}$ & $\begin{array}{c}0.54 \\
(1.38)\end{array}$ & $\begin{array}{c}0.93 \\
(3.55)\end{array}$ & $\begin{array}{c}1.41 \\
(3.50)\end{array}$ & $\begin{array}{c}0.51 \\
(1.32)\end{array}$ & $\begin{array}{c}0.90 \\
(3.39)\end{array}$ & $\begin{array}{c}1.39 \\
(3.46)\end{array}$ & $\begin{array}{c}0.63 \\
(1.68)\end{array}$ & $\begin{array}{c}0.76 \\
(2.93)\end{array}$ & $\begin{array}{c}1.35 \\
(3.37)\end{array}$ & $\begin{array}{c}0.74 \\
(1.99)\end{array}$ & $\begin{array}{c}0.61 \\
(2.45)\end{array}$ \\
\hline 1 & $\begin{array}{c}1.32 \\
(5.28)\end{array}$ & $\begin{array}{c}1.04 \\
(4.48)\end{array}$ & $\begin{array}{c}0.28 \\
(1.75)\end{array}$ & $\begin{array}{c}1.32 \\
(5.33)\end{array}$ & $\begin{array}{c}1.02 \\
(4.59)\end{array}$ & $\begin{array}{c}0.30 \\
(2.07)\end{array}$ & $\begin{array}{c}1.24 \\
(5.07)\end{array}$ & $\begin{array}{c}1.10 \\
(4.97)\end{array}$ & $\begin{array}{c}0.14 \\
(1.06)\end{array}$ & $\begin{array}{c}1.19 \\
(4.87)\end{array}$ & $\begin{array}{c}1.16 \\
(5.16)\end{array}$ & $\begin{array}{c}0.03 \\
(0.21)\end{array}$ & $\begin{array}{c}1.18 \\
(4.92)\end{array}$ & $\begin{array}{c}1.23 \\
(5.46)\end{array}$ & $\begin{array}{c}-0.04 \\
(-0.33)\end{array}$ \\
\hline-1 & $\begin{array}{c}0.82 \\
(1.77)\end{array}$ & $\begin{array}{c}0.80 \\
(1.93)\end{array}$ & $\begin{array}{c}0.02 \\
(0.09)\end{array}$ & $\begin{array}{c}0.91 \\
(2.03)\end{array}$ & $\begin{array}{c}0.85 \\
(1.93)\end{array}$ & $\begin{array}{c}0.06 \\
(0.26)\end{array}$ & $\begin{array}{c}0.86 \\
(1.89)\end{array}$ & $\begin{array}{c}0.71 \\
(1.62)\end{array}$ & $\begin{array}{c}0.15 \\
(0.61)\end{array}$ & $\begin{array}{c}0.92 \\
(2.05)\end{array}$ & $\begin{array}{c}0.83 \\
(1.92)\end{array}$ & $\begin{array}{c}0.09 \\
(0.39)\end{array}$ & $\begin{array}{c}0.90 \\
(2.01)\end{array}$ & $\begin{array}{c}0.82 \\
(1.93)\end{array}$ & $\begin{array}{c}0.07 \\
(0.32)\end{array}$ \\
\hline-2 & $\begin{array}{c}1.84 \\
(1.16)\end{array}$ & $\begin{array}{c}-1.36 \\
(-0.90)\end{array}$ & $\begin{array}{c}3.20 \\
(4.11)\end{array}$ & $\begin{array}{c}0.96 \\
(0.73)\end{array}$ & $\begin{array}{c}-1.04 \\
(-0.71)\end{array}$ & $\begin{array}{c}2.00 \\
(3.10)\end{array}$ & $\begin{array}{c}1.32 \\
(1.06)\end{array}$ & $\begin{array}{c}-0.55 \\
(-0.37)\end{array}$ & $\begin{array}{c}1.87 \\
(2.55)\end{array}$ & $\begin{array}{c}0.88 \\
(0.74)\end{array}$ & $\begin{array}{c}-0.53 \\
(-0.36)\end{array}$ & $\begin{array}{c}1.41 \\
(1.82)\end{array}$ & $\begin{array}{c}0.90 \\
(0.77)\end{array}$ & $\begin{array}{c}-0.35 \\
(-0.23)\end{array}$ & $\begin{array}{c}1.25 \\
(1.59)\end{array}$ \\
\hline
\end{tabular}

This Table presents the average monthly 4ST portfolio returns in percentages for the Long Winner (LW), Long Loser (LL), and Long Winner - Long Loser (LW-LL) portfolios in each of the four states with $J=120$

and holding periods of $K=1,3,6,9$, and 12 months. The $t$-statistics are presented in parentheses. 
Annexure 3C: 4ST Profitability in the Four Individual States ( $=180$ months)

\begin{tabular}{|c|c|c|c|c|c|c|c|c|c|c|c|c|c|c|c|}
\hline States & $\begin{array}{l}\mathrm{K}=1 \\
\mathrm{LW}\end{array}$ & $\begin{array}{l}\mathrm{K}=1 \\
\mathrm{LL}\end{array}$ & $\begin{array}{c}\mathrm{K}=1 \\
\mathrm{LW}-\mathrm{LL}\end{array}$ & $\begin{array}{l}\mathrm{K}=3 \\
\mathrm{LW}\end{array}$ & $\begin{array}{c}\mathrm{K}=3 \\
\mathrm{LL}\end{array}$ & $\begin{array}{c}\mathrm{K}=3 \\
\text { LW-LL }\end{array}$ & $\begin{array}{l}\mathrm{K}=6 \\
\mathrm{LW}\end{array}$ & $\begin{array}{c}\mathrm{K}=6 \\
\mathrm{LL}\end{array}$ & $\begin{array}{c}\mathrm{K}=6 \\
\text { LW-LL }\end{array}$ & $\begin{array}{l}\mathrm{K}=9 \\
\mathrm{LW}\end{array}$ & $\begin{array}{l}\mathrm{K}=9 \\
\mathrm{LL}\end{array}$ & $\begin{array}{c}\mathrm{K}=9 \\
\mathrm{LW}-\mathrm{LL}\end{array}$ & $\begin{array}{c}\mathrm{K}=12 \\
\mathrm{LW}\end{array}$ & $\begin{array}{c}\mathrm{K}=12 \\
\mathrm{LL}\end{array}$ & $\begin{array}{c}\mathrm{K}=12 \\
\mathrm{LW}-\mathrm{LL}\end{array}$ \\
\hline 2 & $\begin{array}{c}1.03 \\
(2.79)\end{array}$ & $\begin{array}{c}0.65 \\
(1.39)\end{array}$ & $\begin{array}{c}0.38 \\
(1.08)\end{array}$ & $\begin{array}{c}1.19 \\
(3.04)\end{array}$ & $\begin{array}{c}0.54 \\
(1.36)\end{array}$ & $\begin{array}{c}0.64 \\
(2.28)\end{array}$ & $\begin{array}{c}1.21 \\
(3.02)\end{array}$ & $\begin{array}{c}0.52 \\
(1.32)\end{array}$ & $\begin{array}{c}0.70 \\
(2.48)\end{array}$ & $\begin{array}{c}1.25 \\
(3.12)\end{array}$ & $\begin{array}{c}0.63 \\
(1.64)\end{array}$ & $\begin{array}{c}0.62 \\
(2.29)\end{array}$ & $\begin{array}{c}1.25 \\
(3.12)\end{array}$ & $\begin{array}{c}0.73 \\
(1.91)\end{array}$ & $\begin{array}{c}0.52 \\
(2.00)\end{array}$ \\
\hline 1 & $\begin{array}{c}1.37 \\
(5.56)\end{array}$ & $\begin{array}{c}1.00 \\
(4.14)\end{array}$ & $\begin{array}{c}0.37 \\
(2.41)\end{array}$ & $\begin{array}{c}1.34 \\
(5.52)\end{array}$ & $\begin{array}{c}0.99 \\
(4.32)\end{array}$ & $\begin{array}{c}0.35 \\
(2.58)\end{array}$ & $\begin{array}{c}1.25 \\
(5.21)\end{array}$ & $\begin{array}{c}1.07 \\
(4.73)\end{array}$ & $\begin{array}{c}0.18 \\
(1.45)\end{array}$ & $\begin{array}{c}1.20 \\
(5.04)\end{array}$ & $\begin{array}{c}1.13 \\
(4.97)\end{array}$ & $\begin{array}{c}0.06 \\
(0.53)\end{array}$ & $\begin{array}{c}1.19 \\
(5.02)\end{array}$ & $\begin{array}{c}1.22 \\
(5.39)\end{array}$ & $\begin{array}{c}-0.03 \\
(-0.25)\end{array}$ \\
\hline-1 & $\begin{array}{c}0.92 \\
(2.05)\end{array}$ & $\begin{array}{c}0.76 \\
(1.84)\end{array}$ & $\begin{array}{c}0.16 \\
(0.69)\end{array}$ & $\begin{array}{c}1.04 \\
(2.45)\end{array}$ & $\begin{array}{c}0.80 \\
(1.91)\end{array}$ & $\begin{array}{c}0.24 \\
(1.14)\end{array}$ & $\begin{array}{c}0.97 \\
(2.25)\end{array}$ & $\begin{array}{c}0.69 \\
(1.63)\end{array}$ & $\begin{array}{c}0.29 \\
(1.37)\end{array}$ & $\begin{array}{c}0.95 \\
(2.23)\end{array}$ & $\begin{array}{c}0.72 \\
(1.72)\end{array}$ & $\begin{array}{c}0.23 \\
(1.19)\end{array}$ & $\begin{array}{c}0.91 \\
(2.13)\end{array}$ & $\begin{array}{c}0.69 \\
(1.67)\end{array}$ & $\begin{array}{c}0.21 \\
(1.14)\end{array}$ \\
\hline-2 & $\begin{array}{c}1.67 \\
(1.14)\end{array}$ & $\begin{array}{l}-1.31 \\
(-0.94)\end{array}$ & $\begin{array}{c}2.98 \\
(4.09)\end{array}$ & $\begin{array}{c}1.01 \\
(0.80)\end{array}$ & $\begin{array}{c}-1.00 \\
(-0.70)\end{array}$ & $\begin{array}{c}2.01 \\
(3.28)\end{array}$ & $\begin{array}{c}1.06 \\
(0.89)\end{array}$ & $\begin{array}{c}-0.65 \\
(-0.44)\end{array}$ & $\begin{array}{c}1.71 \\
(2.42)\end{array}$ & $\begin{array}{c}1.00 \\
(0.88)\end{array}$ & $\begin{array}{c}-0.45 \\
(-0.31)\end{array}$ & $\begin{array}{c}1.45 \\
(1.95)\end{array}$ & $\begin{array}{c}0.81 \\
(0.72)\end{array}$ & $\begin{array}{c}-0.32 \\
(-0.21)\end{array}$ & $\begin{array}{c}1.13 \\
(1.49)\end{array}$ \\
\hline
\end{tabular}

and holding periods of $K=1,3,6,9$, and 12 months. The $t$-statistics are presented in parentheses.

Annexure 3D: 4ST Profitability in the Four Individual States ( $=300$ months)

\begin{tabular}{|c|c|c|c|c|c|c|c|c|c|c|c|c|c|c|c|}
\hline States & $\begin{array}{l}\mathrm{K}=1 \\
\mathrm{LW}\end{array}$ & $\begin{array}{c}\mathrm{K}=1 \\
\mathrm{LL}\end{array}$ & $\begin{array}{c}\mathrm{K}=1 \\
\mathrm{LW}-\mathrm{LL}\end{array}$ & $\begin{array}{l}K=3 \\
L W\end{array}$ & $\begin{array}{l}\mathrm{K}=3 \\
\mathrm{LL}\end{array}$ & $\begin{array}{c}\mathrm{K}=3 \\
\mathrm{LW}-\mathrm{LL}\end{array}$ & $\begin{array}{l}\mathrm{K}=6 \\
\mathrm{LW}\end{array}$ & $\begin{array}{l}\mathrm{K}=6 \\
\mathrm{LL}\end{array}$ & $\begin{array}{c}\mathrm{K}=6 \\
\mathrm{LW}-\mathrm{LL}\end{array}$ & $\begin{array}{l}\mathrm{K}=9 \\
\mathrm{LW}\end{array}$ & $\begin{array}{l}\mathrm{K}=9 \\
\mathrm{LL}\end{array}$ & $\begin{array}{c}\mathrm{K}=9 \\
\mathrm{LW}-\mathrm{LL}\end{array}$ & $\begin{array}{c}\mathrm{K}=12 \\
\mathrm{LW}\end{array}$ & $\begin{array}{c}\mathrm{K}=12 \\
\mathrm{LL}\end{array}$ & $\begin{array}{c}\mathrm{K}=12 \\
\mathrm{LW}-\mathrm{LL}\end{array}$ \\
\hline 2 & $\begin{array}{c}1.42 \\
(4.05)\end{array}$ & $\begin{array}{c}0.20 \\
(0.42)\end{array}$ & $\begin{array}{c}1.22 \\
(3.55)\end{array}$ & $\begin{array}{c}1.53 \\
(4.11)\end{array}$ & $\begin{array}{c}0.10 \\
(0.23)\end{array}$ & $\begin{array}{c}1.44 \\
(5.35)\end{array}$ & $\begin{array}{c}1.54 \\
(4.01)\end{array}$ & $\begin{array}{c}0.14 \\
(0.36)\end{array}$ & $\begin{array}{c}1.39 \\
(5.39)\end{array}$ & $\begin{array}{c}1.54 \\
(4.04)\end{array}$ & $\begin{array}{c}0.29 \\
(0.74)\end{array}$ & $\begin{array}{c}1.25 \\
(5.25)\end{array}$ & $\begin{array}{c}1.50 \\
(3.98)\end{array}$ & $\begin{array}{c}0.46 \\
(1.22)\end{array}$ & $\begin{array}{c}1.04 \\
(4.82)\end{array}$ \\
\hline 1 & $\begin{array}{c}1.39 \\
(5.77)\end{array}$ & $\begin{array}{c}1.03 \\
(4.28)\end{array}$ & $\begin{array}{c}0.36 \\
(2.48)\end{array}$ & $\begin{array}{c}1.35 \\
(5.74)\end{array}$ & $\begin{array}{c}0.98 \\
(4.22)\end{array}$ & $\begin{array}{c}0.37 \\
(2.73)\end{array}$ & $\begin{array}{c}1.29 \\
(5.59)\end{array}$ & $\begin{array}{c}1.00 \\
(4.38)\end{array}$ & $\begin{array}{c}0.29 \\
(2.30)\end{array}$ & $\begin{array}{c}1.29 \\
(5.59)\end{array}$ & $\begin{array}{c}1.03 \\
(4.47)\end{array}$ & $\begin{array}{c}0.25 \\
(2.06)\end{array}$ & $\begin{array}{c}1.27 \\
(5.56)\end{array}$ & $\begin{array}{c}1.06 \\
(4.59)\end{array}$ & $\begin{array}{c}0.21 \\
(1.76)\end{array}$ \\
\hline-1 & $\begin{array}{l}1.16 \\
(2.59)\end{array}$ & $\begin{array}{c}0.66 \\
(1.58)\end{array}$ & $\begin{array}{c}0.50 \\
(1.95)\end{array}$ & $\begin{array}{l}1.15 \\
(2.69)\end{array}$ & $\begin{array}{c}0.62 \\
(1.46)\end{array}$ & $\begin{array}{c}0.54 \\
(2.40)\end{array}$ & $\begin{array}{c}1.17 \\
(2.76)\end{array}$ & $\begin{array}{c}0.59 \\
(1.40)\end{array}$ & $\begin{array}{c}0.58 \\
(2.67)\end{array}$ & $\begin{array}{c}1.09 \\
(2.58)\end{array}$ & $\begin{array}{c}0.61 \\
(1.44)\end{array}$ & $\begin{array}{c}0.48 \\
(2.39)\end{array}$ & $\begin{array}{c}1.04 \\
(2.48)\end{array}$ & $\begin{array}{c}0.61 \\
(1.44)\end{array}$ & $\begin{array}{c}0.43 \\
(2.30)\end{array}$ \\
\hline-2 & $\begin{array}{c}1.84 \\
(1.36)\end{array}$ & $\begin{array}{l}-1.11 \\
(-0.85)\end{array}$ & $\begin{array}{c}2.95 \\
(4.45)\end{array}$ & $\begin{array}{c}1.36 \\
(1.14)\end{array}$ & $\begin{array}{c}-0.81 \\
(-0.59)\end{array}$ & $\begin{array}{c}2.17 \\
(3.77)\end{array}$ & $\begin{array}{c}1.09 \\
(0.96)\end{array}$ & $\begin{array}{c}-0.60 \\
(-0.42)\end{array}$ & $\begin{array}{c}1.70 \\
(2.47)\end{array}$ & $\begin{array}{c}0.97 \\
(0.86)\end{array}$ & $\begin{array}{c}-0.55 \\
(-0.37)\end{array}$ & $\begin{array}{c}1.51 \\
(2.05)\end{array}$ & $\begin{array}{c}0.80 \\
(0.71)\end{array}$ & $\begin{array}{c}-0.38 \\
(-0.25)\end{array}$ & $\begin{array}{c}1.18 \\
(1.58)\end{array}$ \\
\hline
\end{tabular}

This Table presents the average monthly 4ST portfolio returns in percentages for the Long Winner (LW), Long Loser (LL), and Long Winner - Long Loser (LW-LL) portfolios in each of the four states with $J=300$

and holding periods of $K=1,3,6,9$, and 12 months. The $t$-statistics are presented in parentheses 


\section{Chapter 4: Size- and Value-based Market States and Momentum}

\subsection{Introduction}

Chapter 3 demonstrated that market states are able to predict future industry returns. Chapter 4 extends the examination of market states potential influence on anomalous predictive variables, by creating new schemes or states to examine momentum abnormal profits. This empirical chapter investigates how two important components of the market, the small minus big (SMB) factor and high book-to market minus low-book-to market (HML) factor, effect momentum returns across market states.

There has been considerable research showing that the SMB and HML factors can have an anomalous predictive effect, and recently some research examining these components of the market's influence on momentum (see, for example, Asness, Moskowitz and Pedersen, 2013, Fama and French, 2012). There has also been some research into how market states effect momentum profits (Cooper, Gutierrez, and Hameed (2004). I add to the scholarly literature by creating two new schemes that combine market states with size and value factor performances to determine whether these new states provide information to investors about future momentum profitability.

The two new schemes are noted as the MS and MH schemes ("M" is determined by the prior 12-month market return, "S" is determined by the SMB factor's cumulative average return over the past twelve months, and " $\mathrm{H}$ " is determined by the HML factor's cumulative average return over the past 12 months). Each scheme provides four different states, and I investigate momentum profitability following each of these states. 
My results show that size and value past performances combined with a negative market produce useful information about future momentum profitability. For example, a negative market state when large firms are outperforming small firms predicts significantly positive momentum profits over the following 12 months. Similarly, a negative market state when value firms are outperforming growth firms predicts weakly significant positive momentum profits over the following 12 months. I also show that 13 of the 15 worst momentum monthly losses from 1926 to 2013 occur in one of the 12 months that follow a period of small firm outperformance in a negative market. This result is robust for industry and stock momentum.

With this information, I are able to create two trading strategies that utilize the size-negative market state and the value-negative market state interactions. These strategies outperform the corresponding standard momentum strategies with greatly reduced risk. The size-negative market state trading strategy shows a $13.9 \%$ greater profitability than the momentum strategy, with a $31 \%$ stronger Sharpe ratio. The value-negative market state trading strategy shows a $77.7 \%$ greater profit with a $63 \%$ stronger Sharpe ratio compared to the momentum strategy. The findings in this study has important implications for theorists and practitioners alike as the evidence suggests that SMB and HML recent performances combined with the market's recent performance have the ability to predict future momentum returns.

Three of the most studied capital market phenomena are the size, value and momentum effects. Size (small size firms) has long been noted as having higher average returns than large size firms (Banz 1981, Fama and French, 1992, 1993). There is also a great deal of evidence that value stocks (high book to market ratios) have higher average returns than growth stocks (low book to market ratios) (De Bondt and Thaler, 1985; Fama and French, 1992; Lakonishok, Shleifer, and Valishny, 1994). Further, Fama and French (1993) also 
argue that although size and book-to-market equity seem like ad hoc variables for explaining average stock returns, they have reason to expect that they proxy for common risk factors in returns.

Jegadeesh and Titman (1993) show that U.S. stock returns exhibit momentum: buying past winners and selling past losers generates significant average profits. Whilst Moskowitz and Grinblatt (1999), Grundy and Martin (2001), and Chordia and Shivakumar (2002) show that industry momentum is a distinct but related phenomenon to stock momentum.

Our motivation for a regime-switching perspective includes results in Chordia and Shivakumar (2002), Grundy and Martin (2001), Cooper et al. (2004), Stivers and Sun (2010) and Asem and Tian (2010). These studies collectively suggest that the time-series behaviour of momentum profits may be related to economic cycles. Although past studies have shown that momentum profitability is impacted by market states, there is substantial debate about the source of the profits. Cooper et al. (2004) claim that their results show that momentum profits depend on the market state, with strong profits in the positive state, and marginally negative results in a down market state. Further, Cooper et al. (2004) argue that their evidence is consistent with the behavioural models of Daniel, et al. (1998) and Hong and Stein (1999) rather than with rational asset pricing models.

There have been several behavioural theories developed to explain the cross-sectional momentum identified by Jegadeesh and Titman (1993) and the reversal in long-term stock returns reported by DeBondt and Thaler (1985). Daniel, Hirshleifer, and Subrahmanyam (1998) (DHS) assert that investors overreact to private information signals and underreact to 
public information signals, which leads to investor overconfidence and on changes in confidence resulting from biased self-attribution of investment outcomes.

According to Bem (1965), individuals attribute successes to their own ability more than they should and attribute failures to external noise more than they should. This leads to overconfidence during UP markets, as price appreciation reinforces their belief in their own skill, or overconfidence during DOWN markets, as price depreciation reinforces their belief. Therefore, short run momentum profits should be higher when the markets continue in the UP state, and also profitable when the market continues in a DOWN market. It is only when the market transitions, that momentum suffers reversals.

Another prominent theory from Hong and Stein (1999) (HS) argues that news watchers rationally use fundamental news, although they ignore prices. However, if information diffuses gradually across the population, prices underreact in the short run, allowing trend chasers, or momentum traders who ignore fundamental news, to be profitable in the short term. Therefore, momentum traders activity results in an eventual overreaction, and prices revert to their fundamental levels in the long-run. HS also found that risk aversion decreases as wealth increases, leading to a delayed overreaction, which leads to greater momentum profitability following market gains. Sagi \& Seasholes (2007) (SS) argue that higher growth options in a positive market leads to higher return autocorrelations, resulting in higher momentum profits following these markets. Therefore, depending on the past market state, momentum profits should be higher when the subsequent market is positive than when it is negative. 
Asem \& Tian (2010) report that momentum is profitable in continuing up and continuing down market states, and that momentum losses occur when transitioning between market states. They argue that their findings agree with the DHS (1998), HS (1999), and SS (2007) models in an UP market. However, in a DOWN market their results are only consistent with the DHS model. Therefore, consistent with DHS, they argue that the psychological biases that underpin momentum profits are investor overconfidence and biased self-attribution.

In sum, my results show that short-term momentum is profitable following a positive market, agreeing with the DHS (1998), HS (1999), and SS (2007) theories. However, following a negative market, I show that momentum makes both profits and losses, dependant on the value and size factors' past performances. In the case of the MS scheme, large firm outperformance combined with a negative market state predicts future momentum profits, whereas small firm outperformance combined with a negative market state predicts future insignificant momentum losses (and also a strong tendency for the market to rebound).

The MH scheme results show that a negative market state combined with value firm outperformance weakly predicts future momentum profits (and a strong tendency for the market to rebound), whilst growth firm outperformance combined with a negative market state produces future insignificant momentum losses. This finding differentiates Asem and Tien (2010) theory, that momentum is not profitable when the market transitions from a down market to an up market.

Section 4.2 details the data and methodology; Section 4.3 presents the momentum profits of SMB, HML schemes; Section 4.4 presents the momentum profits of MRD scheme; Section 4.5 concludes the chapter. 


\subsection{Data and methodology}

The data for the study covers the sample period July 1926 to December 2013. The monthly returns of the Centre for Research into Security Prices (CRSP) value-weighted market index constructed from all NYSE, AMEX, and NASDAQ stocks and the risk free rate the onemonth Treasury bill rate from Ibbotson Associates) are downloaded from Kenneth French's website, as are the Fama-French size factor (SMB) and the book-to-market factor (HML) returns. ${ }^{1}$ Industry returns used in this study are value-weighted industry monthly returns for 49 U.S. industries downloaded from Kenneth French's website. In addition, the six valueweighted portfolios formed on size and prior (2-12) returns (which are used in this study to construct stock momentum portfolios) were downloaded from the same website.

\subsubsection{Constructing Market-Size and Market-Value States}

The two-state classification scheme uses a non-parametric method similar to that used by Cooper et al. (2004) and Asem and Tian (2010). Whereas Cooper et al. (2004) used a 36-month lagged market return to determine the market state, I follow Asem and Tian (2010) and employ a 12-month lagged market return. Specifically, in the two-state $\mathrm{M}$ scheme the market state for a given month is defined as positive (denoted $\mathrm{M}^{+}$) if the CRSP valueweighted index's return over the most-recent past 12 months is non-negative, otherwise the market state for that month is defined as negative (denoted $\left.\mathrm{M}^{-}\right)$.

\footnotetext{
${ }^{1}$ The Fama-French SMB returns are the average returns on three small-capitalisation portfolios minus the average returns on three largecapitalisation portfolios. The Fama-French HML returns are the average returns on the two value portfolios minus the average returns on the two growth portfolios. By 'value' I mean high book-to-market equity firms, and by 'growth' I mean low book-to-market equity firms. I thank Ken French for providing the data used in my study.
} 
I can define two size and two value states in a similar fashion. For the two size states, let $\mathrm{S}^{+}$ denote the positive size state and $\mathrm{S}^{-}$the negative size state. The size state for a given month is defined as $\mathrm{S}^{+}\left(\mathrm{S}^{-}\right)$if the average return of the SMB factor over the most-recent past 12 months is non-negative (negative). For example, $\mathrm{S}^{+}$means that small firms outperformed large firms in the market over the last 12 months. For the two value states, let $\mathrm{H}^{+}$denote the positive value state and $\mathrm{H}^{-}$the negative value state. The value state for a given month is defined as $\mathrm{H}^{+}$ $\left(\mathrm{H}^{-}\right)$if the average return of the HML factor over the most-recent past 12 months is nonnegative (negative). For example, $\mathrm{H}^{+}$means that value firms outperformed growth firms in the market over the last 12 months.

This study extends the concept of market states to incorporate the performance of important components of the market. The resulting classification schemes employ four states rather than two. These four-state schemes are either the result of combining the two market states with the two size states (creating the MS scheme), or are the result of combining the two market states with the two value states (creating the MH scheme). Consequently, the four states of the MS scheme are denoted as follows: $\mathrm{M}^{+} \mathrm{S}^{+}$(if market and size states are $\mathrm{M}^{+}$and $\mathrm{S}^{+}$, respectively), $\mathrm{M}^{+} \mathrm{S}^{-}$(if market and size states are $\mathrm{M}^{+}$and $\mathrm{S}^{-}$, respectively), $\mathrm{M}^{-} \mathrm{S}^{+}$(if market and size states are $\mathrm{M}^{-}$and $\mathrm{S}^{+}$, respectively), and $\mathrm{M}^{-} \mathrm{S}^{-}$(if market and size states are $\mathrm{M}^{-}$and $\mathrm{S}^{-}$, respectively). Similarly, the four states of the $\mathrm{MH}$ scheme are denoted $\mathrm{M}^{+} \mathrm{H}^{+}$(if market and value states are $\mathrm{M}^{+}$and $\mathrm{H}^{+}$, respectively), $\mathrm{M}^{+} \mathrm{H}^{-}$(if market and value states are $\mathrm{M}^{+}$and $\mathrm{H}^{-}$, respectively), $\mathrm{M}^{-} \mathrm{H}^{+}$(if market and value states are $\mathrm{M}^{-}$and $\mathrm{H}^{+}$, respectively), and $\mathrm{M}^{-} \mathrm{H}^{-}$(if market and value states are $\mathrm{M}^{-}$and $\mathrm{H}^{-}$, respectively). 
The number of months and the percentages for each state in the M scheme, MS scheme, and MH scheme, are listed in Table 4.1. Note that the number of months with positive M states $\left(\mathrm{M}^{+}\right)$is considerably greater than the number with negative $\mathrm{M}$ states $\left(\mathrm{M}^{-}\right)$.

I also plot the number of DOWN months in each year from 1926 to 2013 for the lagged 12month VW index in Figure 4.1. Specifically, the 12-month market definition produces 322 negative months compared to the total months of 1039 months ( $31 \%$ of the sample period).

\section{Table 4.1: Observations for States}

\begin{tabular}{cccccc}
\hline Scheme & $\mathrm{M}^{+}$ & & & $\mathrm{M}^{-}$ & \\
\hline \multirow{2}{*}{$\mathrm{M}$} & 717 & & & 322 & $\begin{array}{c}\text { Obs. } \\
\%\end{array}$ \\
& $69 \%$ & & & $31 \%$ & \\
\cline { 2 - 5 } $\mathrm{MS}$ & $\mathrm{M}^{+} \mathrm{S}^{+}$ & $\mathrm{M}^{+} \mathrm{S}^{-}$ & $\mathrm{M}^{-} \mathrm{S}^{+}$ & $\mathrm{M}^{-} \mathrm{S}^{-}$ & \\
\cline { 2 - 5 } & 475 & 295 & 125 & 144 & Obs. \\
& $45.7 \%$ & $28.4 \%$ & $12.0 \%$ & $13.9 \%$ & $\%$ \\
\hline \multirow{3}{*}{$\mathrm{MH}$} & $\mathrm{M}^{+} \mathrm{H}^{+}$ & $\mathrm{M}^{+} \mathrm{H}^{-}$ & $\mathrm{M}^{-} \mathrm{H}^{+}$ & $\mathrm{M}^{-} \mathrm{H}^{-}$ & \\
\cline { 2 - 5 } & 496 & 274 & 163 & 106 & Obs. \\
& $47.7 \%$ & $26.4 \%$ & $15.7 \%$ & $10.2 \%$ & $\%$ \\
\hline
\end{tabular}

Table 4.1 shows the number and percentage of observations in each state. $\mathrm{M}$ is denoted as the prior 12-month market return, $\mathrm{S}$ is denoted as the SMB factor cumulative average return over the past twelve months, $\mathrm{H}$ is denoted as the HML factor cumulative average past 12 -month returns. The first column shows M, and the two schemes, MS scheme (MS), MH scheme (MH), whilst the top row shows whether the M state is positive or negative, $\mathrm{M}^{+}$or $\mathrm{M}^{-}$with the second + or - sign showing whether the MS or MS states are positive or negative. Time period is from 1926 to 2013 . 
Figure 4.1: Market State Down Months.

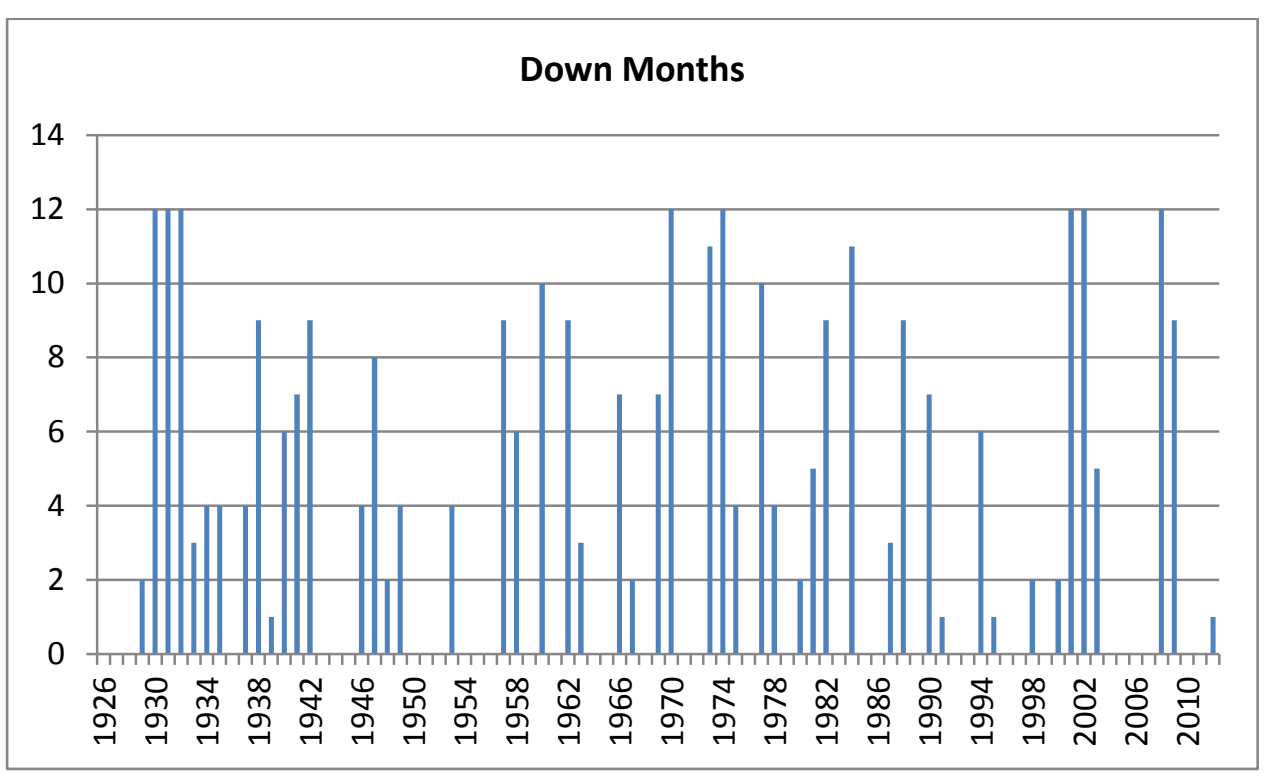

Number of one-year DOWN market states through time. The number of months within a given year for which the holding period return of the VW CRSP index over months $\mathrm{t}-12$ to $\mathrm{t}-1$ is negative during 1926 to 2013 .

\subsubsection{Momentum portfolio construction}

Stock momentum portfolio returns were calculated from momentum portfolio returns downloaded from Ken French's website. Specifically, there are six value-weight portfolios formed on size and prior (2-12) returns used to construct momentum. The portfolios, which are formed monthly, are the intersections of 2 portfolios formed on size (market equity) and 3 portfolios formed on prior (2-12) return. The monthly prior (2-12) return breakpoints are the 30th and 70th NYSE percentiles, and the monthly size breakpoint is the median NYSE market equity.

Winner portfolios contain the average of the small and big size portfolios with the $30 \%$ of stocks with the highest prior (2-12) returns. Loser portfolios contain the average of the small and big size portfolios with the $30 \%$ of stocks with the lowest prior (2-12) returns. The stock momentum strategy (W-L) is long the winner portfolio and short the loser portfolio. 
The industry momentum portfolios are constructed as follows. At the beginning of each month $t$, the 49 US industries are ranked based on their past 12-month returns. The winner (W) portfolio comprises the $20 \%$ of industries that have the highest past 12 -month returns whereas the loser (L) portfolio comprises the $20 \%$ of industries that have the lowest past 12-month returns. The momentum strategy (W-L) buys the winner portfolio and sells the loser portfolio. Consistent with Jegadeesh and Titman (1993, 2001) and many other momentum studies, I skip a month between the end of the formation period and the beginning of the holding period. I then accumulate and average the following 6 and 12 month's momentum portfolio returns (for each state separately and also combined), and use the Newey-West (1987) method to correct for autocorrelation of up to 5 and 11 lags, respectively.

\subsection{Results}

In this section, I examine the M scheme, followed by MS and MH schemes. I first examine the two-state M scheme to check consistency with prior research, and to differentiate the M scheme results from the four-state MS and MH scheme results ${ }^{2}$. For discussion purposes, I will concentrate on the 12-month profit period, unless otherwise stated.

\subsubsection{Scheme}

Table 4.2 reports the stock and industry momentum portfolio average returns for the first six months and 12 months following each state of the M scheme. Stock and industry returns show strong significant momentum profits following the positive $\mathrm{M}$ state $\left(\mathrm{M}^{+}\right)$. Specifically, stocks earned an average return of $0.88 \%$ per month ( $t$-stat 10.67$)$ and industry earned $1.07 \%$

\footnotetext{
${ }^{2} \mathrm{I}$ also examined the $\mathrm{S}$ and $\mathrm{H}$ schemes. However, there are no noteworthy results (see Annexure 4A and 4B).
} 
per month ( $t$-stat 5.76$)$ in the 12 months following $\mathrm{M}^{+}$, whilst there are insignificant profits following the negative $\mathrm{M}$ state $\left(\mathrm{M}^{-}\right)$. To test consistency with previous momentum research over market states by Cooper et al. (2004), I also utilized the lagged 36-month market return to determine market states, and found similar results to Cooper et al.'s (2004) findings (significant profits following the positive market state, and small negative insignificant profits following the negative market state).

Table 4.3 reports the differences in the portfolio returns between the positive and negative states from Table 4.2. Both stock and industry momentum profits show significant differences in both the 6-month and 12-month cases. For example, the W-L profit results show a significance difference between the $\mathrm{M}^{+}$and $\mathrm{M}^{-}$states for both stock $(0.76 \%$ per month, $t$-stat 2.34$)$ and industry $(0.83 \%$ per month, $t$-stat 2.35$)$ over the 12 -month profit period. 
Table 4.2: Market States

\begin{tabular}{|c|c|c|c|c|c|c|c|c|c|c|c|c|}
\hline \multirow[b]{2}{*}{ States } & \multirow[b]{2}{*}{$\mathrm{W}$} & \multicolumn{3}{|c|}{$\begin{array}{l}1-6 \mathrm{M} \\
\text { Stock }\end{array}$} & \multicolumn{3}{|c|}{$\begin{array}{l}1-12 \mathrm{M} \\
\text { Stock }\end{array}$} & \multicolumn{3}{|c|}{$\begin{array}{c}1-6 \mathrm{M} \\
\text { Industries }\end{array}$} & \multicolumn{2}{|c|}{$\begin{array}{c}1-12 \mathrm{M} \\
\text { Industries }\end{array}$} \\
\hline & & $\mathrm{L}$ & W-L & W & $\mathrm{L}$ & W-L & W & $\mathrm{L}$ & W-L & W & $\mathrm{L}$ & W-L \\
\hline $\mathrm{M}^{+}$ & $\begin{array}{c}1.46 \\
(8.76)\end{array}$ & $\begin{array}{c}0.57 \\
(3.57)\end{array}$ & $\begin{array}{c}0.89 \\
(10.32)\end{array}$ & $\begin{array}{c}1.37 \\
(8.61)\end{array}$ & $\begin{array}{c}0.49 \\
(3.14)\end{array}$ & $\begin{array}{c}0.88 \\
(10.67)\end{array}$ & $\begin{array}{c}1.36 \\
(8.13)\end{array}$ & $\begin{array}{c}0.26 \\
(1.43)\end{array}$ & $\begin{array}{c}1.10 \\
(6.34)\end{array}$ & $\begin{array}{c}1.31 \\
(8.32)\end{array}$ & $\begin{array}{c}0.23 \\
(1.28)\end{array}$ & $\begin{array}{c}1.07 \\
(5.76)\end{array}$ \\
\hline $\mathrm{M}^{-}$ & $\begin{array}{c}1.33 \\
(2.99)\end{array}$ & $\begin{array}{c}1.26 \\
(1.94)\end{array}$ & $\begin{array}{c}0.07 \\
(0.20)\end{array}$ & $\begin{array}{c}1.56 \\
(3.53)\end{array}$ & $\begin{array}{c}1.44 \\
(2.42)\end{array}$ & $\begin{array}{c}0.12 \\
(0.38)\end{array}$ & $\begin{array}{c}1.24 \\
(2.99)\end{array}$ & $\begin{array}{c}1.04 \\
(1.77)\end{array}$ & $\begin{array}{c}0.20 \\
(0.58)\end{array}$ & $\begin{array}{c}1.34 \\
(3.47)\end{array}$ & $\begin{array}{c}1.10 \\
(2.09)\end{array}$ & $\begin{array}{c}0.24 \\
(0.80)\end{array}$ \\
\hline Overall & $\begin{array}{c}1.44 \\
(8.18)\end{array}$ & $\begin{array}{c}0.75 \\
(3.53)\end{array}$ & $\begin{array}{c}0.69 \\
(5.84)\end{array}$ & $\begin{array}{c}1.43 \\
(8.12)\end{array}$ & $\begin{array}{c}0.74 \\
(3.58)\end{array}$ & $\begin{array}{c}0.68 \\
(6.14)\end{array}$ & $\begin{array}{c}1.33 \\
(7.89)\end{array}$ & $\begin{array}{c}0.47 \\
(2.20)\end{array}$ & $\begin{array}{c}0.86 \\
(5.36)\end{array}$ & $\begin{array}{c}1.32 \\
(8.07)\end{array}$ & $\begin{array}{c}0.46 \\
(2.25)\end{array}$ & $\begin{array}{c}0.86 \\
(5.04)\end{array}$ \\
\hline
\end{tabular}

Table 2 shows the mean monthly momentum returns for the Market-State, for stock and industries. M is denoted as the prior 12-month market return, and is defined as non-negative (negative) by the returns of the VW CRSP index over the previous twelve months prior to the profit period. Stock momentum portfolios were constructed from portfolios downloaded from Ken French's website. For industry momentum, I use the common measure of the past 12-month cumulative raw return on the asset, skipping the most recent month. The returns of the momentum portfolios (winner minus loser deciles) are averaged across two periods: common measure of the past 12-month cumulative raw return on the asset, skipping the most recent month. The returns of the momentum portfolios (winner minus loser deciles) are averaged across two periods:
months $t+1$ to $t+6$, and months $t+1$ to $t+12$. The first column in Table 4.2 show the non-negative (negative) M state. The Overall row shows the average momentum profits across both states. The results are months $\mathrm{t}+1$ to $\mathrm{t}+6$, and month $\mathrm{t}+1$ to $\mathrm{t}+12$. The first column in Table 4.2 show the non-negative (negative) $\mathrm{M}$ state. The Overall row shows the average momentum profits across both states. The results are
partitioned into four sections, $1-6$ and $1-12$ average monthly returns for stock and industry, the $t$-statistics are in parentheses. Each section shows the winner (W), loser (L), and winner minus loser (W-L) portfolio results. 


\section{Table 4.3: Differences between Market States}

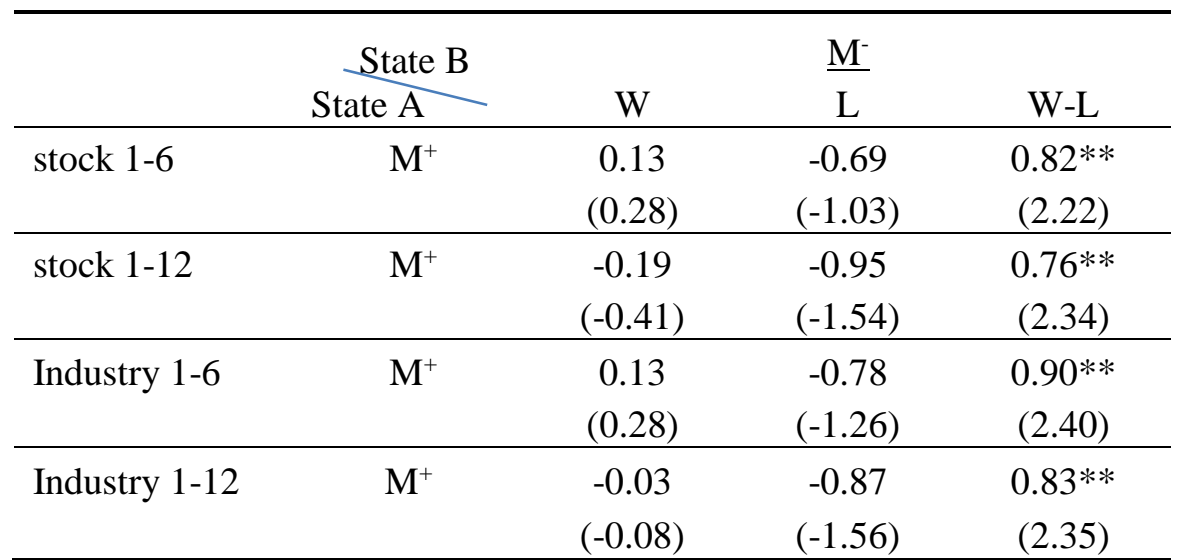

Table 4.3 reports robustness evidence for momentum payoffs for a given market state, by showing the differences in future momentum returns between the non-negative and negative $\mathrm{M}$ state. The results are differences in portfolio returns: the momentum portfolio returns in the M state from the State A column minus the corresponding momentum portfolio's returns in the M state from the row State B. M is denoted as the prior 12month market return, and is defined as non-negative (negative) by the returns of the VW CRSP index over the 12 months prior to the beginning of the strategy's profit period. Stock momentum portfolios were

constructed from portfolios downloaded from Ken French website. For industry momentum. I use the common measure of the past 12-month cumulative raw return on the asset, skipping the most recent month. The returns of the momentum portfolios (winner minus loser deciles) are averaged across two periods: month $t+1$ to $t+6$, and month $t+1$ to $t+12$. Each section shows the winner (W), loser ( $\mathrm{L}$ ), and winner minus loser (W-L) portfolio results. The period is from July 1926 to December 2013.The results are partitioned into four sections, $t+1-6$ and $t+1-12$ month average returns for stock and industry, the $t$-statistics are in parentheses, and the monthly mean differences are defined by one or two asterisk, showing $10 \%$ or $5 \%$ significance respectively. 


\subsubsection{MS Scheme}

Table 4.4 reports stock and industry momentum portfolio average returns over the 6 months and the 12 months following each of the MS scheme's four states. In the 12-month case, my results shows that momentum demonstrates strong and significant profitability following the two states with positive market returns $\left(\mathrm{M}^{+} \mathrm{S}^{+}\right.$and $\left.\mathrm{M}^{+} \mathrm{S}^{-}\right)$. Of particular interest, however, is what happens to momentum profitability following each of the states with negative market states $\left(\mathrm{M}^{-} \mathrm{S}^{+}\right.$and $\left.\mathrm{M}^{-} \mathrm{S}^{-}\right)$. Following the $\mathrm{M}^{-} \mathrm{S}^{+}$state, momentum earns an insignificant negative return, with stock momentum averaging $-0.37 \%$ per month ( $t$-stat -0.69$)$, and industry momentum averaging $-0.36 \%$ per month $(t$-stat -0.72$)$. In contrast, momentum earns significantly positive returns in the 12 months following the $\mathrm{M}^{-} \mathrm{S}^{-}$state. Specifically, following the $\mathrm{M}^{-} \mathrm{S}^{-}$state, stock momentum averages $0.55 \%$ per month ( $t$-stat 2.06) and industry momentum averages $0.76 \%$ per month ( $t$-stat 2.88 ). In short, while Table 4.2 shows that stock and industry momentum earned an insignificantly positive profit following the $\mathrm{M}^{-}$ state, the MS scheme effectively splits this result into an insignificantly negative result following $\mathrm{M}^{-} \mathrm{S}^{+}$and a highly significant positive result following $\mathrm{M}^{-} \mathrm{S}^{-}$. Therefore the MS scheme has shown that the negative $\mathrm{M}^{-}$market state can produce both positive and negative momentum returns.

Momentum's weak negative returns following the $\mathrm{M}^{-} \mathrm{S}^{+}$state means that the loser portfolio returns are larger than winner portfolio returns. For example, in the 12-month case the loser portfolio for stock earns $2.83 \%$ per month ( $t$-stat 3.57 ) and for industry earns $2.36 \%$ per month ( $t$-stat 3.46), whereas the winner portfolio for stock earns $2.46 \%$ ( $t$-stat 4.39$)$ and for industry earns $2.01 \%$ ( $t$-stat 4.39). However, it is important to note that the winner portfolio returns following this state are far stronger than those it achieved following all other states. 
Similarly, it is noticeable in all cases that the loser portfolio returns following the $\mathrm{M}^{-} \mathrm{S}^{+}$state are far larger than its returns following the other states.

Table 4.5 displays the differences in the returns of each portfolio in different MS states. As expected, the profits following the positive $\mathrm{M}$ states $\mathrm{M}^{+} \mathrm{S}^{+}$and $\mathrm{M}^{+} \mathrm{S}^{-}$are significantly (nonsignificant) different to the profits following the negative state $\mathrm{M}^{-} \mathrm{S}^{+}\left(\mathrm{M}^{-} \mathrm{S}^{-}\right)$. Noticeably, following the negative $\mathrm{M}$ state, there is a significant difference between positive and negative $\mathrm{S}$ state $\left(\mathrm{M}^{-} \mathrm{S}^{-} \mathrm{vs} \mathrm{M}^{-} \mathrm{S}^{+}\right)$in industries of $-1.12 \%(t$-stat -1.99$)$ monthly difference in profits for the following 12 month period. The corresponding difference in stock momentum profits of $-0.92 \%$ per month ( $t$-stat -1.52$)$ is economically large but insignificant (probably due to the paucity of observations in these states).

As described above, the negative $\mathrm{W}-\mathrm{L}$ results following the $\mathrm{M}^{-} \mathrm{S}^{+}$state are the differences between unusually high returns for both the winner and loser portfolios, suggesting that the market itself may tend to transition to a positive market state in the 12 months following the $\mathrm{M}^{-} \mathrm{S}^{+}$state. I examine this possibility by investigating the average return of the market (RM) and of the market minus the risk free rate (RM-rf) for the 6 and 12 month periods following the MS states, and list the results in Table 4.6.

Panel A of Table 4.6 reports that the average market return (RM) is a significant $1.64 \%$ per month ( $t$-stat 3.64) for the 12 months following the $\mathrm{M}^{-} \mathrm{S}^{+}$state, whereas it averages only an insignificant $0.37 \%$ per month ( $t$-stat 0.70 ) following the $\mathrm{M}^{-} \mathrm{S}^{-}$state. Panel B shows that the $1.36 \%$ per month difference between average market returns in the 12 months following these two states is also significant ( $t$-stat 1.96). Moreover, the average market return in the 12 months following one of the positive market states $\left(\mathrm{M}^{+} \mathrm{S}^{+}\right)$is significantly less than when 
following the $\mathrm{M}^{-} \mathrm{S}^{+}$state by the amount of $-0.97 \%$ per month $(t$-stat -2.01$)$. Overall, Table 4.6 gives strong evidence of the tendency for market rebounds to occur in the 12 months following the $\mathrm{M}^{-} \mathrm{S}^{+}$state. Thus the poor momentum returns following the $\mathrm{M}^{-} \mathrm{S}^{+}$state that are reported in Table 4.4 can be explained by the stylised fact that momentum strategies tend to do particularly poorly in market rebounds, and market rebounds tend to follow the $\mathrm{M}^{-} \mathrm{S}^{+}$state. However, the results also show momentum's insignificant $0.37 \%$ profit per month following the $\mathrm{M}^{-} \mathrm{S}^{-}$state, which shows that the domination of large size firms in a negative market indicates possible future weak market transitions, with momentum continuing with insignificant profitability.

Momentum crashes occur when momentum strategies underperform dramatically. Daniel and Moscowitz (2013) show that these crashes tend to occur following market falls, and contemporaneously with market rebounds. They show that this momentum poor performance is driven by the option-like payoffs of past losers. As further evidence of the links between poor momentum performance, rebounds and the $\mathrm{M}^{-} \mathrm{S}^{+}$state, Table 4.11 in Section 4.3.5 shows that 13 out of the 15 worst monthly momentum returns in the 1926-2013 period occur in the 12 months following an $\mathrm{M}^{-} \mathrm{S}^{+}$state. The table also shows that all 15 'momentum crash' months were also market rebound months (in the sense that the market return was strongly positive in the 15 worst momentum months).

Why does lagged small size firm outperformance combined with a lagged negative market return predict strong average returns in the market over the next 12 months? One possibility is that small caps tend to suffer severe losses early in a bear market whereas late in a bear market (during the so-called 'capitulation' phase) large firms tend to suffer worse returns than small firms because the prices of small firms have already fallen much more than the 
prices of large firms. Thus small firms outperforming large firms during poor market conditions (the $\mathrm{M}^{-} \mathrm{S}^{+}$state) may be a signal that a bear market is coming to an end. As a result, the 12 months following the $\mathrm{M}^{-} \mathrm{S}^{+}$state is a period with increased likelihood of a market rebound and thus it is a risky time for momentum strategies.

Perhaps this explanation for the link between past small firm outperformance and future market performance may also be relevant to a result of Liew and Vassalou (2000). They report that small firms outperform big firms on average in the 12 months immediately prior to 12-month periods with high growth in GDP. If the observation that small firm outperformance in negative market states is a signal that the market is about to improve is combined with the stylised fact that the stock market is a leading indicator of the economy then I should expect that small firm outperformance in negative market states will also be a leading indicator of the economy.

Another possibility is that in the previous 12 months, small size firms overtook big size firms, as buyers re-entered the market signalling that the market would rebound. I note that Fama and French (2012) has found that momentum is more profitable for small size than for large size, this could account for the strong returns in the winner portfolio. Theory also suggests that small size is negatively affected in a negative market, whilst having stronger returns in a positive market (Liew and Vassalou, 2000, Kim and Bernie, 2002), this could account for the strong returns in the loser portfolio and winner portfolio, as the market transitioned.

I would also argue that in the 12 month formation of the $\mathrm{M}^{-} \mathrm{S}^{+}$state, the outperformance of small stocks could show that investors' risk averseness had diminished, with investors becoming more confident the market would rebound. Momentum would therefore be 
profitable as a DOWN market continued, and again in the UP market following; however; it would have strong negative returns in the transition period.

Asem and Tien (2010) show that the lack of momentum profits in DOWN markets (the $\mathrm{M}^{-}$ state) is due to the offsetting of the profits when the market continues in the DOWN state against the losses when they transition to UP states. My findings in this section add to the literature regarding momentum profits when transitioning from a down market to an up market. The major contribution of the MS scheme is that it allows us to warn investors in advance when momentum strategies are likely to fail. Momentum investors tend to lose money in the 12 months following an $\mathrm{M}^{-} \mathrm{S}^{+}$state, even as the market as a whole rebound. 
Table 4.4: MS Scheme

\begin{tabular}{|c|c|c|c|c|c|c|c|c|c|c|c|c|}
\hline \multirow[b]{2}{*}{ States } & \multirow[b]{2}{*}{$\mathrm{W}$} & \multicolumn{3}{|c|}{$\begin{array}{l}1-6 \mathrm{M} \\
\text { Stock }\end{array}$} & \multicolumn{3}{|c|}{$\begin{array}{l}\text { 1-12M } \\
\text { Stock }\end{array}$} & \multicolumn{3}{|c|}{$\begin{array}{c}\text { 1-6M } \\
\text { Industries }\end{array}$} & \multicolumn{2}{|r|}{$\begin{array}{c}\text { 1-12M } \\
\text { Industries }\end{array}$} \\
\hline & & $\mathrm{L}$ & W-L & $\mathrm{W}$ & $\mathrm{L}$ & W-L & $\mathrm{W}$ & $\mathrm{L}$ & W-L & $\mathrm{W}$ & $\mathrm{L}$ & W-L \\
\hline \multirow[t]{2}{*}{$\mathrm{M}^{+} \mathrm{S}^{+}$} & 1.44 & 0.60 & 0.84 & 1.33 & 0.51 & 0.82 & 1.31 & 0.13 & 1.18 & 1.27 & 0.14 & 1.13 \\
\hline & $(6.36)$ & $(3.21)$ & $(8.01)$ & $(6.51)$ & $(2.92)$ & $(8.44)$ & $(5.65)$ & $(0.50)$ & $(4.50)$ & (6.11) & $(0.59)$ & $(4.05)$ \\
\hline \multirow[t]{2}{*}{$\mathrm{M}^{+} \mathrm{S}^{-}$} & 1.50 & 0.52 & 0.98 & 1.44 & 0.47 & 0.97 & 1.45 & 0.48 & 0.97 & 1.37 & 0.38 & 0.99 \\
\hline & (7.11) & (1.98) & (7.91) & $(6.52)$ & (1.84) & $(8.17)$ & (7.14) & $(2.13)$ & (7.01) & $(6.76)$ & (1.68) & (6.39) \\
\hline \multirow[t]{2}{*}{$\mathrm{M}^{-} \mathrm{S}^{+}$} & 1.78 & 2.19 & -0.41 & 2.46 & 2.83 & -0.37 & 1.54 & 1.92 & -0.38 & 2.01 & 2.36 & -0.36 \\
\hline & $(2.68)$ & $(2.22)$ & $(-0.62)$ & (4.39) & $(3.57)$ & $(-0.69)$ & $(2.52)$ & $(2.23)$ & $(-0.66)$ & $(4.39)$ & $(3.46)$ & $(-0.72)$ \\
\hline \multirow[t]{3}{*}{$\mathrm{M}^{-} \mathrm{S}^{-}$} & 0.94 & 0.45 & 0.49 & 0.78 & 0.24 & 0.55 & 0.98 & 0.28 & 0.70 & 0.76 & 0.01 & 0.76 \\
\hline & $(1.86)$ & $(0.64)$ & (1.82) & $(1.55)$ & $(0.34)$ & $(2.06)$ & $(2.09)$ & $(0.42)$ & $(2.31)$ & (1.67) & $(0.01)$ & $(2.88)$ \\
\hline & 1.44 & 0.75 & 0.69 & 1.43 & 0.74 & 0.68 & 1.33 & 0.47 & 0.86 & 1.32 & 0.46 & 0.86 \\
\hline Overall & (8.18) & $(3.53)$ & $(5.84)$ & (8.12) & $(3.58)$ & $(6.14)$ & $(7.89)$ & $(2.20)$ & $(5.36)$ & $(8.07)$ & $(2.25)$ & $(5.04)$ \\
\hline
\end{tabular}

Table 4.4 shows the mean future monthly momentum returns for the MS scheme's four states, for stocks and industries, over two time periods. M is denoted as the prior 12 -month market return, $\mathrm{S}$ is denoted as the SMB factor cumulative average return over the past twelve months. The M state is defined as non-negative (negative) by the returns of the VW CRSP index over the 12 months prior to the beginning of the strategy's profit period. SMB monthly data downloaded from Ken French's website, and the previous 12 month cumulative return define the POSITIVE (NEGATIVE) S state. Stock momentum portfolios were constructed from portfolios downloaded from Ken French website. For industry momentum, I use the common measure of the past 12-month cumulative raw return on the asset, skipping the most recent month. The returns of the momentum portfolios (winner minus loser deciles) are averaged across two periods: months $t+1$ to $t+6$, and months $t+1$ to $t+12$. The first column in Table 4 show the four MS states, $\mathbf{M}^{+} \mathrm{S}^{+}$(positive $\mathrm{M}$ and $\mathrm{S}$ state) $\mathrm{M}^{+} \mathrm{S}^{-}$( positive $\mathrm{M}$ and negative $\mathrm{S}$ state), $\mathrm{M}^{-} \mathrm{S}^{+}$(negative $\mathrm{M}$ and positive $\mathrm{S}$ state), $\mathrm{M}^{-} \mathrm{S}^{-}$(negative $\mathrm{M}$ and $\mathrm{S}$ state). The period is from July 1926 to December 2013 The Overall row shows the average momentum profits across all states. The results are partitioned into four sections, 1-6 and 1-12 average monthly returns for stock and industry, the $t$-statistics are in parentheses. Each section shows the winner (W), loser (L), and winner minus loser (W-L) portfolio results. 
Table 4.5: Differences between MS States

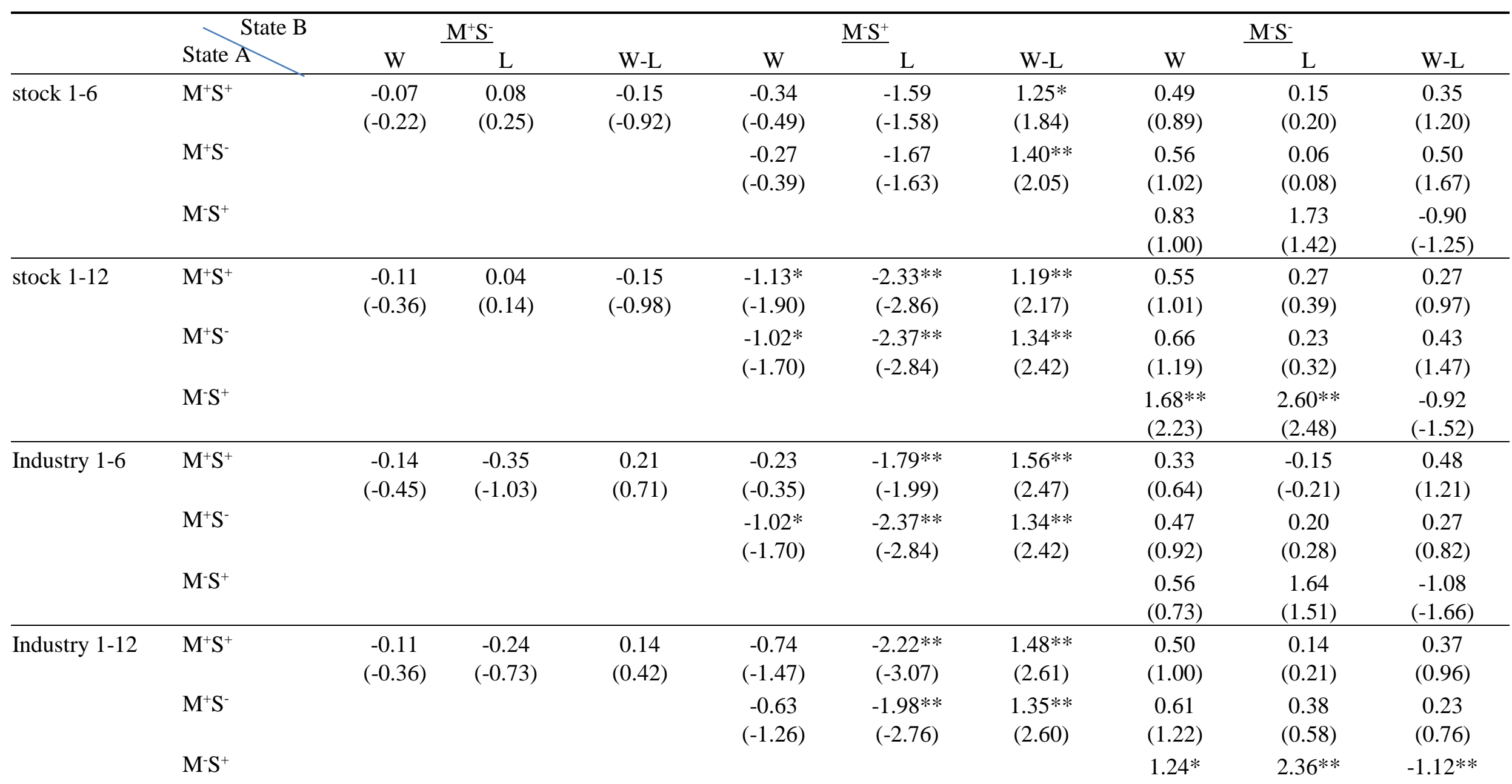


Table 4.5 reports the differences in momentum returns between each state from Table 4.7. The results are differences in portfolio returns: the momentum portfolio returns in the M state from the State A column minus the corresponding momentum portfolio's returns in the M state from the row State B. M is denoted as the prior 12-month market return, S is denoted as the SMB factor cumulative average past 12-month return. The $\mathrm{M}$ states are defined as non-negative (negative) by the returns of the VW CRSP index over the 12 months prior to the beginning of the strategy's profit period. The SMB monthly data was downloaded from Ken French's website, and previous 12 month cumulative returns define the POSITIVE (NEGATIVE) H state. Stock momentum portfolios were constructed from portfolios downloaded from Ken French website. For industry momentum, I use the common measure of the past 12-month cumulative raw return on the asset, skipping the most recent month. The returns of the monentum porttolios (winner minus loser deciles) are averaged across two periods: months $t+1$ to $t+6$, and months $t+1$ to $t+12$. Each section shows the winner (W), loser (L), and winner minus loser (W-L) portfolio results The column (row) in State A ( B) show the four MS states (described in Table 4.6). The period is from July 1926 to December 2013.The results are partitioned into four sections, 1-6 and 1-12 average returns for stock and industry, and shows the $t$-statistics in parentheses. The monthly mean differences are defined by one or two asterisk, showing $10 \%$ or $5 \%$ significance respectively. 
Table 4.6: MS scheme with Market Return

Panel A

\begin{tabular}{|c|c|c|c|c|c|c|c|}
\hline & \multirow{2}{*}{\multicolumn{2}{|c|}{$1-6 \mathrm{M}$}} & \multirow[b]{2}{*}{$1-6 \mathrm{M}$} & \multirow{2}{*}{$\begin{array}{c}1-12 \mathrm{M} \\
\mathrm{RM}\end{array}$} & \multirow{2}{*}{$\begin{array}{l}\text { 1-12M } \\
\text { RM-rf }\end{array}$} & & \\
\hline & & & & & & & \\
\hline & $\mathrm{M}^{+} \mathrm{S}^{+}$ & $\begin{array}{c}0.83 \\
(5.28)\end{array}$ & $\begin{array}{c}0.53 \\
(3.32)\end{array}$ & $\begin{array}{c}0.79 \\
(5.38)\end{array}$ & $\begin{array}{c}0.48 \\
(3.15)\end{array}$ & & \\
\hline & $\mathrm{M}^{+} \mathrm{S}^{-}$ & $\begin{array}{c}1.17 \\
(6.55)\end{array}$ & $\begin{array}{c}0.86 \\
(4.72)\end{array}$ & $\begin{array}{c}1.06 \\
(5.57)\end{array}$ & $\begin{array}{c}0.75 \\
(3.89)\end{array}$ & & \\
\hline & $\mathrm{M}^{-} \mathrm{S}^{+}$ & $\begin{array}{c}1.07 \\
(1.90)\end{array}$ & $\begin{array}{c}0.87 \\
(1.52)\end{array}$ & $\begin{array}{c}1.64 \\
(3.64)\end{array}$ & $\begin{array}{c}1.45 \\
(3.16)\end{array}$ & & \\
\hline & $\mathrm{M}^{-} \mathrm{S}^{-}$ & $\begin{array}{c}0.54 \\
(1.08)\end{array}$ & $\begin{array}{c}0.25 \\
(0.49)\end{array}$ & $\begin{array}{c}0.37 \\
(0.70)\end{array}$ & $\begin{array}{c}0.09 \\
(0.17)\end{array}$ & & \\
\hline & Overall & $\begin{array}{c}0.93 \\
(6.40) \\
\end{array}$ & $\begin{array}{c}0.64 \\
(4.37) \\
\end{array}$ & $\begin{array}{c}0.92 \\
(6.21) \\
\end{array}$ & $\begin{array}{c}0.63 \\
(4.21) \\
\end{array}$ & & \\
\hline \multicolumn{8}{|l|}{ Panel B } \\
\hline Difference & State & RM & $\frac{\mathrm{M}^{+} \mathrm{S}^{-}}{\mathrm{RM}-\mathrm{rf}}$ & RM & $\frac{\mathrm{M}-\mathrm{S}^{+}}{\mathrm{RM}-\mathrm{rf}}$ & RM & $\frac{\mathrm{M}-\mathrm{S}^{-}}{\mathrm{RM}-\mathrm{rf}}$ \\
\hline \multirow[t]{3}{*}{ Stock 1-6 } & $\mathrm{M}^{+} \mathrm{S}^{+}$ & $\begin{array}{c}-0.33 \\
(-1.39)\end{array}$ & $\begin{array}{c}-0.33 \\
(-1.35)\end{array}$ & $\begin{array}{c}-0.24 \\
(-0.40)\end{array}$ & $\begin{array}{c}-0.34 \\
(-0.57)\end{array}$ & $\begin{array}{c}0.29 \\
(0.56)\end{array}$ & $\begin{array}{c}0.28 \\
(0.54)\end{array}$ \\
\hline & $\mathrm{M}^{+} \mathrm{S}^{-}$ & & & $\begin{array}{c}0.10 \\
(0.16)\end{array}$ & $\begin{array}{c}-0.01 \\
(-0.01)\end{array}$ & $\begin{array}{c}0.62 \\
(1.17)\end{array}$ & $\begin{array}{c}0.61 \\
(1.15)\end{array}$ \\
\hline & $\mathrm{M}^{-} \mathrm{S}^{+}$ & & & & & $\begin{array}{c}0.53 \\
(0.70) \\
\end{array}$ & $\begin{array}{c}0.62 \\
(0.82) \\
\end{array}$ \\
\hline \multirow[t]{3}{*}{ Stock 1-12 } & $\mathrm{M}^{+} \mathrm{S}^{+}$ & $\begin{array}{c}-0.27 \\
(-1.12)\end{array}$ & $\begin{array}{l}-0.27 \\
-1.11\end{array}$ & $\begin{array}{l}-0.85^{*} \\
(-1.80)\end{array}$ & $\begin{array}{c}-0.97 * * \\
(-2.01)\end{array}$ & $\begin{array}{c}0.42 \\
(0.76)\end{array}$ & $\begin{array}{c}0.39 \\
(0.71)\end{array}$ \\
\hline & $\mathrm{M}^{+} \mathrm{S}^{-}$ & & & $\begin{array}{l}-0.58 \\
(-1.19)\end{array}$ & $\begin{array}{c}-0.70 \\
(-1.41)\end{array}$ & $\begin{array}{c}0.69 \\
(1.22)\end{array}$ & $\begin{array}{c}0.66 \\
(1.19)\end{array}$ \\
\hline & $\mathrm{M}^{-} \mathrm{S}^{+}$ & & & & & $\begin{array}{l}1.27 * \\
(1.83)\end{array}$ & $\begin{array}{l}1.36 * * \\
(1.96)\end{array}$ \\
\hline
\end{tabular}


returns, the $t$-statistics are in parentheses. Panel B shows the differences in RM and RM-rf between each state in Panel A, with the monthly mean differences defined by one or two asterisk, showing $10 \%$ or $5 \%$ significance 


\subsubsection{MH Scheme}

Table 4.7 reports stock and industry momentum portfolio average returns over the 6 months and 12 months following each of the MH scheme's four states. The results show that momentum is significantly profitable following the two positive market states, $\mathrm{M}^{+} \mathrm{H}^{+}$and $\mathrm{M}^{+} \mathrm{H}^{-}$. However, in the 12 months following the $\mathrm{M}^{-} \mathrm{H}^{+}$state, stock and industry momentum profits are only weakly significant, with stock momentum earning $0.50 \%$ per month $(t$-stat $1.86)$ and industry momentum yielding $0.53 \%$ per month ( $t$-stat 1.75$)$. In contrast, following the $\mathrm{M}^{-} \mathrm{H}^{-}$state produces an insignificant negative return for stock momentum of $-0.47 \%$ per month ( $t$-stat -0.92$)$ and for industry momentum of $-0.21 \%$ per month ( $t$-stat -0.49$)$. The momentum loss in the 12 months following state $\mathrm{M}^{-} \mathrm{H}^{-}$is driven by strong returns for the loser portfolios. Specifically, the stock loser portfolio has an average return of $1.79 \%$ per month ( $t$-stat 1.99$)$ while the industry loser portfolio earns $1.09 \%$ per month ( $t$-stat 1.40$)$.

Table 4.8 provides the differences in momentum portfolio returns between the MH states. Notably, the momentum profits following the positive $\mathrm{M}$ states of $\mathrm{M}^{+} \mathrm{H}^{+}$and $\mathrm{M}^{+} \mathrm{H}^{-}$are significantly different to the profits following the negative state $\mathrm{M}^{-} \mathrm{H}^{-}$. In the 12-month case, there is only a weakly significant difference of $0.97 \%$ ( $t$-stat 1.69$)$ in stock momentum returns between the negative states $\mathrm{M}^{-} \mathrm{H}^{+}$and $\mathrm{M}^{-} \mathrm{H}^{-}$, while the corresponding industry momentum difference of $0.75 \%$ is large but lacks statistical significance ( $t$-stat 1.40 ) (possibly due to the paucity in observations in these market states).

The negative momentum results in the 12 months following the $\mathrm{M}^{-} \mathrm{H}^{-}$state reported in Table 4.7 are the differences between unusually high returns for both the winner and the loser portfolios, suggesting that the market as a whole may tend to transition to a positive market 
state in the 12 months following the $\mathrm{M}^{-} \mathrm{H}^{-}$state. Utilising the same process as used to investigate the possible transitioning following the $\mathrm{M}^{-} \mathrm{S}^{+}$state, I examine the average market return (RM) and excess return (RM-rf) for the 6 and 12 months following the MH scheme's four states. The results are listed in Table 4.9. The key feature of the results for the 12 months following all the states is that all of these RMs are very similar and all are significant. In particular, the average market return $\mathrm{RM}$ following the $\mathrm{M}^{-} \mathrm{H}^{-}$state does not seem substantially larger than any of the RMs following the other states. This is confirmed in Panel B of Table 4.9, which shows that there are no significant differences between the average market returns following the different states.

In short, Table 4.9 does not provide any support for the possibility that the market is more likely to rebound in the 12 months following the $\mathrm{M}^{-} \mathrm{H}^{-}$state than it does following the $\mathrm{M}^{-} \mathrm{H}^{+}$ state. Of course, Table 4.9 does not rule out the possibility either, since the market could be more likely to rebound following the $\mathrm{M}^{-} \mathrm{H}^{-}$state and also to have larger losses when it does not rebound compared to the other states. However, there is no explanation why momentum is weakly significant profitable following the $\mathrm{M}-\mathrm{H}+$ state, nor why there is a weak significant difference between the $\mathrm{M}-\mathrm{H}+$ state and $\mathrm{M}-\mathrm{H}-$ state. At this stage, I can show that the $\mathrm{M}-\mathrm{H}+$ state predicts weak significant momentum profitability when transitioning from a negative market to a positive market on average returns. Further research is indicated.

Table 4.11 from Section 4.3.5 provides further insight to this question. The table lists the 15 worst monthly momentum returns over the full sample from 1926 to 2013 . Note that each of these worst months for momentum occur in months with large market returns. The final column of Table 4.11 answers the question of whether each month is a month that follows within 12 months of an $\mathrm{M}^{-} \mathrm{H}^{-}$state. I observe that 11 out of the 15 worst momentum months 
follow within 12 months of an $\mathrm{M}^{-} \mathrm{H}^{-}$state. In short, the $\mathrm{M}^{-} \mathrm{H}^{-}$state may be used to predict periods of high risk for momentum strategies, but it appears to be less effective in this regard, although more profitable than the $\mathrm{M}^{-} \mathrm{S}^{+}$state from the previous section.

In sum, where literature shows that growth firms are associated with momentum profitability, I show that lagged growth firm outperformance predicts future momentum profits only following a positive market state, and lagged value firm outperformance, predicts future momentum profits following positive and negative market states. 
Table 4.7: MH Scheme

\begin{tabular}{|c|c|c|c|c|c|c|c|c|c|c|c|c|}
\hline \multirow[b]{2}{*}{ states } & \multicolumn{3}{|c|}{$\begin{array}{l}1-6 \mathrm{M} \\
\text { Stock }\end{array}$} & \multicolumn{3}{|c|}{$\begin{array}{l}1-12 \mathrm{M} \\
\text { Stock }\end{array}$} & \multicolumn{3}{|c|}{$\begin{array}{l}1-6 \mathrm{M} \\
\text { Industries }\end{array}$} & \multicolumn{3}{|c|}{$\begin{array}{l}1-12 \mathrm{M} \\
\text { Industries }\end{array}$} \\
\hline & $\mathrm{W}$ & $\mathrm{L}$ & W-L & $\mathrm{W}$ & $\mathrm{L}$ & W-L & $\mathrm{W}$ & $\mathrm{L}$ & W-L & $\mathrm{W}$ & $\mathrm{L}$ & W-L \\
\hline $\mathrm{M}^{+} \mathrm{H}^{+}$ & $\begin{array}{c}1.41 \\
(7.08)\end{array}$ & $\begin{array}{c}0.55 \\
(3.06)\end{array}$ & $\begin{array}{c}0.86 \\
(9.94)\end{array}$ & $\begin{array}{c}1.34 \\
(7.48)\end{array}$ & $\begin{array}{c}0.50 \\
(3.05)\end{array}$ & $\begin{array}{c}0.84 \\
(10.11)\end{array}$ & $\begin{array}{c}1.33 \\
(6.39)\end{array}$ & $\begin{array}{c}0.14 \\
(0.57)\end{array}$ & $\begin{array}{c}1.19 \\
(5.18)\end{array}$ & $\begin{array}{c}1.33 \\
(7.01)\end{array}$ & $\begin{array}{c}0.20 \\
(0.90)\end{array}$ & $\begin{array}{c}1.12 \\
(4.50)\end{array}$ \\
\hline $\mathrm{M}^{+} \mathrm{H}^{-}$ & $\begin{array}{c}1.56 \\
(5.91)\end{array}$ & $\begin{array}{c}0.60 \\
(2.30)\end{array}$ & $\begin{array}{c}0.96 \\
(5.69)\end{array}$ & $\begin{array}{c}1.42 \\
(5.75)\end{array}$ & $\begin{array}{c}0.48 \\
(1.86)\end{array}$ & $\begin{array}{c}0.95 \\
(6.56)\end{array}$ & $\begin{array}{c}1.42 \\
(5.96)\end{array}$ & $\begin{array}{c}0.49 \\
(2.19)\end{array}$ & $\begin{array}{c}0.93 \\
(4.25)\end{array}$ & $\begin{array}{c}1.28 \\
(5.89)\end{array}$ & $\begin{array}{c}0.29 \\
(1.17)\end{array}$ & $\begin{array}{c}0.99 \\
(4.83)\end{array}$ \\
\hline $\mathrm{M}^{-} \mathrm{H}^{+}$ & $\begin{array}{c}1.48 \\
(2.63)\end{array}$ & $\begin{array}{c}1.04 \\
(1.49)\end{array}$ & $\begin{array}{c}0.44 \\
(1.58)\end{array}$ & $\begin{array}{c}1.72 \\
(3.38)\end{array}$ & $\begin{array}{c}1.22 \\
(1.91)\end{array}$ & $\begin{array}{c}0.50 \\
(1.86)\end{array}$ & $\begin{array}{c}1.53 \\
(3.07)\end{array}$ & $\begin{array}{c}0.92 \\
(1.42)\end{array}$ & $\begin{array}{c}0.61 \\
(1.86)\end{array}$ & $\begin{array}{c}1.64 \\
(3.86)\end{array}$ & $\begin{array}{c}1.10 \\
(1.90)\end{array}$ & $\begin{array}{c}0.53 \\
(1.75)\end{array}$ \\
\hline $\mathrm{M}^{-} \mathrm{H}^{-}$ & $\begin{array}{c}1.11 \\
(1.64) \\
\end{array}$ & $\begin{array}{c}1.61 \\
(1.34) \\
\end{array}$ & $\begin{array}{c}-0.50 \\
(-0.70)\end{array}$ & $\begin{array}{c}1.32 \\
(2.02) \\
\end{array}$ & $\begin{array}{c}1.79 \\
(1.99)\end{array}$ & $\begin{array}{c}-0.47 \\
(-0.92)\end{array}$ & $\begin{array}{c}0.79 \\
(1.24) \\
\end{array}$ & $\begin{array}{c}1.23 \\
(1.15)\end{array}$ & $\begin{array}{c}-0.44 \\
(-0.70)\end{array}$ & $\begin{array}{c}0.88 \\
(1.49) \\
\end{array}$ & $\begin{array}{c}1.09 \\
(1.40) \\
\end{array}$ & $\begin{array}{c}-0.21 \\
(-0.49)\end{array}$ \\
\hline Overall & $\begin{array}{c}1.44 \\
(8.18)\end{array}$ & $\begin{array}{c}0.75 \\
(3.53)\end{array}$ & $\begin{array}{c}0.69 \\
(5.84)\end{array}$ & $\begin{array}{c}1.43 \\
(8.12)\end{array}$ & $\begin{array}{c}0.74 \\
(3.58)\end{array}$ & $\begin{array}{c}0.68 \\
(6.14)\end{array}$ & $\begin{array}{c}1.33 \\
(7.89)\end{array}$ & $\begin{array}{c}0.47 \\
(2.20)\end{array}$ & $\begin{array}{c}0.86 \\
(5.36)\end{array}$ & $\begin{array}{c}1.32 \\
(8.07)\end{array}$ & $\begin{array}{c}0.46 \\
(2.25)\end{array}$ & $\begin{array}{c}0.86 \\
(5.04)\end{array}$ \\
\hline $\begin{array}{l}\text { Table } 4.7 \text { sho } \\
\text { factor cumula } \\
\text { monthly data } \\
\text { downloaded } \\
\text { portfolios (w } \\
\text { positive M an } \\
\text { all states. The } \\
\text { portfolio resu }\end{array}$ & $\begin{array}{l}\text { rench we } \\
\text { loser de } \\
\text { Ststele, } \\
\text { partition }\end{array}$ & onthly mome & 2 & 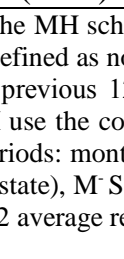 & s & cks and ind & es, over tw & $\begin{array}{l}\text { ime periods } \\
\text { CRSP index } \\
\text { gative (nega } \\
\text { e raw return }\end{array}$ & $\begin{array}{l}I \text { is denoted } \\
\text { er the } 12 \mathrm{~m} \\
\text { e) } \mathrm{H} \text { state. }\end{array}$ & $\begin{array}{l}\text { the prior } 12 \\
\text { hs prior to } \\
\text { ck momen } \\
\text { oping the } \mathrm{m}\end{array}$ & $\begin{array}{l}\text { onth market } \\
\text { eeginning of } \\
\text { portfolios } \\
\text { recent mon }\end{array}$ & $\begin{array}{l}\text { turn, H i ite } \\
\text { e strategy's } \\
\text { re construc } \\
\text { The return } \\
\text { (positive N } \\
\text { erage mom } \\
\text {, and winn }\end{array}$ \\
\hline
\end{tabular}




\section{Table 4.8: Difference between $\mathrm{MH}$ States}

\begin{tabular}{|c|c|c|c|c|c|c|c|c|c|c|}
\hline & \multirow{2}{*}{$\begin{array}{l}\text { State B } \\
\text { State A }\end{array}$} & \multicolumn{3}{|c|}{$\overline{\mathrm{M}^{+} \mathrm{H}^{-}}$} & \multicolumn{3}{|c|}{$\mathrm{M}^{-} \mathrm{H}^{+}$} & \multicolumn{3}{|c|}{$\mathrm{M}^{-} \mathrm{H}^{-}$} \\
\hline & & W & $\mathrm{L}$ & W-L & W & $\mathrm{L}$ & W-L & W & $\mathrm{L}$ & W-L \\
\hline \multirow[t]{5}{*}{ stock 1-6 } & $\mathrm{M}^{+} \mathrm{H}^{+}$ & $\begin{array}{c}-0.16 \\
(-0.48)\end{array}$ & $\begin{array}{c}0.05 \\
(-0.17)\end{array}$ & $\begin{array}{c}-0.10 \\
(-0.55)\end{array}$ & $\begin{array}{c}-0.07 \\
(-0.12)\end{array}$ & $\begin{array}{c}-0.49 \\
(-0.68)\end{array}$ & $\begin{array}{c}0.41 \\
(1.41)\end{array}$ & $\begin{array}{c}0.30 \\
(0.42)\end{array}$ & $\begin{array}{c}-1.06 \\
(-0.87)\end{array}$ & $\begin{array}{l}1.36^{*} \\
(1.89)\end{array}$ \\
\hline & $\mathrm{M}^{+} \mathrm{H}^{-}$ & & & & 0.09 & -0.43 & 0.52 & 0.46 & -1.00 & $1.46^{* *}$ \\
\hline & & & & & $(0.14)$ & $(-0.58)$ & $(1.58)$ & $(0.63)$ & $(-0.82)$ & $(2.00)$ \\
\hline & $\mathrm{M}^{-} \mathrm{H}^{+}$ & & & & & & & 0.37 & -0.57 & 0.94 \\
\hline & & & & & & & & $(0.42)$ & $(-0.41)$ & $(1.23)$ \\
\hline \multirow[t]{6}{*}{ stock 1-12 } & $\mathrm{M}^{+} \mathrm{H}^{+}$ & -0.08 & 0.02 & -0.11 & -0.38 & -0.72 & 0.34 & 0.02 & -1.29 & $1.31^{* *}$ \\
\hline & & $(-0.27)$ & $(0.08)$ & $(-0.65)$ & $(-0.70)$ & $(-1.09)$ & $(1.21)$ & $(0.02)$ & $(-1.41)$ & (2.54) \\
\hline & $\mathrm{M}^{+} \mathrm{H}^{-}$ & & & & -0.29 & -0.74 & 0.45 & 0.10 & -1.31 & $1.41^{* *}$ \\
\hline & & & & & $(-0.52)$ & $(-1.08)$ & (1.47) & $(0.14)$ & $(-1.41)$ & (2.68) \\
\hline & $\mathrm{M}^{-} \mathrm{H}^{+}$ & & & & & & & 0.39 & -0.57 & $0.97 *$ \\
\hline & & & & & & & & $(0.48)$ & $(-0.52)$ & (1.69) \\
\hline \multirow[t]{6}{*}{ Industry 1-6 } & $\mathrm{M}^{+} \mathrm{H}^{+}$ & -0.09 & -0.35 & 0.26 & -0.20 & -0.78 & 0.58 & 0.54 & -1.09 & $1.63^{* * *}$ \\
\hline & & $(-0.28)$ & $(-1.07)$ & $(0.82)$ & $(-0.37)$ & $(-1.13)$ & $(1.46)$ & $(0.82)$ & $(-1.00)$ & (2.44) \\
\hline & $\mathrm{M}^{+} \mathrm{H}^{-}$ & & & & -0.29 & -0.74 & 0.45 & 0.63 & -0.74 & $1.37^{* * *}$ \\
\hline & & & & & $(-0.52)$ & $(-1.08)$ & (1.47) & $(0.94)$ & $(-0.68)$ & (2.06) \\
\hline & $\mathrm{M}^{-} \mathrm{H}^{+}$ & & & & & & & 0.74 & -0.30 & 1.05 \\
\hline & & & & & & & & $(0.92)$ & $(-0.24)$ & $(1.48)$ \\
\hline \multirow[t]{6}{*}{ Industry $1-12$} & $\mathrm{M}^{+} \mathrm{H}^{+}$ & 0.05 & -0.08 & 0.13 & -0.31 & -0.90 & 0.59 & 0.44 & -0.89 & $1.33^{* *}$ \\
\hline & & $(0.16)$ & $(-0.25)$ & $(0.40)$ & $(-0.68)$ & $(-1.44)$ & $(1.49)$ & $(0.71)$ & $(-1.09)$ & (2.66) \\
\hline & $\mathrm{M}^{+} \mathrm{H}^{-}$ & & & & -0.36 & -0.82 & 0.46 & 0.40 & -0.81 & $1.20^{* *}$ \\
\hline & & & & & $(-0.76)$ & $(-1.30)$ & $(1.24)$ & $(0.63)$ & $(-0.99)$ & (2.50) \\
\hline & $\mathrm{M}^{-} \mathrm{H}^{+}$ & & & & & & & 0.76 & 0.01 & 0.75 \\
\hline & & & & & & & & $(1.04)$ & $(0.01)$ & $(1.40)$ \\
\hline
\end{tabular}

Table 4.8 reports the differences in mom' the corresponding momentum portfolio's s returns in the M state from the row State B. M is denoted as the prior 12-month market return, $\mathrm{H}$ is denoted as the HML factor cumulative average past 12-month return. The M states are defined as non-negative (negative) by the returns of the VW CRSP index over the 12 months prior to the beginning of the strategy's profit period. The HML monthly data was downloaded from Ken French's website, and previous 12 month cumulative returns define the POSITIVE (NEGATIVE) H state. Stock momentum portfolios were constructed from portfolios downloaded fromKen French website. For industry momentum, I use the common measure of the past 12-month cumulative raw return on the asset, skipping the most recent month. The returns of the momentum portfolios (winner minus loser deciles) are averaged across two periods: months $t+1$ to $t+6$, and months $t+1$ to $t+12$. Each section shows the winner (W), loser (L), and winner minus loser (W-L) portfolio results The column (row) in State A ( B) show the four MS states (described in Table 4.6). The period is from July 1926 to December 2013.The results are partitioned into four sections, 1-6 and 1-12 average returns for stock and industry, and shows the $t$-statistics in parentheses. The monthly mean differences are defined by one or two asterisk, showing $10 \%$ or $5 \%$ significance respectively. 
Table 4.9: $\mathrm{MH}$ scheme with Market Return

\begin{tabular}{|c|c|c|c|c|c|c|c|}
\hline \multirow{8}{*}{ Panel A } & & \multirow[b]{2}{*}{$1-6 \mathrm{M}$} & \multirow[b]{2}{*}{$1-6 \mathrm{M}$} & \multirow{3}{*}{$\begin{array}{c}1-12 \mathrm{M} \\
\mathrm{RM}\end{array}$} & \multirow{3}{*}{$\begin{array}{l}\text { 1-12M } \\
\text { RM-rf }\end{array}$} & & \\
\hline & \multirow[b]{2}{*}{ States } & & & & & & \\
\hline & & $\mathrm{RM}$ & RM-rf & & & & \\
\hline & $\mathrm{M}^{+} \mathrm{H}^{+}$ & $\begin{array}{c}1.06 \\
(6.18)\end{array}$ & $\begin{array}{c}0.79 \\
(4.59)\end{array}$ & $\begin{array}{c}0.98 \\
(6.60)\end{array}$ & $\begin{array}{c}0.72 \\
(4.70)\end{array}$ & & \\
\hline & $\mathrm{M}^{+} \mathrm{H}^{-}$ & $\begin{array}{c}0.75 \\
(3.92)\end{array}$ & $\begin{array}{c}0.45 \\
(2.34)\end{array}$ & $\begin{array}{c}0.84 \\
(4.58)\end{array}$ & $\begin{array}{c}0.53 \\
(2.88)\end{array}$ & & \\
\hline & $\mathbf{M}^{-} \mathrm{H}^{+}$ & $\begin{array}{c}0.96 \\
(5.24)\end{array}$ & $\begin{array}{c}0.62 \\
(3.30)\end{array}$ & $\begin{array}{c}0.90 \\
(4.84)\end{array}$ & $\begin{array}{c}0.56 \\
(2.94)\end{array}$ & & \\
\hline & $\mathrm{M}^{-} \mathrm{H}^{-}$ & $\begin{array}{c}0.91 \\
(4.01)\end{array}$ & $\begin{array}{c}0.67 \\
(2.92)\end{array}$ & $\begin{array}{c}0.96 \\
(4.58)\end{array}$ & $\begin{array}{c}0.72 \\
(3.43)\end{array}$ & & \\
\hline & Overall & $\begin{array}{c}0.93 \\
(6.40) \\
\end{array}$ & $\begin{array}{c}0.64 \\
(4.37) \\
\end{array}$ & $\begin{array}{c}0.92 \\
(6.21) \\
\end{array}$ & $\begin{array}{c}0.63 \\
(4.21)\end{array}$ & & \\
\hline \multicolumn{8}{|l|}{ Panel B } \\
\hline Difference & State & $\mathrm{RM}$ & $\begin{array}{c}\mathrm{M}^{+} \mathrm{H}^{-} \\
\mathrm{RM} M \mathrm{rf}\end{array}$ & $\mathrm{RM}$ & $\begin{array}{c}\mathrm{M}^{-} \mathrm{H}^{+} \\
\mathrm{RM}-\mathrm{rf}\end{array}$ & $\mathrm{RM}$ & $\begin{array}{l}\mathrm{M}^{-} \mathrm{H}^{-} \\
\mathrm{RM}-\mathrm{rf} \\
\end{array}$ \\
\hline \multirow{2}{*}{ Stock 1-6 } & $\mathrm{M}^{+} \mathrm{H}^{-}$ & & & $\begin{array}{c}-0.20 \\
(-0.76)\end{array}$ & $\begin{array}{c}-0.17 \\
(-0.63)\end{array}$ & $\begin{array}{c}-0.16 \\
(-0.53)\end{array}$ & $\begin{array}{c}-0.22 \\
(-0.74)\end{array}$ \\
\hline & $\mathrm{M}^{-} \mathrm{H}^{+}$ & & & & & $\begin{array}{c}0.04 \\
(0.15) \\
\end{array}$ & $\begin{array}{l}-0.05 \\
(-0.17) \\
\end{array}$ \\
\hline \multirow[t]{3}{*}{ Stock 1-12 } & $\mathrm{M}^{+} \mathrm{H}^{+}$ & $\begin{array}{c}0.14 \\
(0.60)\end{array}$ & $\begin{array}{c}0.18 \\
(0.76)\end{array}$ & $\begin{array}{c}0.09 \\
(0.37)\end{array}$ & $\begin{array}{c}0.15 \\
(0.64)\end{array}$ & $\begin{array}{c}0.03 \\
(0.10)\end{array}$ & $\begin{array}{l}-0.01 \\
(-0.03)\end{array}$ \\
\hline & $\mathrm{M}^{+} \mathrm{H}^{-}$ & & & $\begin{array}{c}-0.06 \\
(-0.21)\end{array}$ & $\begin{array}{c}-0.03 \\
(-0.10)\end{array}$ & $\begin{array}{c}-0.12 \\
(-0.42)\end{array}$ & $\begin{array}{c}-0.19 \\
(-0.68)\end{array}$ \\
\hline & $\mathrm{M}^{-} \mathrm{H}^{+}$ & & & & & $\begin{array}{c}-0.06 \\
(-0.22)\end{array}$ & $\begin{array}{c}-0.16 \\
(-0.57) \\
\end{array}$ \\
\hline
\end{tabular}


Panel A in Table 4.9 shows the future mean monthly return of the market (RM), and the return of the market minus the risk free rate (RM-rf), for the MH scheme's four states, over two time periods, months $t+1$ to $t+$ 6 , and $t+1$ to $t+12$.The construction of the M and $\mathrm{H}$ state is described in Table 4.7, as is the four MH states, found in the first column. The market monthly returns of the Centre for Research into Security Price (CRSP) value-weighted market index constructed from all NYSE, AMEX, and NASDAQ stocks and the risk free rate (the one-month Treasury bill rate from Ibbotson Associates) are downloaded from Kenneth

French's website. The period is from July 1926 to December 2013. The Overall row shows the average RM and RM-rf profits across all states. The results are partitioned into two sections, 1 to 6 and 1 to 12 average

monthly returns, the $t$-statistics are in parentheses. Panel B shows the differences in RM and RM-rf between each state in Panel A, with the monthly mean differences defined by one or two asterisk, showing $10 \%$ or $5 \%$ significance respectively. 


\subsubsection{Profit Comparison Analyses}

This section discusses and illustrates a graphical representation of momentum profitability across the different states of the MS and MH schemes. Table 4.10 offers a comprehensive or overview of the examination of MS and MH schemes, allowing easy analyses to compare the different schemes As shown, Table 4.10 displays the positive and negative $\mathrm{S}$ and $\mathrm{H}$ states combined with the two $\mathrm{M}$ states, for example, the $\mathrm{M}^{+} \mathrm{S}^{+} \mathrm{H}^{+}$notation describes a positive $\mathrm{M}, \mathrm{S}$ and $\mathrm{H}$ state. Examination of the 3 combined states eg. $\mathrm{M}^{+} \mathrm{S}^{+} \mathrm{H}^{+}$was not possible due to the paucity of observations. Momentum profits examined show the MS and MH states for both stock and industries and the two profit periods of 6 and 12 months.

As observed earlier, when the $\mathrm{M}$ state is positive then momentum produces similar profitability following both states of $\mathrm{M}^{+} \mathrm{S}^{+} \mathrm{H}^{+}$and $\mathrm{M}^{+} \mathrm{S}^{-} \mathrm{H}^{-}$irrespective of whether the $\mathrm{S}$ or $\mathrm{H}$ component of the state is positive or negative. Concentrating on the states of $\mathrm{M}^{-} \mathrm{S}^{+} \mathrm{H}^{+}$, momentum profits for both profit periods following the $\mathrm{M}^{-} \mathrm{S}^{+}$state, shows a negative result across stock and industry, whilst the future momentum profits following the $\mathrm{M}^{-} \mathrm{H}^{+}$state shows the opposite, all positive returns. In the states of $\mathrm{M}^{-} \mathrm{S}^{-} \mathrm{H}^{-}$, momentum profits following the $\mathrm{M}^{-} \mathrm{S}^{-}$state are positive across all profit periods, whilst the momentum profits following the $\mathrm{M}^{-} \mathrm{H}^{-}$state produce negative returns. Therefore, lagged small size and value outperformances have opposite effects on future momentum profits when combined with the lagged negative market state. When the lagged market return is negative, lagged small size outperformance is followed by negative momentum profits on average while lagged value firm outperformance is followed by positive momentum profits on average. 
Figure 4.2 graphically shows average monthly momentum future profits following the states in the MS and MH schemes. The states are shown as $\mathrm{M}$ (+or -), $\mathrm{S}$ or $\mathrm{H}$ state as (+or-), the four states are,,,+++--+-- , with the future 12-month average stock momentum returns (graph A) and industry momentum returns (graph B). Notice that fort both stock and industry momentum, the results from all states following the positive $\mathrm{M}$ state are similar, although the momentum results following the state $\mathrm{M}^{+} \mathrm{S}^{+} \mathrm{H}^{+}$for stock (graph A) noticeably underperforms the same state in industry returns (graph B). There is a divergence following the negative $\mathrm{M}$ state, with lagged small size underperformance producing negative results for momentum following the state of $(-+)$, whereas value outperformance produces positive momentum results. Following state (--), lagged size underperformance provides positive momentum profits, whereas negative momentum profits occur when the lagged value underperforms. 
Table 4.10: Comparison between MS MH Schemes

\begin{tabular}{|c|c|c|c|c|c|c|c|c|}
\hline & $\begin{array}{l}1-6 \mathrm{M} \\
\text { Stock } \\
\end{array}$ & & $\begin{array}{l}1-12 \mathrm{M} \\
\text { Stock }\end{array}$ & & $\begin{array}{c}1-6 \mathrm{M} \\
\text { Industries } \\
\end{array}$ & & $\begin{array}{c}1-12 \mathrm{M} \\
\text { Industries } \\
\end{array}$ & \\
\hline states & MS & $\mathrm{MH}$ & MS & $\mathrm{MH}$ & MS & MH & MS & MH \\
\hline \multirow[t]{2}{*}{$\mathrm{M}^{+} \mathrm{S}^{+} \mathrm{H}^{+}$} & 0.84 & 0.86 & 0.82 & 0.84 & 1.18 & 1.19 & 1.13 & 1.12 \\
\hline & $(8.01)$ & (9.94) & $(8.44)$ & (10.11) & $(4.50)$ & $(5.18)$ & $(4.05)$ & $(4.50)$ \\
\hline \multirow{2}{*}{$\mathrm{M}^{+} \mathrm{S}^{-} \mathrm{H}^{-}$} & 0.98 & 0.96 & 0.97 & 0.95 & 0.97 & 0.93 & 0.99 & 0.99 \\
\hline & $(7.91)$ & (5.69) & $(8.17)$ & $(6.56)$ & (7.01) & $(4.25)$ & (6.39) & $(4.83)$ \\
\hline \multirow[t]{2}{*}{$\mathrm{M}^{-} \mathrm{S}^{+} \mathrm{H}^{+}$} & -0.41 & 0.44 & -0.37 & 0.50 & -0.38 & 0.61 & -0.36 & 0.53 \\
\hline & $(-0.62)$ & $(1.58)$ & $(-0.69)$ & $(1.86)$ & $(-0.66)$ & $(1.86)$ & $(-0.72)$ & $(1.75)$ \\
\hline \multirow[t]{2}{*}{$M^{-} S^{-} H^{-}$} & 0.49 & -0.50 & 0.55 & -0.47 & 0.70 & -0.44 & 0.76 & -0.21 \\
\hline & $(1.82)$ & $(-0.70)$ & $(2.06)$ & $(-0.92)$ & $(2.31)$ & $(-0.70)$ & $(2.88)$ & $(-0.49)$ \\
\hline
\end{tabular}

.Table 4.10 compares the future mean monthly momentum profits for the MS and MH scheme states, for stocks and industries, over two profit time periods. M is denoted as the prior 12 -month market return, $\mathrm{S}$ is denoted as the SMB factor cumulative average return over the past twelve months, $\mathrm{H}$ is denoted as the HML factor cumulative average past 12 -month returns. $\mathrm{M}$ states are defined as non-negative (negative) by the returns of the VW CRSP index over the 12 months prior to the beginning of the strategy's profit period. SMB and HML monthly data was downloaded from Ken French's website, and previous 12 month cumulative returns define the POSITIVE (NEGATIVE) S and H state. Stock momentum portfolios were constructed from portfolios downloaded fromKen French website. For industry momentum, I use the common measure of the past 12-month cumulative raw return on the asset, skipping the most recent month. The returns of the momentum portfolios (winner minus loser deciles) are averaged across two periods: months $t+1$ to $t+6$, and months $t+1$ to $t+12$. The first column in Table 4.10 show the different MS and MH scheme states, $\mathrm{M}^{+} \mathrm{S}^{+} \mathrm{H}^{+}$(positive $\mathrm{M}$ and $\mathrm{S}$ or $\mathrm{H}^{-}$state), $\mathrm{M}^{+} \mathrm{S} \mathrm{H}^{-}-\left(\right.$positive $\mathrm{M}$ and negative $\mathrm{S}$ or $\mathrm{H}$ state). $\mathrm{M}^{-} \mathrm{S}^{+} \mathrm{H}^{+}$, (negative $\mathrm{M}$ and positive $\mathrm{S}$ or $\mathrm{H}$ state), $\mathrm{MS}^{-} \mathrm{H}^{-}$(negative $\mathrm{M}$ and $\mathrm{S}$ or $\mathrm{H}$ state). The period is from July 1926 to December 2013. The results are partitioned into four sections, 1 to 6 and 1 to 2 average monthly returns for stock and positive $\mathrm{S}$ or $\mathrm{H}$ state), $\mathrm{MS} \mathrm{H}$ (negative $\mathrm{M}$ and $\mathrm{S}$ or $\mathrm{H}$ state). The period is from July 1926 to December 
Figure 4.2: $M S$ and $M H$ profits in 4 States

\section{Graph A}

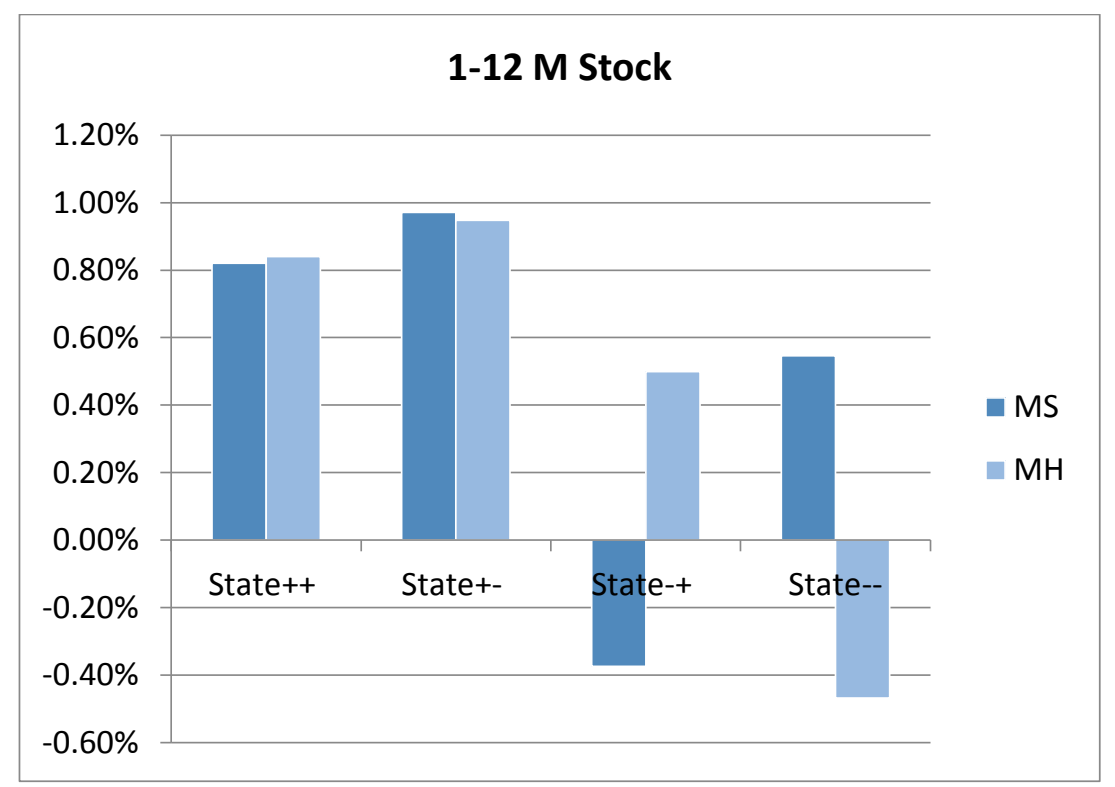

Graph B

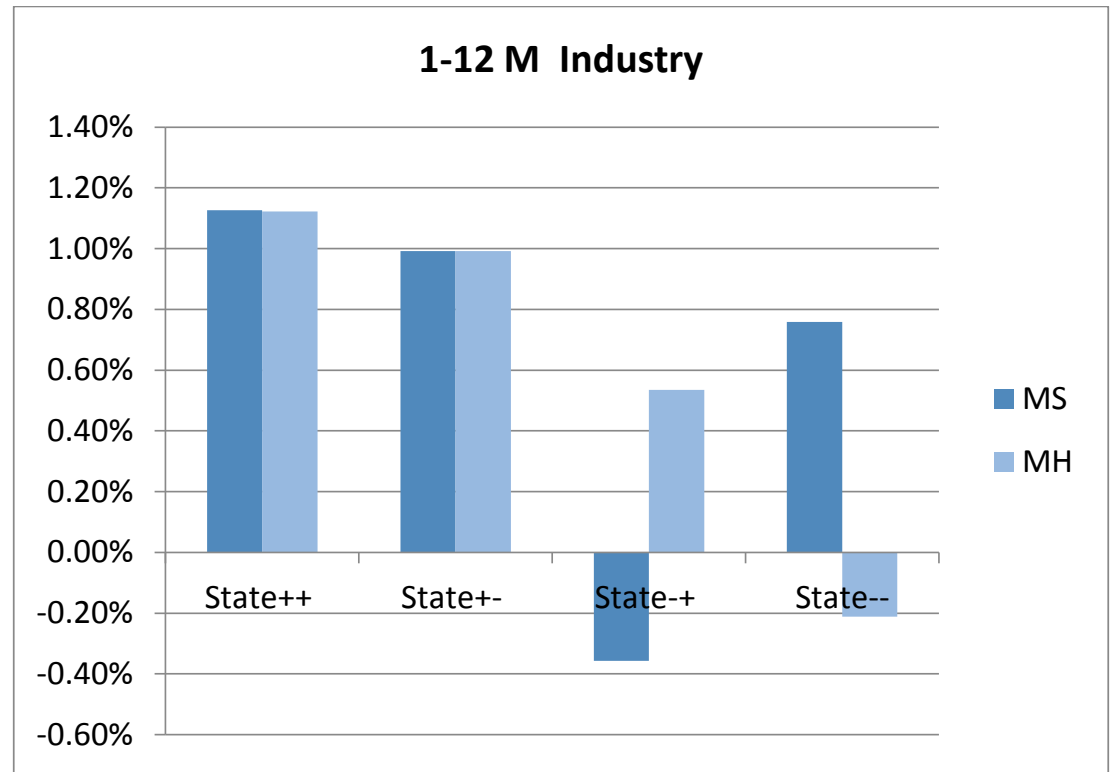

Figure 4.2 reports on the average payoffs for Stocks (Graph A) and Industry (Graph B) from Tables four and six. The graphs illustrate momentum's profit in each state of the MS and MH schemes: State ++, State +-, State -+, State --. State ++, is defined as positive M state and positive S, or H. State +-, is positive M state and negative S, or H, State -+ is negative M state and positive S or , whilst State -- is both negative M state and 


\subsubsection{Trading Strategies}

The results of the preceding analyses suggest that momentum crashes are more likely to occur following the states $\mathrm{M}^{-} \mathrm{S}^{+}$and $\mathrm{M}^{-} \mathrm{H}^{-}$. Let $\mathrm{M}^{-} \mathrm{S}^{+}{ }_{\mathrm{t}+12}$ denote the 12 months following each $\mathrm{M}^{-} \mathrm{S}^{+}$ state and let $\mathrm{M}^{-} \mathrm{H}_{\mathrm{t}+12}^{-}$denote the 12 months following each $\mathrm{M}^{-} \mathrm{H}^{-}$state. According to the results in Tables 4.4 and 4.7 , the $\mathrm{M}^{-} \mathrm{S}^{+}{ }_{\mathrm{t}+12}$ and $\mathrm{M}^{-} \mathrm{H}_{\mathrm{t}+12}^{-}$months are the high risk months for momentum strategies. To investigate this further, Table 4.11 presents the 15 worst monthly stock momentum returns (W-L), together with the contemporaneous monthly market returns, over the sample period from 1926 to 2013. Following Daniel and Moskowitz (2013), I see that the worst momentum losses occurred in months when the market had risen. Clustering is evident, with July and August 1932 showing $1^{\text {st }}$ and $2^{\text {nd }}$ worst momentum losses exceeding $90 \%$, and March, April, and May of 2009 , showing the $14^{\text {th }}, 3^{\text {rd }}$ and $12^{\text {th }}$ worst momentum returns.

Columns five and six of Table 4.11 report whether or not the 15 worst momentum months are $\mathrm{M}^{-} \mathrm{S}^{+}{ }_{t+12}$ and $\mathrm{M}^{-} \mathrm{H}^{-}{ }_{t+12}$ months, respectively. By counting the number of yeses in column five, I can see that the $\mathrm{M}^{-} \mathrm{S}^{+}{ }_{t+12}$ months (the 12 months following $\mathrm{M}^{-} \mathrm{S}^{+}$states) include 13 of the 15 worst momentum months. Similarly, column six shows that the $\mathrm{M}^{-} \mathrm{H}_{\mathrm{t}+12}^{-}$months (the 12 months following $\mathrm{M}^{-} \mathrm{H}^{-}$states) account for 11 of the 15 worst momentum crashes. Overall, the $\mathrm{M}^{-} \mathrm{S}^{+}{ }_{\mathrm{t}+12}$ months covered $85 \%$ and $\mathrm{M}^{-} \mathrm{H}^{-}{ }_{\mathrm{t}+12}$ months covered $80 \%$ of the worst momentum crashes. In terms of relative frequency, the $\mathrm{M}^{-} \mathrm{S}^{+}{ }_{t+12}$ months represent $31.76 \%$ of the sample, while the $\mathrm{M}^{-} \mathrm{H}^{-}{ }_{\mathrm{t}+12}$ months represent $28.39 \%$ of the sample. 
Table 4.11: Worst Monthly Momentum Returns: $\mathrm{M}^{\top} \mathrm{S}^{+} \& \mathrm{M}^{-} \mathrm{H}^{-}$Coverage

\begin{tabular}{cccccc}
\hline Rank & Month & $\mathrm{W}-\mathrm{L}_{\mathrm{t}}$ & $\mathrm{Mkt}_{\mathrm{t}}$ & $\mathrm{M}^{-\mathrm{S}^{+}}{ }_{\mathrm{t}+12}$ & $\mathrm{M}^{-} \mathrm{H}_{\mathrm{t}+12}^{-12}$ \\
\hline 1 & 193208 & -52.15 & 36.49 & Yes & Yes \\
2 & 193207 & -45.03 & 33.63 & Yes & Yes \\
3 & 200904 & -34.72 & 10.20 & Yes & Yes \\
4 & 193909 & -29.19 & 16.97 & No & Yes \\
5 & 200101 & -24.97 & 3.66 & Yes & No \\
6 & 193806 & -24.48 & 23.72 & Yes & Yes \\
7 & 193106 & -17.66 & 13.87 & Yes & Yes \\
8 & 200211 & -16.30 & 6.08 & Yes & No \\
9 & 193304 & -14.99 & 38.14 & Yes & Yes \\
10 & 193102 & -14.22 & 10.78 & No & Yes \\
11 & 197501 & -13.81 & 14.24 & Yes & No \\
12 & 200905 & -12.47 & 5.21 & Yes & Yes \\
13 & 197307 & -11.58 & 5.68 & Yes & No \\
14 & 200903 & -11.36 & 8.97 & Yes & Yes \\
15 & 200305 & -10.74 & 6.14 & Yes & Yes \\
\hline 4.11 list the 15 worst monthly momentum returns over the period from July 1926 to December 2013. Also tabulated are the \\
mporaneous market return, and whether the $\mathrm{M}^{-} \mathrm{S}^{+}{ }_{\mathrm{t}+12}$ and $\mathrm{M}^{-} \mathrm{H}_{\mathrm{t}+12}^{-}$12-month periods included that month (by a yes or no response).
\end{tabular}

The preceding results suggest that a profitable trading strategy could exist that would not only reduce the risk of momentum profits but also show a greater profit. Therefore, the strategy noted as $\mathrm{M}^{-} \mathrm{S}_{\mathrm{t}+12}^{+},\left(\mathrm{M}^{-} \mathrm{H}^{-}{ }_{t+12}\right)$ would first entail stock or industry momentum's returns at the end of each period (month) be fully reinvested. However, when the state of $\mathrm{M}^{-} \mathrm{S}^{+}\left(\mathrm{M}^{-} \mathrm{H}^{-}\right)$ occurs, the following month the portfolio invests all assets in the risk free rate for the next 12 months. When there has been no state of $\mathrm{M}^{-} \mathrm{S}^{+}\left(\mathrm{M}^{-} \mathrm{H}^{-}\right)$occurring for 12 months, the portfolio reinvests assets into stocks or industries. My strategies show increased profits with less risk compared to a pure momentum strategy. All strategies start with a $\$ 1$ investment in May 1927. The graphs in Figure 4.3 plot the cumulative returns to momentum and the $\mathrm{M}^{-} \mathrm{S}^{+}{ }_{\mathrm{t}+12}$ (Graph A) and $\mathrm{M}^{-} \mathrm{H}^{-}{ }_{\mathrm{t}+12}$ (Graph B) strategies, over the May 1927 to December 2013 period. I 
follow a similar method to Daniel and Moskowitz (2013) technique of cumulating returns for momentum and the $\mathrm{M}^{-} \mathrm{S}^{+}{ }_{\mathrm{t}+12}$ and $\mathrm{M}^{-} \mathrm{H}^{-}{ }_{\mathrm{t}+12}$ trading strategies ${ }^{3}$.

Consistent with existing literature, there is a strong momentum profit over the last century. The trading strategy of $\mathrm{M}^{-} \mathrm{S}^{+}{ }_{t+12}$ results in Graph A of Figure 4.3 show a greater profitability than momentum with reduced volatility. The $\mathrm{M}^{-} \mathrm{S}^{+}{ }_{\mathrm{t}+12}$ trading strategy exhibits a considerably improved performance over momentum in the approximate $1^{\text {st }}$ half, whilst underperforms momentum in the majority of the $2^{\text {nd }}$ half of the period, (although at the end of the sample the $\mathrm{M}^{-} \mathrm{S}_{\mathrm{t}+12}$ trading strategy is clearly not affected by the global financial crisis (GFC) period). The $\mathrm{M}^{-} \mathrm{S}^{+}{ }_{t+12}$ strategy ends with a higher value of $\$ 6596$ compared to momentum's final value of $\$ 5788$. The crucial difference is the risk factor, and in Table 12, I show that the $\mathrm{M}^{-} \mathrm{S}^{+}{ }_{\mathrm{t}+12}$ strategy has a Sharpe ratio (SR) of 0.11 , which is $31.49 \%$ higher than momentum's SR of 0.08 .

The $\mathrm{M}^{-} \mathrm{H}_{\mathrm{t}+12}^{-}$strategy is displayed in Graph B of Figure 4.3. While Graph B behaves in a similar manner to momentum, the $\mathrm{M}^{-} \mathrm{H}_{\mathrm{t}+12}^{-}$strategy clearly outperforms momentum in the $1^{\text {st }}$ half and during the GFC period, whilst mimicking momentum in the $2^{\text {nd }}$ half of the period. The $\mathrm{M}^{-} \mathrm{H}_{\mathrm{t}+12}^{-}$strategy has a final value of $\$ 10287$, which is nearly double momentums' final value of $\$ 5788$. Table 12 reports the $\mathrm{M}^{-} \mathrm{H}_{\mathrm{t}+12}^{-}$strategy has a Sharpe ratio of $0.16,63 \%$ larger than momentum's SR of 0.08 . It should be noted that portfolio investment in the risk free rate for the M-S+ trading strategy is 330 observations or $31.76 \%$ of total observations, and for the M-H- trading strategy, 295 observations, or $28.39 \%$ of total observations.

In sum, the trading strategies of $\mathrm{M}^{-} \mathrm{S}^{+}{ }_{t+12}$ and $\mathrm{M}^{-} \mathrm{H}_{\mathrm{t}+12}^{-}$, are clearly more profitable than momentum, the $\mathrm{M}^{-} \mathrm{H}^{-}{ }_{t+12}$ strategy especially, whilst providing less risk.

\footnotetext{
${ }^{3}$ The calculation of the momentum strategies' cumulative monthly returns are described in Annexure 4B.
} 
Figure 4.3: Cumulative Monthly Returns to Momentum with $\mathrm{M}^{-} \mathrm{S}_{t+12}^{+}$and $\mathrm{M}^{-} \mathrm{H}_{t+12}^{-}$ Trading Strategies.

\section{Graph A: Momentum and $M-S^{+}{ }_{t+12}$ Trading Strategy}

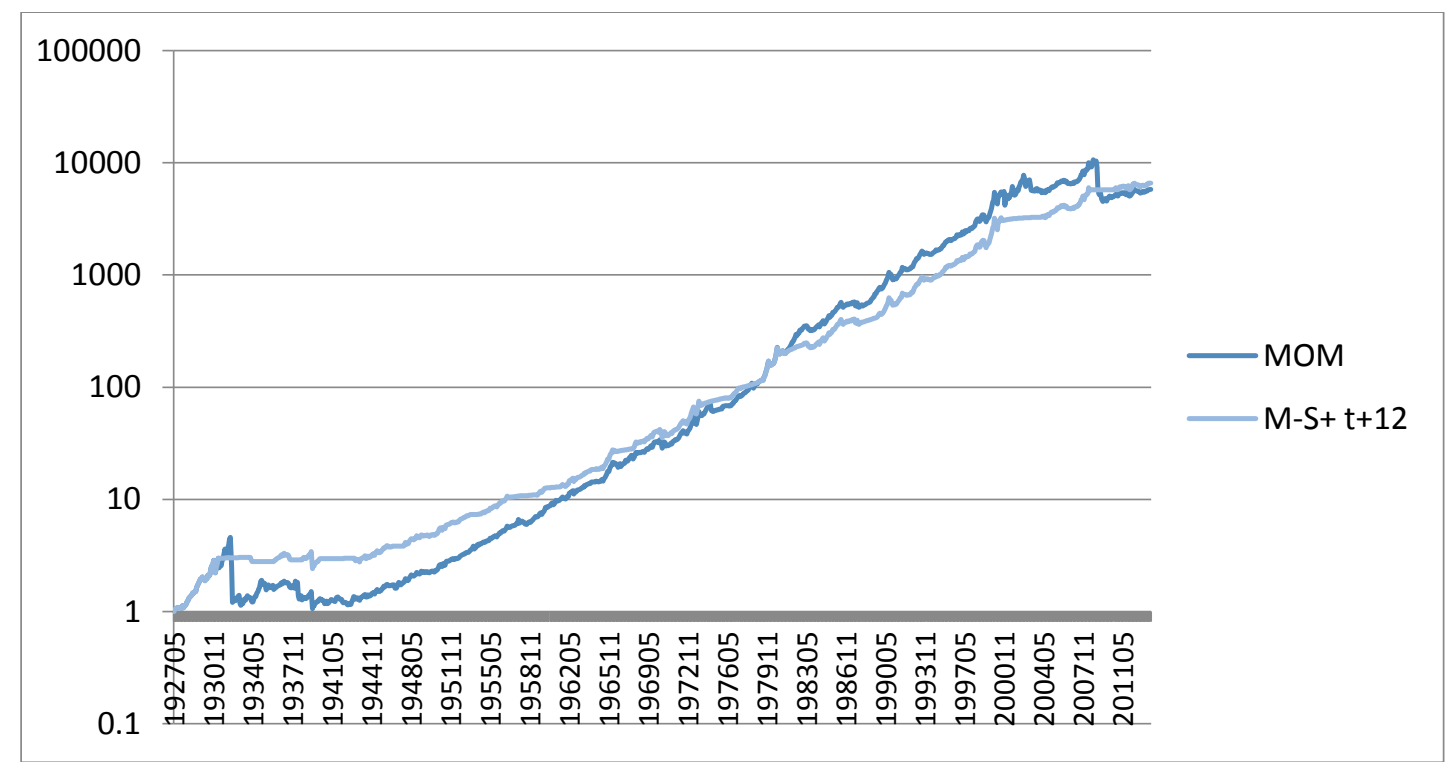

Graph B: Momentum and $\mathbf{M}^{-} \mathbf{H}^{-} \mathbf{t}+12$ Trading Strategy

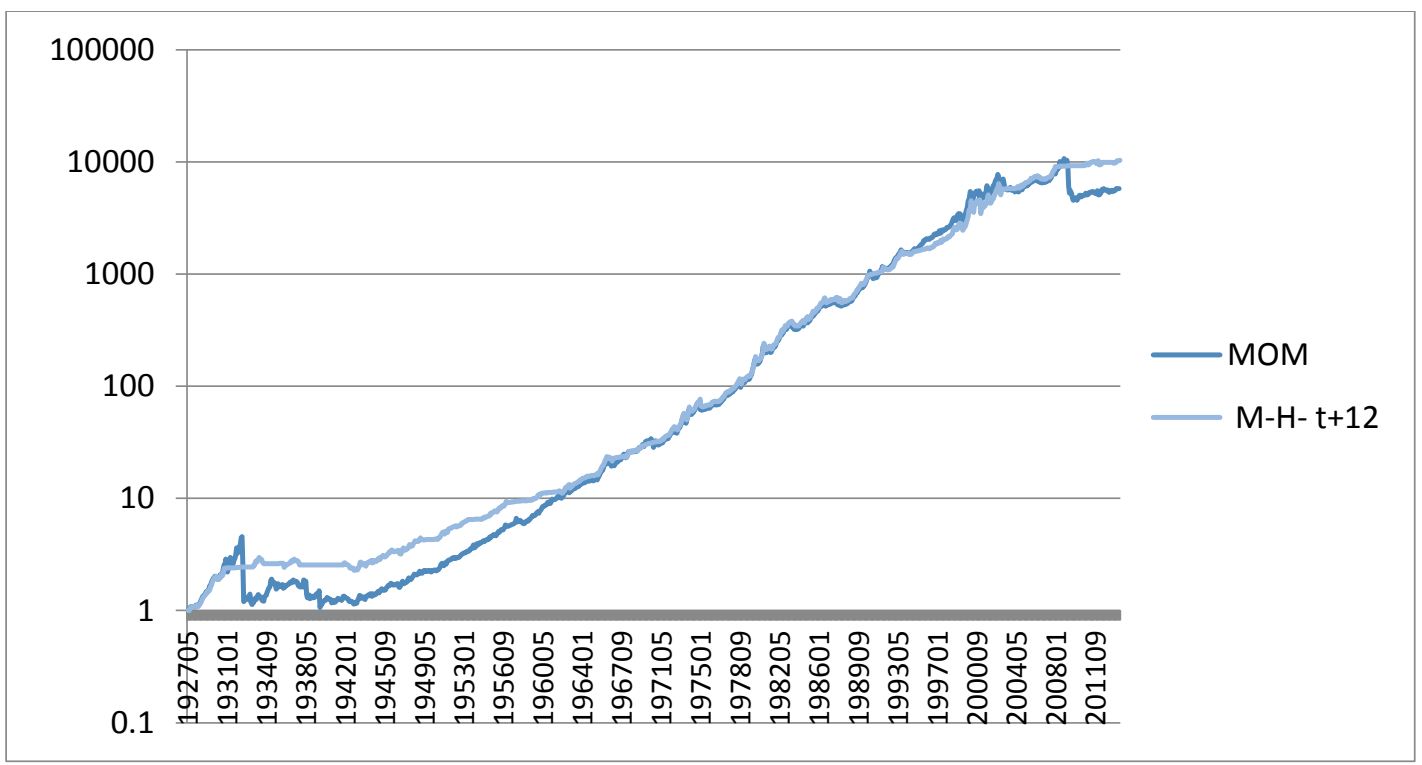

Plotted are the cumulated returns for momentum and the $\mathrm{M}^{-} \mathrm{S}^{+}{ }_{t+12}$ state (Graph A), $\mathrm{M}^{-} \mathrm{H}_{\mathrm{t}+12}$ state (Graph B) over the full sample period from July 1926 to December 2013. 


\section{Table 4.12: Analyses of Risk, $\mathrm{M}^{-} \mathrm{S}^{+}$and $\mathrm{M}^{-} \mathrm{H}^{-}$States vs Momentum Sharpe Ratio}

\begin{tabular}{lccc}
\hline & $\mathrm{M}^{-} \mathrm{S}^{+}$ & $\mathrm{M}^{-} \mathrm{H}^{-}$ & $\mathrm{MOM}$ \\
\hline SR & 0.11 & 0.13 & 0.08 \\
DIF MOM & $31.49 \%$ & $63.34 \%$ & 0.00
\end{tabular}

This Table presents the Sharpe ratio for the $\mathrm{M}^{-} \mathrm{S}^{+} \mathrm{t}_{+12}, \mathrm{M}^{-} \mathrm{H}^{-} \mathrm{t}_{+12}$ states and momentum. The period is from July 1926 to December 2013 . SR shows the Sharpe ratio, whilst the DIF MOM shows the differences in the Sharpe ratio, between each state and momentum.

\subsection{MRD Scheme}

To add to the knowledge of the investigation of momentum returns across market states, I also analyse the return dispersion (RD) effect. I chose return dispersion as Stivers and Sun (2013) had chosen to follow in the footsteps of Cooper et al. (2004) and Asem and Tien (2010) and investigate momentum profitability across market states by examining if return dispersion influences momentum profitability over market states. This section will investigate if my return dispersion market state scheme (MRD) can further clarify RD's effects on momentum profitability over market states.

Recent studies have shown that cross-sectional return dispersion has a predictive effect on momentum profitably. Stivers and Sun's (2013) findings show that there is a predictive positive (negative) relationship between momentum profitability and low (high) RD across market states.

To estimate the cross-sectional return dispersion across US disaggregate stock portfolio returns, I use the 100 size and book-to-market equity ratio portfolios from the Ken French data library. I choose value-weighted portfolio returns from the French library because 
Moskowitz and Grinblatt (1999) and Stivers and Sun (2013) also utilized value-weighted industry portfolios.

Following Stivers and Sun (2013), the RD state is determined by the cross-sectional dispersion in monthly returns for 100 value-weighted portfolios formed from double sorts on size and book-to-market equity ratios. As Sun and Stiver argue, an RD from these 100 portfolios, rather than an RD calculated from firm-level returns, should better capture dispersion attributed to common factor exposure for factors that have proven useful in explaining the cross-sectional variation in expected stock returns. Additionally, a RD from disaggregated portfolio returns should mitigate idiosyncratic noise that does not reflect market-wide conditions. A three-month moving average is chosen as it should be responsive to changes in market conditions, but should also remove some of the noise in month-tomonth variations.

To define the two states of the return dispersion, the high/low state of RD is determined by the lagged three-month rolling average RD at time $t$. If the mean of the 3-month RD moving average is less than the 50th percentile, it is noted as Low $\mathrm{RD}\left(\mathrm{RD}^{\text {low }}\right)$, and above its 50th percentile, it is noted as High $\mathrm{RD}\left(\mathrm{RD}^{\text {high }}\right)$. The use of the 50th percentile to determine the threshold between high and low RD means that the procedure has look-ahead bias as all returns for the research period are needed in the calculations.

Utilising the same methodology as used in the previous MS and MH schemes, the four states of the MRD scheme are denoted as follows: $\mathrm{M}^{+} \mathrm{RD}$ high (if market and RD states are $\mathrm{M}^{+}$and $R D^{\text {high }}$, respectively), $\mathrm{M}^{+} \mathrm{RD}^{\text {low }}$ (if market and $\mathrm{RD}$ states are $\mathrm{M}^{+}$and $\mathrm{RD}^{\text {low }}$, respectively), $\mathrm{M}^{-}$ $\mathrm{RD}^{\text {high }}$ (if market and $\mathrm{RD}$ states are $\mathrm{M}^{-}$and $\mathrm{RD}^{\text {high }}$, respectively), and $\mathrm{M}^{-} \mathrm{RD}^{\text {low }}$ (if market and 
$\mathrm{RD}$ states are $\mathrm{M}^{-}$and $\mathrm{RD}^{\text {low }}$, respectively. The momentum profits of the four states are then cumulated and averaged separately for the 6 months and 12 months following each state.

In Table 4.13, I examine momentum portfolio returns for the MRD scheme in different states. In the 12-month case, my result shows that momentum demonstrates strong and significant profitability following the two states with positive market returns $\left(\mathrm{M}^{+} \mathrm{RD}\right.$ high and $\left.\mathrm{M}^{+} \mathrm{RD}{ }^{\text {low }}\right)$. Of interest is that there is a difference between momentum profits following a negative market state. Following the $\mathrm{M}^{-} \mathrm{RD}^{\text {high }}$ state, momentum earns an insignificant negative return, with stock momentum averaging $-0.09 \%$ per month ( $t$-stat -0.23$)$, and industry momentum averaging $-0.02 \%$ per month $(t$-stat -0.06$)$. In contrast, momentum earns significantly positive returns in the 12 months following the $\mathrm{M}^{-} \mathrm{RD}^{\text {low }}$ state.

Specifically, following the $\mathrm{M}^{-} \mathrm{RD}^{\text {low }}$ state, stock momentum averages $0.67 \%$ per month $(t$-stat 3.32) and industry momentum averages $0.94 \%$ per month ( $t$-stat 4.76$)$. Thus, in a similar result to the MS scheme, the results show that while Table 4.2 shows that stock and industry momentum earned an insignificantly positive profit following the $\mathrm{M}^{-}$state, the RD scheme effectively splits this result into an insignificantly negative result following $\mathrm{M}^{-} \mathrm{RD}^{\text {high }}$ and a highly significant positive result following $\mathrm{M}^{-} \mathrm{RD}{ }^{\text {low }}$. Therefore, the $\mathrm{RD}$ scheme has shown that the negative $\mathrm{M}^{-}$market state can produce both positive and negative momentum returns. As expected, these results also show that momentum is profitable following a positive $\mathrm{M}$ state, irrespective of whether RD is high or low.

Noticeably, following the $\mathrm{M}^{-} \mathrm{RD}^{\text {high }}$ state, momentum's weak negative returns mean that the loser portfolio returns are larger than winner portfolio returns. For example, in the stock 12month case the loser portfolio for stock earns $1.58 \%$ ( $t$-stat 1.98), and for industry earns 
$1.23 \%$ (t-stat 1.79) whereas the winner portfolio for stock earns $1.49 \%$ ( $t$-stat 2.72 ), and for industry earns $1.20 \%$ ( $t$-stat 2.61). The results also show that the winner and loser portfolios following a negative market state were far stronger than the winner and loser portfolios following a positive market state.

Table 4.14, displays the differences in the returns of each portfolio in different RD states As expected, the profits following the positive $M$ states $M^{+} R D^{\text {high }}$ and $M^{+} R D^{\text {low }}$ are significantly (insignificantly) different to the profits following the negative state $M^{-} R D^{\text {high }}\left(M^{-} R D^{\text {low }}\right)$. Noticeably, following the negative $\mathrm{M}$ state, there is a significant difference between positive and negative RD state $\left(\mathrm{M}^{-} \mathrm{RD}^{\text {low }} \mathrm{vs} \mathrm{M}^{-} \mathrm{RD} \mathrm{D}^{\text {high }}\right)$ in industries, of $-0.96 \%$ (t-stat -2.23$)$ monthly difference in profits for the 12 month profit period. There was only $10 \%$ significance difference in stocks of $-0.77 \%$ ( $t$-stat -1.69 ), which is probably due to the paucity in observations. 
Table 4.13: MRD Scheme

\begin{tabular}{|c|c|c|c|c|c|c|c|c|c|c|c|c|}
\hline & & & $\begin{array}{l}1-6 \mathrm{M} \\
\text { Stock }\end{array}$ & & & $\begin{array}{l}1-12 \mathrm{M} \\
\text { Stock }\end{array}$ & & & $\begin{array}{c}1-6 \mathrm{M} \\
\text { ndustries }\end{array}$ & & & $\begin{array}{c}1-12 \mathrm{M} \\
\text { Industries }\end{array}$ \\
\hline States & W & $\mathrm{L}$ & W-L & W & $\mathrm{L}$ & W-L & W & $\mathrm{L}$ & W-L & W & $\mathrm{L}$ & W-L \\
\hline $\mathrm{M}^{+} \mathrm{RD}^{\text {high }}$ & $\begin{array}{c}1.55 \\
(5.23)\end{array}$ & $\begin{array}{c}0.75 \\
(2.67)\end{array}$ & $\begin{array}{c}0.80 \\
(6.01)\end{array}$ & $\begin{array}{c}1.40 \\
(5.00)\end{array}$ & $\begin{array}{c}0.55 \\
(2.11)\end{array}$ & $\begin{array}{c}0.85 \\
(6.56)\end{array}$ & $\begin{array}{c}1.35 \\
(4.46)\end{array}$ & $\begin{array}{c}-0.01 \\
(-0.01)\end{array}$ & $\begin{array}{c}1.35 \\
(3.72)\end{array}$ & $\begin{array}{c}1.24 \\
(4.47)\end{array}$ & $\begin{array}{c}-0.07 \\
(-0.20)\end{array}$ & $\begin{array}{c}1.31 \\
(3.33)\end{array}$ \\
\hline $\mathrm{M}^{+} \mathrm{RD}^{\text {low }}$ & $\begin{array}{c}1.40 \\
(8.33)\end{array}$ & $\begin{array}{c}0.44 \\
(2.67)\end{array}$ & $\begin{array}{c}0.96 \\
(9.23)\end{array}$ & $\begin{array}{c}1.34 \\
(8.77)\end{array}$ & $\begin{array}{c}0.45 \\
(2.69)\end{array}$ & $\begin{array}{c}0.90 \\
(9.20)\end{array}$ & $\begin{array}{c}1.37 \\
(8.35)\end{array}$ & $\begin{array}{c}0.45 \\
(2.91)\end{array}$ & $\begin{array}{c}0.92 \\
(7.69)\end{array}$ & $\begin{array}{c}1.36 \\
(8.97)\end{array}$ & $\begin{array}{c}0.45 \\
(2.75)\end{array}$ & $\begin{array}{c}0.91 \\
(7.53)\end{array}$ \\
\hline $\mathrm{M}^{-} \mathrm{RD}^{\text {high }}$ & $\begin{array}{c}1.28 \\
(2.35)\end{array}$ & $\begin{array}{c}1.54 \\
(1.86)\end{array}$ & $\begin{array}{c}-0.26 \\
(-0.55)\end{array}$ & $\begin{array}{c}1.49 \\
(2.72)\end{array}$ & $\begin{array}{c}1.58 \\
(1.98)\end{array}$ & $\begin{array}{l}-0.09 \\
(-0.23)\end{array}$ & $\begin{array}{c}1.10 \\
(2.22)\end{array}$ & $\begin{array}{c}1.37 \\
(1.90)\end{array}$ & $\begin{array}{c}-0.27 \\
(-0.65)\end{array}$ & $\begin{array}{c}1.20 \\
(2.61)\end{array}$ & $\begin{array}{c}1.23 \\
(1.79)\end{array}$ & $\begin{array}{l}-0.02 \\
(-0.06)\end{array}$ \\
\hline $\mathrm{M}^{-} \mathrm{RD}^{\text {low }}$ & $\begin{array}{c}1.46 \\
(2.61) \\
\end{array}$ & $\begin{array}{c}0.52 \\
(0.81) \\
\end{array}$ & $\begin{array}{c}0.94 \\
(4.19) \\
\end{array}$ & $\begin{array}{c}1.76 \\
(3.10) \\
\end{array}$ & $\begin{array}{c}1.08 \\
(2.28) \\
\end{array}$ & $\begin{array}{c}0.67 \\
(3.32) \\
\end{array}$ & $\begin{array}{c}1.59 \\
(2.94) \\
\end{array}$ & $\begin{array}{c}0.17 \\
(0.25) \\
\end{array}$ & $\begin{array}{c}1.42 \\
(4.84) \\
\end{array}$ & $\begin{array}{c}1.70 \\
(3.19)\end{array}$ & $\begin{array}{c}0.76 \\
(1.39) \\
\end{array}$ & $\begin{array}{c}0.94 \\
(4.76)\end{array}$ \\
\hline Overall & $\begin{array}{c}1.44 \\
(8.18)\end{array}$ & $\begin{array}{c}0.75 \\
(3.53)\end{array}$ & $\begin{array}{c}0.69 \\
(5.84)\end{array}$ & $\begin{array}{c}1.43 \\
(8.12)\end{array}$ & $\begin{array}{c}0.74 \\
(3.58)\end{array}$ & $\begin{array}{c}0.68 \\
(6.14)\end{array}$ & $\begin{array}{c}1.33 \\
(7.89)\end{array}$ & $\begin{array}{c}0.47 \\
(2.20)\end{array}$ & $\begin{array}{c}0.86 \\
(5.36)\end{array}$ & $\begin{array}{c}1.32 \\
(8.07)\end{array}$ & $\begin{array}{c}0.46 \\
(2.25)\end{array}$ & $\begin{array}{c}0.86 \\
(5.04)\end{array}$ \\
\hline
\end{tabular}

Table 4.13 shows the mean future monthly momentum returns for the MRD scheme's four states, for stocks and industries, over two time periods. M is denoted as the prior 12 -month market return, RD is denoted as the cross-sectional dispersion in monthly returns from the previous three months. M states are defined as non-negative (negative) by the returns of the VW CRSP index over the 12 months prior to the beginning of the strategy's profit period. To determine the RD state, I use the dispersion in monthly returns for 100 value-weighted portfolios formed from double sorts on size and book-to-market equity ratios downloaded from Ken French data. The high/low of RD is determined by the lagged three-month rolling average RD is below its 50th percentile or Low RD, and above its 50 th percentile or High RD. Stock momentum portfolios were construct fom conste $\mathrm{M}^{+} \mathrm{D}^{\text {thigh }}$ ( M RD ( Overall section shows the winner (W), loser (L), and winner minus loser (W-L) portfolio results. 
Table 4.14: Difference between MRD States

\begin{tabular}{|c|c|c|c|c|c|c|c|c|c|c|}
\hline & \multirow{2}{*}{$\begin{array}{l}\text { State B } \\
\text { State A }\end{array}$} & \multicolumn{3}{|c|}{ State $\mathrm{M}^{+} \mathrm{RD}^{\text {low }}$} & \multicolumn{3}{|c|}{ State $M^{-}{ }^{-R D^{\text {high }}}$} & \multicolumn{3}{|c|}{ State $\mathrm{M}^{-} \mathrm{RD}^{\text {low }}$} \\
\hline & & W & $\mathrm{L}$ & W-L & W & $\mathrm{L}$ & W-L & W & $\mathrm{L}$ & W-L \\
\hline \multirow[t]{3}{*}{ stock 1-6 } & $\mathrm{M}^{+} \mathrm{RD}^{\text {high }}$ & $\begin{array}{c}0.16 \\
(0.46)\end{array}$ & $\begin{array}{c}0.31 \\
(0.96)\end{array}$ & $\begin{array}{l}-0.15 \\
(-0.91)\end{array}$ & $\begin{array}{c}0.27 \\
(0.44)\end{array}$ & $\begin{array}{c}-0.79 \\
(-0.91)\end{array}$ & $\begin{array}{l}1.06^{* *} \\
(2.16)\end{array}$ & $\begin{array}{c}0.10 \\
(0.15)\end{array}$ & $\begin{array}{c}0.23 \\
(0.33)\end{array}$ & $\begin{array}{c}-0.14 \\
(-0.52)\end{array}$ \\
\hline & $\mathrm{M}^{+} \mathrm{RD}^{\text {low }}$ & & & & $\begin{array}{c}0.11 \\
(0.20)\end{array}$ & $\begin{array}{l}-1.10 \\
(-1.31)\end{array}$ & $\begin{array}{l}1.22 * * \\
(2.51)\end{array}$ & $\begin{array}{l}-0.06 \\
(-0.11)\end{array}$ & $\begin{array}{c}-0.08 \\
(-0.12)\end{array}$ & $\begin{array}{c}0.02 \\
(0.08)\end{array}$ \\
\hline & $\mathrm{M}^{-} \mathrm{RD}^{\text {high }}$ & & & & & & & $\begin{array}{c}-0.18 \\
(-0.22)\end{array}$ & $\begin{array}{c}1.02 \\
(0.98)\end{array}$ & $\begin{array}{l}-1.20 * * \\
(-2.29)\end{array}$ \\
\hline \multirow[t]{3}{*}{ stock 1-12 } & $\mathrm{M}^{+} \mathrm{RD}^{\text {high }}$ & $\begin{array}{l}0.06 \\
(0.19)\end{array}$ & $\begin{array}{c}0.11 \\
(0.35)\end{array}$ & $\begin{array}{l}-0.05 \\
(-0.30)\end{array}$ & $\begin{array}{l}-0.08 \\
(-0.13)\end{array}$ & $\begin{array}{l}-1.03 \\
(-1.22)\end{array}$ & $\begin{array}{l}0.94 * * \\
(2.21)\end{array}$ & $\begin{array}{l}-0.35 \\
(-0.56)\end{array}$ & $\begin{array}{c}-0.53 \\
(-0.97)\end{array}$ & $\begin{array}{c}0.18 \\
(0.73)\end{array}$ \\
\hline & $\mathrm{M}^{+} \mathrm{RD}^{\text {low }}$ & & & & $\begin{array}{c}-0.14 \\
(-0.25)\end{array}$ & $\begin{array}{l}-1.13 \\
(-1.39)\end{array}$ & $\begin{array}{l}0.99 * * \\
(2.37)\end{array}$ & $\begin{array}{c}-0.41 \\
(-0.70)\end{array}$ & $\begin{array}{c}-0.64 \\
(-1.26)\end{array}$ & $\begin{array}{c}0.22 \\
(0.99)\end{array}$ \\
\hline & $\mathrm{M}^{-} \mathrm{RD}^{\text {high }}$ & & & & & & & $\begin{array}{c}-0.27 \\
(-0.34) \\
\end{array}$ & $\begin{array}{c}0.50 \\
(0.54) \\
\end{array}$ & $\begin{array}{l}-0.77 * \\
(-1.69) \\
\end{array}$ \\
\hline \multirow[t]{3}{*}{ Industry 1-6 } & $\mathrm{M}^{+} \mathrm{RD}^{\text {high }}$ & $\begin{array}{c}-0.03 \\
(-0.09)\end{array}$ & $\begin{array}{c}-0.46 \\
(-1.17)\end{array}$ & $\begin{array}{c}0.43 \\
(1.13)\end{array}$ & $\begin{array}{c}0.24 \\
(0.42)\end{array}$ & $\begin{array}{l}-1.38 * \\
(-1.71)\end{array}$ & $\begin{array}{l}1.62 * * \\
(2.93)\end{array}$ & $\begin{array}{c}-0.24 \\
(-0.39)\end{array}$ & $\begin{array}{c}-0.17 \\
(-0.23)\end{array}$ & $\begin{array}{c}-0.07 \\
(-0.14)\end{array}$ \\
\hline & $\mathrm{M}^{+} \mathrm{RD}^{\text {low }}$ & & & & $\begin{array}{c}-0.14 \\
(-0.25)\end{array}$ & $\begin{array}{l}-1.13 \\
(-1.39)\end{array}$ & $\begin{array}{l}0.99 * * \\
(2.37)\end{array}$ & $\begin{array}{l}-0.21 \\
(-0.37)\end{array}$ & $\begin{array}{c}0.29 \\
(0.40)\end{array}$ & $\begin{array}{l}-0.50 \\
(-1.57)\end{array}$ \\
\hline & $\mathrm{M}^{-} \mathrm{RD}^{\text {high }}$ & & & & & & & $\begin{array}{c}-0.48 \\
(-0.66)\end{array}$ & $\begin{array}{c}1.20 \\
(1.21)\end{array}$ & $\begin{array}{c}-1.68 * * \\
(-3.32)\end{array}$ \\
\hline \multirow[t]{3}{*}{ Industry 1-12 } & $\mathrm{M}^{+} \mathrm{RD}^{\text {high }}$ & $\begin{array}{c}-0.12 \\
(-0.38)\end{array}$ & $\begin{array}{c}-0.52 \\
(-1.41)\end{array}$ & $\begin{array}{c}0.40 \\
(0.97)\end{array}$ & $\begin{array}{c}0.03 \\
(0.06)\end{array}$ & $\begin{array}{l}-1.30^{*} \\
(-1.70)\end{array}$ & $\begin{array}{l}1.33 * * \\
(2.42)\end{array}$ & $\begin{array}{c}-0.46 \\
(-0.77)\end{array}$ & $\begin{array}{c}-0.83 \\
(-1.29)\end{array}$ & $\begin{array}{c}0.37 \\
(0.84)\end{array}$ \\
\hline & $\mathrm{M}^{+} \mathrm{RD}^{\text {low }}$ & & & & $\begin{array}{c}0.15 \\
(0.32)\end{array}$ & $\begin{array}{l}-0.78 \\
(-1.10)\end{array}$ & $\begin{array}{l}0.93 * * \\
(2.32)\end{array}$ & $\begin{array}{l}-0.34 \\
(-0.62)\end{array}$ & $\begin{array}{c}-0.31 \\
(-0.54)\end{array}$ & $\begin{array}{c}-0.03 \\
(-0.14)\end{array}$ \\
\hline & $\mathrm{M}^{-} \mathrm{RD}^{\text {high }}$ & & & & & & & $\begin{array}{c}-0.49 \\
(-0.70)\end{array}$ & $\begin{array}{c}0.47 \\
(0.53)\end{array}$ & $\begin{array}{l}-0.96^{* * *} \\
(-2.23)\end{array}$ \\
\hline
\end{tabular}

Table 4.14 reports the differences in momentum returns between each state from Table 4.13. The results are derived from the momentum returns for the states in column State A, deducting the momentum returns of the states in the row State B. M is denoted as the prior 12-month market return, RD is denoted as the cross-sectional dispersion in monthly returns from the previous three months .The M states are defined as non-negative (negative) by the returns of the VW CRSP index over the 12 months prior to the beginning of the strategy's profit period. For the state RD, I use the dispersion in monthly returns for 100 value-weighted portfolios, formed from double sorts on size and book-to-market equity ratios downloaded from Ken French data. The high (low) of RD is determined by the lagged three-month rolling average RD, if RD is above (below) its 
50th percentile, RD is defined as High (Low).Stock momentum portfolios were constructed from portfolios downloaded fromKen French website. For industry momentum, I use the common measure of the past 12month cumulative raw return on the asset, skipping the most recent month. The returns of the momentum portfolios (winner minus loser deciles) are averaged across two periods: months $t+1$ to $t+6$, and months $t+1$ to $t+12$. Each section shows the winner (W), loser (L), and winner minus loser (W-L) portfolio results The column (row) in State A ( B) show the four MS states (described in Table 4.6). The period is from July 1226 to December 2013.The results are partitioned into four sections, 1-6 and 1-12 average returns for stock and industry, and shows the $t$-statistics in parentheses. The monthly mean differences are defined by one or two asterisk, showing $10 \%$ or $5 \%$ significance respectively. 
MRD states produce strong significant momentum profits when the $\mathrm{M}$ state is positive, irrespective RD state is high or low. However, following a negative $\mathrm{M}$ state, profitable returns are dependent on a negative RD state. According to previous research (such as Stivers and Sun (2013)), the market's cross-sectional return dispersion is a leading indicator of market state transitions for momentum profits, and is negatively related to the market's prior three-month RD moving average. However, my study shows that low (high) RD is only an effective predictor of positive (negative) momentum profitability following a negative market state, and ineffectual as a predictor when in a positive market.

\subsection{Concluding Comments.}

Since Jagadeesh and Titman (1993) findings that there is a momentum effect, there has been a plethora of research into momentum effects of different assets, in different countries and over different time periods. In recent times, there has been an investigation into how other well-known anomalies, such as the size and value effects, affect momentum, (Asness, Moskowitz and Pedersen, 2013, Fama and French, 2011). Cooper et al. (2004) examined the effect of market states on momentum.

I add to this research by creating two new schemes: the MS scheme with four states determined by the recent 12-month performances of the market and the size factor, and an MH scheme with four states determined by the recent 12-month performances of the market and the value factor. My findings show that following an UP market, momentum average returns are significantly positive regardless of whether or not the previous $\mathrm{S}$ or $\mathrm{H}$ component of the schemes are positive or negative. However, a negative market with small firms outperforming large firms predicts insignificant negative momentum profits, whereas a 
negative market with large firms outperforming small firms predicts significant positive momentum profits. Value firm outperformance combined with a negative market predicts significant momentum profits, whilst growth firms outperforming value firms in a negative market are followed on average by insignificantly negative momentum returns.

I also demonstrate that the majority of the worst momentum crashes occur in the 12 months following an $\mathrm{M}^{-} \mathrm{S}^{+}$or an $\mathrm{M}^{-} \mathrm{H}^{-}$state. I created trading strategies based on these four-state schemes, and show that these predictive strategies outperform the standard momentum strategy with less risk, especially the $\mathrm{M}^{-} \mathrm{H}^{-}+12$ trading strategy.

My findings show that future short-term momentum is profitable following a positive market, in both MS and MH schemes, agreeing with the DHS (1998), HS (1999), and SS (2007) theories. However, the negative market states in the MS and MH schemes provide the important results of this chapter. In the $\mathrm{MH}$ case, following a negative market state, momentum profit is negatively affected when growth firms outperformed in the previous 12 months, and was profitable when value firms outperformed. As I show there is a strong market transition for the $\mathrm{M}^{-} \mathrm{H}^{+}$and $\mathrm{M}^{-} \mathrm{H}^{-}$states in the next 12-months, the results show on average returns, momentum profitability is relativity unaffected by transitioning market reversals from a down to an up market, when value firms have previously outperformed. Further research is needed to explain this occurrence.

In the MS scheme case, the results show momentum is weakly profitable, with weak transitioning between market states, when large size firms had dominated. Small size firms domination leads to momentum losses, which are caused through transitioning from a down market state to an up market state. Asem and Tien (2010) show that the lack of momentum 
profits in DOWN markets (the M- state) is due to the offsetting of the profits when the market continues in the DOWN state against the losses when they transition to UP states. My findings from the MS and MS scheme add to the literature regarding momentum profits when transitioning from a down market to an up market.

I also follow up Stivers and Sun's (2013) investigation of the RD effect on momentum profits with market states. I created a MRD scheme, incorporating RD and market states, and show that return dispersion's ability to predict momentum profits is determined only following a negative market, with the low RD component predicting momentum profitability. Following the positive market state, the high and low RD component of the MRD scheme produce a similar results. 
Annexure 4A: S Scheme

\begin{tabular}{|c|c|c|c|c|c|c|c|c|c|c|c|c|}
\hline states & Win & Lose & $\begin{array}{l}1-6 \mathrm{M} \\
\text { Stock } \\
\text { W-L }\end{array}$ & Win & Lose & $\begin{array}{c}1-12 \mathrm{M} \\
\text { Stock } \\
\text { W-L }\end{array}$ & Win & Lose & $\begin{array}{c}1-6 \mathrm{M} \\
\text { Industrie } \\
\text { W-L }\end{array}$ & Win & Lose & $\begin{array}{c}\text { 1-12M } \\
\text { Industries } \\
\text { W-L }\end{array}$ \\
\hline State $\mathrm{S}^{+}$ & $\begin{array}{c}1.51 \\
(6.48)\end{array}$ & $\begin{array}{c}0.93 \\
(3.45)\end{array}$ & $\begin{array}{c}0.57 \\
(3.29)\end{array}$ & $\begin{array}{c}1.57 \\
(7.35)\end{array}$ & $\begin{array}{c}1.00 \\
(3.92)\end{array}$ & $\begin{array}{c}0.57 \\
(3.59)\end{array}$ & $\begin{array}{c}1.36 \\
(6.02)\end{array}$ & $\begin{array}{c}0.50 \\
(1.75)\end{array}$ & $\begin{array}{c}0.85 \\
(3.36)\end{array}$ & $\begin{array}{c}1.42 \\
(7.30)\end{array}$ & $\begin{array}{c}0.61 \\
(2.26)\end{array}$ & $\begin{array}{c}0.81 \\
(3.07)\end{array}$ \\
\hline State $S^{-}$ & $\begin{array}{c}1.32 \\
(5.88)\end{array}$ & $\begin{array}{c}0.50 \\
(1.68)\end{array}$ & $\begin{array}{c}0.82 \\
(6.54)\end{array}$ & $\begin{array}{c}1.22 \\
(4.89)\end{array}$ & $\begin{array}{c}0.39 \\
(1.27)\end{array}$ & $\begin{array}{c}0.83 \\
(6.78)\end{array}$ & $\begin{array}{c}1.29 \\
(6.20)\end{array}$ & $\begin{array}{c}0.41 \\
(1.52)\end{array}$ & $\begin{array}{c}0.88 \\
(6.28)\end{array}$ & $\begin{array}{c}1.17 \\
(5.11)\end{array}$ & $\begin{array}{c}0.26 \\
(0.93)\end{array}$ & $\begin{array}{c}0.91 \\
(6.36)\end{array}$ \\
\hline
\end{tabular}

\begin{tabular}{lcccccccccccccc} 
Overall & 1.44 & 0.75 & 0.69 & 1.43 & 0.74 & 0.68 & 1.33 & 0.47 & 0.86 & 1.32 & 0.46 & 0.86 \\
& $(8.18)$ & $(3.53)$ & $(5.84)$ & $(8.12)$ & $(3.58)$ & $(6.14)$ & $(7.89)$ & $(2.20)$ & $(5.36)$ & $(8.07)$ & $(2.25)$ & $(5.04)$ \\
\hline \multirow{2}{*}{ Difference } & 0.19 & 0.44 & -0.25 & 0.35 & 0.61 & -0.26 & 0.07 & 0.09 & -0.03 & 0.25 & 0.35 & -0.10 \\
& $(0.58)$ & $(1.08)$ & $(-1.15)$ & $(1.05)$ & $(1.52)$ & $(-1.32)$ & $(0.21)$ & $(0.23)$ & $(-0.10)$ & $(0.84)$ & $(0.91)$ & $(-0.34)$ \\
\hline
\end{tabular}

Table 4.15 shows the mean monthly momentum returns for the SMB-State, for stock and industries. S is denoted as the SMB factor cumulative average return over the past twelve months. SMB monthly data is

downloaded from Ken French's website, and the previous 12 month cumulative return define the POSITIVE (NEGATIVE) S state. Stock momentum portfolios were constructed from portfolios downloaded fromKen French website. For industry momentum, I use the common measure of the past 12-month cumulative raw return on the asset, skipping the most recent month. The returns of the momentum portfolios (winner minus loser deciles) are averaged across two periods: months $t+1$ to $t+6$, and months $t+1$ to $t+12$. The first column in Table 4.15 show the non-negative (negative) $\mathrm{S}$ state. The Overall row shows the average momentum profits across both states. The results are partitioned into four sections, 1-6 and 1-12 average monthly returns for stock and industry, the $t$-statistics are in parentheses. Each section shows the winner (W), loser (L), and winner minus loser (W-L) portfolio results. 


\section{Annexure 4B: H Scheme}

\begin{tabular}{|c|c|c|c|c|c|c|c|c|c|c|c|c|}
\hline states & Win & Lose & $\begin{array}{l}1-6 \mathrm{M} \\
\text { Stock } \\
\text { W-L }\end{array}$ & Win & Lose & $\begin{array}{c}1-12 \mathrm{M} \\
\text { Stock } \\
\text { W-L }\end{array}$ & Win & Lose & $\begin{array}{c}1-6 \mathrm{M} \\
\text { Industries } \\
\mathrm{W}-\mathrm{L}\end{array}$ & Win & Lose & $\begin{array}{c}1-12 \mathrm{M} \\
\text { Industries } \\
\mathrm{W}-\mathrm{L}\end{array}$ \\
\hline State $\mathrm{H}^{+}$ & $\begin{array}{c}1.42 \\
(6.66)\end{array}$ & $\begin{array}{c}0.67 \\
(2.95)\end{array}$ & $\begin{array}{c}0.75 \\
(7.77)\end{array}$ & $\begin{array}{c}1.43 \\
(7.27)\end{array}$ & $\begin{array}{c}0.68 \\
(3.14)\end{array}$ & $\begin{array}{c}0.75 \\
(7.94)\end{array}$ & $\begin{array}{c}1.38 \\
(6.71)\end{array}$ & $\begin{array}{c}0.33 \\
(1.31)\end{array}$ & $\begin{array}{c}1.05 \\
(5.35)\end{array}$ & $\begin{array}{c}1.40 \\
(7.55)\end{array}$ & $\begin{array}{c}0.43 \\
(1.82)\end{array}$ & $\begin{array}{c}0.97 \\
(4.62)\end{array}$ \\
\hline State $\mathrm{H}^{-}$ & $\begin{array}{c}1.44 \\
(5.17) \\
\end{array}$ & $\begin{array}{c}0.88 \\
(2.25) \\
\end{array}$ & $\begin{array}{c}0.55 \\
(2.23) \\
\end{array}$ & $\begin{array}{c}1.40 \\
(5.01)\end{array}$ & $\begin{array}{c}0.84 \\
(2.49)\end{array}$ & $\begin{array}{c}0.55 \\
(2.71) \\
\end{array}$ & $\begin{array}{c}1.24 \\
(4.91) \\
\end{array}$ & $\begin{array}{c}0.69 \\
(2.02) \\
\end{array}$ & $\begin{array}{c}0.55 \\
(2.20) \\
\end{array}$ & $\begin{array}{c}1.17 \\
(4.69) \\
\end{array}$ & $\begin{array}{c}0.51 \\
(1.73)\end{array}$ & $\begin{array}{c}0.66 \\
(3.08) \\
\end{array}$ \\
\hline Overall & $\begin{array}{r}1.44 \\
(8.18) \\
\end{array}$ & $\begin{array}{r}0.75 \\
(3.53) \\
\end{array}$ & $\begin{array}{r}0.69 \\
(5.84) \\
\end{array}$ & $\begin{array}{c}1.43 \\
(8.12) \\
\end{array}$ & $\begin{array}{c}0.74 \\
(3.58) \\
\end{array}$ & $\begin{array}{c}0.68 \\
(6.14) \\
\end{array}$ & $\begin{array}{c}1.33 \\
(7.89) \\
\end{array}$ & $\begin{array}{c}0.47 \\
(2.20) \\
\end{array}$ & $\begin{array}{r}0.86 \\
(5.36) \\
\end{array}$ & $\begin{array}{c}1.32 \\
(8.07) \\
\end{array}$ & $\begin{array}{c}0.46 \\
(2.25) \\
\end{array}$ & $\begin{array}{r}0.86 \\
(5.04) \\
\end{array}$ \\
\hline Difference & $\begin{array}{c}-0.01 \\
(-0.04)\end{array}$ & $\begin{array}{c}-0.21 \\
(-0.47)\end{array}$ & $\begin{array}{c}0.20 \\
(0.76)\end{array}$ & $\begin{array}{c}0.04 \\
(0.11)\end{array}$ & $\begin{array}{c}-0.16 \\
(-0.41)\end{array}$ & $\begin{array}{c}0.20 \\
(0.90)\end{array}$ & $\begin{array}{c}0.14 \\
(0.42)\end{array}$ & $\begin{array}{c}-0.36 \\
(-0.84)\end{array}$ & $\begin{array}{c}0.50 \\
(1.56)\end{array}$ & $\begin{array}{c}0.24 \\
(0.76)\end{array}$ & $\begin{array}{c}-0.08 \\
(-0.21)\end{array}$ & $\begin{array}{c}0.32 \\
(1.06)\end{array}$ \\
\hline
\end{tabular}




\section{Annexure 4 B}

\section{Cumulative Return Calculations}

I follow the same method as used by Daniel and Moskowitz (2013)

For long-short portfolios, the cumulative return is:

$$
R(t, T)=\prod_{s=t+1}^{T}(1+\mathrm{RL}, \mathrm{s}-\mathrm{Rs}, \mathrm{s}+\mathrm{Rf}, \mathrm{t})-1
$$

where the terms $\mathrm{R}_{\mathrm{L}, \mathrm{s}}, \mathrm{Rs}, \mathrm{s}$, and $\mathrm{R}_{\mathrm{f}, \mathrm{s}}$ are, respectively, the return on the long side of the portfolio, the short side of the portfolio, and the risk-free rate. Thus, the strategy reflects the cumulative return, with an initial investment of $\mathrm{V}_{\mathrm{t}}$, which is managed in the following way:

1. Using the $\$ \mathrm{~V}_{0}$ as margin, you purchase $\$ \mathrm{~V}_{0}$ of the long side of the portfolio, and short $\$ \mathrm{~V}_{0}$ worth of the short side of the portfolio. Note that this is consistent with Reg-T requirements. Over each period s, the margin posted earns interest at rate $\mathrm{R}_{\mathrm{f}, \mathrm{s} .}$

2. At the end of each period, the value of the investments on the long and the short side of the portfolio are adjusted to reflect gains to both the long and short side of the portfolio. So, for example, at the end of the first period, the investments in both the long and short side of the portfolio are adjusted to set their value equal to the total value of the portfolio to $\mathrm{V}_{\mathrm{t}+1}=\mathrm{V}_{\mathrm{t}} \cdot\left(1+\mathrm{R}_{\mathrm{L}}-\mathrm{Rs}_{\mathrm{s}}+\mathrm{R}_{\mathrm{f}}\right)$. 


\section{Chapter 5: Size based Market States and FF Three Factors}

\subsection{Introduction}

Previous chapters have highlighted the importance of market states ability to predict anomalous returns. Chapter 4 shows that two new schemes (derived from the interaction of past market and size factor performances or past market and value factor performances) are able to explain elements of momentum profitability that were not previously known. Chapter 5 uses the market-size MS scheme and its components to examine Fama and French's three factors from a new direction.

The Fama and French (1992) (FF) three factors considered are the return of the market minus the risk free rate (RM-rf), the small minus big (SMB) and the high book-to-market minus low-book-to-market (HML) factors. There has been considerable research showing that the SMB and HML factors can have an anomalous predictive effect. There has also been some research in how market states affect anomalous variables returns, such as momentum (Cooper et al., 2004). I add to the literature by investigating how market states can predict the FF three factors' future returns.

Two of the most studied capital market phenomena are size and value effects. Small size firms as a group have long been noted as having higher average returns than large firms (Banz 1981, Fama and French, 1992, 1993). There is also a great deal of evidence that value stocks (firms with high book-to-market ratios) tend to have higher average returns than growth stocks (firms with low book-to-market ratios) (see, for example, Rosenberg, Reid and Lanstein, 1985; Bondt and Thaler, 1985; Fama and French, 1992; Lakonishok, Shleifer, and 
Valishny, 1994). Fama and French (1992) also claim that size and book-to-market proxy for common risk factors in returns. Liew and Vassalou (2000) agree and claim that their results show that the hypothesis of Fama and French $(1992,1998)$ [that SMB and HML act as state variables in the context of Merton's (1973) inter temporal capital asset pricing model (ICAPM)] is due to the fact the performance of HML and SMB is linked to future economic growth.

Theory suggests that small size effect is negatively affected in a negative market, whilst having stronger returns in a positive market (Liew and Vassalou, 2000, Kim and Bernie, 2002). However, literature investigating size linked with economic or market states, have shown mixed results. Reinganum (1992) tests the cyclical behaviour of small and large stocks between 1926 and 1989, and finds that while small-cap portfolios outperform large-cap portfolios on average, the return behaviour is volatile. The author also finds that the returns reverse in some economic periods. Bhardwaj and Brooks (1993) investigated the size effect in bull and bear stock markets during 1926-88 and claim that small firms do not outperform large firms in a varying risk model, and any outperformance of small firm stocks in a bull market is due to a constant risk model and the January effect. Kim \& Burnie (2002) found small firm size effect occurs in the expansion phase of the economic cycle, with no significant small firm effect, either positive or negative in the contraction phase of the economic cycle.

There have been a number of studies of the performance of value investing over business or market cycles. Liew and Vassalou (2000) claim that the value effect is linked to future GDP growth, while Pontiff and Schall (1998) claim the book-to-market ratio of the Dow Jones Industrial Average predicts market returns over the period 1926 to 1994. Seung-Woog and 
Lee (2006) examine two strategies (growth and value investing) in the context of the business cycle, Their findings show that the superior performance of high book-to-market stocks is robust for all economic conditions, and that the benefits of value investing are larger during periods of contraction than during periods of expansion. Arshanapalli and Nelson (2007) claim that value investments underperformed growth investments during bull markets, however value portfolios outperformed growth portfolios during bear markets. They argue that value investing acts as a hedge during recessions.

Our motivation for a regime-switching perspective was also influenced by the results in Grundy and Martin (2001), Chordia and Shivakumar (2002), Cooper et al. (2004), Sagi and Seasholes (2007), Asem and Tian (2010) and Stivers and Sun (2013), which collectively suggest that some stock market anomalies are influenced by economic cycles or market states. To examine the performances of three FF factors across market states, I utilize the MS scheme introduced and developed in Chapter 4. Recall that in the MS scheme, the "M" is determined by the prior 12-month market return, while the "S" is determined by the SMB factor's cumulative average return over the past twelve months. This produces four different states, and I investigate the performances of the three FF factors over three subsequent periods

A further motivation was to not only ascertain how these important components of the market were effected by market states, but also to determine whether particular market states were effective for predicting future factor returns. My examination includes three future profit periods (from months $t+1$ to $t+6$, from $t+1$ to $t+12$, and from $t+13$ to $t+24$ ) and my results show that there are significant differences in average returns for each of the three FF factors across market states. All three factors produce their strongest profits following a negative 
market state $\left(\mathrm{M}^{-}\right)$when the $\mathrm{S}$ state is positive $\left(\mathrm{S}^{+}\right)$. I find that size and value profitability are strongly dependent on the lagged S state, whilst the RM-rf result was only affected by the lagged S state combined with a lagged negative $\mathrm{M}$ state.

To try to understand these results, I broke down the MS scheme to a $\mathrm{S}$ and $\mathrm{M}$ scheme, resulting in only two states for each scheme, a positive and negative $S$ scheme (S) state, and a positive and negative $\mathrm{M}$ scheme $(\mathrm{M})$ state. The results confirmed that the higher returns for all three factors are derived from the positive $\mathrm{S}\left(\mathrm{S}^{+}\right)$state and the negative $\mathrm{M}\left(\mathrm{M}^{-}\right)$state. I discuss the possible reasons why small firm outperformance in a negative market predicts these returns.

In sum, I show that a negative lagged $\mathrm{M}$ state and a positive lagged $\mathrm{S}$ state can predict positive returns for the SMB and HML factors, and although neither state $\mathrm{M}^{-}$and $\mathrm{S}^{+}$ separately can predict RM-rf returns, in a conundrum, the combination of the $\mathrm{M}^{-} \mathrm{S}^{+}$state can predict strong positive RM-rf returns. The $\mathrm{M}^{-} \mathrm{S}^{+}$state also shows indications of transitioning from a negative market to a positive market, with strong returns in both winner and loser portfolios of the SMB and HML factors. The findings in this study have important implications for theorists and practitioners alike as the evidence shows that the $\mathrm{S}$ state combined with the $\mathrm{M}$ state has the ability to predict future returns for the three FF factors of RM-rf, SMB and HML.

Section 5.2 details the data and methodology; Section 5.3 presents the results of MS, M and S schemes for RM-rf, SMB, HML; Section 5.4 compares profits for these different states; Section 5.5 analyses SMB and HML effect on each other; Section 5.6 concludes the paper. 


\subsection{Data and methodology}

The data for the study covers the sample period June 1926 to December 2013. The monthly returns of the Centre for Research into Security Prices (CRSP) value-weighted market index (denoted VW) constructed from all NYSE, AMEX, and NASDAQ stocks and the risk free rate (the one-month Treasury bill rate from Ibbotson Associates) were downloaded from Kenneth French's website. The monthly returns of the Fama and French market factor (RMrf), small minus big size factor (SMB), and high minus low value factor (HML) were downloaded from the same website ${ }^{4}$.

\subsubsection{Constructing States}

To determine the states of the MS classification scheme, I utilize the same methodology as utilized in chapter 4 . The $\mathrm{M}$ state two-state classification scheme uses a non-parametric method similar to that used by Cooper et al. (2004) and Asem and Tian (2010). Whereas Cooper et al. (2004) used a 36-month lagged market return to determine the market state, I follow Asem and Tian (2010) and employ a 12-month market lagged return. Specifically, in the two-state M scheme the market state for a given month is defined as positive (denoted $\mathrm{M}^{+}$) if the CRSP value-weighted index's return over the most-recent past 12 months is nonnegative, otherwise the market state for that month is defined as negative (denoted $\mathrm{M}^{-}$).

I can define two size states in a similar fashion. For the two size states, let $\mathrm{S}^{+}$denote the positive size state and $S^{-}$the negative size state. The size state for a given month is defined as

\footnotetext{
4 The Fama and French RM-Rf returns are the excess return on the market value-weight return of all CRSP firms incorporated in the US and listed on the NYSE, AMEX, or NASDAQ that have a CRSP share code of 10 or 11 at the beginning of month $t$, good shares and price data at the beginning of $t$, and good return data for $t$ minus the one-month Treasury bill rate (from Ibbotson Associates). The Fama-French SMB returns are the average returns on three small-capitalisation portfolios minus the average returns on three large-capitalisation portfolios. The Fama-French HML returns are the average returns on the two value portfolios minus the average returns on the two growth portfolios. By 'value' I mean high book-to-market equity firms, and by 'growth' I mean low book-to-market equity firms. I thank Ken French for providing the data used in my study.
} 
$\mathrm{S}^{+}\left(\mathrm{S}^{-}\right)$if the average monthly return of the SMB factor over the most-recent past 12 months is non-negative (negative). For example, $\mathrm{S}^{+}$means that small firms outperformed large firms in the market over the last 12 months.

This study extends the concept of market states to incorporate the performance of important components of the market. The resulting classification schemes employ four states rather than two. These four-state schemes are the result of combining the two market states with the two size states (creating the MS scheme). Consequently, the four states of the MS scheme are denoted as follows: $\mathrm{M}^{+} \mathrm{S}^{+}$(if market and size states are $\mathrm{M}^{+}$and $\mathrm{S}^{+}$, respectively), $\mathrm{M}^{+} \mathrm{S}^{-}$(if market and size states are $\mathrm{M}^{+}$and $\mathrm{S}^{-}$, respectively), $\mathrm{M}^{-} \mathrm{S}^{+}$(if market and size states are $\mathrm{M}^{-}$and $\mathrm{S}^{+}$, respectively), and $\mathrm{M}^{-} \mathrm{S}^{-}$(if market and size states are $\mathrm{M}^{-}$and $\mathrm{S}^{-}$).

The number of months and the percentages for each state in the M scheme, S scheme and MS scheme are listed in Table 5.1. Note that the number of months with positive $\mathrm{M}$ states $\left(\mathrm{M}^{+}\right)$is considerably greater than the number with negative $\mathrm{M}$ states $\left(\mathrm{M}^{-}\right)$. I also plot the number of DOWN months in each year from 1926 to 2013 for the lagged 12-month VW index in Figure 5.1. Specifically, the 12-month market definition produces 322 negative $\left(\mathbf{M}^{-}\right)$months compared to the total months of 1039 months ( $31 \%$ of the sample period). 
Table 5.1: Observations for States

\begin{tabular}{|c|c|c|c|c|c|}
\hline Scheme & $\mathrm{M}^{+}$ & & & $\mathrm{M}^{-}$ & \\
\hline \multirow[t]{2}{*}{$\mathrm{M}$} & 717 & & & 332 & Obs. \\
\hline & $69 \%$ & & & $31 \%$ & $\%$ \\
\hline \multirow{3}{*}{ S } & $\mathrm{S}^{+}$ & & & $\mathrm{S}^{-}$ & \\
\hline & 600 & & & 439 & Obs. \\
\hline & $57.70 \%$ & & & $42.30 \%$ & $\%$ \\
\hline \multirow{3}{*}{ MS } & $\mathrm{M}^{+} \mathrm{S}^{+}$ & $\mathrm{M}^{+} \mathrm{S}^{-}$ & $\mathrm{M}^{-} \mathrm{S}^{+}$ & $\mathrm{M}^{-} \mathrm{S}^{-}$ & \\
\hline & 475 & 295 & 125 & 144 & Obs. \\
\hline & $45.70 \%$ & $28.40 \%$ & $12.00 \%$ & $13.90 \%$ & $\%$ \\
\hline
\end{tabular}

Table 5.1 shows the number and percentage of observations in each state. $\mathrm{M}$ is denoted as the prior 12-month market return, $\mathrm{S}$ is denoted as the SMB factor cumulative average return over the past twelve months. The first column shows M, S and MS scheme, whilst the top row shows whether the $\mathrm{M}$ or $\mathrm{S}$ state is positive or negative, $\mathrm{M}^{+}$or $\mathrm{M}^{-}, \mathrm{S}^{+}$or $\mathrm{S}^{-}$with the second + or - sign showing whether the $\mathrm{MS}$ states are positive or negative. Time period is from 1927 to 2013.

Figure 5.1: Market State Down Months

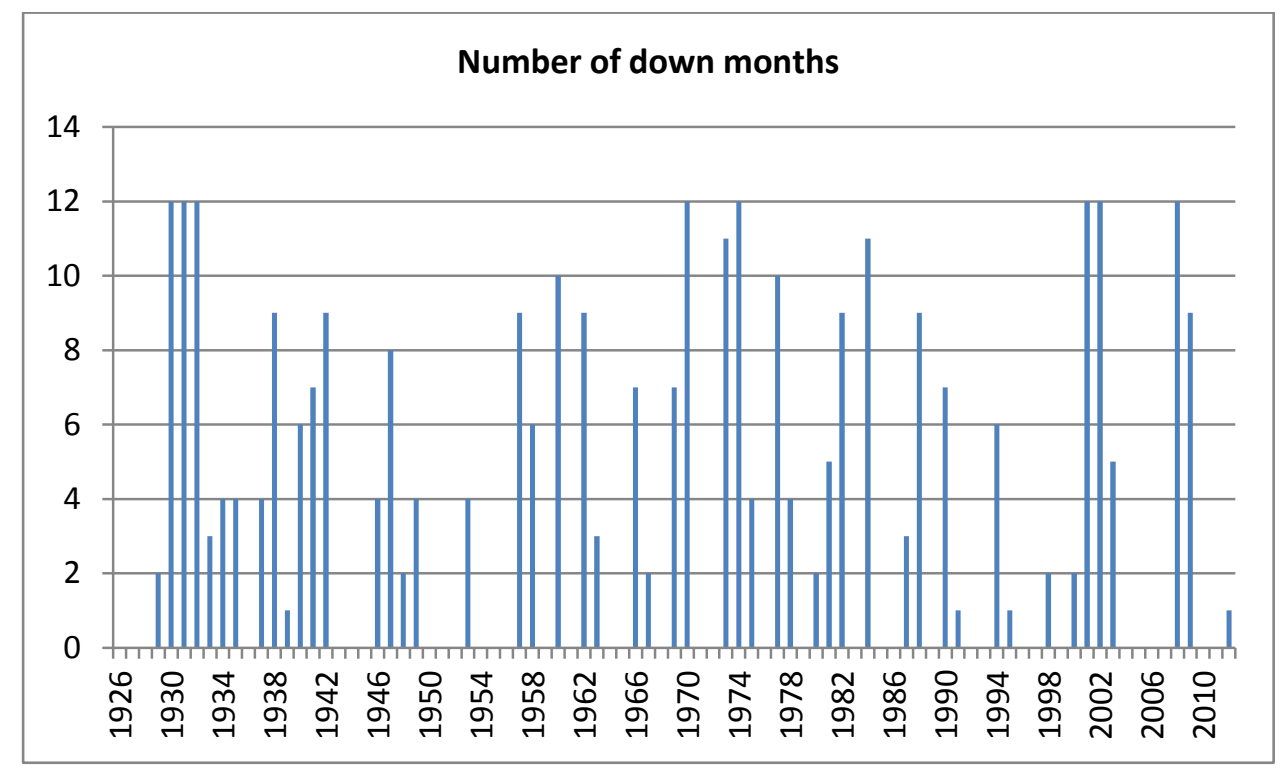

Figure 5.1. Number of one-year DOWN market states through time. The number of months within a given year for which the holding period return of the VW CRSP index over months $t-12$ to $t-1$ is negative during 1927 to 2013. 


\subsection{Results}

In this section, I examine the three factors' (RM-rf, SMB and HML) average returns following each state of the MS scheme. For discussion purposes, I will concentrate on the 12-month profit period, unless otherwise stated.

\subsubsection{MS scheme with the RM-rf factor}

Table 5.2 reports the market return minus the risk free rate (RM-rf) average returns in the six months, 12 months and 13 to 24 months following each of the MS scheme's four states. In the 12-month case, my result shows that RM-rf demonstrates strong and significant profitability following the two states with positive market returns $\left(\mathrm{M}^{+} \mathrm{S}^{+}\right.$and $\left.\mathrm{M}^{+} \mathrm{S}^{-}\right)$with levels similar to the overall results at the bottom of the table. However, it is what happens to RM-rf profitability following each of the states with negative market states $\left(\mathrm{M}^{-} \mathrm{S}^{+}\right.$and $\left.\mathrm{M}^{-} \mathrm{S}^{-}\right)$ that is of interest. Following the $\mathrm{M}^{-} \mathrm{S}^{+}$state, RM-rf earns the strongest significant return, with RM-rf averaging $1.45 \%$ ( $t$-stat 3.16 ) per month. Indeed, the result was nearly double the returns from the positive market returns $\left(\mathrm{M}^{+} \mathrm{S}^{+}\right.$and $\left.\mathrm{M}^{+} \mathrm{S}^{-}\right)$. In contrast, RM-rf earns insignificant positive returns in the 12 months following the $\mathrm{M}^{-} \mathrm{S}^{-}$state, of $0.09 \%$ ( $t$-stat 0.17$)$. Therefore, the MS scheme effectively splits the 12 months following a downmarket $\mathrm{M}^{-}$state into an insignificant positive result following $\mathrm{M}^{-} \mathrm{S}^{-}$and a highly significant positive result following $\mathrm{M}^{-} \mathrm{S}^{+}$.

The 6-month profit period has only significant profits when the lagged $\mathrm{M}$ state is positive. Nevertheless, the result for $\mathrm{M}^{-} \mathrm{S}^{+}$state shows a large profit of $0.87 \%$ per month ( $t$-stat 1.52$)$ which is insignificant (probably due to the paucity of observations in this state with only 125 
out of 1039 observations being classified $\mathrm{M}^{-} \mathrm{S}^{+}$). The lagged $\mathrm{M}^{-} \mathrm{S}^{-}$state shows $\mathrm{RM}-\mathrm{rf}$ with only low insignificant return of $0.25 \%$ per month $(t$-stat $=0.49)$. In the period from $t+13$ to $t$ + 24 months, RM-rf profits show a slight decrease in the $\mathrm{M}^{+} \mathrm{S}^{-}, \mathrm{M}^{-} \mathrm{S}^{+}$states and an improvement following the $\mathrm{M}^{-} \mathrm{S}^{-}$state when compared to the other profit periods.

Table 5.2: MS scheme with RM-rf Factor

\begin{tabular}{cccc}
\hline & $1-6 \mathrm{M}$ & $1-12 \mathrm{M}$ & $13-24 \mathrm{M}$ \\
\cline { 2 - 4 } States & & & \\
\hline $\mathrm{M}^{+} \mathrm{S}^{+}$ & 0.53 & 0.48 & 0.48 \\
& $(3.32)$ & $(3.15)$ & $(2.58)$ \\
$\mathrm{M}^{+} \mathrm{S}^{-}$ & 0.86 & 0.75 & 0.53 \\
& $(4.72)$ & $(3.89)$ & $(2.29)$ \\
$\mathrm{M}^{-} \mathrm{S}^{+}$ & 0.87 & 1.45 & 1.15 \\
& $(1.52)$ & $(3.16)$ & $(3.71)$ \\
$\mathrm{M}^{-} \mathrm{S}^{-}$ & 0.25 & 0.09 & 0.64 \\
& $(0.49)$ & $(0.17)$ & $(1.54)$ \\
\hline & & & \\
& 0.64 & 0.63 & 0.62 \\
Overall & $(4.37)$ & $(4.21)$ & $(4.08)$ \\
\hline
\end{tabular}

Table 5.2 shows the mean monthly RM-rf returns defined by the MS scheme four states. M is denoted as the prior twelve month market return, and is defined as non-negative (negative) by the returns of the VW CRSP index over the 12 months prior to the beginning of the strategy's profit period. S is denoted as the SMB factor cumulative average return over the past twelve months, RM-rf and SMB monthly data downloaded from Ken French's website, and the previous SMB 12-month cumulative return define the POSITIVE (NEGATIVE) S state. The returns of the RM-rf returns are averaged across three periods: month's $t+1$ to $t+6$, month's $t+1$ to $t+12$, months $t+13$ to $t+$ 24. The first column in Table 5.4 show the four MS states, $\mathrm{M}^{+} \mathrm{S}^{+}$(positive $\mathrm{M}$ and $\mathrm{S}$ state), $\mathrm{M}^{+} \mathrm{S}^{-}$(positive $\mathrm{M}$ and negative $\mathrm{S}$ state), $\mathrm{M}^{-} \mathrm{S}^{+}$ (negative $\mathrm{M}$ and positive $\mathrm{S}$ state), $\mathrm{M}^{-} \mathrm{S}^{-}$(negative $\mathrm{M}$ and $\mathrm{S}$ state). The period is from July 1927 to December 2013. The Overall row shows the average RM-rf returns across all states, the $t$-statistics are in parentheses. 
Table 5.3: MS scheme with the RM-rf Factor-Difference between States

\begin{tabular}{|c|c|c|c|c|}
\hline & State & $\frac{\mathrm{M}^{+} \mathrm{S}^{-}}{\mathrm{Rm}-\mathrm{rf}}$ & $\frac{\mathrm{M}^{-} \mathrm{S}^{+}}{\mathrm{Rm}-\mathrm{rf}}$ & $\frac{\mathrm{M}^{-} \mathrm{S}^{-}}{\mathrm{Rm}-\mathrm{rf}}$ \\
\hline \multirow[t]{3}{*}{$1-6 \mathrm{M}$} & $\mathrm{M}^{+} \mathrm{S}^{+}$ & $\begin{array}{c}-0.33 \\
(-1.35)\end{array}$ & $\begin{array}{c}-0.34 \\
(-0.57)\end{array}$ & $\begin{array}{c}0.28 \\
(0.54)\end{array}$ \\
\hline & $\mathrm{M}^{+} \mathrm{S}^{-}$ & & $\begin{array}{c}-0.01 \\
(-0.01)\end{array}$ & $\begin{array}{c}0.61 \\
(1.15)\end{array}$ \\
\hline & $\mathrm{M}^{-} \mathrm{S}^{+}$ & & & $\begin{array}{c}0.62 \\
(0.82) \\
\end{array}$ \\
\hline \multirow[t]{3}{*}{$1-12 \mathrm{M}$} & $\mathrm{M}^{+} \mathrm{S}^{+}$ & $\begin{array}{c}-0.27 \\
(-1.11)\end{array}$ & $\begin{array}{c}-0.97 * * \\
(-2.01)\end{array}$ & $\begin{array}{c}0.39 \\
(0.71)\end{array}$ \\
\hline & $\mathrm{M}^{+} \mathrm{S}^{-}$ & & $\begin{array}{c}-0.70 \\
(-1.41)\end{array}$ & $\begin{array}{c}0.66 \\
(1.19)\end{array}$ \\
\hline & $\mathrm{M}^{-} \mathrm{S}^{+}$ & & & $\begin{array}{c}1.36^{*} \\
(1.96)\end{array}$ \\
\hline \multirow[t]{3}{*}{$13-24 \mathrm{M}$} & $\mathrm{M}^{+} \mathrm{S}^{+}$ & $\begin{array}{c}-0.05 \\
(-0.17)\end{array}$ & $\begin{array}{l}-0.67^{*} \\
(-1.85)\end{array}$ & $\begin{array}{c}-0.15 \\
(-0.34)\end{array}$ \\
\hline & $\mathrm{M}^{+} \mathrm{S}^{-}$ & & $\begin{array}{c}-0.62 \\
(-1.60)\end{array}$ & $\begin{array}{c}-0.10 \\
(-0.22)\end{array}$ \\
\hline & $\mathrm{M}^{-} \mathrm{S}^{+}$ & & & $\begin{array}{c}0.52 \\
(1.00)\end{array}$ \\
\hline
\end{tabular}

Table 5.3 reports the differences in RM-rf returns between each state from Table 5.2. The results are differences in portfolio returns: the portfolio returns in the M state from the State A column minus the corresponding portfolio's returns in the M state from the row State B. M is denoted as the prior twelve month market return, and is defined as non-negative (negative) by the returns of the VW CRSP index over the 12 months prior to the beginning of the strategy's profit period. S is denoted as the SMB factor cumulative average return over the past twelve months, RM-rf and SMB monthly data downloaded from Ken French's website and the previous SMB 12-month cumulative return define the POSITIVE (NEGATIVE) S state. The column (row) in State A (B) show the different MS scheme states, (described in Table 5.2). The period is from July 1927 to December 2013. The $t$-statistics in parentheses and the monthly mean differences are defined by one or two asterisk, showing $10 \%$ or $5 \%$ significance respectively.

Table 5.3 displays the differences in the returns of each portfolio following different MS states. As expected, the profits from the state $\mathrm{M}^{-} \mathrm{S}^{+}$are significantly different to the profits of the $\mathrm{M}^{-} \mathrm{S}^{-}$state $(1.36 \%$ with $t$-stat 1.96$)$, as well as $\mathrm{M}^{+} \mathrm{S}^{+}$state $(-0.97 \%$ with $t$-stat -2.01$)$, with no significant difference to the $\mathrm{M}^{+} \mathrm{S}^{-}$state $(-0.70 \%$ with $t$-stat -1.41$)$. Whilst understandably, there are no significant differences between the other states. To try to understand these results, I break down the MS Scheme down to its individual components; an M scheme and an S scheme, and examine the average returns of the RM-rf factor separately through these two 
schemes. All data and the methodology used to create the two schemes is the same as described for the MS scheme.

Table 5.4 reports the RM-rf average returns the 6,12 and 12 to 24 month periods following each of the $\mathrm{M}$ and $\mathrm{S}$ scheme's two states. For the 12-month period, the result from the $\mathrm{M}$ scheme show that RM-rf average return is positive and significant for the $\mathrm{M}^{+}$state showing $0.58 \%$ per month ( $t$-stat 4.56$)$, and is positive and weakly significant for the $\mathrm{M}^{-}$state $(0.72 \%$ per month with $t$-stat 1.78). There are no significant differences between the average returns in the two states. Comparing the average returns in the $\mathrm{M}$ states to the overall average returns, I can see that they are quite similar. This infers that the $M$ states alone have no power to predict future excess market returns. This is consistent with past studies which show that annual market returns are not serially correlated at order one, meaning that last year's market return is of little value in predicting this year's market return. Similarly, while the S scheme shows that RM-rf returns are significantly positive for both $\mathrm{S}$ states $(0.97 \%$ per month with $t$-stat 6.02 for the $\mathrm{S}^{+}$state, and $0.83 \%$ per month with $t$-stat 3.42 for the $\mathrm{S}^{-}$state), there are no significant differences between them. Thus, the $\mathrm{S}$ states alone have no power to predict the market excess return, RM-rf. 
Table 5.4: 2-State M and S Scheme with RM-rf Factor

\begin{tabular}{lccc}
\hline & $1-6 \mathrm{~m}$ & $1-12 \mathrm{~m}$ & $13-24 \mathrm{~m}$ \\
States & RM-rf & RM-rf & RM-rf \\
\hline $\mathrm{M}^{+}$ & 0.66 & 0.58 & 0.50 \\
& $(5.24)$ & $(4.56)$ & $(3.09)$ \\
$\mathrm{M}^{-}$ & 0.54 & 0.72 & 0.88 \\
& $(1.30)$ & $(1.78)$ & $(2.99)$ \\
& & & \\
All & 0.64 & 0.63 & 0.62 \\
& $(4.37)$ & $(4.21)$ & $(4.08)$ \\
Difference & 0.12 & -0.14 & -0.38 \\
& $(0.28)$ & $(-0.33)$ & $(-1.12)$ \\
\hline $\mathrm{S}^{+}$ & 0.88 & 0.97 & 0.92 \\
& $(4.97)$ & $(6.02)$ & $(5.46)$ \\
$\mathrm{S}^{-}$ & 0.96 & 0.83 & 0.85 \\
& $(4.60)$ & $(3.42)$ & $(3.76)$ \\
& & & \\
All & 0.93 & 0.92 & 0.91 \\
& $(6.40)$ & $(6.21)$ & $(6.07)$ \\
Difference & -0.08 & 0.14 & 0.07 \\
& $(-0.28)$ & $(0.47)$ & $(0.23)$ \\
\hline
\end{tabular}

Table 5.4 shows the mean monthly returns for RM-rf, formed through the M and S scheme's two states. M is denoted as the prior twelve month market return, and is defined as non-negative (negative) by the returns of the VW CRSP index over the 12 months prior to the beginning of the strategy's profit period. S is denoted as the SMB factor cumulative average return over the past twelve months, RM-rf and SMB monthly data downloaded from Ken French's website and the previous SMB 12-month cumulative return define the POSITIVE (NEGATIVE) $\mathrm{S}$ state. The profits results are averaged across three periods: $t+1$ to $t+6, t+1$ to $t+12, t+13$ to $t+24$ months. The first column in Table 5.4 show the different $\mathrm{M}$ and $\mathrm{S}$ states, $\mathrm{M}^{+}, \mathrm{M}^{-}, \mathrm{S}^{+}, \mathrm{S}^{-}$. The period is from July 1927 to December 2013 . The Overall row shows the average profits across all states. The difference rows report the differences in results for RM-rf returns between the positive and negative $\mathrm{M}$ and $\mathrm{S}$ states, by deducting the RM-rf returns in state $\mathrm{M}^{-}\left(\mathrm{S}^{-}\right)$from the returns in $\mathrm{M}^{+}\left(\mathrm{S}^{+}\right)$, the $t$-statistics are in parentheses.

In sum, neither the $\mathrm{M}$ or $\mathrm{S}$ scheme states are able to show significant differences for the future returns of RM-rf, it is only the combination of the two schemes which show significant differences, and only then with the combination of the negative market states of $\mathrm{M}^{-} \mathrm{S}^{+}$and $\mathrm{M}^{-}$ $\mathrm{S}^{-}$. The results from Table 5.4 show that on average returns, the $\mathrm{M}$ state predicts a transition from the previous negative $\mathrm{M}^{-}$state to a future profit for RM-rf and also shows a large part of the average returns from the $\mathrm{M}^{-} \mathrm{S}^{+}$state in Table 5.2 is predicting a transition from a negative market to a positive market. 
Table 5.5: Proportion of positive/negative returns

\begin{tabular}{ccc}
\hline & $\mathrm{M}+$ & $\mathrm{M}-$ \\
\hline & & \\
States & $1-12 \mathrm{M}$ & $1-12 \mathrm{M}$ \\
\hline $\mathrm{M}^{+} \mathrm{S}^{+}$ & $73.39 \%$ & $26.61 \%$ \\
$\mathrm{M}^{+} \mathrm{S}^{-}$ & $79.45 \%$ & $20.55 \%$ \\
$\mathrm{M}^{-} \mathrm{S}^{+}$ & $73.60 \%$ & $26.40 \%$ \\
$\mathrm{M}^{-} \mathrm{S}^{-}$ & $63.89 \%$ & $36.11 \%$ \\
\hline
\end{tabular}

Table 5.5 shows the proportion of months that have a positive or negative result in the different states for the next 12 months. In the top row, the M+ (M-) define the market return for the next 12 months. In the left column, M is denoted as the prior twelve month market return, and is defined as non-negative (negative) by the returns of the VW CRSP index over the 12 months prior to the beginning of the strategy's profit period. S is denoted as the SMB factor cumulative average return over the past twelve months, RM-rf and SMB monthly data downloaded from Ken French's website, and the previous SMB 12-month cumulative return define the POSITIVE (NEGATIVE) S state. The first column in Table 5.4 show the four MS states, $\mathrm{M}+\mathrm{S}+$ (positive $\mathrm{M}$ and $\mathrm{S}$ state), $\mathrm{M}+\mathrm{S}$-(positive $\mathrm{M}$ and negative $\mathrm{S}$ state), M- S+ (negative $\mathrm{M}$ and positive S state), M- S- (negative M and S state). The period is from July 1927 to December 2013

The results from Table 5.4 show that on average returns, the $\mathrm{M}$ state predicts a transition

from the previous negative M- state to a future profit for RM-rf and also shows a large part of the average returns from the $\mathrm{M}^{-} \mathrm{S}^{+}$state in Table 5.2 is predicting a transition from a negative market to a positive market. Table 5.5 supports the transition theory as the $\mathrm{M}^{-} \mathrm{S}^{+}$state shows positive returns for RM-rf in the next 12 months for $73.60 \%$ of the period, with $26.40 \%$ showing losses, compared to the other negative market state $\mathrm{M}^{-} \mathrm{S}^{-}$, which shows a lower proportion of positive returns of $63.89 \%$ of the period, with $36.11 \%$ showing losses. Also notable, the $\mathrm{M}^{-} \mathrm{S}^{+}$state has similar proportions to the $\mathrm{M}^{+} \mathrm{S}^{+}$state, positive proportion $\mathrm{M}^{+} \mathrm{S}^{+}$ (73.39\%) vs $\mathrm{M}^{+} \mathrm{S}^{+}(73.60 \%)$. Both comparisons supporting the fact that the $\mathrm{M}^{-} \mathrm{S}^{+}$state is transitioning from a negative to a positive market state.

Future research into this anomaly will be considered. These results are very relevant, as they show practitioners and academics alike that the MS scheme can predict whether the excess market return following down markets is likely to be either very good or poor.

\subsubsection{MS scheme with the SMB factor}


Next, I investigate whether any of the MS states provide information about the future returns of the size factor, SMB. Table 5.6 reports the SMB average returns over the 6 months, 12 months, and the 13 to 24 months following each of the MS scheme's four states.

In the 12-month case, my result shows that SMB returns demonstrate strong and significant profitability following each of the positive $\mathrm{S}$ states $\left(\mathrm{M}^{+} \mathrm{S}^{+}\right.$and $\left.\mathrm{M}^{-} \mathrm{S}^{+}\right)$. The $\mathrm{M}^{-} \mathrm{S}^{+}$state shows SMB earns a very strong average return of $1.12 \%$ per month ( $t$-stat 4.88 ), and the $\mathrm{M}^{+} \mathrm{S}^{+}$ shows SMB earning a $0.26 \%$ ( $t$-stat 2.20$)$ per month. In contrast, SMB earns insignificant negative returns in the 12 months following the $\mathrm{M}^{+} \mathrm{S}^{-}$state $-0.14 \%$ per month $(t$-stat -1.30$)$, whilst the $\mathrm{M}^{-} \mathrm{S}^{-}$state produces a weakly significant profit of $0.21 \%$ per month ( $t$-stat 1.74$)$. Therefore, the MS scheme shows that the SMB profitability is affected by both the size and market state, with particular emphasis on the $\mathrm{M}^{-} \mathrm{S}^{+}$state.

SMB's strong positive returns following the $\mathrm{M}^{-} \mathrm{S}^{+}$state means that the small firm portfolio returns exceeded the large firm portfolio returns by over $1 \%$ per month For example, in the 12-month case the small firm portfolio earns a remarkable $3.06 \%$ per month ( $t$-stat 4.19$)$, whereas the large firm portfolio earns $1.94 \%$ per month ( $t$-stat 3.47). It is important to note that the loser portfolio returns following this state are far stronger than those achieved following all other states. As noted in Chapter 4 and can also be observed in Table 5.2, the market as a whole earns large average returns in the 12 months following $\mathrm{M}^{-} \mathrm{S}^{+}$state months. Thus the remarkable average performance of $3.06 \%$ per month for small firms following $\mathrm{M}^{-} \mathrm{S}^{+}$state months is a combination of the market tending to rebound at the same time as small firms outperform large firms (and the market). In all cases, the small firm portfolio's average return following the $\mathrm{M}^{-} \mathrm{S}^{+}$state is far larger than its average return following the other 
states. In addition, the pattern of SMB returns across the three time periods are quite similar, with no strong evidence of a reversal in the $t+13$ to $t+24$ month period (except for a loss of significance in the second year following $\mathrm{M}^{+} \mathrm{S}^{+}$).

Table 5.7 reports the differences in the returns of each portfolio in different MS states (State A return - State B return). As expected, the return following the state $\mathrm{M}^{-} \mathrm{S}^{+}$is significantly different from the returns following all other states. In the 12-month case, the differences per month with $\mathrm{M}^{+} \mathrm{S}^{+}, \mathrm{M}^{+} \mathrm{S}^{-}$, and $\mathrm{M}^{-} \mathrm{S}^{-}$are $-0.86 \%$ ( $t$-stat -3.34$),-1.26 \%$ ( $t$-stat -4.96$)$, and $0.91 \%$ ( $t$-stat 3.54), respectively. In addition, the SMB return following the $\mathrm{M}^{+} \mathrm{S}^{-}$state is significantly different to the return following the $\mathrm{M}^{+} \mathrm{S}^{+}$state by of $0.40 \%$ per month $(t$-stat 2.49), while the return following the $\mathrm{M}^{-} \mathrm{S}^{-}$state is significantly different to the return following the $\mathrm{M}^{+} \mathrm{S}^{-}$state by $-0.35 \%$ per month ( $t$-stat -2.16$)$.

I next examine the SMB returns using the individual components of the MS scheme, the M and S schemes. All data and methodology used to create the two schemes are the same as described in the previous section. Table 5.8 reports SMB factor average monthly returns derived from the $\mathrm{M}$ and $\mathrm{S}$ schemes separately for the three profit periods. In the 12-month case, the M scheme shows the SMB factor produces a significant return only following the negative $\mathrm{M}^{-}$state of $0.63 \%$ per month ( $t$-stat 4.00$)$. The latter result when subtracted from the insignificant SMB return following the $\mathrm{M}^{+}$state of $0.10 \%$ per month ( $t$-stat 1.06$)$ produces a significant difference of $-0.53 \%$ per month $(t$-stat -2.84$)$. This result is robust across the other periods in the sense that they also have similar significant differences. The $\mathrm{S}$ scheme results in the second part of Table 5.8 show that the SMB factor is only profitable following a positive $S$ state. Specifically, the return following the $S^{+}$and $S^{-}$states are $0.44 \%$ per month ( $t$-stat 3.67$)$ and $-0.03 \%$ per month ( $t$-stat -0.31$)$, respectively. These returns have a 
significant difference of $0.47 \%$ per month ( $t$-stat 3.13). A similar significant difference is also observable in the six-month period.

Table 5.8 results help explain the findings in Table 5.5. With the lagged negative $\mathrm{M}^{-}$state producing strong SMB profits, and the lagged positive $\mathrm{S}^{+}$state predicting strong SMB profits, the combination of these two states into the $\mathrm{M}^{-} \mathrm{S}^{+}$state results in very large SMB returns. Similarly, the negative SMB result following the lagged $S^{-}$state and the very weak SMB result following the lagged $\mathrm{M}^{+}$state would also help explain the negative SMB return following the combination $\mathrm{M}^{-} \mathrm{S}^{+}$state. Overall, the $\mathrm{M}$ and $\mathrm{S}$ schemes help explain the results of the MS scheme.

As to why the $\mathrm{M}^{-} \mathrm{S}^{+}$state predicts a positive return for SMB in the following 12 months, I can speculate that in a negative market if the SMB is positive then this may indicate buyers have re-entered the market searching for bargains, and small size will continue to be sought after in the next time period. In Chapter 4 as part of an explanation in relation to momentum results, I raised the possibility that small caps tend to suffer severe losses early in a bear market whereas late in a bear market (during the so-called 'capitulation' phase) large firms tend to suffer worse returns than small firms because the prices of small firms have already fallen much more than the prices of large firms. Thus small firms outperforming large firms during poor market conditions (the $\mathrm{M}^{-} \mathrm{S}^{+}$state) may be a signal that a bear market is coming to an end. As a result, the 12 months following the $\mathrm{M}^{-} \mathrm{S}^{+}$state is a period with increased likelihood of a market rebound and such times tend to be particularly profitable for small firm portfolios.

Table 5.6: MS scheme with SMB Factor 


\begin{tabular}{cccccccccc}
\hline & & $1-6 \mathrm{M}$ & & \multicolumn{3}{c}{$1-12 \mathrm{M}$} & \multicolumn{3}{c}{$13-24 \mathrm{M}$} \\
States & $\mathrm{S}$ & $\mathrm{B}$ & $\mathrm{SMB}$ & $\mathrm{S}$ & $\mathrm{B}$ & $\mathrm{SMB}$ & $\mathrm{S}$ & $\mathrm{B}$ & $\mathrm{SMB}$ \\
\hline $\mathrm{M}^{+} \mathrm{S}^{+}$ & 1.26 & 0.92 & 0.34 & 1.14 & 0.88 & 0.26 & 1.07 & 0.88 & 0.19 \\
& $(5.44)$ & $(5.65)$ & $(3.11)$ & $(5.45)$ & $(5.98)$ & $(2.20)$ & $(4.09)$ & $(4.87)$ & $(1.51)$ \\
$\mathrm{M}^{+} \mathrm{S}^{-}$ & 0.98 & 1.21 & -0.23 & 0.94 & 1.08 & -0.14 & 0.87 & 0.90 & -0.03 \\
& $(3.93)$ & $(6.89)$ & $(-1.80)$ & $(4.01)$ & $(5.68)$ & $(-1.30)$ & $(3.63)$ & $(3.79)$ & $(-0.24)$ \\
$\mathrm{M}^{-} \mathrm{S}^{+}$ & 2.32 & 1.32 & 1.00 & 3.06 & 1.94 & 1.12 & 2.40 & 1.48 & 0.92 \\
& $(2.65)$ & $(1.91)$ & $(3.50)$ & $(4.19)$ & $(3.47)$ & $(4.88)$ & $(4.12)$ & $(3.79)$ & $(4.02)$ \\
$\mathrm{M}^{-} \mathrm{S}^{-}$ & 0.87 & 0.61 & 0.26 & 0.61 & 0.40 & 0.21 & 1.42 & 1.05 & 0.38 \\
& $(1.42)$ & $(1.17)$ & $(1.56)$ & $(1.00)$ & $(0.70)$ & $(1.74)$ & $(2.77)$ & $(2.18)$ & $(2.59)$ \\
\hline & 1.26 & 1.02 & 0.24 & 1.25 & 1.01 & 0.24 & 1.24 & 1.00 & 0.24 \\
Overall & $(6.17)$ & $(6.52)$ & $(2.77)$ & $(6.17)$ & $(6.38)$ & $(2.60)$ & $(6.05)$ & $(6.25)$ & $(2.60)$ \\
\hline
\end{tabular}

Table 5.6 shows the mean monthly Small minus Big (SMB) returns defined by the MS schemes four states. M is denoted as the prior twelve month market return, and is defined as non-negative (negative) by the returns of the VW CRSP index over the 12 months prior to the beginning of the strategy's profit period. S is denoted as the SMB factor cumulative average return over the past twelve months, and SMB monthly data is downloaded from Ken French's website, and the previous SMB 12-month cumulative return define the POSITIVE (NEGATIVE) $\mathrm{S}$ state The SMB returns of portfolios (winner minus loser deciles) are averaged across three time periods: months $t+1$ to $t+$ 6 , months $t+1$ to $t+12$, and months $t+13$ to $t+24$. The first column in Table 5.3 show the four MS states, (described in Table 5.2). The period is from July 1927 to December 2013. The Overall row shows the average SMB returns across all states. The $t$-statistics are in parentheses, and each section shows the Small (S), Big (B), and Small minus Big (SMB) portfolio results. 
Table 5.7: MS scheme with SMB Factor-Differences between States

\begin{tabular}{|c|c|c|c|c|c|c|c|c|c|c|}
\hline & \multirow[b]{2}{*}{ State } & \multicolumn{3}{|c|}{$\underline{\mathrm{M}^{+} \mathrm{S}^{-}}$} & \multicolumn{3}{|c|}{$\underline{\mathrm{M}}^{-} \mathrm{S}^{+}$} & \multicolumn{3}{|c|}{$\underline{M}^{-} S^{-}$} \\
\hline & & $S$ & $\mathrm{~B}$ & SMB & $S$ & B & SMB & $S$ & B & SMB \\
\hline \multirow[t]{3}{*}{$1-6 \mathrm{M}$} & $\mathrm{M}^{+} \mathrm{S}^{+}$ & $\begin{array}{c}0.28 \\
(0.82)\end{array}$ & $\begin{array}{c}-0.29 \\
(-1.21)\end{array}$ & $\begin{array}{c}0.57 * * \\
(3.38)\end{array}$ & $\begin{array}{l}-1.06 \\
(-1.17)\end{array}$ & $\begin{array}{c}-0.40 \\
(-0.56)\end{array}$ & $\begin{array}{c}-0.66 * * \\
(-2.16)\end{array}$ & $\begin{array}{c}0.39 \\
(0.60)\end{array}$ & $\begin{array}{c}0.31 \\
(0.57)\end{array}$ & $\begin{array}{c}0.08 \\
(0.41)\end{array}$ \\
\hline & $\mathrm{M}^{+} \mathrm{S}^{-}$ & & & & $\begin{array}{l}-1.34 \\
(-1.47)\end{array}$ & $\begin{array}{c}-0.11 \\
(-0.15)\end{array}$ & $\begin{array}{c}-1.23 * * \\
(-3.93)\end{array}$ & $\begin{array}{c}0.11 \\
(0.17)\end{array}$ & $\begin{array}{c}0.60 \\
(1.09)\end{array}$ & $\begin{array}{c}-0.49 * * \\
(-2.33)\end{array}$ \\
\hline & $\mathrm{M}^{-} \mathrm{S}^{+}$ & & & & & & & $\begin{array}{c}1.45 \\
(1.36) \\
\end{array}$ & $\begin{array}{c}0.71 \\
(0.82) \\
\end{array}$ & $\begin{array}{c}0.74 * * \\
(2.25)\end{array}$ \\
\hline \multirow[t]{3}{*}{$1-12 \mathrm{M}$} & $\mathrm{M}^{+} \mathrm{S}^{+}$ & $\begin{array}{c}0.20 \\
(0.64)\end{array}$ & $\begin{array}{c}-0.20 \\
(-0.83)\end{array}$ & $\begin{array}{l}0.40 * * \\
(2.49)\end{array}$ & $\begin{array}{l}-1.92 * * \\
(-2.53)\end{array}$ & $\begin{array}{l}-1.06^{*} \\
(-1.83)\end{array}$ & $\begin{array}{c}-0.86 * * \\
(-3.34)\end{array}$ & $\begin{array}{c}0.53 \\
(0.84)\end{array}$ & $\begin{array}{c}0.48 \\
(0.81)\end{array}$ & $\begin{array}{c}0.05 \\
(0.31)\end{array}$ \\
\hline & $\mathrm{M}^{+} \mathrm{S}^{-}$ & & & & $\begin{array}{c}-2.12^{* *} \\
(-2.76)\end{array}$ & $\begin{array}{c}-0.86 \\
(-1.45)\end{array}$ & $\begin{array}{c}-1.26 * * \\
(-4.96)\end{array}$ & $\begin{array}{c}0.33 \\
(0.52)\end{array}$ & $\begin{array}{c}0.68 \\
(1.13)\end{array}$ & $\begin{array}{c}-0.35^{* *} \\
(-2.16)\end{array}$ \\
\hline & $\mathrm{M}^{-} \mathrm{S}^{+}$ & & & & & & & $\begin{array}{c}2.45^{* * *} \\
(2.59) \\
\end{array}$ & $\begin{array}{l}1.54^{*} \\
(1.92) \\
\end{array}$ & $\begin{array}{l}0.91^{* *} \\
(3.54)\end{array}$ \\
\hline \multirow[t]{3}{*}{$13-24 \mathrm{M}$} & $\mathrm{M}^{+} \mathrm{S}^{+}$ & $\begin{array}{c}0.21 \\
(0.58)\end{array}$ & $\begin{array}{c}-0.01 \\
(-0.05)\end{array}$ & $\begin{array}{c}0.22 \\
(1.22)\end{array}$ & $\begin{array}{l}-1.32 * * \\
(-2.07)\end{array}$ & $\begin{array}{c}-0.59 \\
(-1.38)\end{array}$ & $\begin{array}{c}-0.73 * * \\
(-2.80)\end{array}$ & $\begin{array}{c}-0.35 \\
(-0.60)\end{array}$ & $\begin{array}{c}-0.16 \\
(-0.31)\end{array}$ & $\begin{array}{c}-0.19 \\
(-0.96)\end{array}$ \\
\hline & $\mathrm{M}^{+} \mathrm{S}^{-}$ & & & & $\begin{array}{l}-2.12 * * \\
(-2.76)\end{array}$ & $\begin{array}{c}-0.86 \\
(-1.45)\end{array}$ & $\begin{array}{c}-1.26 * * \\
(-4.96)\end{array}$ & $\begin{array}{c}-0.55 \\
(-0.98)\end{array}$ & $\begin{array}{l}-0.15 \\
(-0.27)\end{array}$ & $\begin{array}{c}-0.41 * * \\
(-2.08)\end{array}$ \\
\hline & $\mathrm{M}^{-} \mathrm{S}^{+}$ & & & & & & & $\begin{array}{c}0.98 \\
(1.26)\end{array}$ & $\begin{array}{c}0.43 \\
(0.70)\end{array}$ & $\begin{array}{c}0.55^{* *} \\
(2.01)\end{array}$ \\
\hline
\end{tabular}

corresponding SMB portfolio's returns in the M state from the row State B. M is denoted as the prior twelve month market return, and is defined as non-negative (negative) by the returns of the VW CRSP index over the 12 months prior to the beginning of the strategy's profit period. S is denoted as the SMB factor cumulative average return over the past twelve months, and SMB monthly data is downloaded from Ken French's website, and the previous SMB 12-month cumulative return define the POSITIVE (NEGATIVE) S state. The SMB returns of the portfolios (winner minus loser deciles) are averaged across three periods: months $t+1$ to $t+6$, months $t+1$ to $t+12$, and months $t+13$ to $t+24$. The column (row) in State A (B) show the different MS scheme states (described in Table 5.2). The period is from July 1927 to December 2013. The $t$-statistics is in parentheses, and SMB average monthly mean differences are defined by one or two asterisk, showing $10 \%$ or $5 \%$ significance respectively. 
Table 5.8: 2-State M and S Scheme with SMB Factor

\begin{tabular}{lccccccccc}
\hline & & & $1-6 \mathrm{~m}$ & & \multicolumn{3}{c}{$1-12 \mathrm{~m}$} & & \\
States & Small & Big & SMB & Small & Big & SMB & Small & Big & SMB \\
\hline $\mathrm{M}^{+}$ & 1.15 & 1.03 & 0.12 & 1.06 & 0.96 & 0.10 & 1.00 & 0.89 & 0.11 \\
& $(6.43)$ & $(8.22)$ & $(1.27)$ & $(6.31)$ & $(7.71)$ & $(1.06)$ & $(4.94)$ & $(5.57)$ & $(1.05)$ \\
$\mathrm{M}^{-}$ & 1.54 & 0.94 & 0.60 & 1.75 & 1.12 & 0.63 & 1.88 & 1.25 & 0.63 \\
& $(2.72)$ & $(2.03)$ & $(3.49)$ & $(3.16)$ & $(2.43)$ & $(4.00)$ & $(4.13)$ & $(3.55)$ & $(3.93)$ \\
& & & & & & & & & \\
All & 1.26 & 1.02 & 0.24 & 1.25 & 1.01 & 0.24 & 1.24 & 1.00 & 0.24 \\
& $(6.17)$ & $(6.52)$ & $(2.77)$ & $(6.17)$ & $(6.38)$ & $(2.60)$ & $(6.05)$ & $(6.25)$ & $(2.60)$ \\
Difference & -0.39 & 0.09 & -0.48 & -0.68 & -0.16 & -0.53 & -0.88 & -0.36 & -0.53 \\
& $(-0.65)$ & $(0.19)$ & $(-2.45)$ & $(-1.18)$ & $(-0.33)$ & $(-2.84)$ & $(-1.77)$ & $(-0.92)$ & $(-2.77)$ \\
\hline $\mathrm{S}^{+}$ & 1.48 & 1.00 & 0.48 & 1.55 & 1.11 & 0.44 & 1.36 & 1.01 & 0.35 \\
& $(5.48)$ & $(5.02)$ & $(4.27)$ & $(6.10)$ & $(6.21)$ & $(3.67)$ & $(5.15)$ & $(5.70)$ & $(2.83)$ \\
$\mathrm{S}^{-}$ & 0.94 & 1.01 & -0.07 & 0.83 & 0.86 & -0.03 & 1.05 & 0.95 & 0.10 \\
& $(3.55)$ & $(4.76)$ & $(-0.66)$ & $(3.00)$ & $(3.37)$ & $(-0.31)$ & $(4.17)$ & $(3.89)$ & $(0.99)$ \\
& & & & & & & & & \\
All & 1.26 & 1.02 & 0.24 & 1.25 & 1.01 & 0.24 & 1.24 & 1.00 & 0.24 \\
& $(6.17)$ & $(6.52)$ & $(2.77)$ & $(6.17)$ & $(6.38)$ & $(2.60)$ & $(6.05)$ & $(6.25)$ & $(2.60)$ \\
Difference & 0.54 & -0.01 & 0.55 & 0.72 & 0.25 & 0.47 & 0.30 & 0.06 & 0.24 \\
& $(1.42)$ & $(-0.03)$ & $(3.55)$ & $(1.91)$ & $(0.80)$ & $(3.13)$ & $(0.83)$ & $(0.21)$ & $(1.49)$ \\
\hline
\end{tabular}

Table 5.8 shows the mean monthly returns for SMB, formed through the M and S scheme's two states. M is denoted as the prior twelve month market return, and is defined as non-negative (negative) by the returns of the VW CRSP index over the 12 months prior to the beginning of the strategy's profit period. S is denoted as the SMB factor cumulative average return over the past twelve months, and SMB monthly data is downloaded from Ken French's website and the previous SMB 12-month cumulative return define the POSITIVE (NEGATIVE) $\mathrm{S}$ state. The profits results are averaged across three periods: $t+1$ to $t+6, t+1$ to $t+12, t+13$ to $t+24$ months. The first column in Table 5.4 show the different $\mathrm{M}$ and $\mathrm{S}$ states, $\mathrm{M}^{+}, \mathrm{M}^{-}, \mathrm{S}^{+}, \mathrm{S}$. The period is from July 1927 to December 2013 . The Overall row shows the average profits across all states. The difference rows report the differences in results for SMB, between the positive and negative $\mathrm{M}$ and $\mathrm{S}$ states, by deducting the returns of state $\mathrm{M}^{-}\left(\mathrm{S}^{-}\right)$from the returns in $\mathrm{M}^{+}\left(\mathrm{S}^{+}\right)$, the $t$-statistics are in parentheses.

\subsubsection{MS scheme with HML Factor}

Table 5.9 reports HML average returns following the MS scheme's four states over the three profit periods. The results show that HML is significantly profitable following a lagged positive $\mathrm{S}$ state, $\mathrm{M}^{+} \mathrm{S}^{+}$and $\mathrm{M}^{+} \mathrm{S}^{+}$, but $\mathrm{HML}$ is not significantly profitable following the lagged negative $\mathrm{S}$ states, $\mathrm{M}^{+} \mathrm{S}^{-}$and $\mathrm{M}^{-} \mathrm{S}^{-}$. In a somewhat similar result to the SMB returns, HML produces its strongest returns following the $\mathrm{M}^{-} \mathrm{S}^{+}$state across all profit periods. That is, the evidence shows that value firms significantly outperform growth firms in the 12 months following the $\mathrm{M}^{-} \mathrm{S}^{+}$state. For the 12 -month case, the $\mathrm{M}^{-} \mathrm{S}^{+}$state shows $\mathrm{HML}$ producing a 
strong return of $1.04 \%$ ( $t$-stat 3.37) per month, while the $\mathrm{M}^{+} \mathrm{S}^{+}$state earns $0.42 \%$ per month ( $t$-stat 3.05). Following the other two states with past small firm underperformance $\left(\mathrm{M}^{+} \mathrm{S}^{-}\right.$and $\left.\mathrm{M}^{-} \mathrm{S}^{-}\right), \mathrm{HML}$ has insignificant average returns of $0.15 \%$ per month ( $t$-stat 1.12$)$ and $0.31 \%$ per month (t-stat 1.42), respectively.

Table 5.9 also shows that both the high book-to-market $(\mathrm{H})$ and the low book-to-market $(\mathrm{L})$ portfolio returns following the $\mathrm{M}^{-} \mathrm{S}^{+}$state are far larger than the corresponding returns following the other states, with both portfolio returns at least $1 \%$ per month higher than the corresponding returns following the other states. For example, in the 12-month period following $\mathrm{M}^{-} \mathrm{S}^{+}$state the $\mathrm{H}$ portfolio's return is $3.07 \%$ per month $(t$-stat 4.03$)$ and the $\mathrm{L}$ portfolio's return is $2.03 \%$ per month ( $t$-stat 3.46$)$. These strong returns will be partly due to the tendency for the market to rebound strongly in the 12 months following the $\mathrm{M}^{-} \mathrm{S}^{+}$state, as was shown earlier in this chapter. The least effective state is the $\mathrm{M}^{+} \mathrm{S}^{-}$, with average HML returns of $0.15 \%$ per month ( $t$-stat 1.12$)$. Clearly HML shows strong returns following the $\mathrm{S}^{+}$ state, irrespective of whether $\mathrm{M}$ is $\mathrm{M}^{+}$or $\mathrm{M}^{-}$, while the two states with $\mathrm{S}^{-}$have insignificant HML returns. The HML returns across the three profit periods show a striking similarity following the $\mathrm{M}^{+} \mathrm{S}^{+}$state [with future significant average returns per month of $0.41 \%$ ( $t$-stat 3.07), $0.42 \%$ ( $t$-stat 3.05 ), and $0.42 \%$ ( $t$-stat 3.82 ) for the 1-6 month, $1-12$ month, and $13-24$ month periods, respectively]. These returns are very similar to the corresponding overall SMB monthly return premium.

Table 5.10 reports the differences in the HML portfolio returns between the MS scheme states. Notably, there is a significant difference between the HML returns following the $\mathrm{M}^{-} \mathrm{S}^{+}$ and $\mathrm{M}^{+} \mathrm{S}^{-}$states $(-0.89 \%$ per month with $t$-stat -2.69$)$, and weakly significant differences between the returns following the $\mathrm{M}^{-} \mathrm{S}^{-}$and $\mathrm{M}^{-} \mathrm{S}^{+}$states $(0.73 \%$ per month with $t$-stat 1.95$)$, 
and between the returns following the $\mathrm{M}^{-} \mathrm{S}^{+}$and $\mathrm{M}^{+} \mathrm{S}^{+}$states $(-0.62 \%$ with $t$-stat -1.85$)$. As in the previous sections, to help to understand these findings I break down the MS Scheme to the $\mathrm{M}$ and $\mathrm{S}$ scheme, and examine the returns of the HML factor separately through these two schemes. Table 5.11 reports the results. Each scheme shows the HML returns following each state, together with an overall return and difference in returns across the two states of each scheme. All data and methodology used to create the two schemes, is the same as described previously.

The M scheme shows HML with significant returns following both positive and negative $\mathrm{M}$ states, however, the negative M state produces larger HML returns compared to the positive $\mathrm{M}$ state. In the 12-month case, the $\mathrm{M}^{+}$and $\mathrm{M}^{-}$states show a return of $0.31 \%$ ( $t$-stat 3.02 ) and $0.65 \%$ ( $t$-stat 3.20$)$ per month respectively. However, this difference of $-0.33 \%$ per month is not significant ( $t$-stat -1.47$)$. The 6-month and 13 to 24 month cases produce correspondingly similar results.

The S scheme shows HML with a significant return following the positive $\mathrm{S}$ state, with the negative S state showing HML with an insignificant return (except in the 13-24 month case). In the 12-month case, HML returns following the $S^{+}$and $S^{-}$states are $0.55 \%$ per month $(t$-stat 4.06) and $0.20 \%$ per month ( $t$-stat 1.67$)$, respectively. This leads to a weakly significant difference of $0.35 \%$ per month ( $t$-stat 1.91$)$.

Table 5.11 results help to explain several finding in Table 5.9. With the negative $\mathrm{M}^{-}$state predicting strong HML profits, and positive $\mathrm{S}^{+}$state predicting strong profits for HML, there seems to be a contribution from both these states to produce the strong result following the $\mathrm{M}^{-} \mathrm{S}^{+}$state. As well, the weak HML results from $\mathrm{S}^{-}$state help explain the weak returns from 
the $\mathrm{M}^{+} \mathrm{S}^{-}$and $\mathrm{M}^{-} \mathrm{S}^{-}$states. Overall, the $\mathrm{M}$ and $\mathrm{S}$ schemes have provided findings that help explain the HML results following the various MS states.

Table 5.9: MS scheme with HML Factor

\begin{tabular}{|c|c|c|c|c|c|c|c|c|c|}
\hline \multirow[b]{2}{*}{ States } & \multicolumn{3}{|c|}{$1-6 \mathrm{M}$} & \multicolumn{3}{|c|}{$1-12 \mathrm{M}$} & \multicolumn{3}{|c|}{$13-24 \mathrm{M}$} \\
\hline & $\mathrm{H}$ & $\mathrm{L}$ & HML & $\mathrm{H}$ & $\mathrm{L}$ & HML & $\mathrm{H}$ & $\mathrm{L}$ & HML \\
\hline $\mathrm{M}^{+} \mathrm{S}^{+}$ & $\begin{array}{c}1.28 \\
(5.61)\end{array}$ & $\begin{array}{c}0.87 \\
(4.57)\end{array}$ & $\begin{array}{c}0.41 \\
(3.07)\end{array}$ & $\begin{array}{c}1.19 \\
(5.83)\end{array}$ & $\begin{array}{c}0.77 \\
(4.45)\end{array}$ & $\begin{array}{c}0.42 \\
(3.05)\end{array}$ & $\begin{array}{c}1.17 \\
(4.99)\end{array}$ & $\begin{array}{c}0.75 \\
(3.31)\end{array}$ & $\begin{array}{c}0.42 \\
(3.82)\end{array}$ \\
\hline $\mathrm{M}^{+} \mathrm{S}^{-}$ & $\begin{array}{c}1.17 \\
(5.23)\end{array}$ & $\begin{array}{c}1.01 \\
(4.64)\end{array}$ & $\begin{array}{c}0.15 \\
(1.21)\end{array}$ & $\begin{array}{c}1.09 \\
(4.77)\end{array}$ & $\begin{array}{c}0.94 \\
(4.41)\end{array}$ & $\begin{array}{c}0.15 \\
(1.12)\end{array}$ & $\begin{array}{c}1.02 \\
(3.95)\end{array}$ & $\begin{array}{c}0.76 \\
(3.32)\end{array}$ & $\begin{array}{c}0.26 \\
(1.69)\end{array}$ \\
\hline $\mathrm{M}^{-} \mathrm{S}^{+}$ & $\begin{array}{c}2.28 \\
(2.47)\end{array}$ & $\begin{array}{c}1.43 \\
(2.09)\end{array}$ & $\begin{array}{c}0.86 \\
(2.14)\end{array}$ & $\begin{array}{c}3.07 \\
(4.03)\end{array}$ & $\begin{array}{c}2.03 \\
(3.46)\end{array}$ & $\begin{array}{c}1.04 \\
(3.37)\end{array}$ & $\begin{array}{c}2.17 \\
(3.78)\end{array}$ & $\begin{array}{c}1.69 \\
(3.91)\end{array}$ & $\begin{array}{c}0.49 \\
(1.89)\end{array}$ \\
\hline $\mathrm{M}^{-} \mathrm{S}^{-}$ & $\begin{array}{c}1.00 \\
(1.68) \\
\end{array}$ & $\begin{array}{c}0.58 \\
(1.02) \\
\end{array}$ & $\begin{array}{c}0.42 \\
(2.03) \\
\end{array}$ & $\begin{array}{c}0.72 \\
(1.13) \\
\end{array}$ & $\begin{array}{c}0.41 \\
(0.75) \\
\end{array}$ & $\begin{array}{c}0.31 \\
(1.42)\end{array}$ & $\begin{array}{c}1.64 \\
(3.01)\end{array}$ & $\begin{array}{c}1.01 \\
(2.27) \\
\end{array}$ & $\begin{array}{c}0.63 \\
(2.37) \\
\end{array}$ \\
\hline Overall & $\begin{array}{c}1.34 \\
(6.65) \\
\end{array}$ & $\begin{array}{c}0.95 \\
(5.54) \\
\end{array}$ & $\begin{array}{c}0.39 \\
(4.02) \\
\end{array}$ & $\begin{array}{c}1.33 \\
(6.68) \\
\end{array}$ & $\begin{array}{c}0.94 \\
(5.50) \\
\end{array}$ & $\begin{array}{c}0.39 \\
(3.98)\end{array}$ & $\begin{array}{c}1.32 \\
(6.56)\end{array}$ & $\begin{array}{c}0.92 \\
(5.36)\end{array}$ & $\begin{array}{c}0.40 \\
(4.05) \\
\end{array}$ \\
\hline
\end{tabular}

Table 5.9 shows the mean monthly HML returns defined by the MS scheme four states. M is denoted as the prior twelve month market return, and is defined as non-negative (negative) by the returns of the VW CRSP index over the 12 months prior to the beginning of the strategy's profit period. S is denoted as the SMB factor cumulative average return over the past twelve months, HML and SMB monthly data downloaded from Ken French's website and the previous SMB 12-month cumulative return define the POSITIVE (NEGATIVE) S state. The returns of the HML portfolios (winner minus loser deciles) are averaged across three periods: months $t+1$ to $t+6$, months $t+1$ to $t+$ 12 , months $t+13$ to $t+24$. The first column in Table 5.8 show the four MS states (described in Table 5.2). The period is from July 1927 to December 2013. The Overall row shows the average HML returns across all states. The $t$-statistics are in parentheses and each section shows the High (H), Low (L), and High minus (HML) portfolio results. 
Table 5.10: MS scheme with HML Factor-Differences between states

\begin{tabular}{|c|c|c|c|c|c|c|c|c|c|c|}
\hline & \multirow[b]{2}{*}{ State } & \multicolumn{3}{|c|}{$\underline{\mathrm{M}^{+} \mathrm{S}^{-}}$} & \multicolumn{3}{|c|}{$\underline{\mathrm{M}^{-} \mathrm{S}^{+}}$} & \multicolumn{3}{|c|}{$\underline{M^{-}} S^{-}$} \\
\hline & & $\mathrm{H}$ & $\mathrm{L}$ & HML & $\mathrm{H}$ & $\mathrm{L}$ & HML & $\mathrm{H}$ & $\mathrm{L}$ & HML \\
\hline \multirow[t]{3}{*}{$1-6 \mathrm{M}$} & $\mathrm{M}^{+} \mathrm{S}^{+}$ & $\begin{array}{c}0.11 \\
(0.35)\end{array}$ & $\begin{array}{c}-0.15 \\
(-0.51)\end{array}$ & $\begin{array}{c}0.26 \\
(1.40)\end{array}$ & $\begin{array}{l}-1.01 \\
(-1.06)\end{array}$ & $\begin{array}{c}-0.56 \\
(-0.79)\end{array}$ & $\begin{array}{c}-0.45 \\
(-1.05)\end{array}$ & $\begin{array}{c}0.28 \\
(0.44)\end{array}$ & $\begin{array}{c}0.29 \\
(0.48)\end{array}$ & $\begin{array}{c}-0.01 \\
(-0.02)\end{array}$ \\
\hline & $\mathrm{M}^{+} \mathrm{S}^{-}$ & & & & $\begin{array}{l}-1.12 \\
(-1.18)\end{array}$ & $\begin{array}{c}-0.41 \\
(-0.58)\end{array}$ & $\begin{array}{c}-0.70 \\
(-1.68)\end{array}$ & $\begin{array}{c}0.17 \\
(0.27)\end{array}$ & $\begin{array}{c}0.43 \\
(0.71)\end{array}$ & $\begin{array}{c}-0.27 \\
(-1.10)\end{array}$ \\
\hline & $\mathrm{M}^{-} \mathrm{S}^{+}$ & & & & & & & $\begin{array}{c}1.29 \\
(1.17)\end{array}$ & $\begin{array}{c}0.85 \\
(0.95) \\
\end{array}$ & $\begin{array}{c}0.44 \\
(0.97)\end{array}$ \\
\hline \multirow[t]{3}{*}{$1-12 \mathrm{M}$} & $\mathrm{M}^{+} \mathrm{S}^{+}$ & $\begin{array}{c}0.10 \\
(0.31)\end{array}$ & $\begin{array}{c}-0.17 \\
(-0.62)\end{array}$ & $\begin{array}{c}0.27 \\
(1.39)\end{array}$ & $\begin{array}{c}-1.88^{* *} \\
(-2.39)\end{array}$ & $\begin{array}{c}-1.26 * * \\
(-2.05)\end{array}$ & $\begin{array}{l}-0.62 * \\
(-1.85)\end{array}$ & $\begin{array}{c}0.47 \\
(0.71)\end{array}$ & $\begin{array}{c}0.36 \\
(0.63)\end{array}$ & $\begin{array}{c}0.11 \\
(0.43)\end{array}$ \\
\hline & $\mathrm{M}^{+} \mathrm{S}^{-}$ & & & & $\begin{array}{c}-1.98 * * \\
(-2.48)\end{array}$ & $\begin{array}{l}-1.09^{*} \\
(-1.74)\end{array}$ & $\begin{array}{c}-0.89 * * \\
(-2.65)\end{array}$ & $\begin{array}{c}0.38 \\
(0.56)\end{array}$ & $\begin{array}{c}0.53 \\
(0.91)\end{array}$ & $\begin{array}{c}-0.16 \\
(-0.61)\end{array}$ \\
\hline & $\mathrm{M}^{-} \mathrm{S}^{+}$ & & & & & & & $\begin{array}{c}2.35 * * \\
(2.37) \\
\end{array}$ & $\begin{array}{l}1.62 * * \\
(2.02) \\
\end{array}$ & $\begin{array}{c}0.73^{*} \\
(1.95)\end{array}$ \\
\hline \multirow[t]{3}{*}{$13-24 \mathrm{M}$} & $\mathrm{M}^{+} \mathrm{S}^{+}$ & $\begin{array}{c}0.15 \\
(0.44)\end{array}$ & $\begin{array}{c}-0.01 \\
(-0.04)\end{array}$ & $\begin{array}{c}0.17 \\
(0.89)\end{array}$ & $\begin{array}{l}-1.01 \\
(-1.62)\end{array}$ & $\begin{array}{l}-0.94 * \\
(-1.93)\end{array}$ & $\begin{array}{c}-0.06 \\
(-0.23)\end{array}$ & $\begin{array}{c}-0.47 \\
(-0.80)\end{array}$ & $\begin{array}{c}-0.27 \\
(-0.53)\end{array}$ & $\begin{array}{c}-0.21 \\
(-0.72)\end{array}$ \\
\hline & $\mathrm{M}^{+} \mathrm{S}^{-}$ & & & & $\begin{array}{l}-1.16^{*} \\
(-1.84)\end{array}$ & $\begin{array}{l}-0.93^{*} \\
(-1.90)\end{array}$ & $\begin{array}{c}-0.23 \\
(-0.77)\end{array}$ & $\begin{array}{c}-0.62 \\
(-1.04)\end{array}$ & $\begin{array}{c}-0.25 \\
(-0.50)\end{array}$ & $\begin{array}{c}-0.37 \\
(-1.22)\end{array}$ \\
\hline & $\mathrm{M}^{-} \mathrm{S}^{+}$ & & & & & & & $\begin{array}{c}0.54 \\
(0.67)\end{array}$ & $\begin{array}{c}0.68 \\
(1.09)\end{array}$ & $\begin{array}{c}-0.14 \\
(-0.38)\end{array}$ \\
\hline
\end{tabular}

Table 5.10 reports the differences in HML returns between each state in Table 5.8. The monthly HML returns were defined by the MS scheme different states. The difference in results are derived from the HML returns for the states in column State A, deducting the HML returns of the states in the row State B. M is denoted as the prior twelve month market return, and is defined as non-negative (negative) by the returns of the VW CRSP index over the 12 months prior to the beginning of the strategy's profit period. S is denoted as the SMB factor cumulative average return over the past twelve months, HML and SMB monthly data

downloaded from Ken French's website, and the previous SMB 12-month cumulative return define the POSITIVE (NEGATIVE) S state The returns of the HML portfolios (winner minus loser deciles) are averaged across three periods: months $t+1$ to $t+6$, months $t+1$ to $t+12$, months $t+13$ to $t+36$. The column (row) in State A ( B) show the different MS scheme states (described in Table 5.2). The period is from July 1927 to December 2013. The Overall row shows the average HML returns across all states, and the $t$-statistics are in parentheses. Each section shows the High (H), Low (L), and High minus (HML) average monthly mean differences, which are defined by one or two asterisk, showing $10 \%$ or $5 \%$ significance respectively. 
Table 5.11: 2-State M and S Scheme with HML Factor

\begin{tabular}{lccccccccc}
\hline & & & $1-6 \mathrm{~m}$ & & & $1-12 \mathrm{~m}$ & & & $13-24 \mathrm{~m}$ \\
States & High & Low & HML & High & Low & HML & High & Low & HML \\
\hline $\mathrm{M}^{+}$ & 1.24 & 0.92 & 0.31 & 1.15 & 0.84 & 0.31 & 1.11 & 0.75 & 0.36 \\
& $(7.29)$ & $(6.17)$ & $(3.11)$ & $(7.12)$ & $(5.84)$ & $(3.02)$ & $(5.79)$ & $(4.16)$ & $(3.56)$ \\
$\mathrm{M}^{-}$ & 1.60 & 0.97 & 0.62 & 1.81 & 1.16 & 0.65 & 1.89 & 1.33 & 0.56 \\
& $(2.75)$ & $(2.05)$ & $(2.76)$ & $(3.21)$ & $(2.53)$ & $(3.20)$ & $(4.09)$ & $(3.75)$ & $(2.70)$ \\
& & & & & & & & & \\
All & 1.34 & 0.95 & 0.39 & 1.33 & 0.94 & 0.39 & 1.32 & 0.92 & 0.40 \\
& $(6.65)$ & $(5.54)$ & $(4.02)$ & $(6.68)$ & $(5.50)$ & $(3.98)$ & $(6.56)$ & $(5.36)$ & $(4.05)$ \\
Difference & -0.36 & -0.05 & -0.31 & -0.66 & -0.32 & -0.33 & -0.78 & -0.58 & -0.20 \\
& $(-0.60)$ & $(-0.10)$ & $(-1.25)$ & $(-1.12)$ & $(-0.67)$ & $(-1.47)$ & $(-1.56)$ & $(-1.45)$ & $(-0.88)$ \\
\hline $\mathrm{S}^{+}$ & 1.49 & 0.98 & 0.51 & 1.59 & 1.04 & 0.55 & 1.38 & 0.95 & 0.44 \\
& $(5.43)$ & $(4.55)$ & $(3.61)$ & $(6.31)$ & $(5.11)$ & $(4.06)$ & $(5.70)$ & $(4.42)$ & $(3.82)$ \\
$\mathrm{S}^{-}$ & 1.11 & 0.87 & 0.24 & 0.97 & 0.77 & 0.20 & 1.22 & 0.84 & 0.38 \\
& $(4.47)$ & $(3.59)$ & $(2.15)$ & $(3.44)$ & $(2.99)$ & $(1.67)$ & $(4.49)$ & $(3.73)$ & $(2.67)$ \\
& & & & & & & & & \\
All & 1.34 & 0.95 & 0.39 & 1.33 & 0.94 & 0.39 & 1.32 & 0.92 & 0.40 \\
& $(6.65)$ & $(5.54)$ & $(4.02)$ & $(6.68)$ & $(5.50)$ & $(3.98)$ & $(6.56)$ & $(5.36)$ & $(4.05)$ \\
Difference & 0.38 & 0.11 & 0.27 & 0.62 & 0.27 & 0.35 & 0.16 & 0.10 & 0.06 \\
& $(1.02)$ & $(0.34)$ & $(1.48)$ & $(1.63)$ & $(0.83)$ & $(1.91)$ & $(0.43)$ & $(0.33)$ & $(0.31)$ \\
\hline
\end{tabular}

Table 5.11 shows the mean monthly returns for HML, formed through the M and S scheme's two states. M is denoted as the prior twelve month market return, and is defined as non-negative (negative) by the returns of the VW CRSP index over the 12 months prior to the beginning of the strategy's profit period. S is denoted as the SMB factor cumulative average return over the past twelve months, RM-rf and SMB monthly data downloaded from Ken French's website, and the previous SMB 12-month cumulative return define the POSITIVE (NEGATIVE) $\mathrm{S}$ state. The profits results are averaged across three periods: $t+1$ to $t+6, t+1$ to $t+12, t+13$ to $t+24$ months. The first column in Table 5.4 show the different $\mathrm{M}$ and $\mathrm{S}$ states, $\mathrm{M}^{+}, \mathrm{M}^{-}, \mathrm{S}^{+}, \mathrm{S}^{-}$. The period is from July 1927 to December 2013 . The Overall row shows the average profits across all states. The difference rows report the differences for HML returns, between the positive and negative M and $\mathrm{S}$ states, by deducting the returns of state $\mathrm{M}^{-}\left(\mathrm{S}^{-}\right)$from the returns in $\mathrm{M}^{+}\left(\mathrm{S}^{+}\right)$, and the $t$-statistics are in parentheses.

I also examined whether the MH scheme introduced in Chapter 4, was able to provide information about future average returns for the Fama-French three factors. However, the results showed insignificant differences between the factor returns following the $\mathrm{MH}$ states and therefore have not been included in this thesis. However, I have included an $\mathrm{H}$ only scheme (reported in Table 5.16 in the Annexure 5A) with two states determined by whether the average HML return over the past 12 months is positive $\left(\mathrm{H}^{+}\right)$or negative $\left(\mathrm{H}^{-}\right)$. The results show that the positive and negative states of the $\mathrm{H}$ state predict similar future profitability for RM-rf and SMB, although, a negative $\mathrm{H}$ state shows a slightly stronger result for HML. 
These results are inconsistent with previous literature, including Liew and Vassalou (2000), who claim that HML could predict future GDP growth, and with Pontiff and Schall (1998) who predict HML could predict future market returns.

To further clarify the MS scheme's usefulness in providing information about the future returns of the SMB and HML factors, I utilize a $5 \times 5$ matrix table, with the variation in average returns of 5 size quintiles and 5 quintiles based on book-to-market. The portfolio returns are reported determined by the four MS states, in the 12-month case.

Table 5.12 reports the row of size quintile average returns increase with $\mathrm{BE} / \mathrm{ME}$ in all states, however, the $\mathrm{M}^{-} \mathrm{S}^{+}$state still dominates by producing average returns showing that the highest and lowest BE/ME portfolios in a size quintile differ by $1.16 \%$ ( $3.48 \%-2.32 \%)$ monthly return. The other three states produce similar weaker results, of $\mathrm{M}^{+} \mathrm{S}^{+} 0.48 \%, \mathrm{M}^{+} \mathrm{S}^{-} 0.28 \%$ and $\mathrm{M}^{-} \mathrm{S}^{-} 0.60 \%$. Looking down the columns of the average returns matrix, shows there is a strong negative relationship between average return and size in the $\mathrm{M}^{-} \mathrm{S}^{+}$state. On average, the returns across the size portfolio in $\mathrm{M}^{-} \mathrm{S}^{+}$state $\mathrm{BE} / \mathrm{ME}$ group is $1.84 \%(3.70 \%-1.86 \%)$ per month, with the $\mathrm{M}^{+} \mathrm{S}^{+}$producing $0.27 \%$ per month. The negative size state produces negative or indifferent average returns, $\mathrm{M}^{+} \mathrm{S}^{-}-0.27 \%$ and $\mathrm{M}^{-} \mathrm{S} 0.02 \%$ per month respectively. 
Table 5.12: MS Scheme: SMB and HML 5x5 portfolio Returns in the Four States

\begin{tabular}{lcccccc}
\hline \multicolumn{7}{c}{ Book-To-Market-Portfolios } \\
\hline States & & Low & 2 & 3 & 4 & High \\
\hline M+S+ & Small & 0.68 & 0.87 & 1.13 & 1.42 & 1.53 \\
& 2 & 0.84 & 1.13 & 1.19 & 1.25 & 1.41 \\
& 3 & 0.85 & 1.12 & 1.17 & 1.25 & 1.29 \\
& 4 & 0.82 & 0.92 & 1.09 & 1.12 & 1.04 \\
& Big & 0.66 & 0.76 & 0.95 & 0.90 & 0.99 \\
\hline M+S- & Small & 0.50 & 0.72 & 0.96 & 0.98 & 1.13 \\
& 2 & 0.51 & 0.90 & 1.04 & 1.01 & 1.05 \\
& 3 & 0.90 & 1.05 & 1.10 & 0.98 & 1.13 \\
& 4 & 1.04 & 0.90 & 1.00 & 1.02 & 1.07 \\
& Big & 1.18 & 1.03 & 1.06 & 1.04 & 1.16 \\
\hline M-S+ & Small & 3.37 & 3.26 & 3.73 & 3.76 & 4.37 \\
& 2 & 2.49 & 2.65 & 3.11 & 3.34 & 3.62 \\
& 3 & 2.39 & 2.33 & 2.52 & 2.95 & 3.33 \\
& 4 & 1.98 & 2.22 & 2.51 & 2.85 & 3.35 \\
& Big & 1.38 & 1.61 & 1.70 & 1.87 & 2.74 \\
\hline M-S- & Small & -0.19 & -0.13 & 0.70 & 0.62 & 0.80 \\
& 2 & 0.36 & 0.65 & 0.57 & 0.75 & 1.06 \\
& 3 & 0.37 & 0.59 & 0.59 & 0.56 & 0.87 \\
& 4 & 0.43 & 0.41 & 0.50 & 0.62 & 0.93 \\
& Big & 0.41 & 0.37 & 0.03 & 0.19 & 0.69 \\
\hline
\end{tabular}

Table 5.12 reports the four state average monthly returns derived from the MS scheme, for 5x5 portfolio returns of SMB and HML. The 5x5 SMB and HML portfolio returns were downloaded from Ken French website. ${ }^{5}$ The left hand column show the four MS states (described in Table 5.2). The headings on the top row show HML five portfolios (Low, 2, 3, 4, High), whilst the second column show the five portfolios of SMB (Small, 2, 3, 4, Big) across the four states. The portfolio returns are for the time period of $\mathrm{t}+1$ to $\mathrm{t}+12 \mathrm{months}$. The period is from July 1927 to December 2013.

\subsection{Profit Comparison Analyses}

This section discusses and illustrates a graphically representation of the three factors RM-rf,

SMB, HML profitability across the different states of the MS scheme.

In Table 5.13, I compare the three factor's average returns from Tables 5.2, 5.4, and 5.7. Concentrating first on the 12-month case, the $\mathrm{M}^{+} \mathrm{S}^{+}$state produces significant average

\footnotetext{
${ }^{5}$ The SMB and HML 5x5 portfolio construction is available from Ken French website
} 
monthly profits for all three factors, although SMB profits is considerably lower than RM-rf and $\mathrm{HM}$ profits. The $\mathrm{M}^{+} \mathrm{S}^{-}$state shows that $\mathrm{SMB}$ profits become negative $-0.14 \%$ ( $t$-stat 1.30), whilst HML profits become weak and insignificant $0.15 \%$ ( $t$-stat 1.12 ). RM-rf profits $0.75 \%$ ( $t$-stat 3.89 ) have strengthened compared to the $\mathrm{M}^{+} \mathrm{S}^{+}$state $0.48 \%$ ( $t$-stat 3.15$)$. The $\mathrm{M}^{-}$ $\mathrm{S}^{+}$state produces the strongest significant profits across all three factors, compared to the other states. Each factor shows an above $1 \%$ average monthly profits, with RM-rf factor showing the strongest result at $1.45 \%$ ( $t$-stat 3.16), compared to SMB 1.12 ( $t$-stat 4.88), and HML $1.04 \%$ ( $t$-stat 3.16). The final state $\mathrm{M}^{-} \mathrm{S}^{-}$shows insignificant weak profits across all three factors.

The results demonstrate that the lagged $\mathrm{M}$ state is not the pertinent factor in determining significant profits; rather, it is the lagged $\mathrm{S}$ state. Noticeable, it is when the lagged $\mathrm{S}$ state is positive, that all three factors show significant average monthly profits. However, there is a clear divergence between the RM-rf state and the SMB and HML states following the $\mathrm{M}^{+} \mathrm{S}^{-}$ state. SMB and HML show weak insignificant profits, whilst RM-rf produces a $0.75 \%$ ( $t$-stat 3.89) profit.

Noticeably, when the $\mathrm{M}$ state is positive, $\mathrm{M}^{+} \mathrm{S}^{+}, \mathrm{M}^{+} \mathrm{S}^{-}$, the results are similar across all three future profit periods. Following the $\mathrm{M}^{-} \mathrm{S}^{+}$state, the profits are similar across all states except for HML, which shows a strong weakening of profits in the 13-24 month period. Following the $\mathrm{M}^{-} \mathrm{S}^{-}$state, the HML profits are the strongest across the profit periods. Interestingly, the 13 to 24 month period does not show clear reversals, compared to the other profit periods, showing that the profitable returns are long lasting. 
Table 5.13: Summary Comparison across Factors

\begin{tabular}{|c|c|c|c|c|c|c|c|c|c|}
\hline \multirow[b]{2}{*}{ States } & \multicolumn{3}{|c|}{$1-6 \mathrm{M}$} & \multicolumn{3}{|c|}{$1-12 \mathrm{M}$} & \multicolumn{2}{|c|}{$13-24 \mathrm{M}$} & \multirow[b]{2}{*}{ RM-rf } \\
\hline & SMB & HML & RM-rf & SMB & HML & RM-rf & SMB & HML & \\
\hline $\mathrm{M}^{+} \mathrm{S}^{+}$ & $\begin{array}{c}0.34 \\
(3.11)\end{array}$ & $\begin{array}{c}0.41 \\
(3.07)\end{array}$ & $\begin{array}{c}0.53 \\
(3.32)\end{array}$ & $\begin{array}{c}0.26 \\
(2.20)\end{array}$ & $\begin{array}{c}0.42 \\
(3.05)\end{array}$ & $\begin{array}{c}0.48 \\
(3.15)\end{array}$ & $\begin{array}{c}0.19 \\
(1.51)\end{array}$ & $\begin{array}{c}0.42 \\
(3.82)\end{array}$ & $\begin{array}{c}0.48 \\
(2.58)\end{array}$ \\
\hline $\mathrm{M}^{+} \mathrm{S}^{-}$ & $\begin{array}{c}-0.23 \\
(-1.80)\end{array}$ & $\begin{array}{c}0.15 \\
(1.21)\end{array}$ & $\begin{array}{c}0.86 \\
(4.72)\end{array}$ & $\begin{array}{c}-0.14 \\
(-1.30)\end{array}$ & $\begin{array}{c}0.15 \\
(1.12)\end{array}$ & $\begin{array}{c}0.75 \\
(3.89)\end{array}$ & $\begin{array}{c}-0.03 \\
(-0.24)\end{array}$ & $\begin{array}{c}0.26 \\
(1.69)\end{array}$ & $\begin{array}{c}0.53 \\
(2.29)\end{array}$ \\
\hline $\mathrm{M}^{-} \mathrm{S}^{+}$ & $\begin{array}{c}1.00 \\
(3.50)\end{array}$ & $\begin{array}{c}0.86 \\
(2.14)\end{array}$ & $\begin{array}{c}0.87 \\
(1.52)\end{array}$ & $\begin{array}{c}1.12 \\
(4.88)\end{array}$ & $\begin{array}{c}1.04 \\
(3.37)\end{array}$ & $\begin{array}{c}1.45 \\
(3.16)\end{array}$ & $\begin{array}{c}0.92 \\
(4.02)\end{array}$ & $\begin{array}{c}0.49 \\
(1.89)\end{array}$ & $\begin{array}{c}1.15 \\
(3.71)\end{array}$ \\
\hline $\mathrm{M}^{-} \mathrm{S}^{-}$ & $\begin{array}{c}0.26 \\
(1.56)\end{array}$ & $\begin{array}{c}0.42 \\
(2.03)\end{array}$ & $\begin{array}{c}0.25 \\
(0.49)\end{array}$ & $\begin{array}{c}0.21 \\
(1.74)\end{array}$ & $\begin{array}{c}0.31 \\
(1.42)\end{array}$ & $\begin{array}{c}0.09 \\
(0.17)\end{array}$ & $\begin{array}{c}0.38 \\
(2.59)\end{array}$ & $\begin{array}{c}0.63 \\
(2.37)\end{array}$ & $\begin{array}{c}0.64 \\
(1.54)\end{array}$ \\
\hline $\begin{array}{l}\text { onth } \\
\text { ginnir } \\
\text { MB ar } \\
\text { SSITI } \\
\text { onths. } \\
\text { t } t \text {-sta }\end{array}$ & 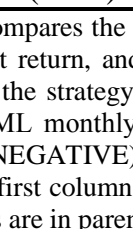 & 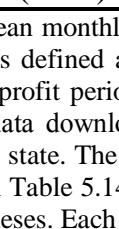 & 2 & 2 & f for & ( & $\begin{array}{l}\text { urns. } \mathrm{M} \text { is } \\
\text { ndex over } t \\
\text { over the p } \\
2 \text {-month cu }\end{array}$ & th a th & $\begin{array}{l}\text { rior twelve } \\
\text { orior to the } \\
\text { ths, RM-rf } \\
\text { define the } \\
13 \text { to } t+2 \\
\text { mber } 2013 \\
\text { ms. }\end{array}$ \\
\hline
\end{tabular}

Figure 5.2 displays the returns of the 3 factors discussed in Table 5.13, and shows the average monthly returns for SMB, HML and RM-rf formulated through the MS scheme states. The states are shown as $\mathrm{M}^{+} \mathrm{S}^{+}, \mathrm{M}^{+} \mathrm{S}^{-}, \mathrm{M}^{-} \mathrm{S}^{+}, \mathrm{M}^{-} \mathrm{S}^{-}$, with the cumulative average 1 to 6 month returns (graph A), 1 to 12 months returns(Graph B), 13 to 24 months returns (Graph C).

Concentrating on the 12-month case, Graph B displays the fact that the 3 factors have very strong profits following the $\mathrm{M}^{-} \mathrm{S}^{+}$state, with over $1 \%$ average monthly return. Obviously the best result, compared to the other states. The $\mathrm{M}^{+} \mathrm{S}^{+}$states provide low to medium future profits for the 3 factors, the $\mathrm{M}^{+} \mathrm{S}^{-}$state shows only RM-rf is strongly profitable in the future, and the $\mathrm{M}^{-} \mathrm{S}^{-}$state shows all 3 factors with minimal future profits. 
Figure 5.2: 4-State Returns Across 3 Profit Periods

\section{Graph A}

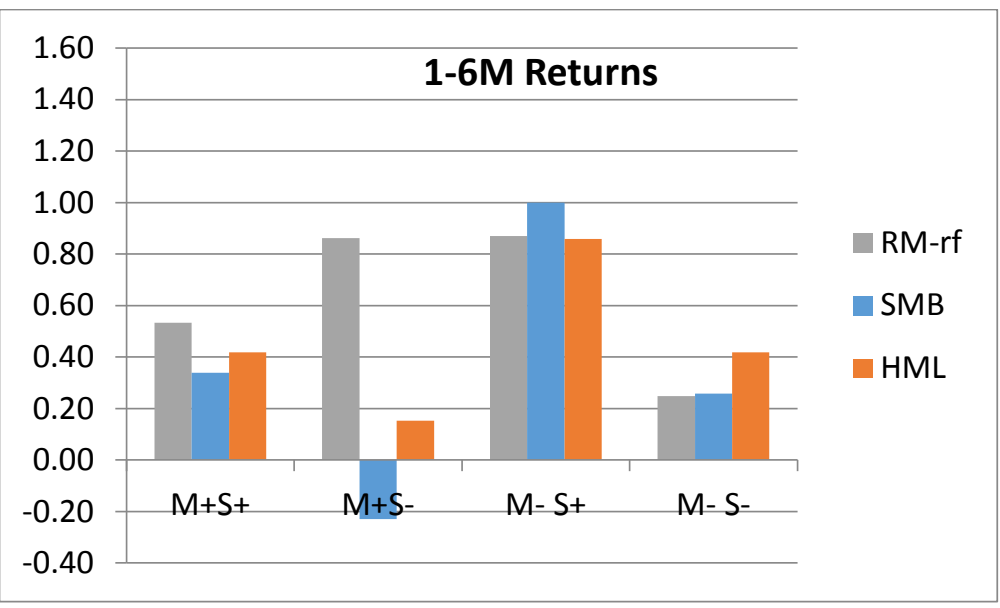

\section{Graph B}

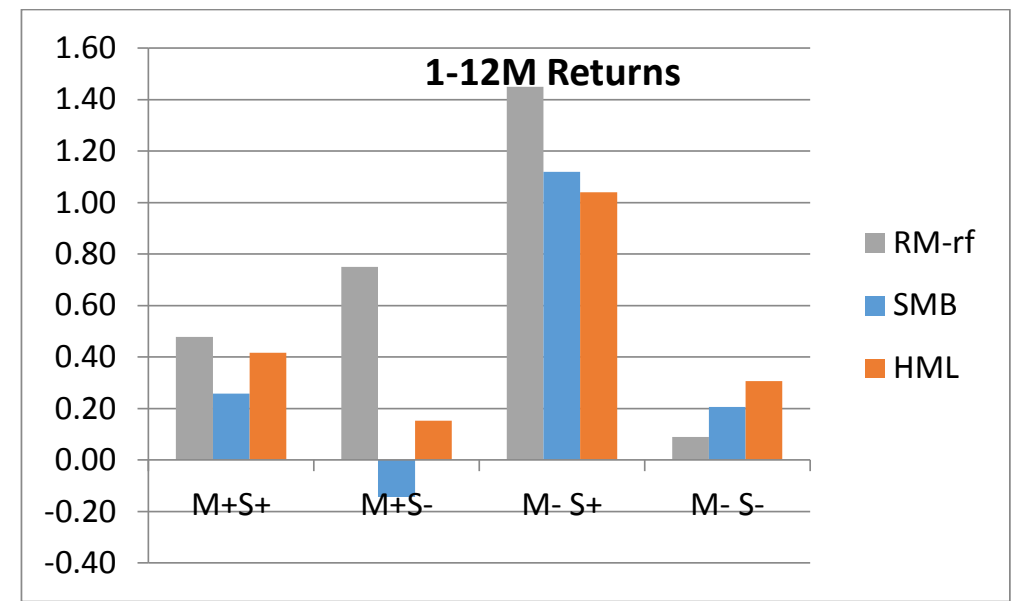

Figure 5.2 illustrates the MS average monthly payoffs from Table 5.14, for the three factors RM-rf, SMB, HML profits in the four different states of the MS scheme, for the periods of $t+1-t+6$ months (Graph A), $t+1$ to $t+12$ months (Graph B), and $t+13$ to $t+24$ months (Graph C). All graphs show the different MS states (described in Table 5.2 ). The scale is from $1.60 \%$ to $-0.40 \%$ per month

Graph C

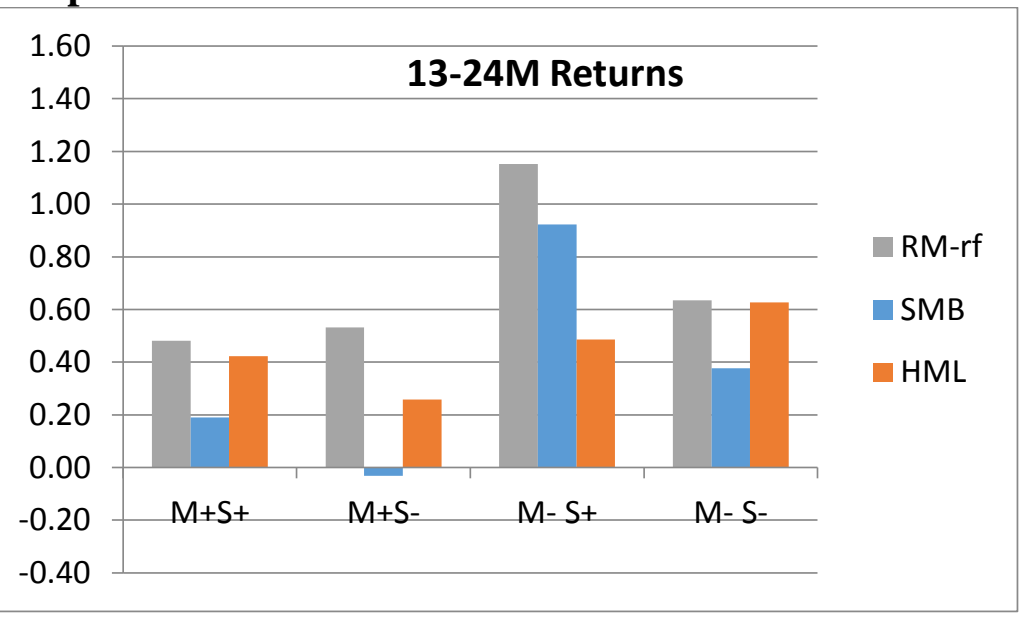




\subsection{Concluding Comments.}

This empirical study combines the component SMB, with market states, to form a new scheme (MS) to examine the future profitability of FF three factors over three time periods from 1926 to 2013. The MS scheme 4-state results show that future size and value profitability is strongly affected by the lagged $S$ state, whilst the future RM-rf returns was only affected by the lagged $\mathrm{S}$ state with a lagged negative $\mathrm{M}$ state. My findings show that all three factors are profitable when the $\mathrm{M}$ and $\mathrm{S}$ state were positive, show weak insignificant profits when in the 12-month case, both $\mathrm{M}$ and $\mathrm{S}$ state are negative, and surprisingly, produce their strongest results in the following a 12-month period with a negative market $\left(\mathrm{M}^{-}\right)$ combined with a positive $\mathrm{SMB}$ return $\left(\mathrm{S}^{+}\right)$.

To understand these results, I separated the MS scheme into an M and an S scheme, and examined FF three factors through these 2-state schemes. My results show that the returns from the MS scheme for SMB and HML are explained by the $\mathrm{M}$ and $\mathrm{S}$ schemes, with significant strong returns derived from the positive $S$ state $\left(\mathrm{S}^{+}\right)$and the negative $\mathrm{M}$ state $\left(\mathrm{M}^{-}\right)$. The $\mathrm{M}$ and $\mathrm{S}$ schemes were unable to separately explain the significant differences for the future returns of RM-rf, in a conundrum, it is only the combination of the $\mathrm{M}$ and $\mathrm{S}$ schemes (the MS scheme) which differentiate the RM-rf returns, and only then between the negative market states $\mathrm{M}^{-} \mathrm{S}^{+}$and $\mathrm{M}^{-} \mathrm{S}^{-}$.

I also examined MS, M and S schemes interaction with SMB and HML via a matrix, and found that the combined small size and value show very strong returns following the $\mathrm{M}^{-} \mathrm{S}^{+}$ state, positive returns following the $\mathrm{M}^{+} \mathrm{S}^{+}$and $\mathrm{M}^{-} \mathrm{S}^{-}$states, and slightly negative returns following the $\mathrm{M}^{+} \mathrm{S}^{-}$state. The negative market $\left(\mathrm{M}^{-}\right)$state produced the best profits for HML. I 
also show that a prior positive market state has limited effect on the performance of the size factor, it is the prior negative market state that proves to be the driving force for an SMB anomalous effect.

Finally, this paper fills a gap in academic literature by showing how the future performances of Fama and French's (1993) three risk factors, RM-rf, SMB and HML can be successfully predicted across market cycles by employing the MS scheme introduced in this thesis. Thus, the findings in this chapter have important implications for theorists and practitioners alike. 
Annexure 5A: 2-State $H$ with RM-rf, SMB and HML Factor

\begin{tabular}{|c|c|c|c|c|c|c|c|c|c|}
\hline & & 1-6mths & & & $1-12 \mathrm{mths}$ & & & $3-24 \mathrm{mth}$ & \\
\hline & & & RM-rf & & & RM-rf & & & RM-rf \\
\hline $\mathrm{H}+$ & & & $\begin{array}{c}0.59 \\
(3.53)\end{array}$ & & & $\begin{array}{c}0.60 \\
(3.76)\end{array}$ & & & $\begin{array}{c}0.59 \\
(3.57)\end{array}$ \\
\hline $\mathrm{H}-$ & & & $\begin{array}{c}0.69 \\
(2.70)\end{array}$ & & & $\begin{array}{c}0.65 \\
(2.57)\end{array}$ & & & $\begin{array}{c}0.61 \\
(2.37)\end{array}$ \\
\hline All & & & $\begin{array}{c}0.64 \\
(4.37)\end{array}$ & & & $\begin{array}{c}0.63 \\
(4.21)\end{array}$ & & & $\begin{array}{c}0.62 \\
(4.08)\end{array}$ \\
\hline Difference & & & $\begin{array}{c}-0.09 \\
(-0.31)\end{array}$ & & & $\begin{array}{c}-0.05 \\
(-0.18)\end{array}$ & & & $\begin{array}{c}-0.02 \\
(-0.05)\end{array}$ \\
\hline States & Small & Big & SMB & Small & $\mathrm{Big}$ & SMB & Small & $\mathrm{Big}$ & SMB \\
\hline $\mathrm{H}+$ & $\begin{array}{c}1.21 \\
(4.82)\end{array}$ & $\begin{array}{c}0.97 \\
(5.40)\end{array}$ & $\begin{array}{c}0.24 \\
(2.25)\end{array}$ & $\begin{array}{c}1.21 \\
(5.20)\end{array}$ & $\begin{array}{c}0.96 \\
(5.64)\end{array}$ & $\begin{array}{c}0.25 \\
(2.29)\end{array}$ & $\begin{array}{c}1.13 \\
(5.20)\end{array}$ & $\begin{array}{c}0.90 \\
(4.96)\end{array}$ & $\begin{array}{c}0.23 \\
(2.26)\end{array}$ \\
\hline $\mathrm{H}-$ & $\begin{array}{c}1.32 \\
(4.07)\end{array}$ & $\begin{array}{c}1.06 \\
(3.89)\end{array}$ & $\begin{array}{c}0.26 \\
(1.92)\end{array}$ & $\begin{array}{c}1.29 \\
(4.31)\end{array}$ & $\begin{array}{c}1.07 \\
(4.07)\end{array}$ & $\begin{array}{c}0.22 \\
(1.66)\end{array}$ & $\begin{array}{c}1.40 \\
(3.71)\end{array}$ & $\begin{array}{c}1.14 \\
(4.32)\end{array}$ & $\begin{array}{c}0.27 \\
(1.75)\end{array}$ \\
\hline All & $\begin{array}{c}1.26 \\
(6.17)\end{array}$ & $\begin{array}{c}1.02 \\
(6.52)\end{array}$ & $\begin{array}{c}0.24 \\
(2.77)\end{array}$ & $\begin{array}{c}1.25 \\
(6.17)\end{array}$ & $\begin{array}{c}1.01 \\
(6.38)\end{array}$ & $\begin{array}{c}0.24 \\
(2.60)\end{array}$ & $\begin{array}{c}1.24 \\
(6.05)\end{array}$ & $\begin{array}{c}1.00 \\
(6.25)\end{array}$ & $\begin{array}{c}0.24 \\
(2.60)\end{array}$ \\
\hline Difference & $\begin{array}{c}-0.11 \\
(-0.28)\end{array}$ & $\begin{array}{c}-0.09 \\
(-0.27)\end{array}$ & $\begin{array}{c}-0.03 \\
(-0.16)\end{array}$ & $\begin{array}{c}-0.08 \\
(-0.20)\end{array}$ & $\begin{array}{c}-0.11 \\
(-0.34)\end{array}$ & $\begin{array}{c}0.03 \\
(0.16)\end{array}$ & $\begin{array}{c}-0.27 \\
(-0.62)\end{array}$ & $\begin{array}{c}-0.24 \\
(-0.75)\end{array}$ & $\begin{array}{c}-0.03 \\
(-0.18)\end{array}$ \\
\hline & High & Low & HML & High & Low & HML & High & Low & HML \\
\hline $\mathrm{H}+$ & 1.28 & 0.89 & 0.38 & 1.25 & 0.92 & 0.34 & 1.12 & 0.92 & 0.19 \\
\hline $\mathrm{H}-$ & $\begin{array}{c}(5.28) \\
1.42 \\
(4.21)\end{array}$ & $\begin{array}{c}(4.43) \\
1.01 \\
(3.51)\end{array}$ & $\begin{array}{c}(3.83) \\
0.41 \\
(2.14)\end{array}$ & $\begin{array}{c}(5.62) \\
1.45 \\
(4.73)\end{array}$ & $\begin{array}{c}(4.84) \\
0.94 \\
(3.50)\end{array}$ & $\begin{array}{c}(3.45) \\
0.51 \\
(2.98)\end{array}$ & $\begin{array}{c}(5.06) \\
1.65 \\
(4.65)\end{array}$ & $\begin{array}{c}(5.20) \\
0.87 \\
(2.74)\end{array}$ & $\begin{array}{c}(1.82) \\
0.78 \\
(4.98)\end{array}$ \\
\hline All & 1.34 & 0.95 & 0.39 & 1.33 & 0.94 & 0.39 & 1.32 & 0.92 & 0.40 \\
\hline
\end{tabular}




\begin{tabular}{cccccccccc} 
& $(6.65)$ & $(5.54)$ & $(4.02)$ & $(6.68)$ & $(5.50)$ & $(3.98)$ & $(6.56)$ & $(5.36)$ & $(4.05)$ \\
Difference & -0.14 & -0.11 & -0.03 & -0.19 & -0.02 & -0.17 & -0.54 & 0.06 & -0.59 \\
& $(-0.34)$ & $(-0.32)$ & $(-0.13)$ & $(-0.51)$ & $(-0.06)$ & $(-0.88)$ & $(-1.28)$ & $(0.15)$ & $(-3.10)$ \\
\hline
\end{tabular}

Table 5.15 shows the mean monthly returns for RM-rf, SMB and HML formed through the $\mathrm{H}$ scheme's two states. $\mathrm{H}$ is denoted as the HML factor cumulative average return over the past twelve months, RM-rf, SMB and HML monthly data downloaded from Ken French's website and the previous HML 12-month cumulative return define the POSITIVE (NEGATIVE) S state. The profits results are averaged across three periods: $t+$ 1 to $t+6, t+1$ to $t+12, t+13$ to $t+24$ months. The first column in Table 5.15 show the different $\mathrm{H}$ states, $\mathrm{H}^{+}, \mathrm{H}$. The period is from July 1927 to December 2013 . The All row shows the average profits across all states. The difference rows report the differences in returns for RM-rf, SMB and HML returns between the positive and negative H states, by deducting the RM-rf, SMB and HML returns in state H- from the returns in $H+$ the $t$-statistics are in parentheses. 


\section{Chapter 6: Conclusion}

\subsection{Introduction}

Business and economic cycles have played a major factor in economies and people lives for centuries. Indeed, it can be argued that the economic crises and economic good times affect all people's wellbeing. As financial markets have developed in modern economies, researchers have observed that market cycles tend to be leading indicators of business cycles. While there is a long history of academic research into business cycles, research into how market states differentially influence security returns is a more recent phenomenon. The aim of this thesis is to examine the influence of market states on security returns.

The first empirical study (Chapter 3) examines if market states can predict future industry returns. The second study (Chapter 4) of this thesis extends the notion of market states in an innovate approach that creates states by combining recent market performance with the recent performances of two important components of the market: the size and value factors. The four states are then utilized to examine future momentum profitability. The third and final study (Chapter 5) utilises the market-size scheme created in study 2 to examine whether its four states contain information about the future performances of the three Fama-French market, size, and value factors. Throughout these three studies, I focused on the empirical effects that market states have on future industry returns, on future stock and industry momentum profits, on future excess market returns (the Fama-French market factor), and on the future returns of the Fama-French size and value factors. The results show that market states can be used to predict the returns for these important variables. 
In closing, this study contributes a number of new findings to the current body of scholarly work in asset selection, allocation and asset pricing through its study of the interaction between market states and the future returns of industries, stock and industry momentum, the market, and the Fama-French size and value factors. As well, this study holds significant practical implications for investors who wish to better understand the changing risk/return profile of different stocks and industries.

\subsection{Relevance}

The study of asset allocation plays an important part in the trading strategies of managed funds, superannuation funds and hedge funds throughout the financial world. Indeed, a vast literature explores profitable trading strategies and anomalies in asset allocation. The findings in this thesis provide new insights which are relevant to theoretical researchers and practical investors alike.

For investors, the findings in Chapter 3 show that utilising market states to determine industry rotation provides future abnormal returns. Market states based on past market performance provide information about the relative performances of industries over the next 12 months. The second paper shows that new states (a combination of market and size or value states) can be used to predict momentum profits. This enables the development of two new trading strategies that outperform the traditional momentum strategy with less risk. The third and final study utilises the new market-size scheme and shows that it is possible to predict the future excess returns for the market and for the Fama-French size and value factors. Importantly, one state (poor market with small firms outperforming large firms) tends 
to be followed within 12 months by strong market returns. In short, the market-size scheme is useful for predicting transitions from down markets to up markets.

For scholarly researchers, the extended market states used in this thesis provide valuable information about a number of important anomalies. Study one adds to the literature by using a market state scheme to identify a new industry anomaly. Industry performance following the same state in the past as the current market state contains useful information about the likely relative performance of the industry in the coming 12 months. This industry effect cannot be explained by the Fama-French four-factor model. Studies 2 and 3 create new fourstate schemes (the combination of market and size or value factor states). Study 2 shows that different states are followed by significantly different momentum profitability. Study 3 shows that particular states are followed by significantly different market excess returns, significantly different small firm versus large firm relative performances, and significantly different value firm versus growth firm relative performances.

\subsection{Research contribution}

This thesis makes a number of contributions to the market predictability and market anomalies literature. The findings to emerge from this thesis provide the following contributions to the literature.

Chapter 3 provides an important empirical contribution concerning the usefulness of market states for predicting future industry returns. Specifically, using a new four-state scheme I investigated whether an industry's past relative performance in the same market state as the current one predicts the industry's future performance. The findings show that market states 
can be used to construct significantly profitable dynamic industry rotation strategies. My results suggest that this new industry effect can be regarded as an anomaly since the strategy profits cannot be explained by the Fama-French four-factor model. In support of market practitioners' theory of investment of specific industries at different states of the market, the results show that those industries dependant on discretionary (non-discretionary) spending are heavily featured in the extreme positive state in long winner (long loser) portfolios, and in the extreme negative state in long loser (long winner) portfolios.

Chapter 4 of this thesis extends the notion of market states in an innovate approach that creates states by combining recent market performance with the recent performances of two important components of the market: the size and value factors. The resulting two new schemes are used to examine the predictability of momentum, one of the most studied anomalous capital market phenomena. The study covers both stock-level and industry-level momentum returns from 1926 to 2013.

The findings show that momentum's future profitability significantly depends on the particular market states and different size or value states. Importantly, the results show that one market-size state and one market-value state are able to predict momentum crashes in average returns because more than $80 \%$ of the worst 15 momentum crashes occur in these two states. Momentum crashes typically occur when the market transitions from DOWN to UP. In particular, periods with poor market performances combined with small firms outperforming large firms tend to be followed by periods with strong market returns and poor momentum profits. However, periods with poor market performances combined with large firms outperforming small firms tend to be followed by periods with strong momentum profits. 
I also follow up Stivers and Sun's (2013) investigation of a return dispersion (RD) effect on momentum profits across market states. I created an MRD scheme (combines market performance with return dispersion) and show that return dispersion's ability to predict momentum profits only occurs following a negative market. Similar momentum results follow periods with both high and low RD in combination with a positive market. Only following a negative market state is momentum profitable when there is a low RD component, partially disputing the findings by Stivers and Sun (2013).

Chapter 5 is the third and final empirical chapter. This chapter continues the investigation with the previously created market-size (MS) scheme from study two. In the third study, I examine whether the four states of the market-size scheme contain information about the future performances of the Fama-French (FF) three factors. The findings show that that the market-size scheme is successful in this respect. The MS scheme four-state results show that future size and value profitability are strongly affected by the prior S state, while the future excess market returns are only affected by the prior $\mathrm{S}$ state in a prior negative market. Our findings show that all three factors are profitable when the prior $\mathrm{M}$ and $\mathrm{S}$ state were positive, but show weak insignificant profits when both the prior $\mathrm{M}$ and $\mathrm{S}$ state were negative. Importantly, all three factors produce their strongest returns following a negative market in which small firms outperformed large firms $\left(\mathrm{M}^{-} \mathrm{S}^{+}\right)$. That is, this state (negative market with small firm outperformance) tends to be followed by an upturn in the market, with small firms strongly outperforming large firms and with value firms strongly outperforming growth firms.

As this thesis has also shown that certain market states are able to predict the market, some might argue that this implies market inefficiency; however, this remains an open question, as 
it could also imply investor risk aversion. As previously discussed, when there is a transition from a negative to a positive market following a M-S+ state, it could be argued that in the 12 month formation of the M-S+ state, small size firms overtook big size firms, as buyers reentered the market signalling that the investors were becoming more confident the market would rebound, therefore signalling investors' risk averseness had diminished.

Or, that small caps tend to suffer severe losses early in a bear market whereas late in a bear market (during the so-called 'capitulation' phase) large firms tend to suffer worse returns than small firms because the prices of small firms have already fallen much more than the prices of large firms. Thus small firms outperforming large firms during poor market conditions (the M-S+ state) may also be a signal investors' risk averseness had diminished. Therefore, the result of this thesis leave open the question of market inefficiency versus risk based explanation.

\subsection{Future Avenues of Research}

The findings of these studies and the limitations of this thesis provide a number of avenues for future research. The thesis examines the importance and usefulness of market states in understanding stocks, factors and industries from the well-developed United States equity markets. As previous studies have sometimes shown differences between countries in terms of return predictability and the significance of various anomalies, many of the market state analyses applied in this thesis to the U.S. market could be tested in other international equity markets. 
Of the various schemes for classifying stocks in this thesis, the four-state scheme in Chapter 3 and the market-size (MS) scheme in Chapters 4 and 5 are particularly successful in identifying predictability in industry returns, in stock and industry momentum profitability, and in the returns of the three Fama-French factors. A second avenue for future research would be to examine whether these classification schemes are successful in predicting the time-varying profitability of other known anomalies.

Importantly, as the M-S+ state seemingly predicts a transition from a negative to a positive market state, a comprehensive understanding of this anomalous behaviour could allow further pertinent findings. Specifically, to determine if there is indeed a transition, and determine the probability of the transition, as well, further research could investigate if this anomalous behaviour is related to macroeconomic factors or conditions, specific to certain countries etc. or unknown influences.

This thesis has also shown that extending the concept of market states (by incorporating the performance of important components of the market rather than just the performance of the market as a whole) improves our understanding of market behaviour. This success may lead other researchers to employ a broader concept of market states in their future research.

\subsection{Conclusion}

In summary, the findings of this thesis are important as they have broadened our knowledge of the predictability of industries, momentum, the market, and the size and value effects. Not 
only has the thesis demonstrated the importance of market states, it has provided new insights into the interplay between market states and other anomalies.

The first part of the thesis has shown market states can be used to construct profitable dynamic industry rotation strategies. This is an industry effect not previously seen in the literature. Moreover, in support of the market practitioners' approach of investment in specific industries in different states of the market, certain industries are shown to have very different average returns following particular market states.

The second and third parts of the thesis created innovative new schemes, combining market states with the well-known size and value effects to investigate momentum and performances of the Fama-French market, size and value factors. The findings show that certain states of the market-size or market-value schemes are the main drivers for the observed predictability in momentum and the returns of the Fama-French three factors. Importantly, the findings show that momentum crashes are predictable in the sense that the worst crashes tend to follow within 12 months of one particular state while the market simultaneously swings from a poor market to a strong market. Also of importance, the magnitude of the size effect is shown to be highly dependent on a particular market state.

In closing, this study contributes a number of new findings to the current body of scholarly work in asset selection, allocation and pricing through its study of the interaction between market states and the future returns of industries and several anomalous effects. The creation of new schemes combining market states with size and value has enhanced our understanding of the behaviour of momentum, the market, and the size and value effects. In addition, this study holds significant practical implications for investors who wish to better understand the 
changing risk/return profile of industries, momentum, the market, and the Fama-French size and value factors. As outlined in this thesis, it is important for researchers investigating anomalous effects to remember that these effects do not take place on a linear way, but rather, the effects are averages across the peaks and troughs of the stock market. Ignoring market states could be neglecting a significant impact on future returns. 


\section{References}

Alexakisa, C., Patrab, T., \& Poshakwalec, S. (2010). Predictability of stock returns using financial statement information: evidence on semi-strong efficiency of emerging Greek stock market. Applied Financial Economics, 99999(1), 1-6.

Amihud, Y., \& Mendelson, H. (1986). Asset pricing and the bid-ask spread. Journal of Financial Economics, 17(2), 223-249. doi: 10.1016/0304-405x(86)90065-6

Ang, A., \& Bekaert, G. (2007). Stock return predictability: Is it there? Review of Financial studies, 20(3), 651-707.

Arnott, R. D., \& Copeland, W. A. (1985). The Business Cycle and Security Selection. Financial Analysts Journal, 41(2), 26-32.

Arshanapalli, B. G., \& Nelson, W. B. (2007). Small cap and value investing offer both high returns and a hedge. The Journal of Wealth Management, 9(4), 44-50.

Artis, M. J., Kontolemis, Z. G., \& Osborn, D. R. (1997). Business Cycles for G7 and European Countries*. The Journal of Business, 70(2), 249-279.

Asem, E., \& Tian, G. Y. (2010). Market dynamics and momentum profits. Journal of Financial and Quantitative Analysis, 45(6), 1549.

Asness, C. S., Moskowitz, T. J., \& Pedersen, L. H. (2013). Value and momentum everywhere. The Journal of Finance, 68(3), 929-985.

Bacharach, B., \& Galia, D. (1979). The Risk-Return relationship and Stock Pricess. Journal of Financial and Quantitative Analyses, 14, 421-441.

Baker, M., \& Wurgler, J. (2000). The Equity Share in New Issues and Aggregate Stock Returns. The Journal of Finance, 55(5), 2219-2257. doi: 10.1111/0022-1082.00285

Ball, R. (1978). Anomalies in relationships between securities' yields and yield-surrogates. Journal of Financial Economics, 6(2-3), 103-126. doi: 10.1016/0304-405x(78)90026-0 
Banz, R. W. (1981). The relationship between return and market value of common stocks. Journal of Financial Economics, 9(1), 3-18. doi: 10.1016/0304-405x(81)90018-0

Barbee, W. C., Jr., Mukherji, S., \& Raines, G. A. (1996). Do Sales-Price and Debt-Equity Explain Stock Returns Better than Book-Market and Firm Size? Financial Analysts Journal, 52(2), 56-60.

Basu, S. (1977). Investment Performance of Common Stocks in Relation to Their Price-Earnings Ratios: A Test of the Efficient Market Hypothesis. The Journal of Finance, 32(3), 663-682.

Basu, S. (1983). The relationship between earnings' yield, market value and return for NYSE common stocks : Further evidence. Journal of Financial Economics, 12(1), 129-156. doi: 10.1016/0304$405 \times(83) 90031-4$

Bauman, W. S., \& Miller, R. E. (1995). Portfolio performance rankings in stock market cycles. Financial Analysts Journal, 51(2), 79-79.

Beaudry, P., \& Portier, F. (2004). Stock prices, news and economic fluctuations: National Bureau of Economic Research.

Beber, A., Brandt, M. W., \& Kavajecz, K. A. (2011). What Does Equity Sector Orderflow Tell Us About the Economy? Review of Financial Studies, 24(11), 3688-3730. doi: 10.1093/rfs/hhr067

Beller, K. R., Kling, J. L., \& Levinson, M. J. (1998). Are industry stock returns predictable? Financial Analysts Journal, 54(5), 42-57.

Bem, D. J. (1965). An experimental analysis of self-persuasion. Journal of Experimental Social Psychology, 1(3), 199-218.

Bhandari, L. C. (1988). Debt/Equity Ratio and Expected Common Stock Returns: Empirical Evidence. Journal of Finance, 43(2), 507-528. doi: http://www.blackwellpublishing.com/journal.asp?ref=0022-1082

Bhardwaj, R. K., \& Brooks, L. D. (1992). Stock Price and Degree of Neglect as Determinants of Stock Returns. Journal of Financial Research, 15(2), 101-112. doi: http://www.blackwellpublishing.com/journal.asp?ref=0270-2592 
Bhardwaj, R. K., \& Brooks, L. D. (1993). Dual betas from bull and bear markets: reversal of the size effect. Journal of Financial Research, 16(4), 269-283.

Biscarri, J., \& Gracia, F. (2004). Stock market cycles and stock market development in Spain. Spanish Economic Review, 6(2), 127-151. doi: 10.1007/s10108-003-0078-7

Black, F. (1972). Capital Market Equilibrium with Restricted Borrowing. The Journal of Business, 45(3), 444-455.

Black, F., Jenson, M. C., \& Scholes, M. (1972). The Capital Asset Pricing Model: Some Empirical Tests. STUDIES IN THE THEORY OF CAPITAL MARKETS, 79-121.

Blume, M. E., \& Husic, F. (1973). Price, Beta, and Exchange Listing. The Journal of Finance, 28(2), 283299.

Bolten, S. E., \& Weigand, R. A. (1998). The generation of stock market cycles. Financial Review, 33(1), 77-84. doi: 10.1111/j.1540-6288.1998.tb01608.x

Bondt, W. F., \& Thaler, R. (1985). Does the stock market overreact? The Journal of finance, 40(3), 793-805.

Boudoukh, J., Michaely, R., Richardson, M., \& Roberts, M. R. (2007). On the Importance of Measuring Payout Yield: Implications for Empirical Asset Pricing. The Journal of Finance, 62(2), 877-915.

Boudoukh, J., Richardson, M., \& Whitelaw, R. F. (1994). Industry Returns and the Fisher Effect. The Journal of Finance, 49(5), 1595-1615.

Breen, W., Glosten, L. R., \& Jagannathan, R. (1989). Economic Significance of Predictable Variations in Stock Index Returns. The Journal of Finance, 44(5), 1177-1189.

Brush, T. H., Bromiley, P., \& Hendrickx, M. (1999). The relative influence of industry and corporation on business segment performance: an alternative estimate. Strategic Management Journal, 20(6), 519-547. doi: 10.1002/(sici)1097-0266(199906)20:6<519::aid-smj32>3.0.co;2-8

Bry, G., \& Boschan, C. (1971). Front matter to" Cyclical Analysis of Time Series: Selected Procedures and Computer Programs" Cyclical Analysis of Time Series: Selected Procedures and Computer Programs (pp. -13--12): UMI. 
Campa, J. M., \& Fernandes, N. (2006). Sources of gains from international portfolio diversification. Journal of Empirical Finance, 13(4-5), 417-443. doi: 10.1016/j.jempfin.2006.01.001

Campbell, J., \& Shiller, R. (1988). The dividend-price ratio and expectations of future dividends and discount factors. Review of Financial Studies, 1(3), 195-228. doi: 10.1093/rfs/1.3.195

Campbell, J., Y., \& Shiller, R. (1987). The dividend-price ratio and expectations of future dividends and discount factors. Review of Financial Studies 1(3), 195-228.

Campbell, John Y., \& Cochrane, John H. (1999). By Force of Habit: A Consumption-Based Explanation of Aggregate Stock Market Behavior. Journal of Political Economy, 107(2), 205-251.

Campbell, J. Y., \& Shiller, R. J. (1998). Valuation ratios and the long-run stock market outlook. The Journal of Portfolio Management, 24(2), 11-26.

Campbell, J. Y., \& Shiller, R. J. (2001). Valuation ratios and the long-run stock market outlook: an update: National bureau of economic research.

Campbell, J. Y., \& Vuolteenaho, T. (2004). Inflation Illusion and Stock Prices. The American Economic Review, 94(2), 19-23.

Campbell, S. D., \& Diebold, F. X. (2009). Stock Returns and Expected Business Conditions: Half a Century of Direct Evidence. Journal of Business \& Economic Statistics, 27(2), 266-278. doi: 10.1198/jbes.2009.0025

Candelon, B., \& Metiu, N. (2009). Testing for exceptional bulls and bears: a non-parametric perspective: Maastricht University. FdEWB. METEOR.

Candelon, B., \& Metiu, N. (2011). Linkages between Stock Market Fluctuations and Business Cycles in Asia. Frontiers of Economics and Globalization, 9, 23-51.

Carhart, M. M. (1997). On Persistence in Mutual Fund Performance. The Journal of Finance, 52(1), $57-82$.

Cavaglia, S., Brightman, C., \& Aked, M. (2000). The increasing importance of industry factors. Financial Analysts Journal, 56(5), 41-54. 
Chan, K., Hameed, A., \& Wilson, T. (2000). Profitability of Momentum Strategies in the International Equity Markets. The Journal of Financial and Quantitative Analysis, 35(2), 153-172.

Chan, K., \& Lakonishok, J. (1993). Are the Reports of Beta's Death Premature? Journal of Portfolio Management, 19(4), 61-62.

Chan, L., Hamao, Y., \& Lakonishok, J. (1991). Fundamentals and stock returns in Japan. Journal of finance, 1739-1764.

Chan, L. K. C., Jason, K., \& Lakonishok, J. (2003). The Level and Persistence of Growth Rates. The Journal of Finance, 58(2), 643-684.

Chan, L. K. C., Jegadeesh, N., \& Lakonishok, J. (1999). The Profitability of Momentum Strategies. Financial Analysts Journal, 55(6), 80-90.

Chauvet, M. (1998). Stock Market Fluctuations and the Business Cycle. Journal of Economic and Social Measurement, 25(3-4), 235-257. doi: http://www.iospress.nl/html/07479662.php

Chauvet, M., \& Potter, S. (2000). Coincident and leading indicators of the stock market. Journal of Empirical Finance, 7(1), 87-111.

Chen, N.-F., Roll, R., \& Ross, S. A. (1986). Economic forces and the stock market. Journal of business, 383-403.

Chen, N. (2012). Financial investment opportunities and the macroeconomy. The Journal of Finance, 46(2), 529-554.

Chen, S.-S. (2009). Predicting the bear stock market: Macroeconomic variables as leading indicators. Journal of Banking \&amp; Finance, 33(2), 211-223. doi: 10.1016/j.jbankfin.2008.07.013

Cheung, Y. W., He, J., \& Ng, L. K. (1997). Common predictable components in regional stock markets. Journal of Business \& Economic Statistics, 15(1), 35-42.

Chordia, T., \& Shivakumar, L. (2002). Momentum, Business Cycle, and Time-Varying Expected Returns. The Journal of Finance, 57(2), 985-1019. 
Chou, P.-H., Ho, P.-H., \& Ko, K.-C. (2012). Do industries matter in explaining stock returns and assetpricing anomalies? Journal of Banking \&amp; Finance, 36(2), 355-370. doi: 10.1016/j.jbankfin.2011.07.016

Clare, A., Priestly, R., \& Stephen.T. (1997). Is Beta Dead? The Role of Alternative Estimation Methods. Applied Economics Letters, 4(9), 559-562.

Connor, G., \& Korajczyk, R. A. (1988). Risk and return in an equilibrium APT: Application of a new test methodology. Journal of Financial Economics, 21(2), 255-289. doi: 10.1016/0304$405 \times(88) 90062-1$

Conover, M., Jensen, G., Johnson, R.,, \& Mercer, J. (2008). Sector rotation and monetary conditions. Journal of Investing 34-46.

Cook, T. J., \& Rozeff, M. S. (1984). Size and Earnings/Price Ratio Anomalies: One Effect or Two? Journal of Financial and Quantitative Analysis, 19(04), 449-466. doi: doi:10.2307/2330785

Cooper, I., \& Priestley, R. (2009). Time-Varying Risk Premiums and the Output Gap. Review of Financial Studies, 22(7), 2801-2833. doi: 10.1093/rfs/hhn087

Cooper, M. J., Gulen, H., \& Schill, M. J. (2008). Asset Growth and the Cross-Section of Stock Returns. The Journal of Finance, 63(4), 1609-1651. doi: 10.1111/j.1540-6261.2008.01370.x

Cooper, M. J., Gutierrez Jr, R. C. G., \& Hameed, A. (2004). Market States and Momentum. The Journal of Finance, 59(3), 1345-1365.

Cosslett, S. R., \& Lee, L.-F. (1985). Serial correlation in latent discrete variable models. Journal of Econometrics, 27(1), 79-97.

Daniel, K. (2011). Momentum crashes. Columbia Business School Research Paper(11-03).

Daniel, K., Hirshleifer, D., \& Subrahmanyam, A. (1998). Investor psychology and security market under-and overreactions. the Journal of Finance, 53(6), 1839-1885.

Daniel, K. D., \& Moskowitz, T. J. (2013). Momentum crashes. Swiss Finance Institute Research Paper(13-61), 14-16. 
Desai, H., Rajgopal, S., \& Venkatachalam, M. (2004). Value-glamour and accruals mispricing: One anomaly or two? The Accounting Review, 79(2), 355-385.

DeStefano, M. (2004). Stock Returns and the Business Cycle. Financial Review, 39(4), 527-547. doi: 10.1111/j.0732-8516.2004.00087.x

Diebold, F. X., \& Rudebusch, G. D. (1994). Measuring business cycles: A modern perspective: National Bureau of Economic Research.

Driesprong, G., Jacobsen, B., \& Maat, B. (2008). Striking oil: Another puzzle? Journal of Financial Economics, 89(2), 307-327. doi: 10.1016/j.jfineco.2007.07.008

Edwards, S., Biscarri, J. G., \& Perez de Gracia, F. (2003). Stock market cycles, financial liberalization and volatility. Journal of International Money and Finance, 22(7), 925-955. doi: 10.1016/j.jimonfin.2003.09.011

Eleswarapu, V. R., \& Tiwari, A. (1996). Business Cycles and Stock Market Returns: Evidence Using Industry-Based Portfolios. Journal of Financial Research, 19(1), 121-134. doi: http://www.blackwellpublishing.com/journal.asp?ref=0270-2592

Estrella, A., \& Mishkin, F. S. (1998). Predicting U.S. Recessions: Financial Variables as Leading Indicators. Review of Economics and Statistics, 80(1), 45-61. doi: 10.1162/003465398557320

Estrella, A., \& Mishkin, F. S. (1998). Predicting US recessions: financial variables as leading indicators. Review of Economics and Statistics, 80(1), 45-61.

Fama, E. F. (1965). Random Walks in Stock Market Prices. Financial Analysts Journal, 21(5), 55-59.

Fama, E. F. (1970). Efficient Capital Markets: A Review of Theory and Empirical Work. The Journal of Finance, 25(2), 383-417.

Fama, E. F. (1990). Stock Returns, Expected Returns, and Real Activity. The Journal of Finance, 45(4), $1089-1108$.

Fama, E. F., \& French, K. R. (1988). Permanent and temporary components of stock prices. The Journal of Political Economy, 246-273. 
Fama, E. F., \& French, K. R. (1989). Business conditions and expected returns on stocks and bonds. Journal of Financial Economics, 25(1), 23-49. doi: 10.1016/0304-405x(89)90095-0

Fama, E. F., \& French, K. R. (1992). The Cross-Section of Expected Stock Returns. The Journal of Finance, 47(2), 427-465.

Fama, E., \& French, K. (1993). Common risk factors in the returns on stocks and bonds* 1. Journal of financial economics, 33(1), 3-56.

Fama, E. F., \& French, K. R. (1998). Value versus Growth: The International Evidence. The Journal of Finance, 53(6), 1975-1999. doi: 10.1111/0022-1082.00080

Fama, E. F., \& French, K. R. (2004). The Capital Asset Pricing Model: Theory and Evidence. The Journal of Economic Perspectives, 18(3), 25-46.

Fama, E. F., \& French, K. R. (2008). Dissecting Anomalies. The Journal of Finance, 63(4), 1653-1678. doi: 10.1111/j.1540-6261.2008.01371.x

Fama, E. F., \& French, K. R. (2011). Size, Value, and Momentum in International Stock Returns. SSRN eLibrary.

Fama, E. F., \& French, K. R. (2012). Size, value, and momentum in international stock returns. Journal of financial economics, 105(3), 457-472.

Fama, E. F., \& French, K. R. (2015). A five-factor asset pricing model. Journal of Financial Economics, 116(1), 1-22.

Fama, E. F., \& MacBeth, J. D. (1973). Risk, Return, and Equilibrium: Empirical Tests. Journal of Political Economy, 81(3), 607-636.

Fama, E. F., \& Schwert, G. W. (1977). Asset returns and inflation. Journal of Financial Economics, 5(2), 115-146. doi: 10.1016/0304-405x(77)90014-9

Ferreira, M. A., \& Gama, P. M. (2005). Have World, Country, and Industry Risks Changed over Time? An Investigation of the Volatility of Developed Stock Markets. Journal of Financial and Quantitative Analysis, 40(01), 195-222. doi: doi:10.1017/\$0022109000001794 
Ferson, W. E., \& Harvey, C. R. (1991). The Variation of Economic Risk Premiums. Journal of Political Economy, 99(2), 385-415.

Ferson, W. E., \& Harvey, C. R. (1993). The risk and predictability of international equity returns. Review of Financial Studies, 6(3), 527-566.

Flavin, T. J. (2004). The effect of the Euro on country versus industry portfolio diversification. Journal of International Money and Finance, 23(7-8), 1137-1158. doi: 10.1016/j.jimonfin.2004.08.004

Fritzemeier, L. H. (1936). Relative Price Fluctuations of Industrial Stocks in Different Price Groups. The Journal of Business of the University of Chicago, 9(2), 133-154.

Goldfeld, S. M., \& Quandt, R. E. (1973). A Markov model for switching regressions. Journal of Econometrics, 1(1), 3-15.

Gonzalez, L., Powell, J. G., Shi, J., \& Wilson, A. (2005). Two centuries of bull and bear market cycles. International Review of Economics \&amp; Finance, 14(4), 469-486. doi: 10.1016/j.iref.2004.02.003

Goodwin, T. H. (1993). Business-cycle analysis with a Markov-switching model. Journal of Business \& Economic Statistics, 11(3), 331-339.

Goyal, A., \& Welch, I. (2008). A comprehensive look at the empirical performance of equity premium prediction. Review of Financial Studies, 21, 1455-1508.

Grauer, R. R., Hakansson, N. H., \& Shen, F. C. (1990). Industry rotation in the U.S. stock market: 1934-1986 returns on passive, semi-passive, and active strategies. Journal of Banking \& Finance, 14(2-3), 513-538. doi: http://dx.doi.org/10.1016/0378-4266(90)90062-7

Griffin, J. M., Ji, X., \& Martin, J. S. (2003). Momentum Investing and Business Cycle Risk: Evidence from Pole to Pole. The Journal of Finance, 58(6), 2515-2547.

Grinblatt, M., Titman, S., \& Wermers, R. (1995). Momentum Investment Strategies, Portfolio Performance, and Herding: A Study of Mutual Fund Behavior. The American Economic Review, 85(5), 1088-1105. 
Grundy, B. D., \& Martin, J. S. (2001). Understanding the Nature of the Risks and the Source of the Rewards to Momentum Investing. The Review of Financial Studies, 14(1), 29-78. doi: $10.2307 / 2696756$

Guidolin, M., \& Timmermann, A. (2007). Asset allocation under multivariate regime switching. Journal of Economic Dynamics and Control, 31(11), 3503-3544.

Guidolin, M., \& Timmermann, A. (2008). Size and value anomalies under regime shifts. Journal of Financial Econometrics, 6(1), 1-48.

Guo, H. (2004). Limited stock market participation and asset prices in a dynamic economy. Journal of Financial and Quantitative Analysis, 39(3).

Guo, H. (2006). On the Out-of-Sample Predictability of Stock Market Returns. The Journal of Business, 79(2), 645-670.

Hamilton, J. D. (2005). What's real about the business cycle? : National Bureau of Economic Research.

Hamilton, J. D., \& Lin, G. (1996). Stock market volatility and the business cycle. Journal of Applied Econometrics, 11(5), 573-593.

Hamilton, J. D., \& Lin, G. (1998). Stock market volatility and the business cycle. Journal of Applied Econometrics, 11(5), 573-593.

Hamilton, J. D., \& Perez-Quiros, G. (1996). What do the leading indicators lead? Journal of business, 27-49.

Harding, D., \& Pagan, A. (2002). Dissecting the cycle: a methodological investigation. Journal of monetary economics, 49(2), 365-381.

Harding, D., \& Pagan, A. R. (2000). Knowing the Cycle, in Backhouse and Salanti (eds.) Macroecomics and the Real World-. Econometric Techniques and Macroeconometrics, Vol 1.

Harris, J. (2009). Market Cycles and Safe Withdrawal Rates. Journal of Financial Planning, 22(9), 3840,42-48. 
Haugen, R. A., \& Baker, N. L. (1996). Commonality in the determinants of expected stock returns. Journal of Financial Economics, 41(3), 401-439. doi: 10.1016/0304-405x(95)00868-f

Hawawini, G., Subramanian, V., \& Verdin, P. (2003). Is performance driven by industry-or firmspecific factors? A new look at the evidence. Strategic Management Journal, 24(1), 1-16. doi: $10.1002 / \mathrm{smj} .278$

Hendricks, D., Patel, J., \& Zeckhauser, R. (1993). Hot Hands in Mutual Funds: Short-Run Persistence of Relative Performance, 1974-1988. The Journal of Finance, 48(1), 93-130.

Henkel, S. J., Martin, J. S., \& Nardari, F. (2011). Time-varying short-horizon predictability. Journal of Financial Economics, 99(3), 560-580. doi: 10.1016/j.jfineco.2010.09.008

Heston, S. L., \& Rouwenhorst, K. G. (1994). Does industrial structure explain the benefits of international diversification? Journal of Financial Economics, 36(1), 3-27. doi: 10.1016/0304$405 \times(94) 90028-0$

Heston, S. L., \& Rouwenhorst, K. G. (1995). Industry and country effects in international stock returns. The Journal of Portfolio Management, 21(3), 53-58.

Hirshleifer, D., Hou, K., \& Teoh, S. H. (2009). Accruals, cash flows, and aggregate stock returns. Journal of Financial Economics, 91(3), 389-406. doi: 10.1016/j.jfineco.2007.11.009

Hong, H., \& Stein, J. C. (1999). A unified theory of underreaction, momentum trading, and overreaction in asset markets. The Journal of Finance, 54(6), 2143-2184.

Hong, H., Torous, W., \& Valkanov, R. (2007). Do industries lead stock markets? Journal of Financial Economics, 83(2), 367-396. doi: 10.1016/j.jfineco.2005.09.010

Horrigan, J. (1968). A Short History of Financial Ratio Analysis The Accounting Review, Vol. 43 (2), 284-294.

Hou, K. (2007). Industry Information Diffusion and the Lead-lag Effect in Stock Returns. Review of Financial Studies, 20(4), 1113-1138. doi: 10.1093/revfin/hhm003

Hou, K., Karolyi, G. A., \& Kho, B.-C. (2011). What factors drive global stock returns? Review of Financial Studies, 24(8), 2527-2574. 
Hou, K., \& Robinson, D. T. (2006). Industry Concentration and Average Stock Returns. The Journal of Finance, 61(4), 1927-1956. doi: 10.1111/j.1540-6261.2006.00893.x

Huang, D. (2006). Market states and international momentum strategies. The Quarterly Review of Economics and Finance, 46(3), 437-446. doi: 10.1016/j.qref.2004.07.009

Hung, S.-Y., \& Glascock, J. (2008). Momentum Profitability and Market Trend: Evidence from REITs. The Journal of Real Estate Finance and Economics, 37(1), 51-69. doi: 10.1007/s11146-0079056-4

Ibbotson, R. G., \& Sinquefield, R. A. (1989). Stocks, bonds, bills, and inflation: Historical returns (1926-1987): Irwin Professional Publishing.

Jegadeesh, N., \& Titman, S. (1993). Returns to Buying Winners and Selling Losers: Implications for Stock Market Efficiency. The Journal of Finance, 48(1), 65-91.

Jegadeesh, N., \& Titman, S. (2001). Profitability of momentum strategies: An evaluation of alternative explanations. The Journal of Finance, 56(2), 699-720.

Kaminsky, G., \& Schmukler, S. (2003). Short-run pain, long-run gain: the effects of financial liberalization: National Bureau of Economic Research.

Keim, D. (1980). Asset pricing anomalies and capital market seasonality: Empirical evidence. Unpublished manuscript (University of Chicago, Chicago, IL).

Keim, D. B. (1983). Size-related anomalies and stock return seasonality : Further empirical evidence. Journal of Financial Economics, 12(1), 13-32. doi: 10.1016/0304-405x(83)90025-9

Kim, C.-J., \& Nelson, C. R. (1999). State-space models with regime switching: classical and Gibbssampling approaches with applications. MIT Press Books, 1.

Kim, M. K., \& Burnie, D. A. (2002). The firm size effect and the economic cycle. Journal of Financial Research, 25(1), 111-124.

Kole, E., \& Van Dijk, D. J. C. (2010). How to Identify and Predict Bull and Bear Markets? . working paper Available at SSRN: http://ssrn.com/abstract=1695501. 
Kose, M. A., Otrok, C., \& Whiteman, C. H. (2003). International business cycles: World, region, and country-specific factors. The American Economic Review, 93(4), 1216-1239.

Kothari, S., \& Shanken, J. (1997). Book-to-market, dividend yield, and expected market returns: A time-series analysis. Journal of financial economics, 44(2), 169-203.

Kothari, S. P., Shanken, J., \& Sloan, R. G. (1995). Another Look at the Cross-Section of Expected Stock Returns. The Journal of Finance, 50(1), 185-224.

Kross, W. (1985). The Size Effect Is Primarily a Price Effect. Journal of Financial Research, 8(3), 169179. doi: http://www.blackwellpublishing.com/journal.asp?ref=0270-2592

Lakonishok, J., Shleifer, A., \& Vishny, R. W. (1994). Contrarian Investment, Extrapolation, and Risk. The Journal of Finance, 49(5), 1541-1578.

Lamont, O. (1998). Earnings and Expected Returns. The Journal of Finance, 53(5), 1563-1587.

Lau, S., Lee, C., \& McInish, T. (2002). Stock returns and beta, firms size, E/P, CF/P, book-to-market, and sales growth: evidence from Singapore and Malaysia. Journal of multinational financial management, 12(3), 207-222.

Lee, J.-S., Yen, P.-H., \& Chanc, K. C. (2013). Market states and disposition effect: evidence from Taiwan mutual fund investors Applied Economics Letters, 45(10), 1331-1342.

Leledakis, G., \& Davidson, I. (2001). Are Two Factors Enough? The U.K. Evidence. Financial Analysts Journal, 57(6), 96-105.

Lettau, M., \& Ludvigson, S. (2001). Consumption, Aggregate Wealth, and Expected Stock Returns. The Journal of Finance, 56(3), 815-849. doi: 10.1111/0022-1082.00347

Lewellen, J. (2004). Predicting returns with financial ratios* 1. Journal of financial economics, 74(2), 209-235.

Liew, J., \& Vassalou, M. (2000). Can book-to-market, size and momentum be risk factors that predict economic growth? Journal of Financial Economics, 57(2), 221-245. doi: 10.1016/s0304$405 \times(00) 00056-8$ 
Lintner, J. (1965). The valuation of risk assets and the selection of risky investments in stock portfolios and capital budgets. The Review of Economics and Statistics, 47(1), 13-37.

Lo, A. W., \& MacKinlay, A. C. (1995). Maximizing predictability in the stock and bond markets: National Bureau of Economic Research.

Lunde, A., \& Timmermann, A. (2004). Duration dependence in stock prices. Journal of Business \& Economic Statistics, 22(3).

Maheu, J. M., \& McCurdy, T. H. (2000). Identifying bull and bear markets in stock returns. Journal of Business \& Economic Statistics, 18(1), 100-112.

Malkiel, B. G. (2005). Reflections on the Efficient Market Hypothesis: 30 Years Later. Financial Review, 40(1), 1-9. doi: 10.1111/j.0732-8516.2005.00090.x

Mascarenhas, B., \& Aaker, D. A. (1989). Strategy over the business cycle. Strategic Management Journal, 10(3), 199-210.

Maysami, R. C., \& Sim, H. H. (2001). An empirical investigation of the dynamic relations between macroeconomic factors and the stock markets of Malaysia and Thailand. Jurnal Pengurusan, 20.

McGahan, A. M., \& Porter, M. E. (1997). How Much Does Industry Matter, Really? Strategic Management Journal, 18(ArticleType: research-article / Issue Title: Summer 1997 Special Issue: Organizational and Competitive Interactions / Full publication date: Jul., 1997 / Copyright (C) 1997 John Wiley \& Sons), 15-30.

Menzly, L., \& Ozbas, O. (2006). Cross-industry momentum. Paper presented at the AFA 2005 Philadelphia Meetings.

Menzly, L., \& Ozbas, O. (2010). Market Segmentation and Cross-predictability of Returns. The Journal of Finance, 65(4), 1555-1580. doi: 10.1111/j.1540-6261.2010.01578.x

Merton, R. C. (1973). An intertemporal capital asset pricing model. Econometrica: Journal of the Econometric Society, 867-887. 
Merwin, C. L. (1942). Financing small corporations in five manufacturing industries, 1926-36. NBER Books.

Modigliani, F., \& Cohn, R. A. (1979). Inflation, rational valuation and the market. Financial Analysts Journal, 35(2), 24-44.

Moskowitz, T., Ooi, Y. H., \& Pedersen, L. H. (2011). Time series momentum. Journal of Financial Economics.

Moskowitz, T. J., \& Grinblatt, M. (1999). Do Industries Explain Momentum? The Journal of Finance, 54(4), 1249-1290. doi: 10.1111/0022-1082.00146

Næs, R., Skjeltorp, J. A., \& Ødegaard, B. A. (2011). Stock market liquidity and the business cycle. The Journal of Finance, 66(1), 139-176.

Nelson, C. R. (1976). Inflation and Rates of Return on Common Stocks. The Journal of Finance, 31(2), 471-483.

Neuman, L. (2006). Social research methods:Qualitative and quantitative approach. 6th edition.

Nicholson, S. F. (1968). Price Ratios in Relation to Investment Results. Financial Analysts Journal, 24(1), 105-109.

O'Neal, E. S. (2000). Industry momentum and sector mutual funds. Financial Analysts Journal, 56(4), $37-49$.

Pagan, A. R., \& Sossounov, K. A. (2003). A simple framework for analysing bull and bear markets. Journal of Applied Econometrics, 18(1), 23-46. doi: 10.1002/jae.664

Pangarkar, N., \& Lie, J. R. (2004). The Impact of Market Cycle on the Performance of Singapore Acquirers. Strategic Management Journal, 25(12), 1209-1216.

Phylaktis, K., \& Xia, L. (2006). The Changing Roles of Industry and Country Effects in the Global Equity Markets. The European Journal of Finance, 12(8), 627-648. doi:

$10.1080 / 13518470500460202$

Pollet, J. (2005). Predicting asset returns with expected oil price changes. Available at SSRN 722201. 
Ponti, J., \& Schall, L. D. (1998). Book-to-market ratios as predictors of market returns. Journal of Financial Economics, 49(141-160).

Pontiff, J., \& Schall, L. D. (1998). Book-to-market ratios as predictors of market returns. Journal of Financial Economics, 49(2), 141-160. doi: 10.1016/s0304-405x(98)00020-8

Puchkov, A. V., Stefek, D., \& Davis, M. (2004). Sources of Return in Global Investing. [Article]. Journal of Portfolio Management, 31(2), 12-21.

Ramchand, L., \& Susmel, R. (1998). Volatility and cross correlation across major stock markets. Journal of Empirical Finance, 5(4), 397-416. doi: 10.1016/s0927-5398(98)00003-6

Rangvid, J. (2006). Output and expected returns. Journal of Financial Economics, 81(3), 595-624. doi: 10.1016/j.jfineco.2005.07.010

Reinganum, M. R. (1981). Misspecification of capital asset pricing : Empirical anomalies based on earnings' yields and market values. Journal of Financial Economics, 9(1), 19-46. doi: $10.1016 / 0304-405 \times(81) 90019-2$

Reinganum, M. R. (1992). A revival of the small-firm effect. The Journal of Portfolio Management, 18(3), 55-62.

Roll, R., \& Ross, S. A. (1980). An Empirical Investigation of the Arbitrage Pricing Theory. The Journal of Finance, 35(5), 1073-1103.

Rosenberg, B., Reid, K., \& Lanstein, R. (1985). Persuasive evidence of market inefficiency. Journal of Portfolio Management, 11(3), 9-16.

Ross, S. (1976). Arbitrage Theory of Capital Asset Pricing. Journal of Economic Theory, 13, 341-360. doi: citeulike-article-id:1204397

Rouwenhorst, K. G. (1998). International Momentum Strategies. The Journal of Finance, 53(1), 267284.

Rozeff, M. S. (1984). Dividend yields are equity risk premiums. The Journal of Portfolio Management, 11(1), 68-75. 
Rumelt, R. P. (1991). How much does industry matter? Strategic Management Journal, 12(3), 167185. doi: $10.1002 / \mathrm{smj} .4250120302$

Sagi, J. S., \& Seasholes, M. S. (2007). Firm-specific attributes and the cross-section of momentum. Journal of Financial Economics, 84(2), 389-434.

Schwert, G. W. (1990). Why does stock market volatility change over time? : National Bureau of Economic Research Cambridge, Mass., USA.

Seung-Woog, K., \& Lee, S. W. (2006). Value Investing and the Business Cycle. Journal of Financial Planning, 19(1), 64-66,68-71.

Sharpe, W. (1964). Capital asset prices: A theory of market equilibrium under conditions of risk. Journal of finance, 19(3), 425-442.

Short, J. C., Ketchen, D. J., Palmer, T. B., \& Hult, G. T. M. (2007). Firm, strategic group, and industry influences on performance. Strategic Management Journal, 28(2), 147-167. doi: $10.1002 / \mathrm{smj} .574$

Sorensen, E. H., \& Burke, T. (1986). Portfolio returns from active industry group rotation. Financial Analysts Journal, 43-50.

Stangl, J., Jacobsen, B., \& Visaltanachoti, N. (2009). Sector Rotation over Business Cycles. working paper, found at http://69.175.2.130/ finman/Reno/Papers/Sector_Rotation_across_Business_Cycles_FMA_2 009.pdf.

Stattman, D. (1980). Book values and stock returns. Chicago MBA: A Journal of Selected

Papers, 4, 25-45.

Steliaros, M., \& Thomas, D. C. (2006). The cross-sectional variability of stock-price returns: Country and sector effects revisited. J Asset Manag, 7(3-4), 273-290.

Stivers, C., \& Sun, L. (2010). Cross-sectional return dispersion and time variation in value and momentum premiums. 
Stivers, C., \& Sun, L. (2013). Market Cycles and the Performance of Relative Strength Strategies. Financial Management, 42(2), 263-290.

Stovall, S. (1996). Standard \& Poor's Guide to Sector Investing. New York: McGraw-Hill.

TSUI, C. (2010). Extracting Factors from Industries to Predict the Value and Size Premia: The US Case. working paper, found at http://infoshako.sk.tsukuba.ac.jp/ databank/thesis/2009/a2009tsuji.pdf.

Tsuji, C. (2012). Do industries contain predictive information for the Fama-French factors? . Quantitative Finance 12(6), 969-991.

Victor, Z. (1993). What is a Business Cycle? (Vol. 3863): national Bureau of Economic Research, NBER working paper.

Wang, C.-J., Lee, C.-H., \& Huang, B.-N. (2003). An analysis of industry and country effects in global stock returns: evidence from Asian countries and the U.S. The Quarterly Review of Economics and Finance, 43(3), 560-577. doi: 10.1016/s1062-9769(02)00173-4

Watson, M. W. (1994). Business-cycle durations and postwar stabilization of the US economy. American economic review, 84(1), 24-46.

Wermers, R. (1996). Momentum investment strategies of mutual funds, performance persistence, and survivorship bias. Working paper, Graduate School of Business and Administration,

University of Colorado at Boulder, Boulder, Col.

White, H. (1980). A Heteroskedasticity-Consistent Covariance Matrix Estimator and a Direct Test for Heteroskedasticity. Econometrica, 48(4), 817-838.

Willard, T., \& Lakonishok, C. J. (1986). The Size Anomaly: Does Industry Group Matter? . The Journal of Portfolio Management 12(3), 36-40.

Woodward, G., \& Anderson, H. M. (2009). Does beta react to market conditions? Estimates of 'bull'and 'bear'betas using a nonlinear market model with an endogenous threshold parameter. Quantitative Finance, 9(8), 913-924. 
Xiaowei Liu, Chengru Hu, Biqing Huang, \& Maggie Foley. (2010). MOMENTUM AND MARKET STATES:

INTERNATIONAL EVIDENCE. [Article]. Journal of International Finance \& Economics, 10(4), 80-88.

Zarnowitz, V. (1997). Business Cycles Observed and Assessed: Why and How They Matter. SSRN elibrary.

Zarnowitz, V. (1999). Theory and history behind business cycles: Are the 1990s the onset of a golden age? The Journal of Economic Perspectives, 13(2), 69-90. 